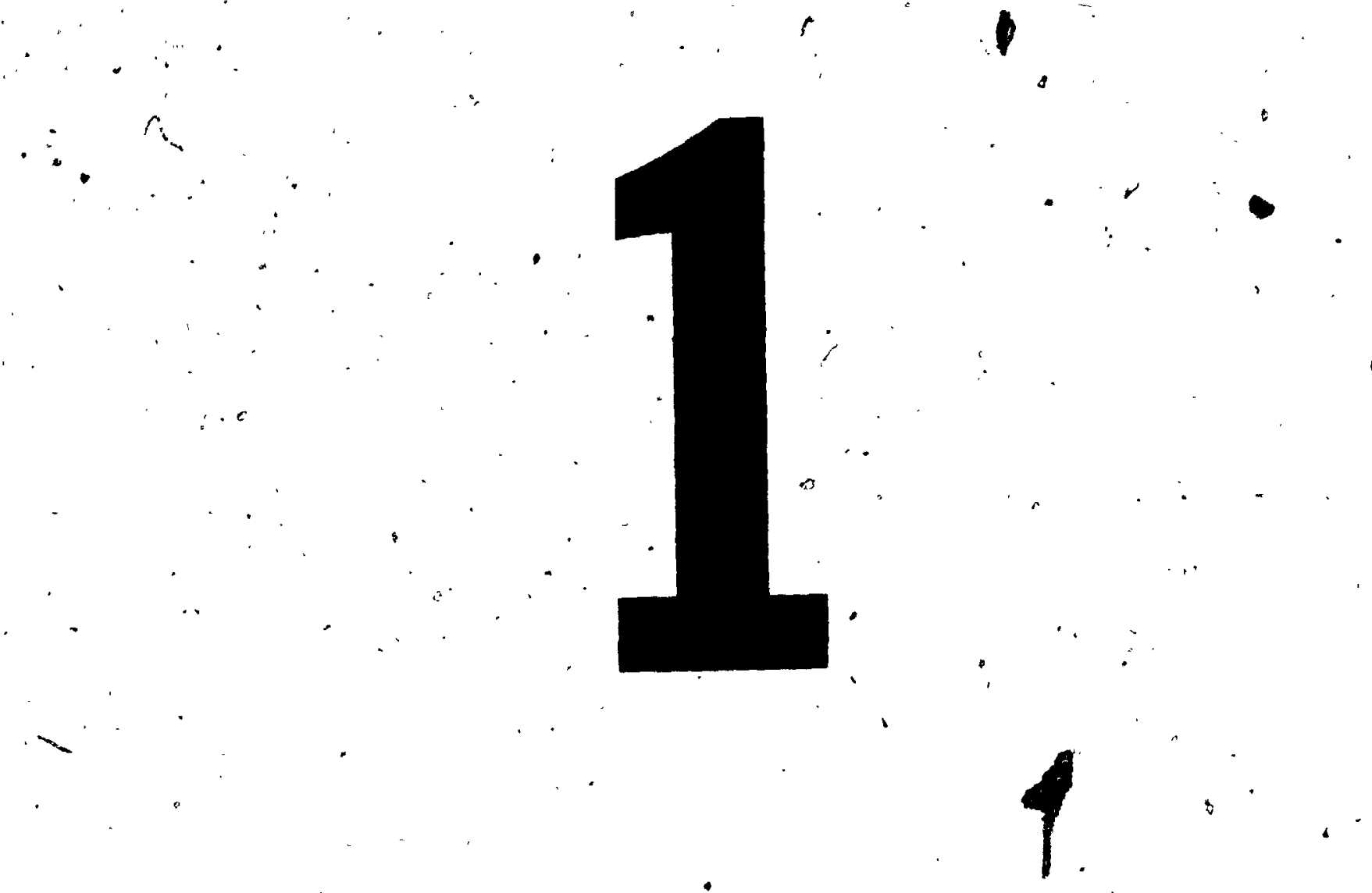

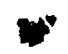

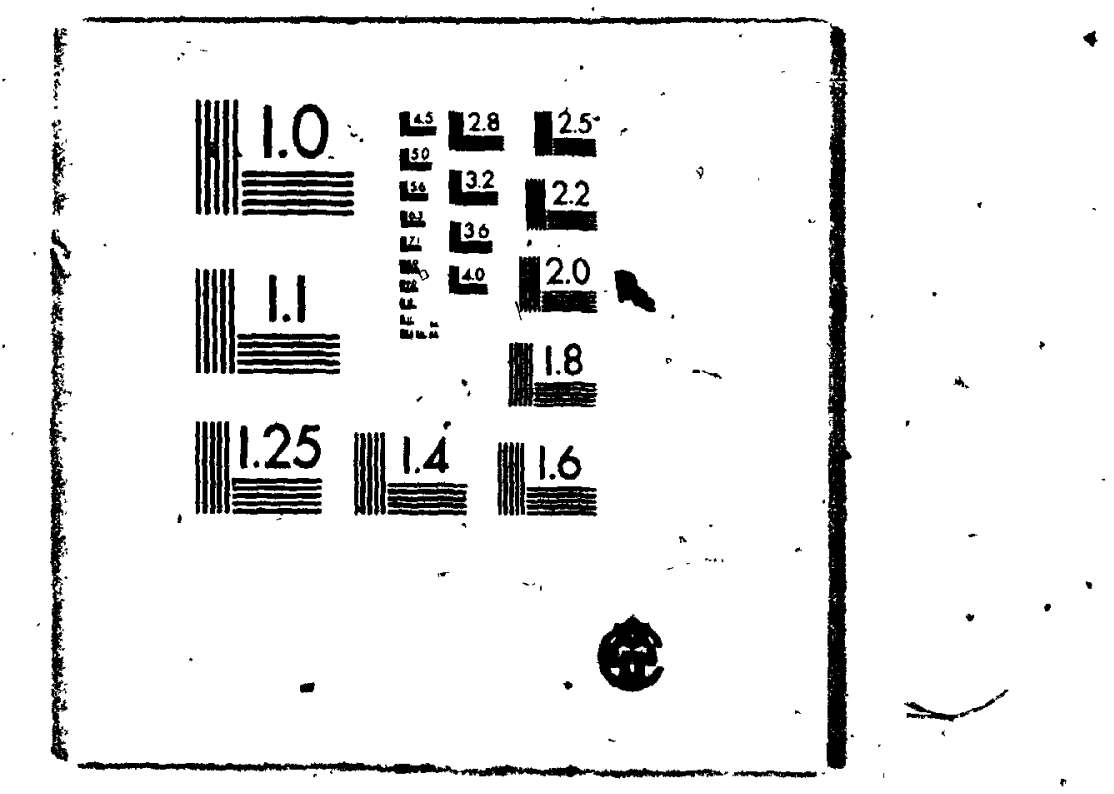


National Library of Canada
Bibliotheque natipnale du Canada
CANADIAN THESES ON HICROFICHE
THESES CANADIENNES SUR HICROFICHE

Name of aUthor/nOm de L'aUteur_ David Andrew Shaw

TITLE OF THESIS/TITRE DE LA THĖSE. Structural Setting of the Adamant Pluton, Northern Selkirk Mountains, British Columbia

UNIVEASITY/UNIVEASITE

Carleton

DEGAEE FOA WHICH THESIS WAS, FRESENTEO/. GRAOE POUA LEQUEL CETTE THESE FUT PRÉSENTËE

Ph.D.

YEAR THIS DEGREE CONFEAREO/ANWEE D'OBTENTION DE CE DEGAÉ

NAME OF SUPERVISOR/NOM DU DIRECTEUR DE THESE_R.L. BrOWn

Permission is hereby granted to the NATIONAL LIBRARY OF CANADA to microfilm this thesis and to lend or sell copies of the film.

The author reserves other publication rights, and neither the thesis no extensive extracts from-itmay be printed or otherwise reproduced without the author"s written permission.
L'autorisation est, par la présente, accordé a la BIBLOTHEेQUE NATIONALE QU CANADA do microfilmer cetto thise at de prêter ou do vendre des exemplaires du film.

L'outeur so réservo les autres draits de publication: ni la theseni do longs extraits do colleci ne doivent être imprimss ou autrement reproduits sans rautorisation écrite de rauteur.
DATEO/DATE December $1,-1980$ SIGNED/SIGNE

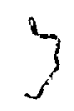

15 Bean Close

Littleover

Derby DE3 7EF

England 
Natıonal Library of Canada Collections Development Branch

Canadian Theses on Microfiché Service
Biblıothèque nationale dụ Canada

Direction du développement des collections

Service des thèses canadiennes sur microfiche
The quality of this microfiche is heavily dependent upon the quality of the original thesis submitted for microfilming. Every effort has been made to ensure the Kighest quality of reproduction possible.

If pages are missing, contact the unniversity. which granted the degree.

Some pages may have jndistim print especially if the original pages were typed with a poor typewriter ribbon or if the university sent us a poor photocopy.

Previously copyrighted materials (journal articles, published tests, etc.) are not filmed.

Reproduction in full or in part of this film is governed by the Canadian Copyright Act, R.S.C. 1970, c. C-30. Please read the authorization forms which accompany this thesis.
La qualité de cette microfiche dépend grandement de la qualité de la thèse soumise au microfilmage. Nous avons tout fait pour assurer une qualité supérieure de reproduction.

S'il manque des pạges, veuillez communiquer avec l'université qui a conféré le grade.

Là qualité d'impression de certaines pages peut laisser à désirer, surtout si les pages originales ont été dactylographiéés à l'aide d'un ruban usé ou si l'univer. sité nous a fait parvenir une photocopie de mauvaise qualité.

Les documents qui font déjà l.'objet d'un droit d'auteur (articles de revwe, examens publiés, etc.) ne sont pas microfilmés.

La reproduction, mếme partielle, de ce microfilm est soumise à la Loi canadienne sur le droit d'auteur, SRC 1970, c. C-30. Veuillez prendre connaissance des formules'd'autorisation qui accompagnent cẹtte thèse.
THIS DISSERTATION HAS BEEN MICRÖFILMED EXACTLY AS RECEIVED'

\author{
L'A THĖSE A ÉTÉ \\ MICROFILMÉE TELLE QUUE \\ NOUS L'AVONS RECUE.
}




\section{STRUC̈TURAL SETTING OF THE ADAMANT PLUTON, NORTHERN SELKIRK MOUNTAINS, BRITISH COLUMBIA.}

by

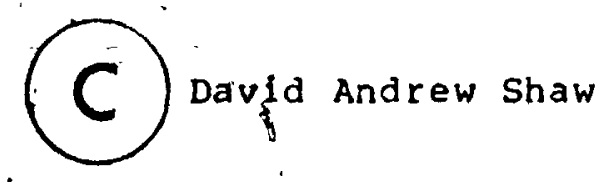

A thesis submitted to the Faculty of

Graduate Studies and Research in partial

fulfilment of the requirements for the degree of Doctor of Philosophy

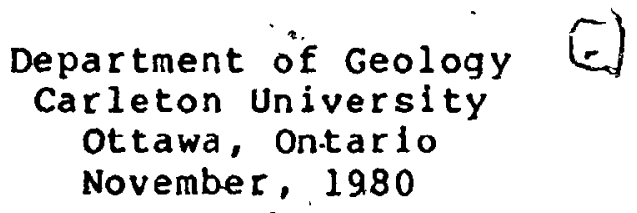

E.

Carleton University

ottawa, Ontario

November, 1980

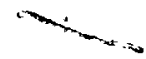




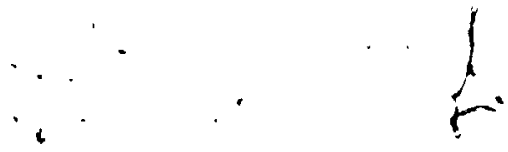

The undersigned recommend to the. Faculty of Graduate Studies and Research acceptance of the thesis

"Structural setting of the Adamant pluton, - Northern Selkirk Mountains, British Columbia"

submitted by David Andrew Shaw, B.Sc..

in partial fulfilment of the requirements for the degree of Doctor of Philosophy.

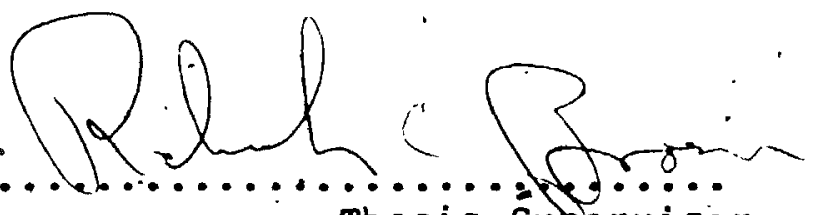

Thesis Supervisor
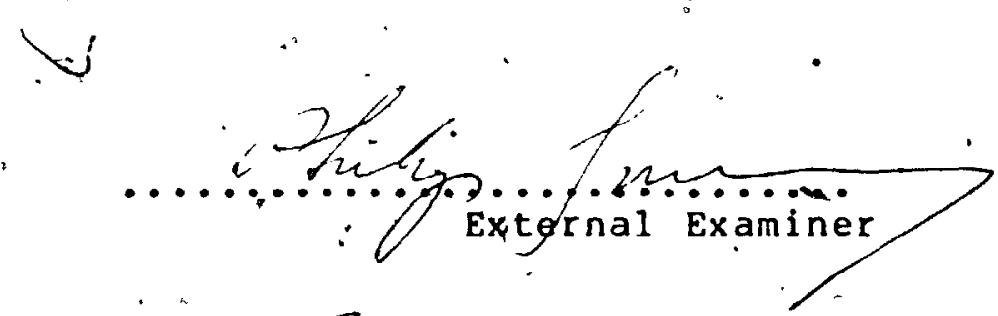

$\cdot$

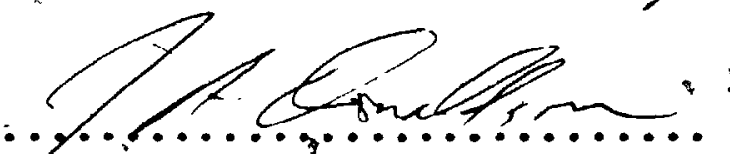

Chairman, Department of Geology

a

Carleton University November 27, 1980

Q3: 


\section{ABSTRACT}

Rock types within the concentrically zoned Adamant pluton range from hypersthene-augite monzonite in the core to biotite-hornblende granodiorite and quartz diorite in the outermost zone. The core has maintained an igneous petrological and structural character whilst the outer zones contain secondary,hydrous minerals. Chemically the body is grossly homogenous petrological differences between the core and perimeter may be accounted. for by the addition of water to. the outer zones.

The Adamant pluton has been emplaced into rocks of the Horsethief creek croup, of proterozolic age, "which is subdivided into the Lower Pelite member, the Middle Marble. member and the Upper. Pelite member. These members have been correlated with the Isaac, Cunningham and Yankee Belle Formations, respectiyely in the cariboe, Mountains to the northwest of the Northerrn. Selkirk Mounțains.

The Northern Selkirk Mountains have experienced three main phases of. deformation, the first of which probably occuried during the Paleozoic. "During this phase at least one large - scale nappe was formed that inverted the stratigraphy to the west of the study area. A planar fabric $\left(s_{1}\right)$ was produced that is generally'parallel to primary. layering $\left(S_{0}\right)$ throughout the region. The second and third phases of deformation are thought to have occurred during the Middle Jurassic. The earlier phase formed tight to 
isoclinal folds, the fxial surfaces of which strike northwest-southeast and dip towards the northeast... The form of the third phase varies from a strong crenulation to large scale, tight folds with axial surfaces that also.strike northwest - southeast but dip towards the southwest. Planar fabrics $\left(S_{2}\right.$ ard $\left.S_{3}\right)$ generally have similar attịtudes but diverge sufficiently to allow phase two hinges to be deformed about phase thrẻe structures.

On the basis of petrological composition three planar "fabrics are recognized.within the pluton. In the core zone plafioclase arystals form $a^{\star}$ semi-circular pattern that bulges towards the east. In/the outermost zones a planar. fabric, defined by compoșitional layering and composed of hydrous mineral phases, is orientated parallel to the márgin of the body. It is thought that both the core area fabric and the fabric of the outer zone' were produced as a result qf lateral,magmatio flow during the emplacement of the body. The present day differences in petrological composition of the fabrics are" a secongary feature related to the hyoration of the body, the hydrous minerals having grown during a period in which the outer part of the body was hydrated and the primary. flow fabric mimetically recrystallized. Phase two folds deform the compositional layering in the outer. part of the body and contain a. biotite foliation that is orientated parallel to their axial surfaces. 
An agje of 169 . Ma $\pm 4 \mathrm{Ma}$ was derived from zircons collected from the hyglated, part of the body. This age is interpreted to reflect the peak of regional metamorphism that achieved middle amphibolite; faciẹs and occurred after the second, but before the third; phase of deformation.

The emplacement of the pluton preceded at least the second and third phases of deformation and probably the 'first. The presence of a relatively rigid mass of Ignéous rock during the application of regional compressive stress influenced the orientation of fold.axial surfaces adjacent to the body, a' structuràl aureolé being produced around the pluton.

Analogy with the results of finite element analysis and mathematical and laboratory models suggests that the pluton has' experienced at least 9 degrees of rigid body rotation since its emplacement. The present discordant trend of the body,with respect to regional structural trends,is related to a combination of factors, the viscosity of the intruding magina. and the nature and orientation of the intruded strata being foremost.

The Adamant pluton'can be no younger 'than' the Middle Jurassic but a much older age is highly probable. 


\section{ACKNOWLEDGEMENTS}

During the cpurse of this project I have benefitted from the advice had suggestions qiven by many. I am particularly indebted "to Dick" Brown for suggesting: superyising and showing a keen interest in this project:

Qthers that merit my thanks include: clint rippett, an enthusiastic and enlightening co-worker; " John Moore and" Giorgio Ranalli. my thesis advisors; John Blenkinsop and Mike Perkins (Department, of Geology. Carleton University) ; Tom krogh'(Royal. Ontario Museum) and Mike Gorton (Department of Geology, University iof. "Torontol: William, Bowes. (Department of Enqipeering, Carleton University): Rick Maliet and cordon shorti computing services, carleton University).

The field work was financed by N.S.E.R.C. Operating Grant A2593 and by E.M.R. Résearch Agreement 2239-4-182/77. 
3

5. Metamorphic geology and textural relationships

5a. Metamorphic geology

5b. Textural relationships

5c. Minor. Igneous rocks

6. Geochronometry

6a. Introduction

6b. Previous work

6c. Recent work

7. The behaviour of an elliptlcal body in a deforming matr $1 x$

7a. Introduction

7b. Finite element analysis

7c. Mathematical and physical models

122

8. Mode of emplacement

8a. Introduction

151

8b. Discussion

8c. Emplacenent imechanisms

9. . Comparison.with Belchertown pluton

10. Summary and Conclusions

Bibliography

Append1x tables

Plates 


\section{LIST OF FFGURES}

page

1. Columbia River Big Bend location within

Canàda.

2. Study location withingig Bend of Columbia

3. Northeirn Selkirks - project areas, Adamant pluton and its structural aureole.

i.f. $\therefore$

4. Structural features of the Oinineca Crystalline Belt.

5. Major peaks within and adjacent to study area.

6. Topography and drainage - Zone A.

I.f.

7. Station Iocation map - Zone A.

i. $\mathbf{E}$.

8. Lithological map - Zone A.

$I_{1}, \boldsymbol{F}$.

9a. Structural domains around Adamant pluton.

9. Divergence zone locations.

10. Orientation of $S_{0}$ and $S_{1}$ - Zone $A$.

i.f.

11. Stereoplot of $D_{0 / 1}, D_{2}$ and $D_{3}$ fabric elentents
- Zone $A$ :

i.f.

12. $D_{2}$ minor structures - Zone $A$.

I.f.

13. $D_{2}$ and $D_{3}$ fold axial surface traces, with.

i.f. structural cross-sections.

14. $D_{3}$ minor structures - Zone $A$

I. F:

15. Stereoplot of $D_{0 / 1}$ and $D_{2}$ fapric elements.,

i. $\mathbf{f}:$ - Zone B.

16. Stereoplot of $D_{3}$ and $D_{4}$ fabric elements - Zone B.

i.f .

17. Axial surface trace map - Zone B.

i.f. 
18. Major folds adjacent to Adamante pluton.

19. Deflection of regional trends around Adamant I.E. pluton:

20. Diagrams of Mount Enterprise structure.

21. Progressive tịghtening of Argonaut Mountain structire away from Adamant piduton.

22. A.Modal classification diagram.

B. Generalized mineralogical composition and modal variation in different rock units.

23. Fabric elements within Adamant pluton.

I.f.

24. Stereoplot of linear structures within Adamant pluton.

25. Structural core of Adamant. pluton.

26. Metamorphic assemblages - Zone A."

27. Sample location map - Isotopic analysis.

28. $\mathrm{Rb} / \mathrm{Sr}$ values within Adamant pluton.

29a.uranium - lead concordia plot of Adamant pluton zircons.

29. Distribution of zircon within Adamant pluton.

30. Distribution of $\mathrm{TiO}_{2}$ within pluton.

i.f.

31: Distribution of elements." layout 1 .

i. $\mathbf{f}$.

32. Key to nodes, layout 1 .

i.f.

33. Principal stres's components, layout 1 .

i.f.

34. Trend of principal stress 2, layout ' 1 .

i.f.

35. Distribution of elements, layout 2. .

i.f.

35. Key to nodes., layout 2 .

i.f.

37. Principal stress components, layout 2.

i.f.

38. Trend of principal stress 2, layout 2.

1.f. 
39. Rotation direction with respect to initial orientation.

113

40. Finite element analysisoresult $\$$. ., 118

41. Swerving of Araxes in the matrix around a

126 rigid inclusion.

42. Relationship.between schistosity and deformed 129 pebbles.

43. Ranges of orientation for forward and backward 132 rotation of inclusions.

44. Pure shear deformation paths.

45. Total strain in an elliptical cylinder v. $\because . .137$. t. total strain.

46. Notation for definition of drag.

139

47. Types of drag patterns of passive markers

143 around rigid, elongate inclusions

$$
\text { 1.F. - in folder }
$$

XI 

$\because:$

LIST OF PLATES

A. Pluton" - country rock contact:

B. The Palisade Massif structure.

c. Folds present in the Guardsman Peak Ridge.

D. Major structures outlined by the Middle Marble member.

E. Lithology and structure.

F. Fold form.

G. Fold form.

H. Fold form and Mount sir Sanford.

I. Fold form.

J. Igneous structure and, petrology.

K.) Metamorphic petrology and microfablics.

L. Varieties of garnet form.

M. Metamorphic petrology and microfabrics.

XIII 
Q

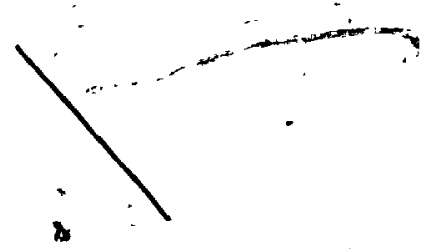

1. INTRODUCTION

1a. Purpose

On the map of the Adamant pluton by Fox (1969) a distinct change in the orieltation of compositional layering and planar foliations within Horsethief Creak Group strata is apparent adjacent to the plutor. Especially noteworthy is the outcrop pattern of the Marble unit of the Horsethief Creek Group (Unit 2 on the map) around the eastern end of the pluton and along the norehern margin of the body. The overall form of the 'pluton fesembles that of a giant porphyroblast that is strongly discordant to a foliation that wraps around it.

An investigation of the factors controlling the re-orifntation of the . planar structures and outcrop pattern around the body was suggested to the author by R. L. Brown. In understanding the relationship" of the regional phases of deformation,to. the pluton it was also hoped to determine a precise time of emplacement of the body. Fox (1969) believed the pluton to have been emplaced synkinematically". but given such a discordant orientation with respect to the regional structural trend, this' hypothesis did not appear feasible.

The investigation was an integral part of a group project being carried out by graduate students at ćarleton University under the supervision of. R. L. Brown. In ช 
studying the geology of the Adamant pluton and its environs a link was provided between the area to the south, studied by Tippett; and that to the north being. studied by Perkins (Figure 3).

In order to understand the emplacement history of the pluton it was first necessary to establish the stratigraphic shuccession and the deformation and metamorphic histories of the surrounding country, rocks.

1b. $\begin{aligned} & \text { Previous work } \\ & \text { Brief descri }\end{aligned}$

Brief descriptions of the Adamant pluton and. Its environs are presented in the Geological survey of Canada reconnaissance maps and reports covering the Rogers pass map. area (Wheeler, 1963) and the Big Bend map area. (Wheeler, 1955).

The only detailed geological study related to the Adamant pluton is that by Fox (1969), based on his M.Sc. and Ph.D theses. His study was primarily a petrological one, minor attention being given to the structural complexity of the rocks around the pluton.

The Selkirk Mountains, Dogtooth Range and Esplanade Range (flgure 2) have been extensively mapped by workers fro:y, the" University of Calgary ôwind, 1967; Elilison, 1967; Jones, 1969; Ghent, Jones and Nicholls, 1970; 'Simony and Wind, 1970; Poulton, 1970; De Vries, 1971; De Vries, Ghent, Jones and Simony, 1971; Ghent and De Vries, 1972; Jones, 1972; Poulton, 1973; Ghent, 1975; Ghent and McKee, 1975; 
ONeill, and Ghent, 1975; Simony, 1975). Their studies have emphasized. the fields of metamorphic petrology, structural geology. stratigraphy and sedimentology.

Sỉnce. 1973 students from Carleton Univérsity, Ottawa, - under the supervision of R.L. Brown, have been warking in the region enclosed by the Big Bend as fair south as the Esplanade Range of Pranzen, 1974; Van der Leeden, 1975; Tippett, 1976; Lane, 1977; Psutka, 1978; Perkins, in progress, Leatherbarrow, in progress). The work presented here is an integral part. of Carleton University's Northern Selkirks project (Figure 3).

1c. Location and Physiography

The Selkirk Mountains are centrally located in the eastern Canadian Cordillera of southeast British Columbia and are enclosed on the west, north and east by the Big Bend of the columbia River (figures 1 and 2 ).

That part of the Northern Selkirk Mountains studied during the course of this project is, outlined in Figures 2 and 3 .

Elevations 'in the area reach a maximum of $3,665 \mathrm{~m}$ above set level at the peak of mountffir sandford (Plate H3), with valiey floors descending tó $1,000 \mathrm{~m}$ above sea level. Above $1,750 \mathrm{~m}$ the terrain is commonly ice-or 'snow-covered; below' $1,259 \mathrm{~m}$, the valley slopes and lower reaches are densely vegetated (Figures 5 and 6 ).

July and August are the optimum moriths for mapping 


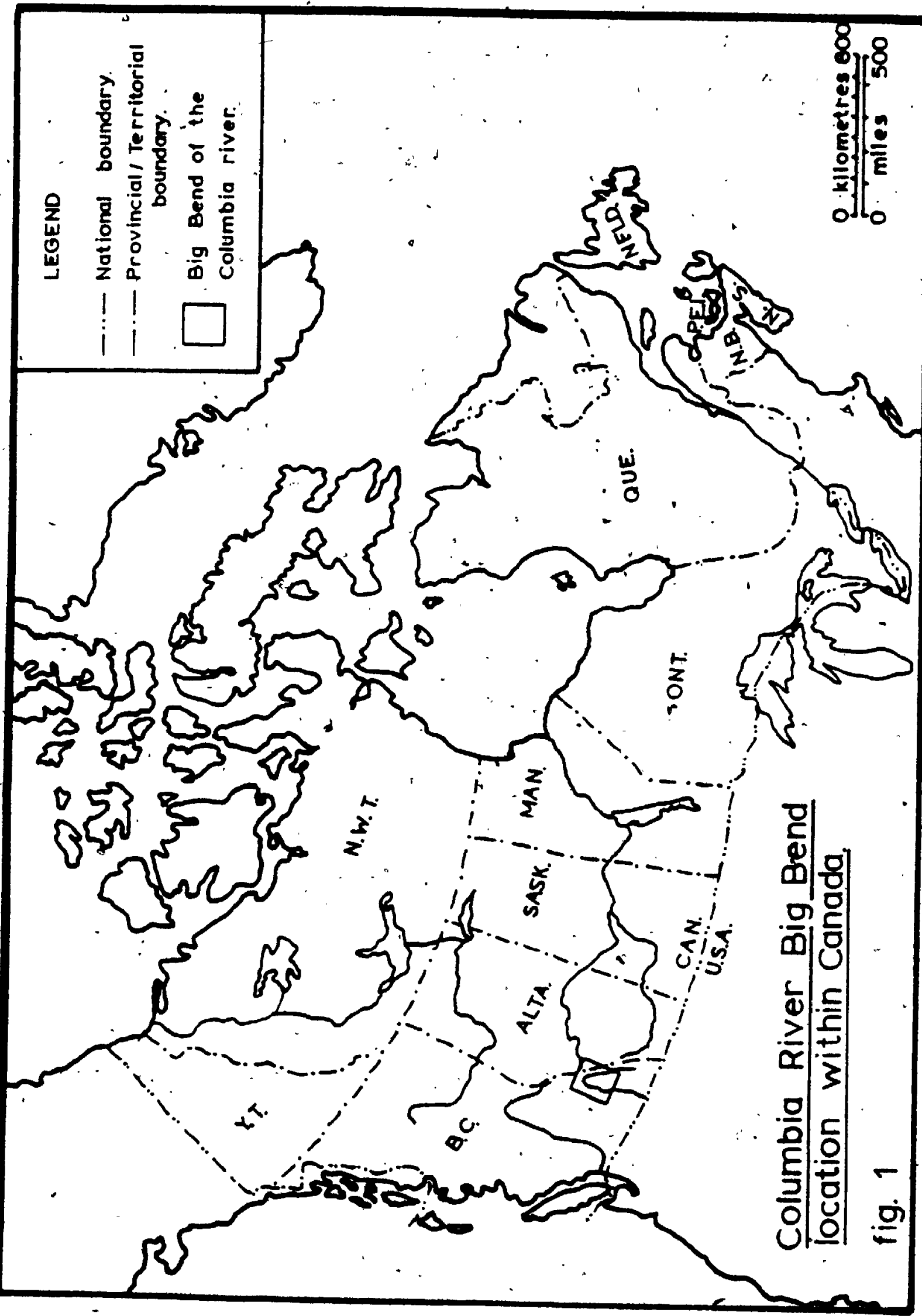


although' the field season was always extended into late June and early September. Mapping was undertaken in 1974, 1975, 1976 and 1977, the latter three years being spent exclusively on and around the Adamant pluton.

The'study area lies within.N.T.S.9"1:50,000 map sheets $82 \mathrm{~N} / 12,8 Z \mathrm{~N} / 13,82 \mathrm{M} / 9$ and $82 \mathrm{M} / 16$.

1d. Regional Geology,

The Selkirk Mountains are part, of the Omineca Crystalline Belt (Douglas et al., 1976) which also includes the Kootenay ArC and Monashee Mountains (Figure 4).

Within the Monashee Mountains is a terrain of high grade metamorphic rocks termed the "Shuswap Metamorphic Complex" (Jones, 1959; Reesor, 1970). The vầrious gneiśs domes composing, this complex have ylelded isotopic ages ranging. Erom 3 Ga (Dunçan, 1978) to 1.9 Ga (Wanless and Reesor, 1975). These core gneisses appear to be continuous betyeen Individual domes (Read, 1980; Brown, 1980a) and form a basement terrain with a minimum age of 2 billion years.

overlying this basement is a succession of shallow marine platform sediments, which form an autochthonous cover of. 1. to $3 \mathrm{~km}$ thickness (Brown and Psutka, 1979). Lithology is variable; a basal quartzite is overlain by carbonate, calc-silicate and-pelitic rocks. These rocks have been variously asslgied a Cambrian age. (Wheeler et al.. 1972; Reesor, 1970; Hoy and McMilian, 1979) or correlated with early Proterozolc (Belt-Purcell) sediments (Brown and 


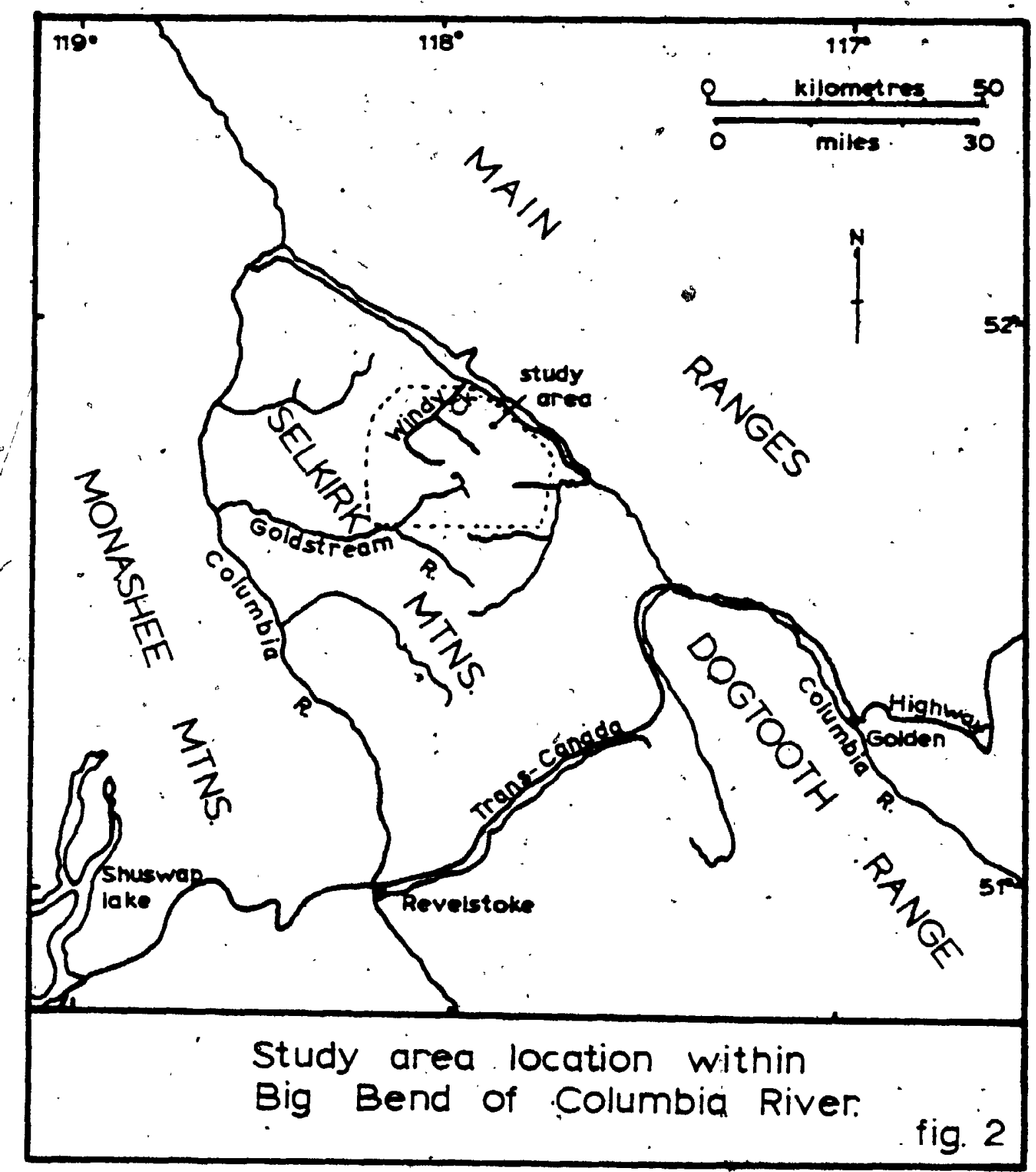


7

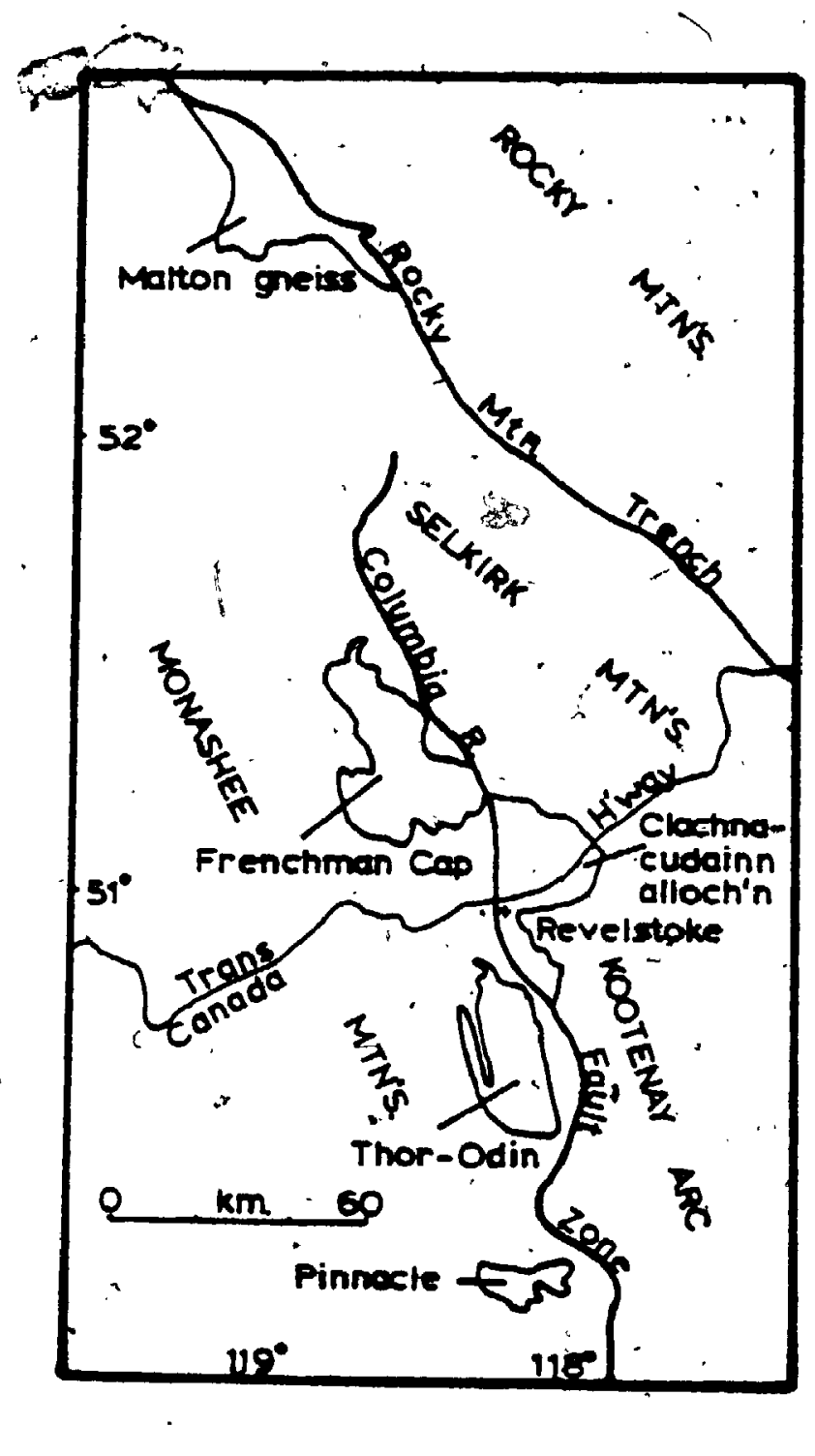

Figure 4 Structural and physiographic features of the ominece crystalline pelt.

3

from Brown, 1980. 
Psutka, 1979; Brown and Read, 1979).

A thick succession of pelitic and amphibolitic rocks structurally overlies the autochthonous strata. "Mylonitic fabric together with fault breccia and gouge occur along the length of this zone (Brown and Psutka, 1979; Browh,1980a; Brown, $1980 \mathrm{~b}$ in press). The rocks that crop out in the Northern Selkirk Mountains are contained within this. allochthonous sequence. They consist of the Upper Proterozoic Horsethief creek Group and the Lower Paleozoic Hamill, Badshót and Lardeau, successions. The strata represent a westerly prograding cycle that culminates in the, Lower Cambrian Badshot Formation, a cárbonate gank deposit. The Lardeau Group consists primarily of a' deep water sedimentary accumulation (wheelér et al., 1972; Sheeler and Gabrielse; 1972).

Allochthonous " cover rocks occur as fault slices along. the eastern flank of the columbia River fault zone (Figure 4) (Wheeler, 1955;. Brown and Psutka, 1979; Read, 1979; Brown, 1980a). Selkirk Mountain and Kootenay Arc strata havę been transported eastward relative to the shuswap basement rocks and are located above the hanging wall of the colunbia River fault (Read, 1979; Brown, 1980b):

1e. Regional Tectonje History

In the Omineca, Belt there is evidence of four major episodes of deformation. These occurred in the proterozolc (Racklan, - East Kootenay orogeny), Ordovician, Devorian to 
Éarly Mississippian (Carlbooan or Antler orogeny) and during the Middle Jurassic.

In the Northern Selkirk Mountain's the earliest event recognized is the probable pre-Mississippian one (see Read 1975. 1976) where large nappes are developed along the western flank of the Selkirk-Kootenay terrain.

During the Middle Jurassic extensive deformation and metamorphism occurred in the omineca terrain. Two, and lacally three, phases of folding during this period are recognized in the Northern Selkerk, Mountains. The first occuried before the. regional metamorphism peaked at mid-upper amphibolite grade, and produced folds that were overturned towards the west. After the metamorphic peak, structures overturned towards the east were generated. Interference between these two successive phases produced the Selkirk Fan Structure-(Brown and Tippett, 1978).

During this tectonic activity granitic plutons were emplaced. The beginning of the Late Jurassic is thought to mark the termination of regional ductile deformation, based on $\mathrm{Rb} / \mathrm{Sr}$ dating of post-tectonic intrusive events (see Duncan et al.. (1979).

Brown (1978) argued that late- to post-metamorphicfolds located in the hanging wall of the purcell Fault, adjacent to the Rocky Mountain. Trench in the Northern Selkirk Mountains, are contemporaneous with the initiation of thrust faulting in the western margin of the Rocky Mountain 
Foreland.

Uplift of the Omineca Belt from Late Jurassic to Eocene time is indicated by data from the Wolverine Complex of the Omineca Belt (Pigage, 1976), and by $K / A r$ ages on late Jurassic plutonic rocks in the Omineca Belt (Duncan et al.. 1979).

Some high angle normal faults in the Rocky Mountain Belt have been shown by (Prlee (1965) to have been active in Upper Eocene and later times.

1f. Regional Tectonic Models

The traditional view concerning the evolution of the Rocky Mountain Foreland Thrust and Fold Belt has been that it is younger than the orogenic activity that gave rise to : the metamorphic core complexes of the omineca Belt.

Price and Mountjoy (1970) presented a new vilewpoint when they proposed a cause and effect relationship between the emergence of the core complexes and the generation of the thrusts and folds to the east. An allochthonous origin is required"for the metamorphic core complexes in the Prig and Mountjoy model because they assume that cratonic ro as far west as the Rocky Mountain Trench remained $r$ whilist. the cover rocks were contracted over a iminfum distance of $320 \mathrm{~km}$.

High angle faulting involving basement beneath the Main Ranges was invoked in the model proposed by campbell (197.3) although he accepted the presence of a passive basement 


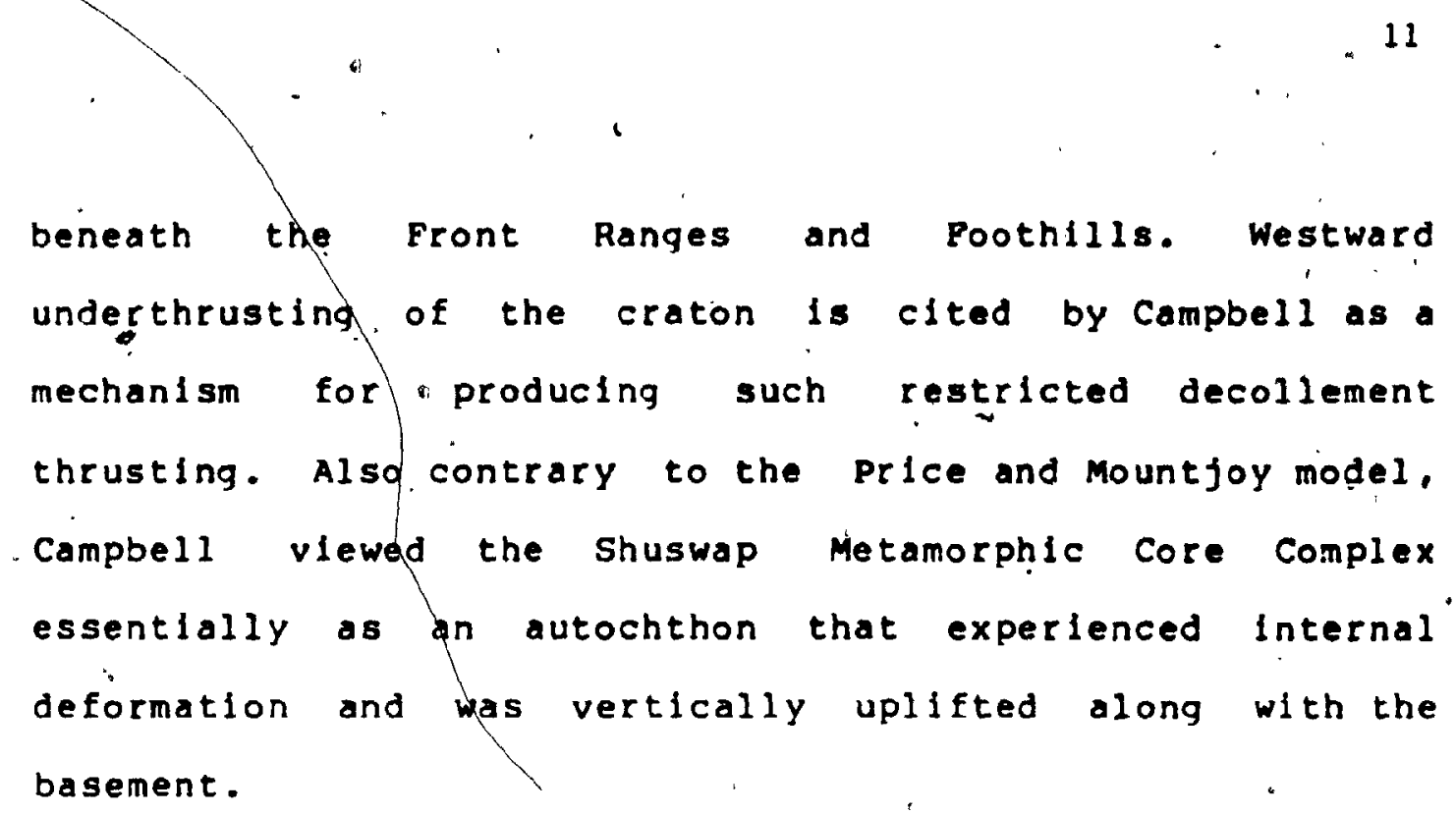

The most recent tectonic model is that proposed by Brown and Tippett (1978) which was subsequently expanded by Brown (1980b) to include the Shuswap Metamorphlc Complex as well as the selkirk-Kootenay terrain. In this model there are three main elements present during the proterozoic and part of the Paleozolc. In the west the Aphebian gneisses, that now crop out as domes in the Omineca Crystalline Belt, formed a platform upon which a shallow marine succession of probable precambrian aqe was. deposited. To the east lay the distal edge of the Rocky Mountain miogeocline, the Proterozoic cover forming a westerly thickening wedge. overlying these distal sheif to slope sediments, which are recognized in the Selkirk Mountalns, were Upper proterozoic-Cambrian shallow marine clastics. In the model proposed by Brown (1980b) the eastern and western elements were separated by the Selkirk-Kootenay Basin. Ellled with'. over $10 \mathrm{~km}$ of proterozolc sediments and volcanics, which was then overlapped by a westerly prograding wedge of cambrian 
shallow marine clastics (Wheeler, 1965; Wheeler and. Gabrielse, 1972; Brown et al.. 1978). Transitional or oceanic, cather than continental, basement is thought to have originally. floored this basin (Brown, 1980b).

The pre-Middle Mississipplan nappes in the Kootenay terrain (Read, 1975, 1976) were believed by Brown to be related to a paleozolc periot of plate convergence. Oceanic crust to the west was subducted below the omineca terrain resulting in plutonism and the initiation of the coliapse of the western margin of the selkirk-Kootenay Basin (Brown, 1980b). Data initially presented by Brown and Tippett (1978). from the Northern Selkirk Mountains, and later amended by Bgrown and Read (1979), suggest nappe displacement from east to west, 1.e. from the Basin westward across the Shuswap basement terrain.

Westerly-overturned structures were generated in the Selkirk - Kootenay Basin as a result of deformgtion during the Middle Jurassic (Brown, 1980b). Brown and Tippett (1978) kinematically accounted for these structures by invoking an inclplent underthrusting of the shuswap basement below the strata of the Selkirk-kootenay. Basin.

Timing of uplift of "the Onineca terrane is constralned by a pressure environment of at least flve kb. during and immediately after this phase of deformation. The peak of metamorphism occurred between this deformation phase and the next. 
8

- Shuswap terrain encroached further upon the cratonic margin with continued collapse of the slkirk-kootenay Basin, "basement" material of the latter being consumed ët ther beneath the shuswap basement or below the cratonic marqin to the east.

Easterly-overturned folds were generated in the eastern part of the Basin as the tectonfically thickened and buoyant Omineca terrain was underthrust ingtially by the basement of the collapsing Basin and then by the cratonic rocks of the tontinental sứrgin (Brown and Tippett, 1978; Brown, 1980p).

continued uplift of the omineda terrain and progressive underthrusting of the basement initiated easterly-imigrating decollement thrust faults in the Rocky Móntain Foreland (Brown, 1980b). Progressive thickening and uplift of the western. end of the Foreland wedge would account for the edstward miqration of the deformation (Chapple, 19787).

Eastward displaçement, along the columbia River fault zone," af detached shuswap cover rocks occurred in conjunction with post metamorphic uplift (Brown, 1980b). This early movement was possibly a distal manifestation of thrust faulting in the Rocky Mountain Foreland.

Price and Mountjoy (1970) in their model showed that this decoliement thrusting in the eastern part ofothe Rocky Mountains continued into the Paleocene.

From this brief, review it appears that the Adamant pluton has been emplaced into what is now the selkirk 
14

allochthon. In this thesis the author will contend that the pluton was emplace early in the evolution of the mountain. $\rightarrow$ belt before displacement of the selkirk allochthon.

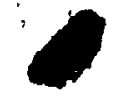


2. STRATIGRAPHY

2.a Introduction

Westward thickening an'd prograding wedges of sediment were characteristic of the initial deposition in the Cordilleran' geosynçine, a structure initiated more than 1.300 Ma ago. The Belt-purcell Superorap, a continental terrace wedge deposited on the western flank of the North American craton, is the oldest sedimentary succession exposed in southeastern British Columbia and the northern United states. Overlying is the windermere supergroup, of Hadrynian age, represented in the Northern Selkirk Mountains "by" the Horsethief Creek Group. In parts of southeastern British Columbia the basal part of this Group includes a cọarse diamictite and conglomerate, overlain by thick feldspathic grits and pelites. However in the Northern Selkirk Mountains the basal part is not recognizedi instead the lowest member is one of transitional slate which in turn is overlain by a carbonate-rich member and a mixed carbonate and clastic 'member.

Crossbedded sandstones. and orthoquartzites of the tamill Group, with a probable age of Lower Cambrian, overlie the windermere Supergroup. The Hadrynian clastic sedímentary. wedge is covered by pelites and archaecyathid 1 imestones deposited on a shallow marine platform.

The three members of the upper part of the Horsethief Creek Group, outlined above, are exposed in the study area, 
each member recognized can be correlated with subdivisions recognized to the north and south. These formations have been tentatively correlated by Brown et al. (1978) with formations of the Cariboo Grobp in the Cariboo Mountains (Campbell et al., 1973).

Detailed lithological descriptions of the individural sub-units that compose the three members of the Horsethief Creek Group within the study area are presented in Appenaix tables 1 to 5 . The distribution of the rock types within

$\therefore$ the study area is shown in Figure 8; geographical locations referred to in the text are shown in Figure 5.

2b. The Lower Pelite member.

The Lower Pelite member (L.P.m.) is exposed predominantly in the northwest quarter of the study area (Figure 8). It lies in the core of the Gold River anticline. (Figures 12, 16) which is the northern extension of the large Cherub Mountain - Esplanade Range anticline (Tippett, 1976; Brown and Tippett, 1978): The axial surface trace of this structure strikes northwest, from the Esplanade, Range, towards the southeast corner of the Adamant pluton. Here it diverges around the eastern end of the plution and part-way. along the northern margin before resuming. a northwest strike in the Windy Range (Figure 12). Stratigraphic sections of the western limb are detailed in Appendix Tables 1 and 2; the eastern limb was not examined.

The base of this member is not exposed in the study 
area. The top is defined by the first occurrence of major pure ant impure carbonates which mark the base of the overlying Middle Marble membẹ.

The Lower Pelite member is at least 1,300, m thick; in Tippett's section to the south (Tippett) 1976, p. 24) a thickness of at least 900 metres is recorded. Poulton (1970) gave a thickness of 1,000 metres in the Dogtooth Range. Neither poulton nor Tippett observed the base of the member .

- Within thl member there are five main units, detailed in Appendix. Table 1. The lowest, Unit $A$, comprises interbedded pelites and psammites characterized by the presence of a thin marble horizon.

Sparselyscattered thraughout this unit are thin, continuous amphlbolite bands, both discordant and concordant on a local scale (Plate H2): Kyanite and garnet are extensively developed within the pelites.

Unit : B conşists mainly of pelite and semi-pelite. Amphibolite layers, with an average thickness of $15 \mathrm{~cm}$, are more numerous " than in Unit $A$. Because of their consistent concordancy with bedding and lateral persistence they are presumed to be para-amphobolites. In the Lake Sarah section (Appendix Table 1) a clean, light grey, medium grained, grit horlzon overlies the amphibolite-rich section.

Unit $C$ is transitional between the underlying and overlying units. It consists of thin $(5$ to $15 \mathrm{~cm})$, 
concordant and laterally persistent amphibolite layers with an aluminosllicate-poor pelite and semi-pelite host rock. Towards the top of this unit the pelite tends towards a rusty appearance and the amphibolites become thicker and more discordant.

The rusty yellow pelite and flaggy semi-pelite of Unit D are the most commonly outcropping rock types of the Lower Pelite member. Thick, massive and locally concordant amphibolite layers are a distinctive feature, the associated brown staining of adjacent strata making the unit easy to locate from a distance. Para-amphibolites similar to those described in, Units $A$ and $B$ are also common. A deeply weathered and "crumbly" muscovite-rich pelite' is usually associated with the massive amphibolites.

On the south side of the Mount Palmer - Mount sir Sandford ridge a quartz-pebble conglomerate, with calcareous pellte matrix, occurs in the upper part of this unit. This horizon has not been recognized elsewhere in the Lower Pelite member although there is a con̈spicuous quartz-pebble conglomerate in the Upper pelite member.

The abundance of amphibolite decreases within Unit $E$, which is predominantly carbonate-rich pelite and rusty marble representing a transition into the overlying Middle. Marble member (Plate G3).

In the Mount Stockmer section, (Appendix Table 2), Unit E is much thicker than elsewhere. At its base and top, there 
is carbondte-rich pelite and rusty pelite, both with abundant tremolite and diopside. The lower carbonate-rich zone overlies. a massive amphibolite layer with a thickness of at least $10 \mathrm{~m}$. The upper and lower carbonate zones are separated by a considerable thickness of flaggy pelite. In the Lake Sarah section (Appendix Table 1), and on the south side of the Mount sir Sandford - Mount Palmer ridge, Unit $E$ has only a relatively minor thickness with sparse. amphibolites underlying the Middle Marble member.

2c. Middle Marble nember

The base of the Middle Marble member (M.M.m) is marked by the first occurrence of massive pure and impure calcitic and dolomitic marbles (Appendix Tables $1-5$, Plate E4).

It crops out almost continuouslyoaround the pluton and forms the peaks of Mount sir sandford, Shaw Peak, Mount Stockmer, Ravelin Motrtain, Palisade Mountain and Mount Enterprise, as well as numerous unnamed peaks that border the northern edge of the pluton.

The top of the member is exposed mainly along the southern perimeter of the body and is marked by a relatively rapid transition into pelites, psammiţes, and grits, the basal strata of the conformably overlying upper Pelite member (Uึ.P.m). The Middle Marble member is wrapped around the eastern end of the pluton where it generaliy crops out as two layers of marble separated by interbedded pelite, carbonate-rich pelite, psammite, quartzite and rusty marble. 
The basal main marble layer is commonly the thicker of the two and is the one that forms the massif of Mount sir Sandford (Plates Dl, H3).

A layer of quartzite is usually associated with the basal marble. At Mount Stockmer there is a layer of dirty grey quartzite directly below the lower main marble; in the Palisade. massif there are quartzite layers directly below and above the lower main marble. Tippett (1976) also noted the presence of quartzite, in close proximity to the lower marble in the area to the south. such an association implies a rapid facies change, the nature of which is discussed by Tippett, before and after the marble was deposited.

A distinctive feature of the lower main marble unit (Unit 2a) in the Mount stockmer section is the presence of pods and lenses of amphibolite'(Plate EI). The amphibolite is offen rimmed by a reaction zone of brown carbonate and diopside.

The M.M.m. exhibits a rapid variation in thickness along strike, a feature also described by Tippett (1976) and by Perkins (pers comm., March, 1978). In the Palisade massif: (Appendix Table 4) it is at least $180 \mathrm{~m}$ thick, whereas in the Buardsman ridge it decreases to $40 \mathrm{~m}$. In the south wall of palmer creek the member thins rapidly, in the lower part of the valley it is absent. The member reappears in the lower part of the north wall and thickens rapidly. 
adjacent to and in the Mount stockmer massif. Whilst some of this thickness variation may be primary it is thought that the main control is secondary and related to the mode of emplacement of the Adamant pluton, a topic discussed further in Chapter 8.

Towards the top of this member in the Goldstream massif there is a carbonate conglomerate horizon with elongate, carbonate clasts in a matrix of blue-grey marble (Plate G4). A distinctive feature of this clastic horizon in the lack of terrigenous material, possibly indicating an isolated carbonate bank source area (Tippett, 1976).

2d. Upper Pelite Member

"The Upper Pelite member (U.P.m.) rests conformably upon the Middle Marble member and crops out along the souther $n$ margin of the pluton. The top of the U.P.m. was not recognized within the "ftudy area but'it is overlain elsewhere by the Late Proterozoic-Cambrian Hamill Group.

The maximum thickness recorded in. the study area is $3,175 \mathrm{~cm}$ (Appendix table 5 ). To the south Tippett (1976) records a $2,900 \mathrm{~m}$ thick section from the top of the Middle Marble member to the base of the Hamill Group. Within the region to the south a northwestward thickening of the U.P.m. is observed (Tippett, 1976).

Within the U.P.m. there are 5 main units (Appendix Table (5). Unit $A$, at the base of the member, is transitional in the lower part from the underlying M.M.m. 
Calc-rich pelites are succeeded by slaty pelites and these in turn are overlain by interbedded quartzite, psammite, pelite and semi-pelite $1,500 \mathrm{~m}$ thick.

. Traces of copper mineralization are evident in the upper part of Unit $A$ and in Unit $B$; this latter unit is "predominantly composed of finely laminated pelite containing thin layers. of green and brown, carbonate-rich rock. This unit can be traced eastwards along the southern margin of the pluton and southwards into the area of Sonata Mountain where it was recorded by Tippett (1975).

Overlying the striped pelite is a thin horizon of rusty yellow pelite that contains iron-stained, carbonate nodules. Uni.t $C$ is a massive quartzite-pebble conglomerate, the - lower contact of which is sharp whilst the upper contact is transitional into the finer grained, grit sequence of Unit $D$ (Plate E3). Within this unit grits are interbedded with psammite, quartzite and pelite.

Finely laminated pelites, rich, in.fuchsite (Brown. 1980, pers. comm.) and metamorphic index minerals, form Unit E. The rock is migmatitic, having pods of quartz and feldspar throughout. 
3. STRUCTURAL GEOLOGY OF THE ROCKS SURROUNDING THE ADAMANT

PLUTON

3a. Introduction

Peripheral to, and concentric with, the Adamant pluton.

is a belt of country rock within which the structural geometry has been influenced by the presence of the pluton. This area is termed the structurat aureole (Figure 3). The study area includes the structural aureole in its entirety and a part of the Northern Selkirk Mountains that lies outside. of it.

The study area has been divided for convenience, of description into three parts: Zones $A, B$, and C (Figure 3).

Zone $A$ is that part of the structural oureole that lies to the east of Norman Wood Creek (Figure 3), and was mapped by the author. This zone has been subdivided into nineteen domains (Figure $9 a$ ). A domain is defined as an area within which there is a similarity in the orientation of structures

- associated with individual phases of deformation. Domain boundaries are bocated where changes in structural orientation occur; each domain therefore contains a unique set of structural orientations.

zone $B$ is the remainder of the structural aureole and lies to the west of Norman Wood Creek (Figure-3). This zone was mapped and reported by Franzen (1974), and van der Leeden (1975).

zone $C$ lies outside of the structural aureole (Figure 


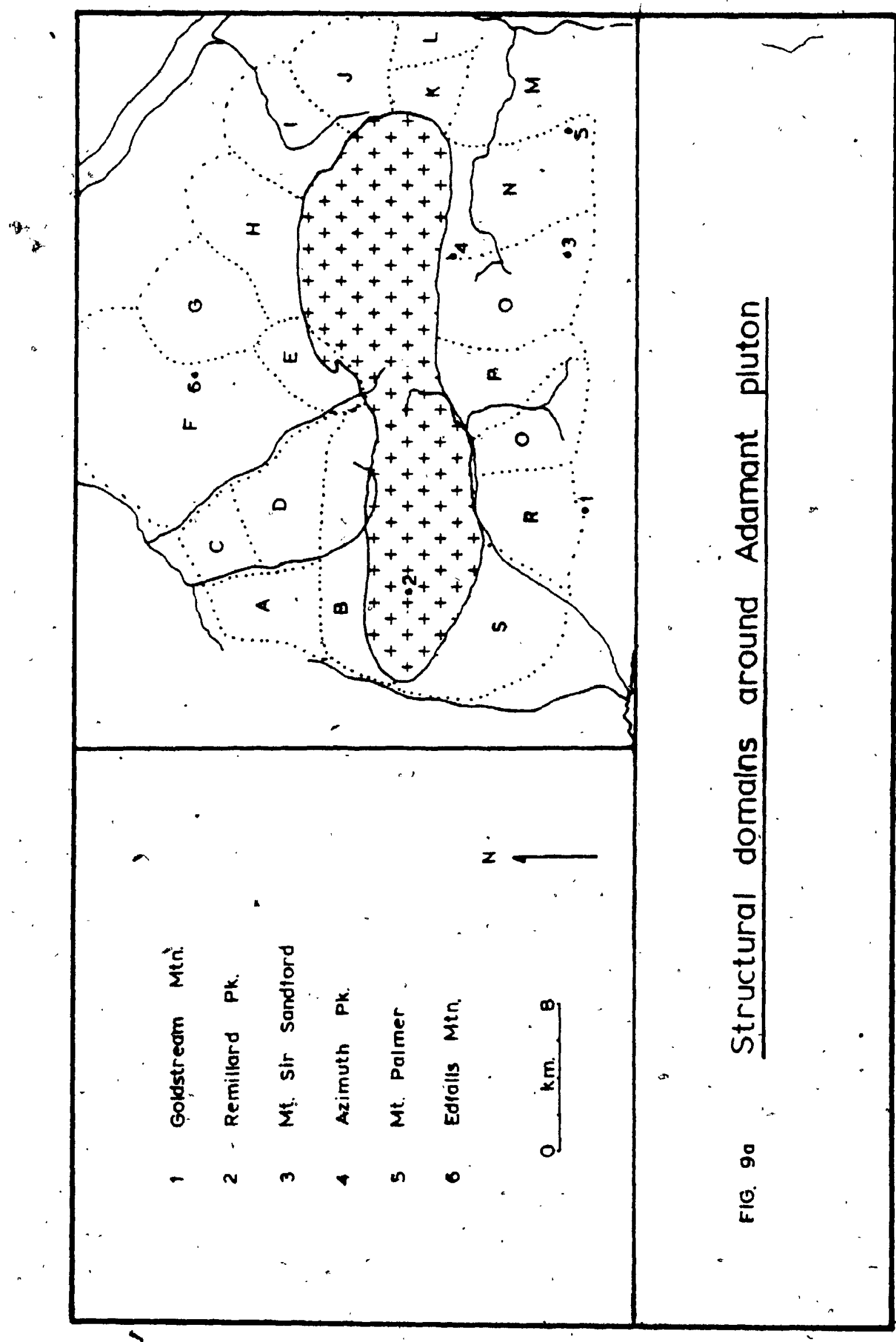


3) and was mapped by Lane (1977). Perkins (In progress), Brown and Tippett $(1978)$ and this author'.

Three majot phases of deformation have been recognized in the study area; each of these phases can be correlated with deformation events in adjacent areas and throughout the Northern Selkirk Mountalns, (Frarizen, 1974; Van der Leeden, 1975; Tippett, 1975; Lane, 1977; 'Perkins, pers. comm., $1978)$.

A description of the structures associated with each phase, generally applicable throughout the Northern sepkirk Mountains, is qiven below. A more detalled description of the deformation within the study area is presented later. The reader s referred to the following figures for. this chapter:

Fiqure $7^{\circ}$ : Station location map - Zore ' $\dot{A}$.'

8 : Litholoqical map - Zone A.

9 : Divergence zone locations.

9a: Structural domains around Adamant ṕluton."

10 : Orientation of $s_{0}$ and $s_{1}$ - Zone $A$.

11 : Stereoplot of $D_{0}-1, D_{2}$ arid $D_{3}$ fabric elements Zone A.

12 : $D_{2}$ minor istructures - Zone $A$.

13 - $D_{2}$ and $D_{3}$ fold axial surface traces with structural cross sections - Zone $A$.

$14: D_{3}$ minor structures? Zone $A$.

15 : Stereoplot of $D_{0-1}$ and $D_{2}$ fabric element - 
Zone $B$.

15 : Stereoplot of $D_{3}$ and $D_{4}$ fabric elements Zone $B$.

$17^{\circ}$ : Axlal surface trace map - zone B.

18 : Major folds adjacent to Adamant pluton.

19 : Deflection of regional trends around Adamant pluton.

20 : Diagrams of Mount Enterprise structure.

21 : Progressive tightening of-Argonaut Mountain

: structure away from Adamant pluton.

3b. Reqional phases of deformation

Phase one

The initial phase of deformation produced tight to isoclinal folds varying in size from minor folds, with limb lengths of $0.3 \mathrm{~m}$ (Plate Fl), to nappes with limb lengths of at léast $10 \mathrm{~km}$.

Within Zone B, adjacent to the Goldstream River.a. phase two folds are superimposed upon. Inverted strata, thus indicating the presence of, a pre-phase two nappe (Van der Leeden, 1975; Brown et al., 1978). This westward-facing structure (Brown and Read, 1979) has a limplength of at least $10 \mathrm{~km}$.

Whereas the noppe described above appears to be an isolated, major phase one structure within the immediate periphery of the stury area, it is only one of a number in the reglon between the Shuswap and Rocky Mountains teerrains. 
In the Kootenay Arc, nappes attributed to a fitst phase of deformation have been described by fyles (1964)," Ross (1970), Hoy (1974, 1975), Read and Wheeler (1975) and Read (1975, 1975). Thompson (1972) and Zwangig (1973) described nappes involving Paleozoic strata which overlie gnelsses of the Clachnacudainn Salient. To the north of the Big Bend of the Columbia River, near Mica Creek, simony (1975) and Robbins (1975) also reported evidence of nappe formation. The regional development of these nappes is believed to have occurred during the early Mississippian Caribooan of Antler orogeny (wheeler et al., 1972).

Associated with the Goldstream nappe and other, but minor, phase one folds in the study area and adjacent areas is a foliation orientated parallel to the axial planes of those folds and paraliel to bedding ( $S_{0}$ h except in hinge areas. This fabric is composed of biotite and muscovite plates, èlongated grains gf quartz and carbonate, being most conmonly developed in pelites, semi-pelites and psammites. This fabric has been strongly transposed by later deformation phases.

Phase one folds, other than the 'nappe referred to above, are rare within the Northern Selkirk Mountains. They. generally occur as isolated, isoclinal, minor closures with younger structures supertimposed.

Phașe Two

The second phase of deformation produced tight to open,

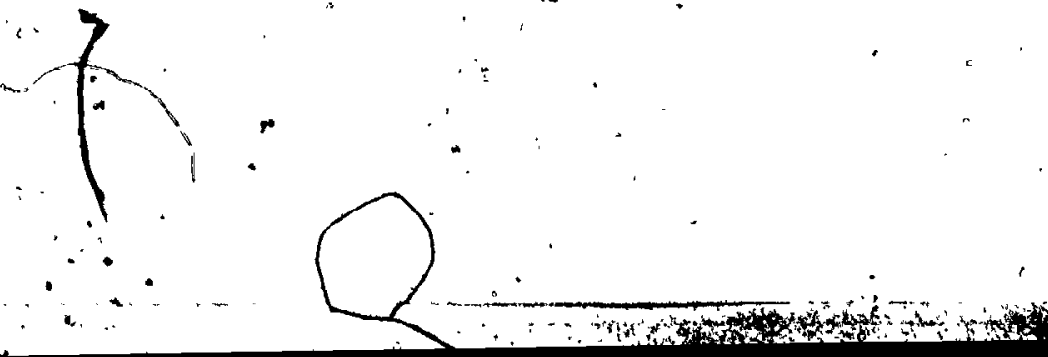


asymmetric folds along with a strongly developed cleavage orientated parallel to the axial surfaces: (Plates, FI, F2, F3, G1, G2, G3, H1, H2, I1, I2, J1, J2). The planar fabric $\left(s_{2}\right)$ is composed of muscovite and biotite plates, elongated grains of quartz and calcite, Elattened pebbles of carbonate and quartzite, kyanite, fibrolite and rare epidote (Plates J1, J2, KI, L1, L2, MI): Second phase axial surfaces regionally, trend northwest - southeast' and are' 'either horizontal or dip at a low to, moderate angle towards the northeast.

To the south of the structural aureole associated with the Adamant pluton second phase fold pinges zently plunge predominantly towards the southeast: To the north of the structural aureole they plunge predominantly towards the nor thwest. ,

Phase Three

Large scale tight to open folds, which'caused a strong crenulation of compositional layering $\left(s^{\prime \prime}\right), s_{1}$ and $s_{2}$ ' were generated during the final major phase of deformation (Plates Bi, C, D1, D2, F3, F4, G4, H2, I1, K2, K4):

Axial planes of phase three folds dipit steep to shaliow angles to. the southwest, fold hinges plunge 'at a moderate angle to the southeast. Major phase three structures can be traced. along the length of the Northern Selkirk Mountains.

The type of axilal planar cleavage $\left(s_{3}\right)$ developed during 
this phase varies with the host lithology. In pelitic rocks $s_{1}$ and more commonly $s_{2}$ ' (as $s_{1}$ is generally trănsposed into $S_{z_{1}}$ are, strongly crenulated to produce a crenulation cleavage 'Plates F3, F4, I3, K2, K4)? The spacing and Intensity. of this cleavage are variable. In impure carbonate rocks scattered plates of muscovite are aligned with elongated grains, of carbonate. Psammitic rocks developed a cleavage composed of aligned, elongated quartz grains and rare plates of mica.

3c. Deformation within zone $A$

Phase one deformation

No majoì phase one structures were recognized within zone A. There are occurrences of small, isoclinal folds, with axial surfaces parallel to compositional layering, that are assumed to have beèn formed during the initial phase of deformation. "The limbs of one such phase" one fold (Plate F1) are folded by second phase folds. A planar mineral fabric orientated parplel to the axial'surface of the later fold, $s_{2}$, is crenulated by phase three structures. A weakty, defined $s_{1}$ is parallel to compositional layering except in the noses of the rare phase one folds.

Where $s_{1}$ is not deformed by phase two andor phase" thiree structures it is orientated parallel/sub-parallel to . the margin of the pluton. However the very istrongly developed $\mathrm{s}_{2}$ appears to have been formed at the expense of $s_{1}$. the zatter fabric being much less apparent. 
$S_{1}$ is not orientated parallel to the pluton in the zones of divergence adjacent to the northwest and southeast margins of the pluton. (See later in this section).

The similarity in orientation between the margin of the pluton and $S_{1}$ increases towards the pluton. Around"the eastern end of the pluton and along the northern marqin, the Middle Marble member rims the pluton (Figure 8), exactly reflecting the orientation of $S_{1}$ (Plate $A$ ).

Phase two and phase three deformation.

During both phases tight to open folds were generated. Associated with phase three is a strong crenulation cleavage in the pelitic rocks. Planar mineral fabrics, órientated parallel to the axial surfaces of associated folds, were generated during both phases. However fabric formed during the earlier phase, $S_{2}$, is much more commonly and intensely developed than the fabric generated during the later phase, $S_{3}$, which is relatively rare.

A major feature of the deformation during both phases is that axial surfaces, when traced in either a northerly or southerly direction towards the pluton, exhibit a significant change in orientation adjacent to the northwest and southeast corners of the body. Each indlvidual phase of deformation produced two zones of divergence, located adjacent to the southeastern and the northwestern parts of the pluton (Fiqure 9). A more detalled description of these divergence zones is given below. 


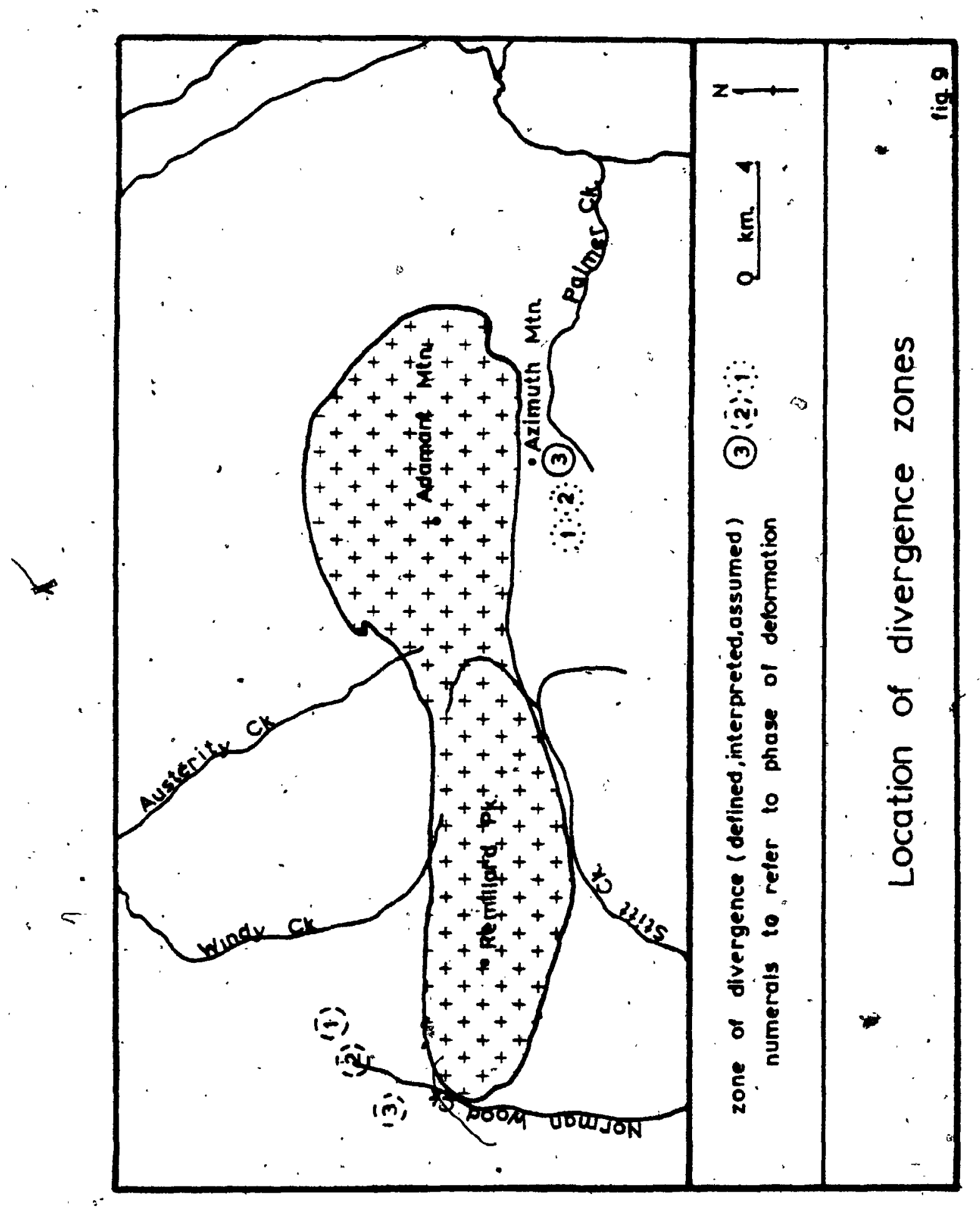


The structural geology within zone A is predominantly the result of interference betwen the second and third. phases of deformation (Plate B)! the latter phase being dominant, especially in the northeastern part of the study area. The descriptions of both phases within the individual domains are combined below in order to compare their respective geometries.

Domain $A$

No major folds of either phase/ were recognized within this domain but minor folds are common. Phase two folds are seen to go around the hinges of phase three folds producing numerous examples of Ramsay (1967)' type 3 interference patterns (Plate H.2).

$S_{2}$, which strikes northwest-southeast and dips to the southwest at moderate to steep angles, is seen as either a mica foliation or it is outlined by ellipsoidal quartz-feldspar blebs, the two major axes of which lie in the plane of $S_{0}$. These blebs may be crenulated by phase three folds.

The axial surfaces of phase three folds strike northwest-southeast and dip at a steep angle towards the southwest. Hinges plunge to the west/northwest.

Domain $B$

Phase two folds and fabric are strongly developed whereas those of phase three are rare (Plates F2, F3).

At the northern perimeter of domain $B S_{2}$ strikes 
approximately 290-110 degrees and dips toward the south-southwest.' Adjacent to the pluton $s_{2}$ strikes east-west and is either vertical or dips steeply to the north or to the south. This bend in strike and change in dip direction is exhibited by the najor structural feature within the domain, a large phase two anticline-syncline pair. These two structures are outlined on the west bank of windy creek, station 378, by the Middle Marble member (Figures 8, 14 ). Two very apparent features of the outcrop pattern are the intense minor folding on the limbs of these structures and the extended noses of the folds (Plate F2). Adjacent to the pluton the axial surface traces of the structural pair are paraliel to the margin with the southern limb of the syncline being in contact with it (Figure 13 ). S s $_{2}$ isery strongly developed in most rock types; the strength of $S_{2}$ in the carbonates is a notable feature. Ellipsoidal migmatitic pods of quartz and feldspar in the pelites are orientated with the major and intermediate" axes parailel, to $5_{2}$.

Evidence of phase -three deformation is sparse and is only well documented at station 388 (Plate F3). Here phase two minor folds are wrapped around phase three hinge ifines and $s_{2}$ is strongly crenulated. The sense of these folds indicates a structural position on the southern limb of the Gold River anticline (Figure 18), the culmination of which is located to the north. Domain $\mathrm{C}$ 
34

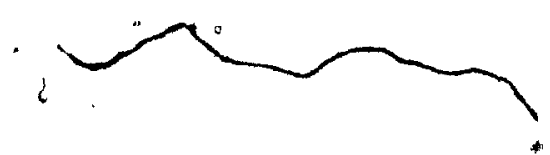

Figure 18 Major folds adjacent to the Adamant pluton

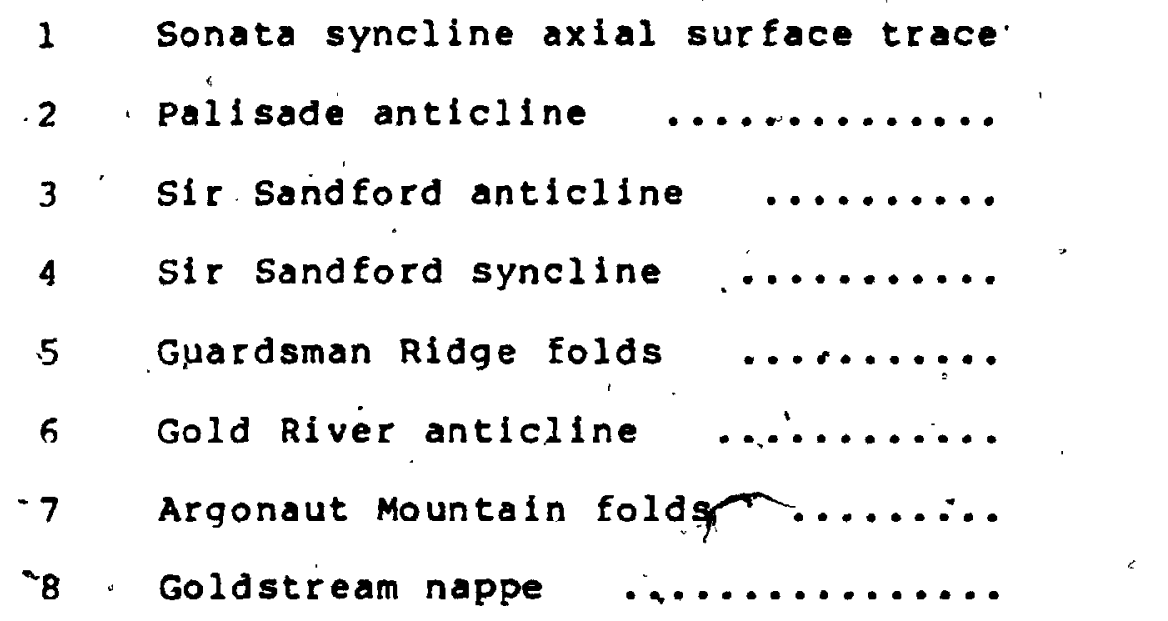




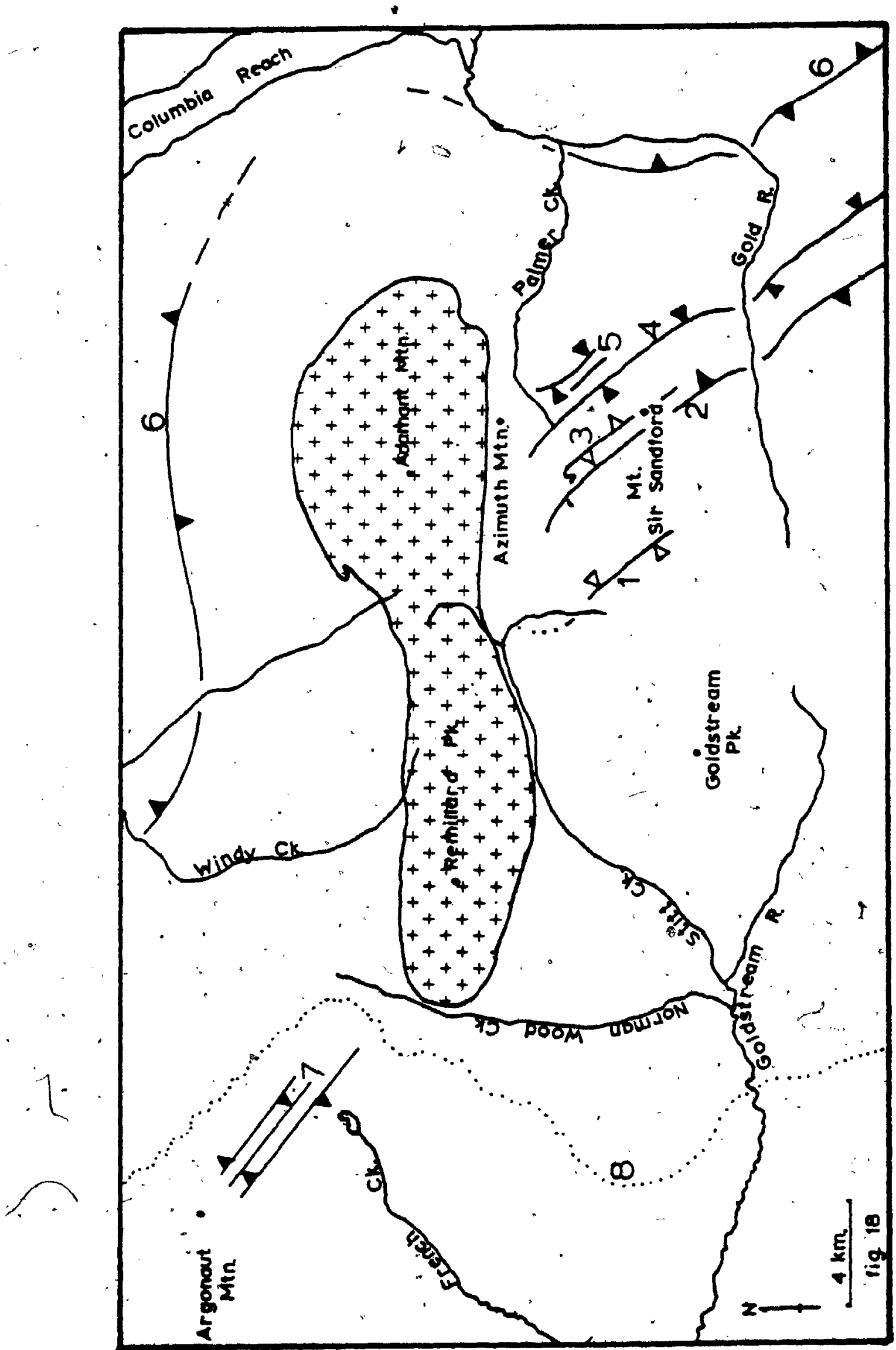


This domain comprises a series of phase two and phase three minor folds of varylng size that are structurally located on the southwestern limb of the Gold River anticline. The hinge zone of the major structurfe/trends across the extreme north of the domain (Figure 33 \%.

The axial surfaces of phase two and phase three folds are similarly orientated with a northwest-southeast strike and a southwesterly dip. Hinges of phase two folds plunge to the west/northwest wh $f$ lst those of phase three folds plunge towards the southwest.

The dominant 1 ithology. in the domain is a rusty, semi-pelite with much amphibolite and pegmatite. The relative paucity of mica in the semi-pelite may account for the absence of a strongly developed $s_{2}$, consequentily there is little evidence of phase three crenulation.

Some phase two minor folds are seen to go around the hinges of phase three miñor folds resulting in type 3 . interference patternș.

Domain $D$

The strike orientations of phase two and phase three. axial surfaces within this domain are transitional between the near regional attitudes described in domain $C$ and the east-west striking axial surfaces described within domain $B$. Phase, two deformation is dominant in domain $\vec{D}$, axial surfaces strike at $110-290$ degrees. $S_{2}$ dips to the south-southwest and the hinges of phase two minor folds 


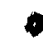

plunge towards the west. A single phase three fold hinge was identified, the plunge direction was opposite to that of local phase two folds.

$S_{2}$ is recognized as an aliqnment of mica plates and miqmatitic pods. The lithology is similar to but more mica-rich than, that of domain $\mathrm{C}$.

Doma in $\mathrm{E}$

Deformation within domain $E$ is distinctive because of the intimate involvement of the outer zone of the pluton with phase two activity. A series of phase two folds, with axial surfaces striking grossly parallel to the margin of the pluton, but dipping steeply away from the interior of it, deform the outer granodioritic zone and the adjacent country-rock. Four major phase'two folds, with associated minor folding strongly developed, are identified (Figure 14). Granodiarite can be successlvely traced around a synclinal and an anticlinal closure (Fiqure' 13), the former being cored by upper. Pelite member quartzite. Immediately north of the anticline which deforms. the extreme periphery of the pluton is another phase two syncline-anticline palr. The synciine is cored by grits of the upper Pelite member whilst the anticline to the north is strongly outlined in the summit and slopes of Mount. Enterprise by carbonate bands of the Middle Marble member (Plate D2, Figure 20).

Phase two axial surfaces and planar fabric in the eastern. part of domain $E$ strike east-west, as does the 


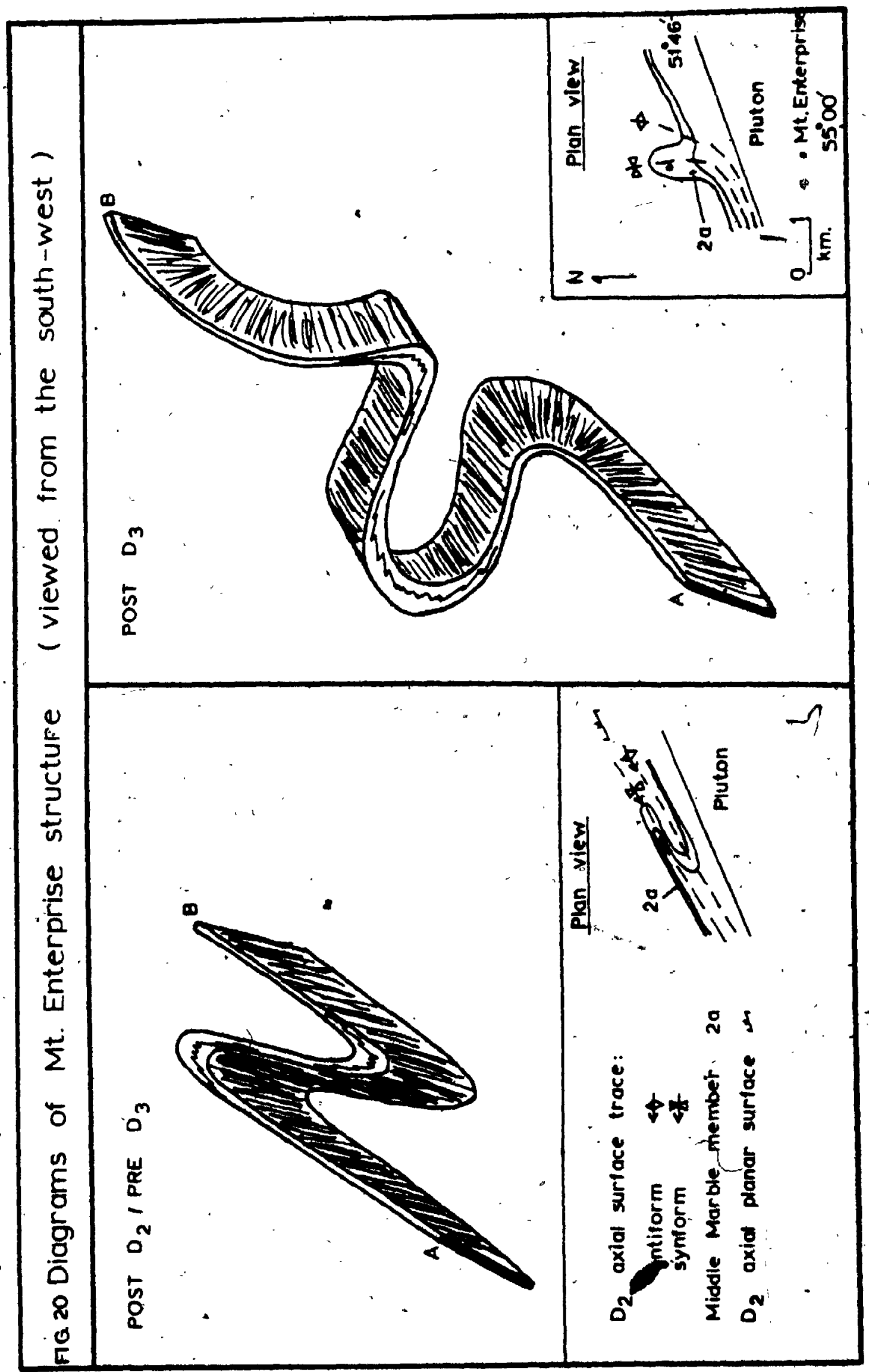


margin of the pluton (Plate A3). In the central. and western part of the domain the pargin of the pluton trends northwest -soutbwest, this change in trend is reflected by a similar change 'in the strike of phase two structures. Phase two Eold hinges plunge towards the west except where phase three deformation has re-orientated them?

Phase three minor folds äre common and varied in size, structurally they are located on the southern fimb of the Gold River anticline. $\mathrm{S}_{3}$, seen as a crenulation cleavage in the mica-rich pelites, is essentially parallel to $s_{0}$, and dips steeply away from the pluton towards the north. The margin of the pluton in domain $E$ is efther vertical or dips steeply towards the north.

Interference between phase $\because$ two and phase three structures is well illustrated in the summit region of mount Enterprise (Plate D2). Here the major phase two synclinal antiform, outlined by marble layers and referred to abave, plunges very gently to the east or is horizontal as it is folded; around a phase three'structure to "produce a type 3 interference pattern (Eigure 13, 20). Within the outer zone of the pluton the effect of phase three deformation. is not recognlzed, it is assumed that the phase two structures. therelin retain their original orientation.

$\mathrm{S}_{2}$ is best developed in the migmatitic pelites.in which both, the mica plates and quartz feldspar blebs are aligned In a plane paralle? to the axial surfaces of phase.two 
folds. A strong crenulation of this fabric is commont and a crenulation cleavare, $S_{3}$, parallel to the axial surface of phase three folds is often recognized, Pháse two folds within the granodiorite deform a pre-existing, metamorptift, planar fabric. This fabric and other structural features within the pluton are discussed later (Chapter 4). Domain $\mathbf{F}$

phase two and phase three ftructures are both strongly develaped within this dọnin, the latter beinj dominant. A distindive structural feature is the juxtaposition of a major phase three anticline and a major phase three syncline as a result of normal faulting (stations 311 and 312). The fault obviously post dates the third phase of deformation and would appear, to strike parallel to compositional layering. Strata of the Lower. Pelite member outcrop on either!side of the fault, the throw on the fault being equal tö or less than the thickness of that member." The limbs of the major folds must have been sheared out to some extent in: order for the 'hinge zones to be in such "close proximity. To the immediate north of station 311 (Figure $7^{\prime}$ ), interference between phase 'two and phase three structures is ver̀y apparènt (Figure 13):

" $\mathrm{S}_{2}$, in the " $10 \mathrm{cally}$, common, migmatitic, siliver-qrey, kyanite pelite, is compored of aligned mica plates and quartz feldspar blebs. This fabric is often strongly crenulated. $\dot{S}_{3}$ is seen as a well developed, crenulation 
cleavage.

In the northern part of the domain both $\mathrm{s}_{2}$ and $\mathrm{s}_{3}$ striké northwest-southeast and dip towards the southwest. In- the central and southern part of the domain the strike direction apptoaches east - west, the dip direction is southerly. Hinges of phase thicee minor folds generally plunge in an easterly direction, as do those of the more rare: phase twó folds.

Domain. G

Pháse three, minor folds throughout domain $G$ are structuraliy loceted on the southerly-limb.of the Gold River $l$ anticline: Axial surfaces vary in strikedirection from northwest-southeast to east-west, the dip direction is squthwest and south respectively.

$s_{2}$ has a similar orientation to that of $s_{3}$ described above. Hinges of the much more rifie second phase folds. plunge towards the" west whilst those of third phase structures plunge at. moderate angles towards the east (Figures 11, 12, 13,.14).

Mica pfates and ellipsoidal biébs of quartz and feldspar within.the; mighatio pelites are usually orientated paraliel to $s_{2}$ and crénulated by phase three deformatiof:" $s_{3}$ is recogntzed as a crenulation cleavage.

Domain $\mathrm{H}$

Deformation characteristics within the domain are dominated by a prolific occurrence of phase three minor o 
fords and an intense crenulation of $\mathrm{s}_{2}$ (Plate F.4) In the central part of the domain a very micaceous, migmatitic pelite hosts a strongly developed and crenulated $\mathrm{S}_{2}$. In the north and northwest part of the domain rusty, amphibolitic pelite. lacks such a pronounced fabric and accompanying crenulation. Phase three minor. folds are common in the carbonate and, rusty jajble-carbonaterich pelite of the Midile Marble member that crops out adjacent to the pluton. "Whilst the carbonate-rich" strata'develops onlya" weakly defined $\mathrm{s}_{2}$, composed ef elongated grains of carbonate and dispersed mica. plates, the associated pelite contains a strọngly crenulated planar fabric.

The strike direction of phase three fold axlal surfaces varies from northwest-southeast to east-west, dip directions. being southwest and south respectively. The magnitude of dip increases "towaras the margin of the pluton as adjacent strata' 'assume an orientation very similar to that of the east-west striking and' steeply inward dipping margin of the body (PIste A2).

Phase three fold hinges plunge in ap easterly direction and indicate a structural position on the southerly limb of the Gold River anticlifie. In the outer zone of the pluton, a few metres in from
the contact, there are number of minor folds outlined by a gneissic layering and by quarte stringers, that are parallel/sub-paraliel "tos the layering. The layering is 
poorly defined compared to that described in domain $E$ and strikes paraliel to the contact, dipping steeply inwards as does the contact itself.

The axial surfaces of the folds reflect the orlentation of the margin. No axial surface mineral fabric was recognized in the field. Both in orientation and structural position the folds are very similar to those in the adjacent metasediments that have been identified as phase three structures:

Domain $J^{\circ}$

Whilst both phase two and phase three folds are very common there is very ittele interference recognized between, - the two. Axial surface orientations are similar, the strikedirection:being northwest-southeast and the dip direction is southwest. Hinges of minor folds plunge in opposite . directions, those of phase two folds plunge towards, the east whllst those of the later phase plunge towards the west.

In the carbonates and rusty carbonates of the Middle Márble member $s_{2}$ is developed as an alignment of ellipsoidal calcite qrains and mica plates. In the pelites $s_{2}$ is crénulated by phase three deformation, $\mathrm{L}_{3}$ being formed as a crenulation lineation.

The north trending ridge on the east side of rabernacle Creek (Fiqure 6) contains a series of large phase two folds. strata deformed by these folds are structurally located on the southwesterly limb of the Gold River anticline. 
A northwest-southeast trending zone of structural discontinuity occurs in the western part of the domain. Second phase structures do not maintain continuity across the zone; strata on both sides of the break belong to the Lower Pelite member, the strata on the southwest side being... stratigraphically higher than that on the northeast. A normal fault, postdating at least the second phase of deformation, and dipping towards the soduthwest is indicated, (section E-F of Figure 13). The throw on the fault is equal to, or more probably unuch less than, $1,350 \mathrm{~m}$.

Doma in $\mathrm{K}$

A northeast-southwest trending ridge, due east of Mount stockmer, is the locale for, the majority of the data gathered in domain " $k$.

Structurally the ridge consists of a series of phase two folds, the axial surfaces of which strike northwest -soutbiast and dip towards the southwest. Along the ridge. phase two fold hinges plunge both to the northwest and southeast, the hinge zones passing through the-rorizontal.

Phạse three deformation is occasionally recognized and consists usúally of a crenulation of $S_{2}, L_{3}$ is developed as a crenulation lineation. There are rare phase three minor folds recogrigd.

Towards the southern end of the ridge the phase two fold succession is discontinuous. The 5trata on both sides of the discontinuity belong to the Lower pelite member. It 
is assumed that this break is continuous with that described in domain $J$ (section $C-D$, in Figure 13).

Domain L

This domain is dominated by Mount Stockmer, located at the southern erd of a carbanate-cored massif adjacent to the extreme southeast corner of the pluton (Figure 5). structurally the massif is located on the upper limb of the Gold River anticline:

Large scale phase three minor folds, limb lengths of 25 metres, "outlined by qrey carbonate", form a 2 shape on the southern flanks of $\dot{M t}$. Stockmer. Tectonic thinning is very apparent in the carbonate, over a distance of 800 metres the thickness increases from a couple of metres to many tens of metres. Axial surfaces of the folds dip to the southwest, hinges vary in plunge direction from southwest at the south end of the massif, station 288 , to" northwest in the centrai part of the massif.

The phase three folds described above are superimposed on less spectacular phase two folds, the axial surfaces of which dip to the southwest whilst hinges trend to the west and southwest. Interference between the two fold sets, plus the varlety of plunge trends associated with them, produces a complicated structural picture.

Whilst phase three deformation is very visible in the massif it is subordinate to phase two structures in the remainder of the domain. In the ridge trending northwest- 
southeast at the south end of the massif, stations 268 and 269, rusty pelite hosts a well developed $\mathrm{s}_{2}$ and associated minor folds. Where the pelite is mica rich the planar fabric is crenulated by the later deformation. Where the pelite is carbonate $r$ ich $s$, is composed. of mica plates and elongated carbonate qrains, this lithology does not host a phase three crenulation.

Phase two minor folds in the ridge are similar in form and style to those described in domains $x$ and $J$, those in domian L occurring in the upper part of the Lower Pelite member. Axial surfaces dip at moderate angles to the southwest, hinges generally plunge towards the south. Domain- $\mathrm{N}$

A pronounced change in strike direction of phase three axlal surfaces is the dominant structural feature. Within this domain. In the southern part of the domain $s_{3}$ strikes northwest-southeast and dips steeply to the southwest... In the central part, about $1 \mathrm{~km}$ south of Palmer Creek, the strike direction is approaching north-south, the dip direction is west and the amount of dip has decreased to a moderate amount. On the banks of Palmer Creek the strike direction is northeast-southwest, the dip direction is northwest with the amount of dip being moderate to steep. A kllometre north of the.creek, adjacent to the southern margin of the pluton, $s_{3}$ parallels the contact and dips steeply toward it. 
In the southern part of the domain, hinges go through the horizontal, plunge directions being either to the northwest or to the southeast. Further north the plunge. direction is consistently towards the north-northwest.

Phase, three folding varjes in size from a strong crenulation of precexisting planar fabrics; $s_{2}$ being by far the more common; to rarge scale minor folds with limb lengths of up to 30 metres. These folds are structurally located on the westerly limb of the Goldiviver anticline. Examples of the latter are located in the ridge at station 428 where, they are strotigiy defined by carbonate within the Middle Marble member. These folds and stratigraphy can be traced northwestwards where they'crop out in the Guardsman. ridge section, stations 121 and 122 (Figures 8, 13), Here an anticline-syncline pair form a large $z$ shaped minor fold, outlined by. carbonate. (Plate c). The folds plunge steeply towards the northwest and are structurally located on the lower limb of a major. syncline (the sir sandford syncline) the hinge zane of which is within domain $\ddot{\circ}$, and on the upper limb of a major anticline (the Gold River anticline), the hinge zone of which is to the east northeast.

Phase two deformation is much less apparent, folds of this phase being involved with phase three closures in type 3 interference. patterns. $S_{2}$ is well developed in both the pelites and carbonates and exhibits aimilar change, in orientation to that described for $s_{3 ;}$ this latter fabric 
being predominantly a crenulation cleavage formed from Domain 0 .

As with the previous domain a dominant feature of the structural qeology is the pronounced change in the strike direction of $\mathrm{S}_{3}$ within the domain. In the far southeast corner of the domain, $S_{3}$ strikes northwest-southeast and dips steeply towards the southwest. . Immediately northwest of the confluence of the Palmer Creek tributaries (Figure 5) the strike direction is approaching east-west and the dip. direction is to the porth. This change of dip direction, coupled with the change in strike, is accomplished by $\mathrm{s}_{3}$ passing through the vertical. An east-west strike, and steep dip to the north is maintained in the northern'part of the domain, adjacent to the margin of the pluton.

Hinges of' phase' three "minor folds plunge' moderately towaris the northwest in the southern part of the domain. In the northein part of the domain the amount of plunge increases and the trend is towards the northwest.

Equally significant however is a complex interference pattern produced by the folding of major. phase two folds over and/or around the hinges of major phase three folds. such interference is well lllustrated by the Palisade Hook (Fiqures 12, 13, Plate B).

Palisade Mountain is situated appioximately $4 \mathrm{~km}$ to the northwest of Mount sir" sandford (Figure 5), at the southwestern end of anortheast-southwest trending ridge. 
Structurally Palisade Mountain is located on the broad, crestal zone of a major phase three structure, the palisade anticline, the axial surface of which strikes northwest -southeast and dips very steeply to elther the northeast or southwest, or is vertical. The hinge of this major fold plunges. at a moderate to. steep angle towards the west/northwest. .

On the northeast limb of this structure is the phase two sir sandford anticline, which is outlined by carbonate of the Middle Marble member. This structure was initially mapped" to the south by Brown and Tippett (1978). The hinge zone of this major phase two fold. has been tightly refolded by a large scale, overturned, s shaped fold (Plate B). The interference pattern produced is a type 3. The phase three minor folds that deform the sir sandford anticline have steeply dipping axial surfaces that strike northwestsoutheast, hinges plunge steeply to the northwest. Phase two ininor folds associated. with the sir sandford anticline can be traced over the broad hinqe, zone of the Palisade anticline and onto its southwestern limb:

paralleling the axial surface" trace of the palisade - anticline and located $1.5 \mathrm{~km}$ s to the northeast is the axial surfałe trace of the sir sandford syncline, a major phase theer structure first referred to by Brown and Tippett (1978). In the northeast-southwest trending ridqe that connects Mount sir sandford with Guardsman Mountain. (Plate 
Di) the syncline is outlined by the Middle Marble member. An upright and broad hinge zone is flanked on the west by the palisade anticline and on the east by the anticline-syncline pair in Guardsman Mountain ridge (Plate c), described in domain $\mathrm{N}$.

The axial surface of the sir sandford syncline can be traced northwestwards from the Mount Sir Sandford-Guardsman Mounitain ridge to the confluence on Palmer Creek where the rivers flowing from Sir Sandford glacier and Howarth glacier meet (Figure 5). Immediately north of the confluence; in the vicinity, of station 29 (Figure 7), a phase two anticline-syncline pair outlined by a distinctive layer of green, carbonate $r$ ich pelite within the upper pelite member, can be traced around the hinge zone of the sir sandford syncline (Figure 13). At this location the strike of the. axial surface of the major phase three fold is approaching 110-290 degrees. When traced from this location towards the pluton it assumes an orientation sub-parallel/parallel to that of the east-west trending, vertical to steeply inward dipping, pzlaton margin.

The, orientation of $S_{0}$ within the domain, except where adjacent to the metasedimentary contact with the pluton, is strongly influenced by the major phase three folds described above. Adjacent to the pluton the orientation of $S_{0}$ reflects the form of the contact.

Domain $P$ 
The hinge zone of the palisade anticline, described in domain 0 , strikes into domain $\dot{p}$ where it is well defined by the axial surface traces of phase two folds which are folded over/around it.

In the ridge to the south of Redan Mountain (Fiqure 5) a phase two anticline-syncline pair, stations 219 and 220 respectively, is structurally located on the palisade* anticline hinge zone. Axial surfacestof the paired phase two structures strike northeast-southwest and dip to the northwest. From the ridge they can be traced onto the western limb of the later structure where they strike northwest-southeast and dip towards the northeast. Hinges change from plunging towards the north to the northwest.

Phase three minor folds qenerally strike northwest southeast, they dip very steeply towards either the northeast or to the southwest." Phase 'three hinges plunge" steeply towards the northwest:

Domain $?$

At the head of the southeastern, subsiduary, tributary. of Stitt Creek, stations 200 to 202 (Fiqure 7.), phase two. minor folds are stronqly developed, and are structurally. located on the upper limb of an overturned phase two. syncline: In the southern part of domain $Q$ the axial, surface of the majoir structuré trends northwest-southeast and dips at a moderate angle to the northeast. Brown and Tippett (1978) describe this major fold in the area to the 
south and refer to it as the'Sonata syncline. The hinge zone of this fold can be traced adjacent to the southeastern bank of the southwestern tributary of stitt creek, at station 189. From this location the axial surface can be traced northwestwards across the tributary and into a ridge where It passes between stations 184 and 185 . At this point the strike direction is approacing 290-110 degrees, the dip direction is north-northeast.

Along the ridge that parailelf the west bank of the main southern tributary of stitt creek, stations 184 to fis. $S_{2}$ progressively changes in strike direction from northwest southeast to northeast southwest. Dip direction changes from northeast to northwest as $S_{2}$ passés through the vertical close to station. 19:3. This behaviour may be explainẹd by $s_{2}$ being folded over the hinge of the. Pallisade anticline, which at this location is striking east-west and dipping. in a northerly direction. Concomitant with the change in orientation of $s_{2} ;$ the sonata syncline is gradualiy opened out and "unfolded" by the phase three deformation.

Phase three deformation within this domain is also recognized as a crenulation of $s_{2}$, axial surfaces of crenulations strike northwest-southeast and dip steeply to either the northease or southwest. Throughout domain $Q$ wherever phase three crenulation-' is recognized the structural position is on the eastern limb of an anticline.

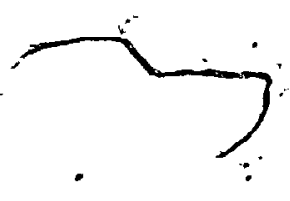


Domain $R$

Domain $R$ is composed of a series of large scale, (limb lengths of up to $500 \mathrm{~m})$, phase three minor folds, the axial surfaces of which strike north northwest-south southeast and dip véry steeply towards the west. Associated hinges plunge at a moderate angle towards the north. These folds are structuraliy. located on the eastern and lower limb of a major phase three anticline, herein-referred to as the stitt Creek anticline.

Phase two planar fabric and folds are folded around the ninges of the later folds producing type 3 interference patterns. The dominant stratigraphy within this domaln is that of the. Middle Marble member and consequently $\mathrm{s}_{2}$ is developed as an alignment of elongated,-grains of carbonate and also clasts of carbonate (P1ate G4). In tho overlying Upper Pelite member the more micaceous layers host a well developed fabric; in the grits. $S_{2}$ is recognized as an aliqnment of ellipsoidal grains of quartz and quartzite.

The structural. position of minor phase two folds with respect to major phase two folds was not resolved. However it is to be expected that any phase tho folds within this domain are located on the lower limb of the sonata'syncline, 1. previously discussed in domain $Q$. Dotnain $\mathbf{S}$

With'respect, to stratigraphy and structur 'there" is a distinct similarity between this domain and domain $R$ The 
dominant Iithology is marble and carbonate rich pelite of the Middle: Marble member. the structural geology is controlled by large scale, phase three minor folds. The strike direction. of these folds varies from northeast-southwest to east-west with respective dip directions of northwest and north. Hinges plunge steeply towards the northwest. It is proposed that these folds are located on the same limb of the stitt creek antieline as are. those folds î́ domain $R$.

s. stpikes: northwest. - southeast and dips in a northeasterly direction, this orientatión, being similar to that of the adjacent marqin of the pluton. A single phase two minor fold hinge was measured, it plunged steeply in a northeasterly direction towards the inward dippind margin of the plutoin.

3d. Zorie $B$

Zone B is that part of the structural aureole that lies to the west of Norman. Wood Creek. (Fiqures 3, 6). Parts of this zone. were mapped by Franzen'(1974) and parts by van der Leeden '(1.975) * At least four phases of: deformation were recognized bý "Franzen and Van der Leeden, the fírst triree of which in each case are analogous to those described within. Zones $A$ and $C$.

Phase One

The existence of a phase one nappe was first inferred by van der Leeden (1975) on the $\because$ basis of phase two folds 
being superimposed on inyerted stratigraphy. This structure is ireferred, to as the coldstream nappe (Brown et al...1977) and In zone $C$ to the south is thought to have a limb length of $20 \mathrm{~km}$. (Lane, 1977 ).

To, the south of zone B the axlal surface trace of this nappe strikes nocthest-southeast and dips to the southwest (Lane, 1977): Within zone B the strike direction changes. from northwest-southeast to north-south and in the vicinity of the headwaters of Norman Wood Creek. it is striking northeast-southwest. concomifant with this change in strike the dip direction changes from southwesterly to southeasterly. within the phase one zohe of divergence, located adjacient" to the notthwestern margin of the plutoh. This is most. easily explaitied if the axial surface goes. though the vertical as it is traced northwards adjacent. to the western end of the pluton "wiere $i t$ assumes a n -orientation similar to that of the inward dipping margin. In the southern part of the phase one divergence zone the axlal surface strikes northeast-southwest and dips to the southeast; in the: central part of the divergence zone the axial surface" assumes a north-south strike and in the northern part it strikes northwest-southeast (Pigure-17). At the northern perimeter, of zone $B$ the axial surface strikes northwest-soiutheast and dips, to the southwest. Phase one planar surfaces are parallel to compositional layering except in the noses of rare phase one folds 
(Franzen, 1975; Van der Leeden, 1975); consequently the orientation of bedding around the western end of the platon is similar to that of the major phase one axial surface trace outlined above. Phase two deformation

Franzen (1974) and Van der Leeden (1975) documented phase, two folds that have similar axial surface orientations to those préviously described for the phase one nappe. The phase two planar. surfaces exhibit similar changes in 'orientation' both around the "western end of the pluton and also thin the western half of the divergence zone produced during the second phase of deformation, that is located adjacent-to the northwestern margin of the pluton. Phase throe deformation

Phase three folds dominate the struatural geology of zone $B$, the main feature being the Argonaut Mountain structure (Franzen, 1974; Brown and Tippett, 1978). Across this structure the dip direction of phase three axial surfaçes and the culpination direction of phase three folds" changes. The margin of this fanning structure occurs in domain's 5 and 6 , but the cented part of the structure is located in domains 7, 8,9 and 10 (Figure 16), where large scale folds with steep to vertical axial surfaces occur. In domạins 7 to 10 inçlusive, phașe three, folds tighten and steepen to become tight to isoclinal closures with very steeply plunging hinges (Figures 16, 17): The axis'of the 
fanning structure strikes northwest-southeast as do the bther phase three structures withio zone $B$.

In the area mapped by Van der Leeden (1975) phase three axiar surfaces dip to the northeast and hinge lines plunge to the southeást towards the margin of the pluton. superposition of phase three folds upon phase two folds has produced type three interference patterns.

3e. Phase four deformation - Zóne A

Structures associated with " the fourth: phase of deformation are recorded in domains $\mathrm{O}$ and $\mathrm{N}$ and are best developed in the upper pelite member.

Within these two domains second phase axial surfaces and planar fabrics are folded by tiqht crenulations and small scale tolds (Plate. I4). Axial surfaces strike rotitheast-southwest and Jip to either the northwest or southeast at an average anglè of 50 degrees. Such a strike direction aiffer ofonificantly. from the "local strike direction of phase three structures; also the hinges of phase three folds plunge steeply to the southwest.

Tippett, (1976) recognized post phase three crenulations ? and conjugate folds, with a similar orientation to those described above, in the region to the south.

3E. Norman Wood Creek Fault zone

At the southwestern end, of the windy Range, to the north of Norman Wood Creek (Figure 14, map reférence $41.5(85 / 5735387), a \cdot$ northwest - 'southeast striking, 
southwesterly dipping fault juxtaposes upper Pelite member - strata of the Horsethief Creek Group against probable Cambrian. Hamill Group rocks. "The sense of assymetry of minor folis changes across the fault zone.

The fault is thought to extend in a northwestward direction for a distance of at least $28.0 \mathrm{kms}$ (M. Perkins, pers. comm, 1978).. The extension of the fault in a southerly direction is: unclear. Adjacent to the northwestern corner of the pluton this author has observed stratigraphic and structural continuity therefore the fault does not extend" for any appreciable distance ín a southeasterly direction. The most likely route for a southerly" extension of, the fault is down the valiey of Norman. Wood Creek; this"would involve the fault undergoing a change in strike direction adjacent to the northwestern corner of the pluton similar to. that described for the axial surface trace of the Goldstream nappe.

. Using pressute and temperature estimates made on metamorphic mineral assemblages in Horsethief creek Group rocks that crop out in the Argonaut Mountain area, Leatherbarrow (work in progress) proposes up to $7 \mathrm{~km}$ of vertical displacement across the fault, with the western side down.

3g, Summary and Discussion

Regional structural trends in the central part of: the Northern Selkirk Mountains are strongly affected by the 
presence of the Adamant pluton. within a weli-defined structural aureole. Folds and planar and linear fabrics all assume an orientation different from the regional in order to accommodate to the space problem produced by the discordant and rheologically rigid pluton.

Axial. surfaces, when traced towards and around the body, diverge within specif. zones to go around opposite ends of the pluton; each deformation should produce two such zones of divergence about the body. The best documented is that produced by the third phase of deformation adjacent to the southeastern end of the body in the vicinity of Azimuth Mountain. Phase three structures, when traced towards the pluton, diverge within the divergence zone either to the west, e.g. the sir sandford syncrtme, or to the east, e.g. the western limb of the Gold River anticline, which goes around the eastern end of the pluțon. Within the central part of the divergence zone the stratigraphy and phase three structures and fabric jare fiattened against the east-west trending walls of the pluton.

It appears that the third phase of deformation was most intensely developed along the eastern side of the Northern Selkirk Mountains; a similar conclusion was first presonted by Brown et al...(1977). Consequently the other deflection zone associated with the third phase of deformation, located at the northwestern end of the pluton and in the western part of the Northern Selkirk Mountains, is not as well 
defined. It is interpreted to be centred around the Arqonaut Mountain Tștructure (Figures 18, 21), ạ very tiqht and steeply plunging fold that is progressively opened and Elattened towards the not too distant walls of the pluton. Third phase structures to the northeast of this zone of divergence are traced around the eastern end of the pluton. The relative rarity of third phase folds to the southwest of the zone hinders the recognition of a similar pattern around the western end of the body.

Adjacent to the northwestern end of the bodya and, situated $0.8 \mathrm{~km}$ to the northeast of the phase three deflection zone, is one of the two zones of divergence associated with, the second phase of deformation. Second phase folds that lie to the northeast of this zone diverge around the eastern end of the body, othose that $11 \dot{\text { e to the }}$ southwest diverge around the western end (Figures 13 and 17j: The other zone of divergence associated with the second phase of deformation is almost certainly located at the southeastern end of the body near the third phase divergence zone at Azimuth Mouritain. Due to the intense development of third phase structures in this particular area however it is thought that form of the second phase zone has been masked.

$1.25^{\circ} \mathrm{km}$ to the northeast of the second phase zone of divergence, adjacent to the northwestern margin of the 
pluton, is, the zone in which the axial surface of the major phase one fold experiences a pronounced change in orientation. This change is interpreted to occur in the western part of a diveraence zone associated with the first phase of deformation. Unfortunately there is insufficient phase one structural data in this particular area to provide an accurate outline of the zone.

The implications of the separate, yat close, locations of the three divergence zones adjacent to the northwestern margin, and of their assumed counterparts adjacent to the southeastern margin, are significant with respect to the interpretation of the behaviour of the body during events of regional compressive stress. If both the direction of reqional compressive stress and the orientation of the pluton have, remained constant during the successive phases of deformation then it is highly probable that the divergence" zones fssociated with the deformation events would be superimposed. As this is not the case there has either been a change in the direction of the regional - compression during the history of the plutom, or the orientation of the body itself has been altered, this being most probably, accomplished by rotation during deformation. Immediately adjacent to the pluton the orlentation of the axial surfaces of both second and third phase folds reflects that of the walls of the body, being either vertical or steeply inward-dipping. The strike direction of 
such axial. surfaces is controlled by their particular location with respect to the adjacent walls. Those axial surfaces that are juxtaposed against the northern margin strike east-west, an exception being in domain $E$ of zone $A$ where the marqin of the plutgh is folded. Thoseathat lie adjacent to the eastern and western ends of the body have a general strike direction of north-south. Along the southern margin axial surfaces strike west northwest-east southeast.

Linelar fabrics.within the structural aureole assume a plunge direction towards the body, "the amount of plunge generally iricreasing towards the usually inward-dipping margin. :

The shape of the folds is.either: tightened or opened depending upon the angular relationship between the strike direction of the axial surface of the fold with the adjacent margin of the body. Where the two have a similar strike direction e.q. second phase folds in domain $B$ of zone $A$, the folds are progressively tiqhtened against the walls of the body. However where there is a definite, difference in the respective strike directions, e.q. the Sonata syncline in domain $P$, zone $A$, the fold is progressively, opened and flattened against the pluton. (It should be pointed out that part of the "unfolding" appears to be due to the third phase. of deformation). The plunge direction and amount of plunge are important controls in the deqree of flattening: those folds that plunge towards the inward-dipping. walls of the 

4. THE INTERNAL STRUCTURE OF. THE ADAMANT PLUTON

4a. Introduction

The Adamant pluton has a grossly elliptical outine; the long axis of which is aligned east-west. The pluton is 27. kms in length and may be divided into two parts; a circular shaped. eastern part joined to an elongated western part (Figure 23).

Within the eastern part an anhydrous core zone of. hypersthene-augite monzonite is successively enclosed by a partially hydrated zone of monzonite with variable-amounts of hypersthene, augite, hornblende and biotite; a hydrated zone of hornblende granodiorite with quartz monzonite and. a hydrated zone of biotite-hornblende granodiorite with quartz diorite.

Two isolated, elliptical pods of partially hydrated monzonite grade- Into and are surrounded by hydrated quartz monzonite in the western part of the body (Figure 23).

For a detalled description of the petrology and geochemistry of the Adamant pluton the reader is referred to Fox (1969).

Modal analyses and petrological classification by-Fox are presented in Figure 22: Fox noted that the pluton-country rack contact is sharp.and straight or gently curving (Plate' $A$ ). There is neither evidence of a chilled margin nor of any veins or apophyses of plutonic rock that cut the country rack. 


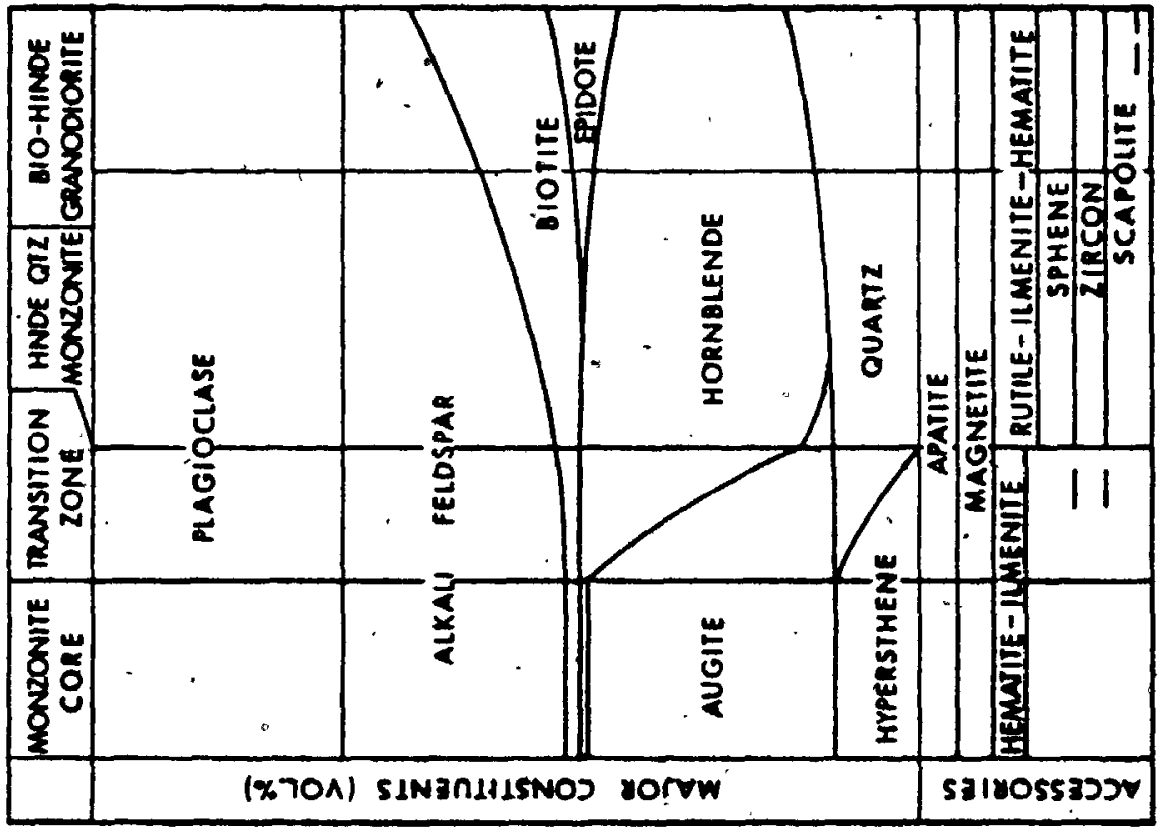



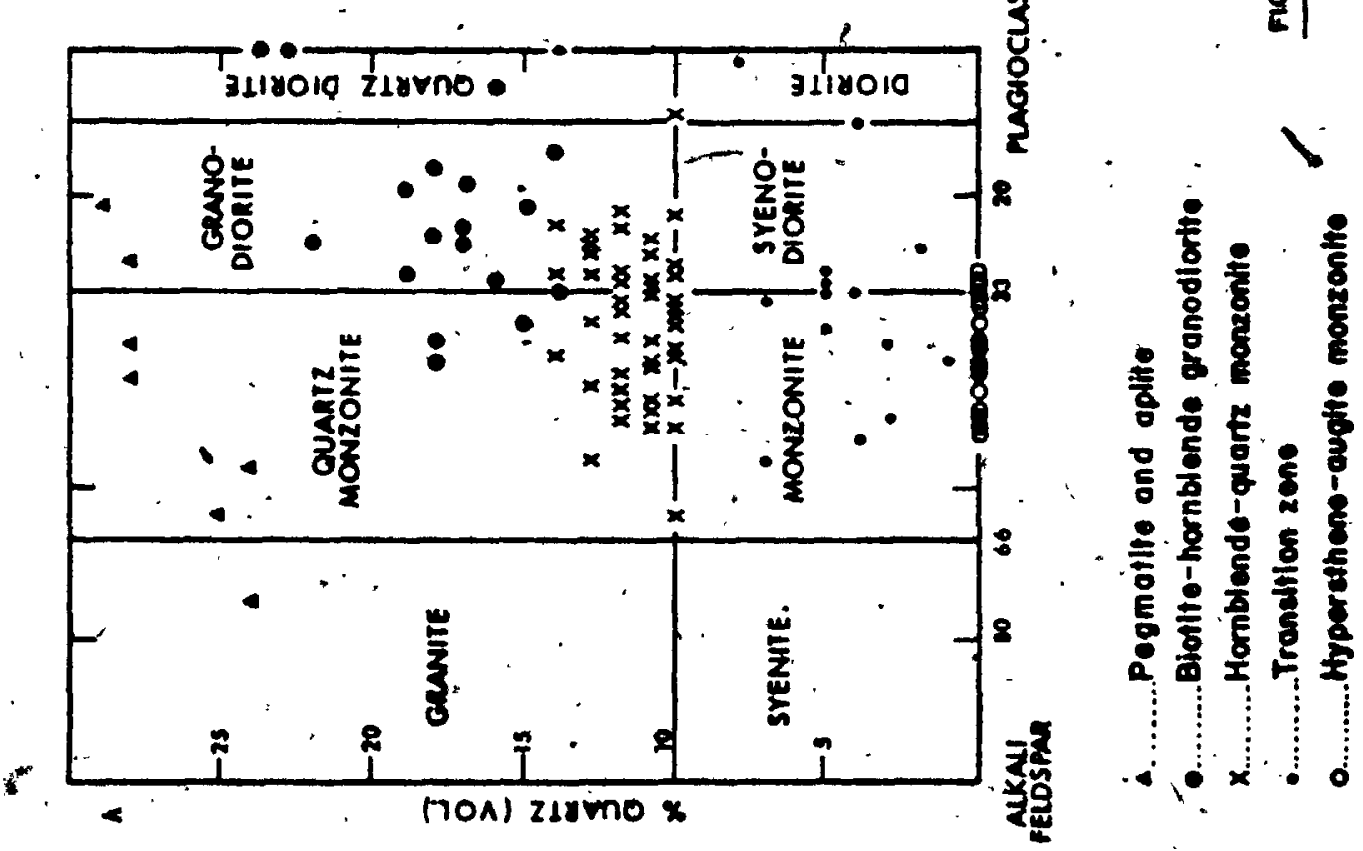


The reader'is referred to the following figures:Fiqure $12: D_{2}$ minor structures - Zone $A$.

$13: D_{2}$ and $D_{3}$, fold axial surface traces, with structural cross-sections - zone $A$.

23 : Fabric elements within the Adamant pluton. 24 : A stereo-plot of linear structures thin Adamant pluton.

25 : Trace of planar fabric within central part of Adamant pluton.

4b: Internal structure of thé Adamant Pluton

The nature of the internal structure of the Adamant plute has been investigated by Fóx (1969) and this author.

Fox reported planar fabrics to be the most prominent structural feature; the degree of follation varles but is generally best developed in the outer zones of the body (Flgure 23). Fox described three main fabric groups:

1. A northwest striking fabric located in that part of fhe plution to the west of the hypersthene-auglte monzonite core: "Fox relates this" fabric, which he traced from the outer zone into the outer part of the transition zone (the ione of $\because$ hornblende-quartz monizonite), to the regional northwest-southeast thend of structures in the country rock. This fabric is defined by hornblende.

$\therefore 2$. A hornblende and:blotite follation was described in the perlpheral rocks of the eastefn part of the pluton. Fox believed this fabilc to have been influenced by the walls of 
the body as they have a similar orlentation.

3. In the hypersthene-augite monzonlte zone 'and transition zone Fox described a plagloclase foliation (Plate J3): that is replaced. at the outer boundary of, the transition zone by a mafic follation. The plagloclase fabric is not oriented paraliel to any petrological zone boundary but defines a semi-elrcular shape that bulges to the east.

As well as the three planar fabrics Fox also described two linear fabries. The. first is a "faint" structure defined by hornblende prisms and located in the peripheral zone. The second linear fabric, recorded at three stations only, is defined by traing of hornblende crystals that have grown as mantles around pyroxene gralns. The first set are steep or vertical along the walls of the body but, plunge from 40 to 60 degrees northwest in the interior of the quartz mogzonite and granodiorite zones. The second set plunge at a moderate angle towards the east (Figure 24).

Fox related the two sets of linear structures to the northwest and northeast trending regional fold axes that he reported in the country rock. The formation of hornblende mantles around, the train's of pyroxene ciystals in the core zone was interpreted by Fox as mimetic after a pre-existing structure in the monizonite body.

The hornblende and biotite foliation that Fox rearted only in the eastern part of the pluton was found by this 


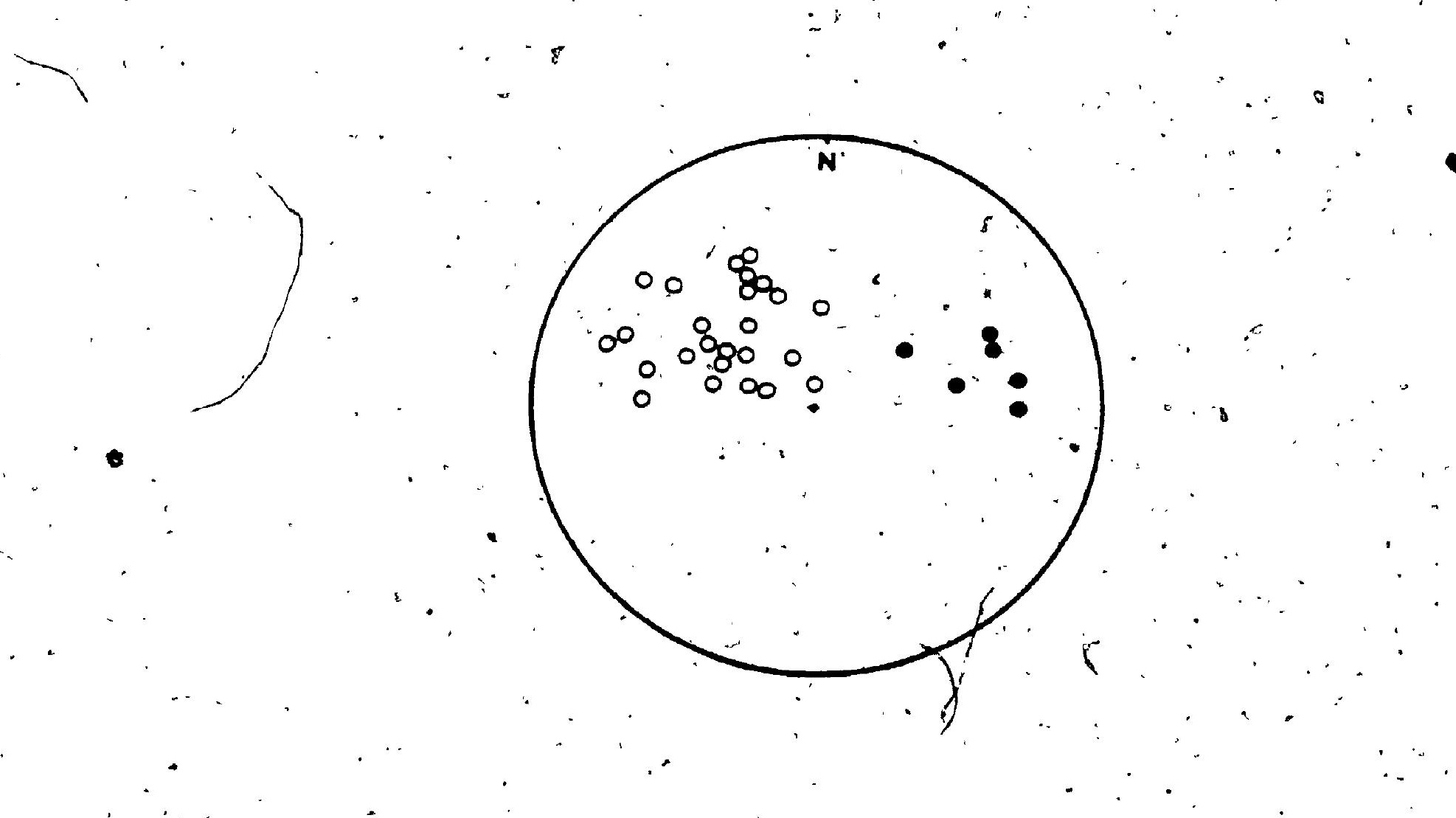

Figure 24 A staieoplot of linear wuctires within the Adamant pluton ( Exam Fox, 1969 ).

$\therefore \quad: \quad$ solid circle : libation in monzonite core

. open circles. : .. peripheral rook

total member "of points $=47$

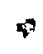




\section{2}

)

author to occur at varlous other localities within the perlpheral zone" of the body. This zone commonly contains a: compositional layering formed of thin, lone centimetre or - less), altẹnating mafic and quartzofeldspathic layers (PIate $J 1,32 J$. The orfentation of the individual minerals within the separate layers is random and unrelated to the orfentation of the layers themselves. Away from the perimeter of the body and towards the core zones this fabric decreases in strength. The orientation of this fabric is concordant with that of the margin of the body:

At certain localities, this fabric is deformed by folds that range in shape from open to tight. Hinge thickening is common in the minor folds, the slilicic layers being much thanned on the 21 imbs. A biotite foliation is oriented *. $\%$ paraller to the axtal surfaces of the folds, (Plates Ji. J 2) .

4c. Discussion

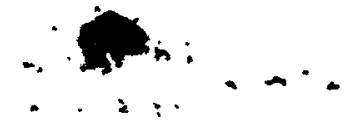

The presence of planar fabriasis characteristic of the. internal structure of many granitic bodies. A feature common to the outer, eariy-copled shells of such granttlc bodies is - planar fabric orlentated parallel/sub-parallel" to"the pluton - "country. rock contact.: Im. the vidal granite. Narway, such a planar fabric is composed of infcrocline megacrysts. (sylvester.l, 1954). In the rogart granite, scotlana, hotilende and plagloclase crystals form the concordant fabric (Seper; ' 1963 ). Granitle bodie's at Ardara, 
ran

Ireland (Arkaad, 1956), Flamanivilie, France (Holder, 1978), Ploumanac'h, France (Barrier, 1977), Birch Creek, California (Nelson and sylvester, 197\%), apd numerous examples, as well as Ardara, within the Donegal granite complex, Ireland (Pitcher and Berger, 1972), ajl contain a planar fabric orlented parallel or sub-paralleil to the margin of the body. A further feature common to many of these bodies is that the foliation becomes weaker with increasing distance ayay from the perimeter and towards the core. In the Enchanted Rock pluton, Texas (Hutchinson, 1960) a strong arcuate mineral foliation in the periphery give's way to a meandering mineral alignment in the-core.

a However internal fabrics are not restricted soledy to the peripheral.: zones of granitic bodles: soper (1963) descrlbes a plandir fabric within the central area of the Rogart granite. 'In this instance and also at other localitiés e.g. Ellicott city, granlte, máryland (cloos, 1933): the Loon Lake (Cloos, 1934) and Chandos lake granites (Saha, 1959), rontarto, a funnel shape is implied by planar fabric oriéntatian.:

$\because$ There is genéral consensus that penetrative, planar mineral aligniments form parallel with the plane containing the intermediate $(Y)$ and long $(X)$ axes of the deformation ellipsold, that is parallel with the plane of flow (Berger and Pitcher, 1970): In the L-S fabric system (Flinn, 1965) the linear component; of the mineral alignment forms parallel $>$ 
with the direction (x) of maximum flow (Ramsay, 1967).

However, a general similarity between. mineral alignment in granitic intrusions, resulting "from magma flow under regional or diapiric stress, whether it be uniform prot (Balk, 1937; Maclin, 1947), and metamorphic Eabrics complicates their interpretation.

Pitcher and Berqer. (1972). provide evidence thớt a strong structural qrain can develop in granitic rocks below their. liquidus temperature but before they have cooled completely. Whether or not the internal fabric in the peripheral part of a body is everywhere parallel to the margin of the body appears to be of prime importance: in deciding which mechanism produced the fabric. The Fannad, Ardara and Thorr plutons of the Donegal complex (Pitcher and Berger, $\ddot{1972)}$ all contain a fabric that is generally concordant but locally oblique. Pitcher and Berger interpret these fabicics to belthe result of forces applied to the bodies when they were in a near-solid state. They invoke a "reciprocial mechanism for producing such a fabric; the country rocks, heabd aside by a forcefully emplaced pluton, driven by buoyancy differences in the crust (Ramsay, 1967), exert a stress on the pluton once it reaches a tectonic level at which further vertical or lateral movement is not possible. This model depends upon the ability of the country rocks, away from the contact aureole to store up strain energy without experiencing. fore thañ a minimal 
degree of deformation. other important factors would be the rate of emplacement, the crustal level, the ductility contrast between pluton and country rócks.

Pitcher and Berger are of the opinion that it would be virtually impossible to distingulsh between this model and one involving a reqional stress system that is unrelated to the ascent of the pluton. It is however difficult to visualize how a reglonal, stress system could produce a planar fabric within a pluton that is everywhere parallel to the contact of the body with adjacent country rocks.

Local discordancies of fabric alignment with the contact ralse problems as to whether a fabric is solely related to laminar flow or to a stress system operating when the body is virtualiy solidified, or to a combination of both.

\section{4d. Summary and Conclusions}

A synthesis of the work by Fox (1959) and of this author establishes that there are two fabrics in the outer part of the pluton along with the plagloclase fabric in the inner part of the pluton.

on the basis of petrology and chemistry fox believed that the core zone represents the original igneous-state of the body: the plagloclase fabric can therefore be expected to have. a primary igneous origin. The concordant compositional layering fabric in the outer part is composed of hydrous mineral phases which are thought to have 


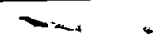

crystalized in a mimetic fashion rafter an original igneous fabric. An important character of the concordant fabric is the random orientation of the individual minerals in both the mafic and silicic layers. This implies that the mimetic crystalization occurred at a time when little or no stress was being applied to the Adamant pluton and tes country rocks. Consequently the mimetic crystalization is unrelated to any tectonic event and probably occurred during a time of kinematic quiescence and thermal activity. As the fabric is deformed by phase two folds, it appears that this deformation post dated the secondary crystallization.

It is proposed that the fabric in. the inner part and the fabric in the outer part of the body both formed as a result of laminar, magmatic flow during emplacement.o The plagloclase fabric can be traced out of the anhydrgas core zone and into the hydrated outer zone where it is fcomposed of: mafic minerals. This compositional differgnce is secondary, brought about by the hydration of the outer part of the pluton. When mineralogical differences are ignored the fabric pattern, in the western part of the hypersthene-augite monzonite zone and transition zone and the area to the immediate west, is concentric (Figure 25). This concentric, planar, fabric pattern in the interior of the pluton probably defines the structural core of the body whilst the concordant, planar, fabrlc that occurs in the outer part of the pluton defines the structural margin of 


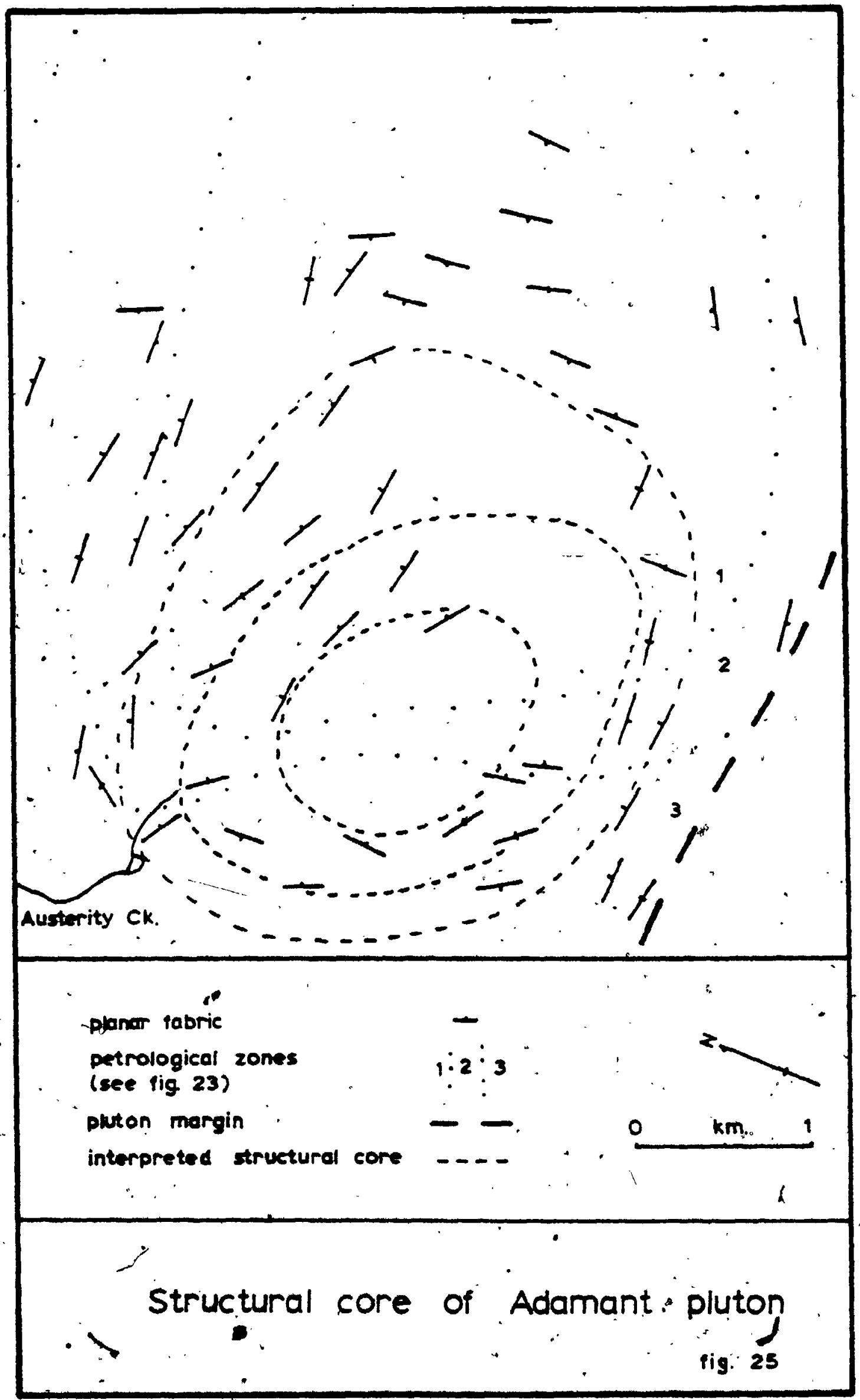


the body.

The second planar fabrlc recognized by the author in the outer part of the pluton is almost certainly related to a post-emplacement stress system. This biotite fabric is oriented parallel to the axial surfaces of folds that deform the concordant, planar fabric discussed above. These folds have axial surfaces that strike northeastmouthwe'st and dip steeply towards the northwest. Hinges plunge towards the west. Phase two folds and fabric in the adjacent country. rock' can be traced into the perimeter zone of the pluton where they are correlated with the folds that deform the concordant fabric. The phase two age of these folds places a constraint wupon the minimum age of the pluton, the folds and associated fabric being younger than the concentric and concordant fabric and also younger than the perlod of mimetlc crystallization.

The structural history of the pluton may be summarized as follows:-

1. Emplacement, during which timer a laminar flow fabric was formed: This fabric presumably was established initially in the outer part of the body where it was concordant with, and defined, the margin of the body. progressive erystallization towards the interior of the. pluton followed, the centrally located, concentylc planar fabric defines the structural core of the body and formed the final primary structural feature. 
76

2. Hydration of the outer part of the body accompanied by mimetic recrystallization of the concordant fabric in the outer part of the pluton.

3. Deformation of the outer part of the pluton during the second phase of regional kinematic activity. This produced folds and fabric which are discordant to the margin of the body. 


\section{METAMORPHIC GEOLOGY AÑD TEXTURAL RELATIONSHIPS}

5a. Metamorphic Geology

Barrovian reqional metamorphism; ranging from chlorite to potassic feldspar-silimanite arades, has affected the rocks of the Northern Selkirk Mountains.. A metamorphic culmination, defined by the coexistance of silimanite and potassic feldspar, is centrally located within the region and mineral zoneș on elther side trend northwest-southeast (Leatherbarrow and Brown, 1978).

Four distinct mineral assemblages are recognized within the study area (Figure 26 ).

1. Staurolite-garnet-biotite-muscovite-quartz

This zone occurs in the southwestern and south-central part of the study area (Figure 25, Plate M2).

staurolite is very common and the grains are typically poikiloblastic in habit, inclusions invariably "being composed of quartz. Grain outlines are euhedral to subhedral.

Garnets vary in outline from euhedral to anhedral; - adjacente to staurolite grains they may have embayed." boundaries. The arenet grains are commonly poikiloblastic with quartz, mica and opaques forming the inclusions. Some. of the garnet grains are surrounded by rims of retrograde chlorite.

$: \div$

Biotite occurs as either course or fine grains, the fórmer usualiy contain inclusions of quartz and opaque 
minerals. Muscovite is fine grained in form.

2a. Kyanite-staurólite-garnet-biotite-muscovite-quartz

This assemblage marks the first appearance of kyanite and i's located to the north of zone $l$ and to the south of the pluton. (Fiqure 25). It occurs associated with assemblaqe $2 b$.

Kyanite varies in outline from anhedral to subhedral, often poikiloblastic with quartz and opaques enclosed; grain outlines are usually embayed.

2b. Kyanite-garnet-biotite.

The difference between this assemblage and the previous one is the absence of staurolite and muscovite (Plate $\mathrm{k} 2$ ).

Kyanite tends to be more common than in the previously mentioned assemblage and it has a làth-like form with better defined qrain boundariés.

3. Sillimanite-garneţ-blotite

This assemblage, occurs adjacent to the southern. perimeter of the pluton and in the area to the north of it. (Figure 25).

sillimanite occurs as fibrolitic interdrowths associated with biotite and muscovite. It may form in: rándomly orientated sheaves or be aligned parallel to $s_{0}$. Discussion

The mineralogical changes between assemblages detailed within the study area are controlled by two reactions. The first involves the breakdown of staurolite and the 
introduction of kyanite, This reaction occurs between assemblage 1 and $2 b ;$ assemblage $2 a$ is presumably transitional:

$$
\mathrm{st}+\dot{\mathrm{m} u} \mathrm{u}+\mathrm{qz}=\mathrm{ky}+\mathrm{qa}+\mathrm{bi}+\mathrm{H}_{2} \mathrm{O}
$$

(Leatherbatrow, 1980 , unpübl ished)

The second reaction is the one involving the introduction of sillimanite, at the expense of kyanite. Kyanite and silimarite are seen: to coexist at certain localities (Fiqure $2 h$ and Plate $\mathrm{K} 2$ ).

$$
k y=s i
$$

The assemblage of silimanite + potasicic feldspar: detalled by Leatherbar.row and Brown (1978), that. is located to the northwest of the pluton, was not recognized within. the study area, perhaps due to rather restricted sampling. Textural Relationships

The earliest foliation recognized within the country rock ( $\left(s_{1}\right)$ is that.associated with the first phase of deformation. This foliation is variously defined by laths of hornblende, elongated grains of quartz, plates of muscovite, epidote grains and. elonqated grainsiof opaque minierals.

$S_{1}$ appears to have been strongly transposed by later fabrics and is not as apparent in thin section. as it is in the area to the south studied by Tippett (1976). The planar foliation is usually parallel to compositional rayering, except in the nosés of rare, first phase folds. 
- Alanar fabric associated with the seciond phase of deformation $\left(S_{2}\right)$ is extensively developed and variously defined, by plates of biotite and muscovite, phlogopite, laths of hornblende, elongated grains of quartz, quartzite, calcite and dolomite. This fabric is developed.in a variety of rock types ranging from marble and quartitite to mica schist and amphibolite? It is' seen as alignment of lathis, plates and elongated"qrains rather than as a crenulation of a "pre-existing fabric". (Plates.J1, J2, K2, LI, L2, MI and M2)

Some of the garnets, còntainęd within amphibolites bearing second phase planar fabric, have equant, $\because$ poikiloblastic core zones surrounded by inclusion-free rims which are elongated in a direction pargllel to that of the second phasë linear fabric, $L_{2}$. - These cores are believed to have grown before. the onset of the secont phase of deformation. The rims grew syrikinematically and were e'ither flattened as a result of applied stress, or, more ilikely, qrew by a process of diffusion flow in a preferred orientation. Elongated grain, outlines are also observed in the quartzites, grits and conglomerates (Plates' E2, E3, G4), the grains and the clasts in the latter two being composed of quartzite. The major and mean axes of the ellipsoidal grains and clasts lie within $\mathrm{s}_{2}$, the direction of elongation being parallel to $L_{2}$.

The most prollfic period of mineral growth occurred. between the waning stages of the second phase and the onset 
of the third phase of deformation. Phase two planar fabrics were overgrown by plates of biotite and muscovite, staurolite, kyanite, sillimanite and garnet grains, all of which contain straight inclusion trails composed. of elongated grains'of quartz (Plates K1, L1, L2, MA). The highest grade of metamorphic minerals grew during this period, culminating in the breakdown of staurolite and muscovite, to produce fibrolite. The metamorphic peak is bracketed between the second and thi-rd phases. of deformation; Franzen (1974), Van der Leeden (1975). Tippett (1976), Ghent et al (1977), Lane.(1977), Leatherbarrow and Brown (1978) and Perkins (pers.comm.1979) all reached a similar conclusion in their. respective study areas. Kyanite overgrew $\mathrm{S}_{2}$ and some kyanite laths grew parallel to $L_{2}($ Plate Kl). Sillimainite occurs as fibrolite and forms either rand: omly orientated clusters or has overgrown and assumed a similar orientation to that of $\mathrm{L}_{2}$ ( Plate K2) :

Many of the garnets with straight inclusion trails. having overgrown the pre-existing second phase fabric, have - inclusion-free rims that show no preferential elongation, indicating further growth' after the second phase of deformation but before the third phase.

With the advent of the third phase pre-existing porphyroblasts wers rotated, consequently the internal fabrics these: porphyróblasts are not continuous with the 
fabric of the aroundmass (Plate L?). In rocks where the porphyroblastis are of a similar size, outline and species, the deqree of rotation is remarkably similar. Rare garnet and staurolite grains are seen to have overgrown a weakly curved $s_{2}$ indicating that growth odeurfed in"the initial stage of the third phase.. (Plates L3, M2). "Such gralns were rotated as the deformation. Intensified. and the surrounding matix was strongly: crenulated.. porphyroblast growth diminished "ropidiy during the thic phase of deformation, only biotite is a perslistent phase."

$S_{2}$ was strongly crenulated durling the third phase and a widely spaced crenulation cleavage was formed in the mica-rich rocks, (plates R3, K4). Where this fabric is well develioped it transposes all previous fabrles. Layers rich in mica alternate with those rich.in quartz, the mica plates being jenerally aligned obliquely, to the follation. A rare third phase fabtic composed of biotite laths and orientated. parallel to the axial surfaces of third phase folds is reçognized.

Some biotite growth continued after the third phase of deformation; rafe and large plates of biotite are seen to have oveigrown a very stiongly crenulated $s_{2}$.

5c. Minor Iqneous Rocks

The only igneous rock type recognized, outside af those associatied with the plution was a mass of amyqdaloldal diabase having a circular outline with a diameter of 
the body has had a multiple intrusive history. This author agrees with the original. interpretation of Fox (1969), that" the pluton was formed during a single Intrusive event.

Any primary distribution pattern of a major, or trace. element "that exhlbits" a variation in abundance within the body should seflect the primary structure of the body. An example of: "this is the distribution pattern of Tio (Figure 30) which appears to show a definite relationship to the inferred internal strueture of the body. The highest values of $\mathrm{TiO}_{2}$ content are in the perimeter zones: présumably this was the first part of the body to crystallize. "Its content decreases progressively until the lowest, values are encountered, in the inferred structural core off the body, these rocks presumably being the final ones to crystallize. A distribution pattern such as this is thought to be a primary feature associated with intrusion of the body.:

Any comparision between the distribution patterns of: $\mathrm{TiO}_{2}$ and zirconium is seriously. hindered py the Iinited number of zirconium analyses avalfable. Whilst both species incresase in abundance away from the central part of the pluton, they do so in a distinctly differeñt manner. Tio 2 does not exhibit the pronounced perimeter enrichment shown in zirconium (Table 2 and Figure 27.).

From the trace element analyses (Table 2) it appears that the threshold level of zirconium content required to form zircon iles between 51.58 and 91.79 p.p.m. 

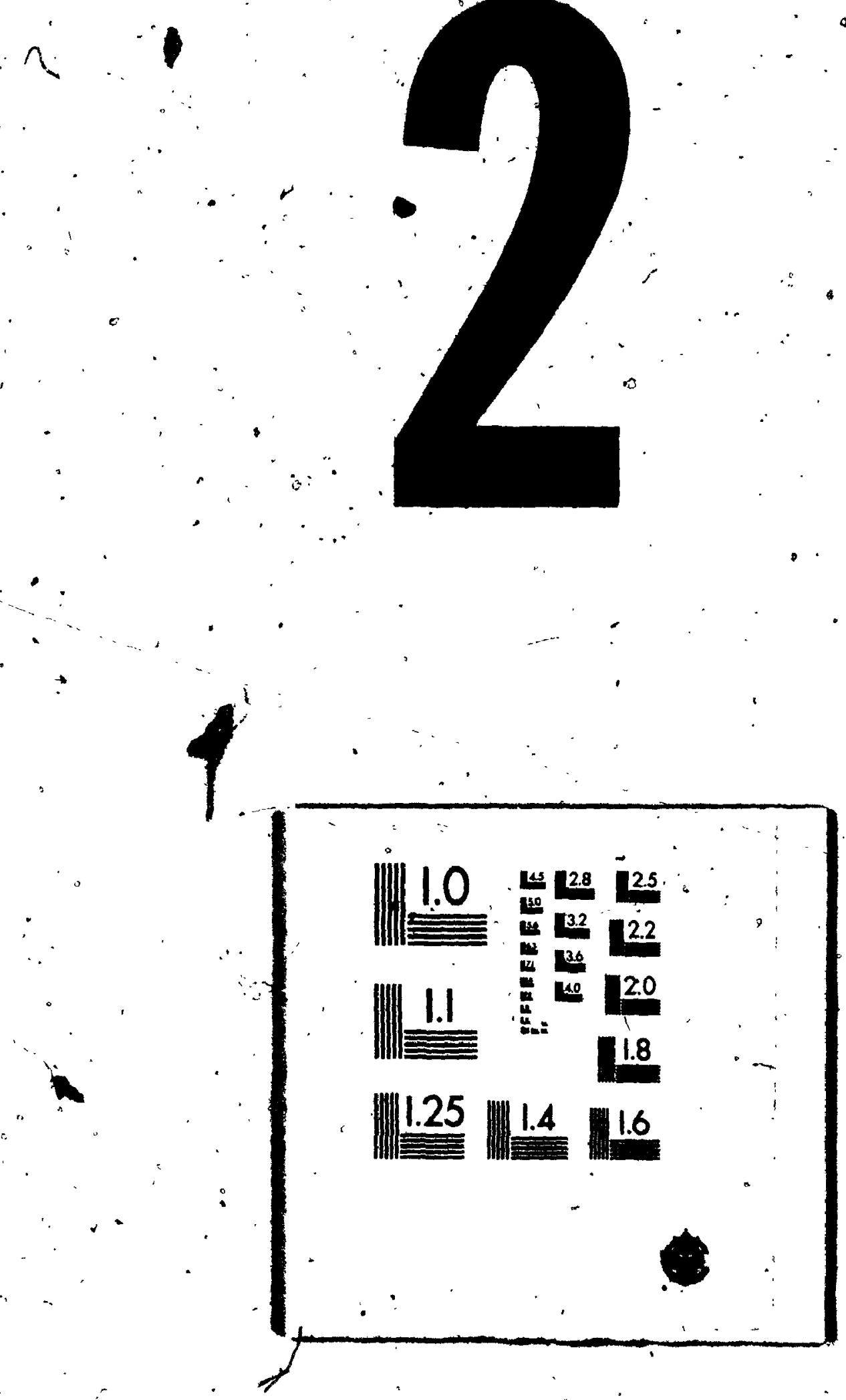
83

approximately $15 \mathrm{~m}$. The amygdales are predominantly filled. with calcite (Plate J4). The rock does not contain any tectonic fabric, nor does it appear to have been deformed, although it is surrounded by meta-sediments that contain. strongly crenulated $\mathrm{s}_{2}$. This indicates that the intrusive event was no older than the Middle Jurassic. 


\section{GEOCHRONOMETRY -}

ha. Introduction

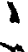

The Adamant plutorf, on the basis of fleld data; is as old as the second phase of deformation. Comparing field data with the results of finite element analysis indicates that the pluton may be as old,or older, than the first phase of deformation.

It was boped "that a more precise age of emplacement would be given. by an isotopic study.

6b. Previous Work

Potássium-argon isotope analysés.

Six Adamant pluton, samples wẹe analyzed tồ potassium-argon at the Geological survey of canada laboratory, ottawa. These samples were collected by Fox; the results were published in Geological survey of canada Papers 62-17 and 63-17. A compilation of the results is presented in Table li sample locations are shown in Figure 27.

Four of the six analyses were carried qut on qranodiorite samples, these qave a spread in apparent ages. from 281 Ma to $9 / 2 \mathrm{Ma}$. of these four analyse's two were done on biotite qralns (analyses 61-21 and 61-23) collected at separate localitles but situated at similar distances fron the margin of the pluton. These two blotites differ in apparent age by $81 \mathrm{Ma}$, a fact that Fox lin G.S.C.'Report 62-17, 1952) found inexplicable. The remaining twa of the 



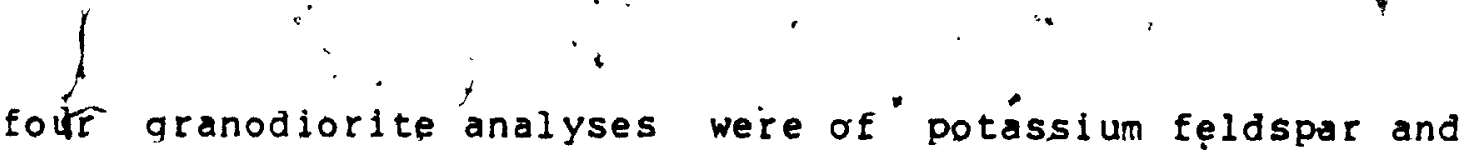
hornblende crystals (analyses 52-24 and 62-25). They prọduced ": apparent ages - of 92 Ma and 115 Ma respectively: The hornblente was separated from the sample that yielded biotite ( analysis 61-23), which gave a much older apparent age. As hornblende is more retentive' with'respect to radiogenic argon (Faure, 1977) the. older age would be experted from the hornblende and not as in this case from the biotite. Reesor (in Leech et al., 1953) attributes they young apparent ages of the feldspar and hornblende to a lates thermal event in the history of the Adamant pluton.

Analyses $51-22$ and $51-24$ are of biotites from a pegmatite vein and fom a quartz vein respectiveiy, both veins occurring within the granodiorite zone. Apparent-ages - of the vein rocks differ by a minimum of $70^{\circ} \mathrm{Ma}$. from the host rock, granodiorite, a rather excessive disparity to be attributed solely to a period of crystalization.

Discussion

In thie results' for analyses $51-22$ and $51-24$ the tạdiogenic argón content is given as 1008; for analyses 61-21 and $51-24$ the amounts of.radiogenic argon are 89.9 and 878 respectlvely. These analyses" were performed in 1951 and 1952 raspectively during a deriod when the G:S.C., I aboratory was experiencing problems in determining correct radiogenic argon levels. "This problem is well iliustrated by the results from successive studies of the Guichon batholith, 
British Columbia.

The initial study of this batholith was done by the G.S.C. (G.S.C. Reports $53-17$ and 64-17). Eleven samples were analyzed; the mineral employed in each case was biotite. Results from the first report gave apparent ages ranging from. $224 \mathrm{Ma}$ to $245^{\circ} \mathrm{Ma}$, the latter report gave. apparent ages ranging from $240 \mathrm{Ma}$ to $260 \mathrm{Ma}$. The arithmetic mean. of the two groups is 240 Ma. In each analysis the radiogenic argon level given was 100.

These results contrast with those presented by white et al., (1967), derived-from twenty-four "samples analyzed at the University of British Columbia. Their samples gave an - arithmetic mean apparent age of 200 Ma with standard error of +5 Ma, error limits for eacb samplée being 28, or $4 \mathrm{Ma}$, this being the limbt of analytical precision in their 1aboratory. All bar one. of the samples fell within the 200 Ma $\neq 5^{-}$Ma bracket, the single exception to this.being isuspect due to its low potasolium content. None of the twenty-four samples were lisked with radiogenic argon levels of 1008 , the highest recorded being $93 \%$, the lowest 278 , and the average 748 .

The above comparison highlights the questionable nature of the Adamant pluton analyses, (Table'1). Internal inconsistencles $9.9:$ the difference in age of 81 Ma between blotites in adjacent samples, analyses $51-21$ and $51-23$, of the same rock type, add further to the doubt. 
8

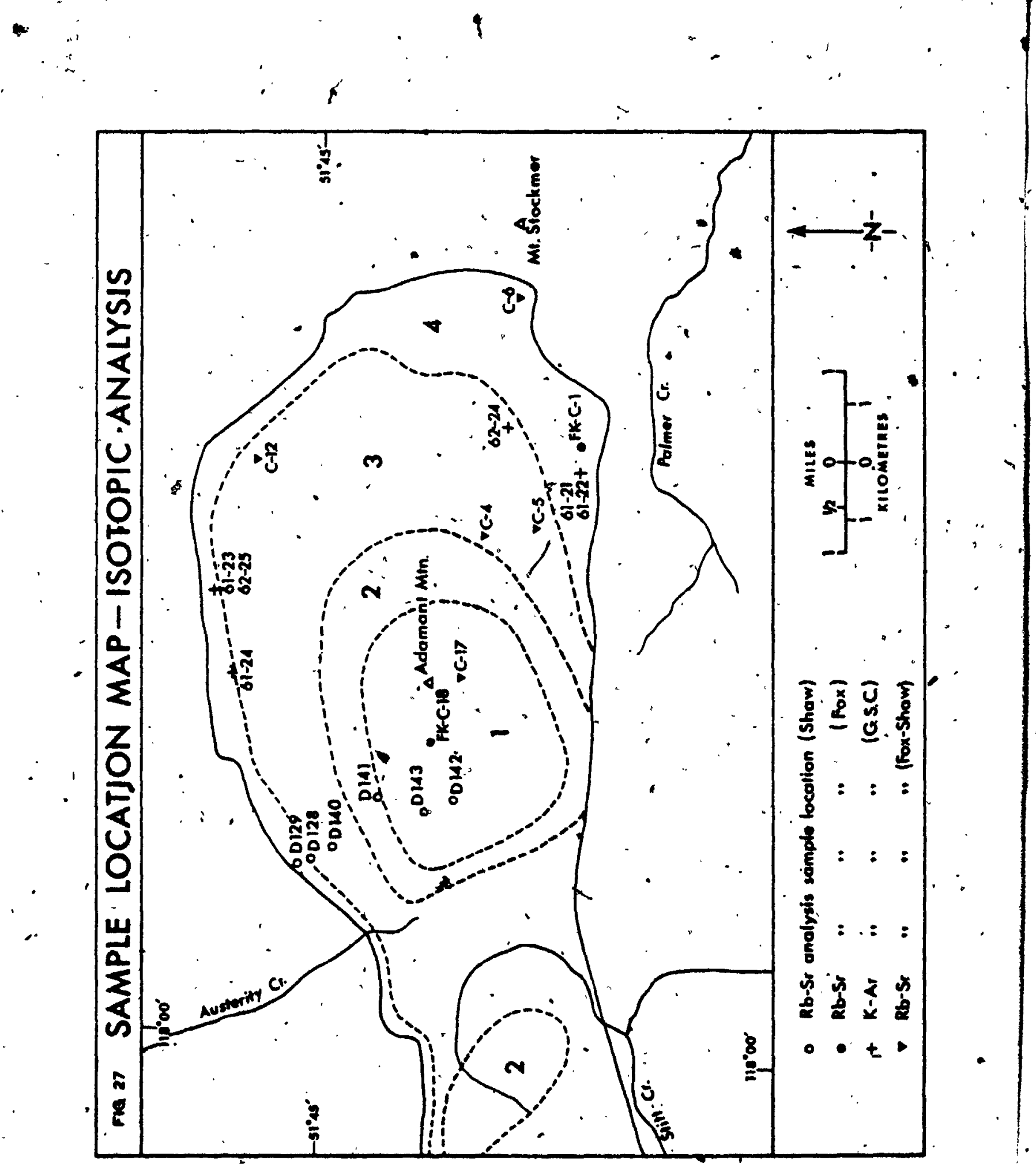


Rubidium-strontium isotope analyses

Samptes collected by Fox were analyzed.at, the Geological Survey of Canada's 'laboratory, Ottawa. The varlation in the Ŕb/Sr values was Ansufficient to derive an i sochron.

5c. Present wớrk

Rubidium-stróntium işotopic analyses

During the summer of 1975 six samples were collected by the author along a traverse (Fiqure 27) that included the four petrographic zones of the pluton. These samples varied by only 0.08 in their Rb/Srvalues, indicating that the plutón. is "arossly homogeneous with respect to Rb/Sr values. (Fiqure 28). Consequently it was/not possible to dérive an isochron.

Uranium-lead isotope analysès

In view of the inconclusive results obtained.from the potassium-arqon analyses and the lack of results from both the rubidium-strontium stury made, by Fox and that done by this author, a uranium-lead atudy was undertaken. Sampiles were collected by the author from both the hydrous and anhydrous parts of the pluton.

Three groups of samples were collected, and analyzed for zircon content.

$\mathrm{U}-\mathrm{Pb} z i x \operatorname{con}$ study

Group. A: This group was assembled from samples collected by Fox. Each sample within this group was. 


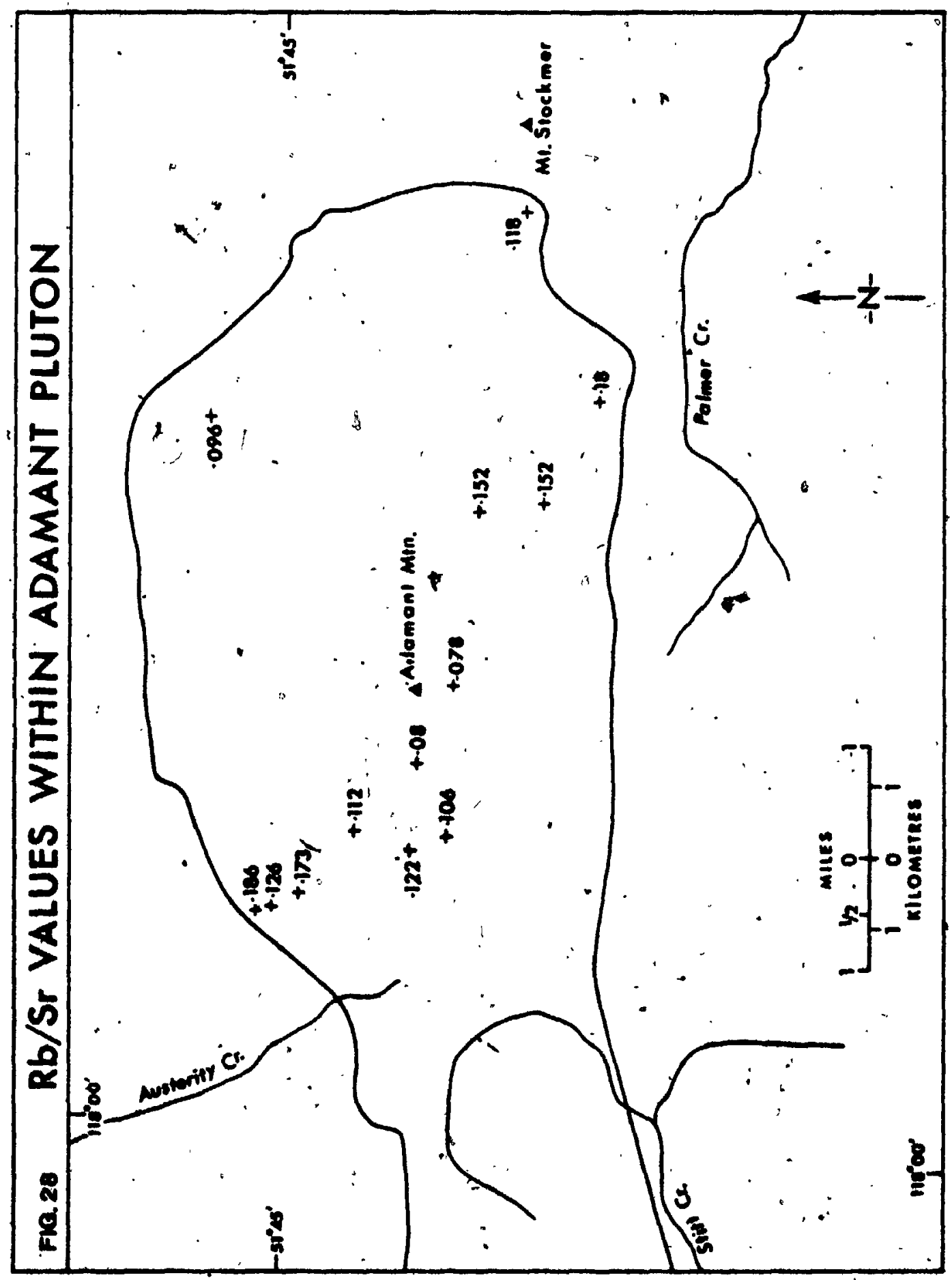

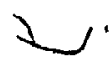


collected from a locality in " the hydrous outer. zones of the plutor (Fiqure 2.3).

Group B: The samples in this group were collected by the author in the southern ipart of the hypersthene-augite moneonite core zone (Figure 27).

Group $c:$ The samples in this group were coligcted by the author from a single. locality in the biotite-hornblende granodiorite zone at the western end of the pluton (Figure 27)

Zircons Were abundant in sample groups $A$, and $C_{\text {i- }}$ sample group $B$ was devold of zirconit

Analytiçal technique and results

For a detailed account of the analytical techiniqué and results the reader is referred to shaw (1980).

An averaqe age of $169 \pm 4$ Ma (Figure 29a) was derived Erom nine isotopic ages, determined from three size fractions' of sample group $C$.

The distribution of zircion and zirconium

The distribution of zircon within the Adamant pluton is limited to the hydrated part of the body only (Fiqure 29). with, respect to the major elements the body is essentially homogeneous, the only dififerences between core and perimeter, being variation in the sio, and Mgo content -(Fox, 1959). Petrological differences between core and perimeter may be simply explained by the addition of water 
$\therefore \%$

${ }^{*} \cdot{ }^{\circ} \cdot$

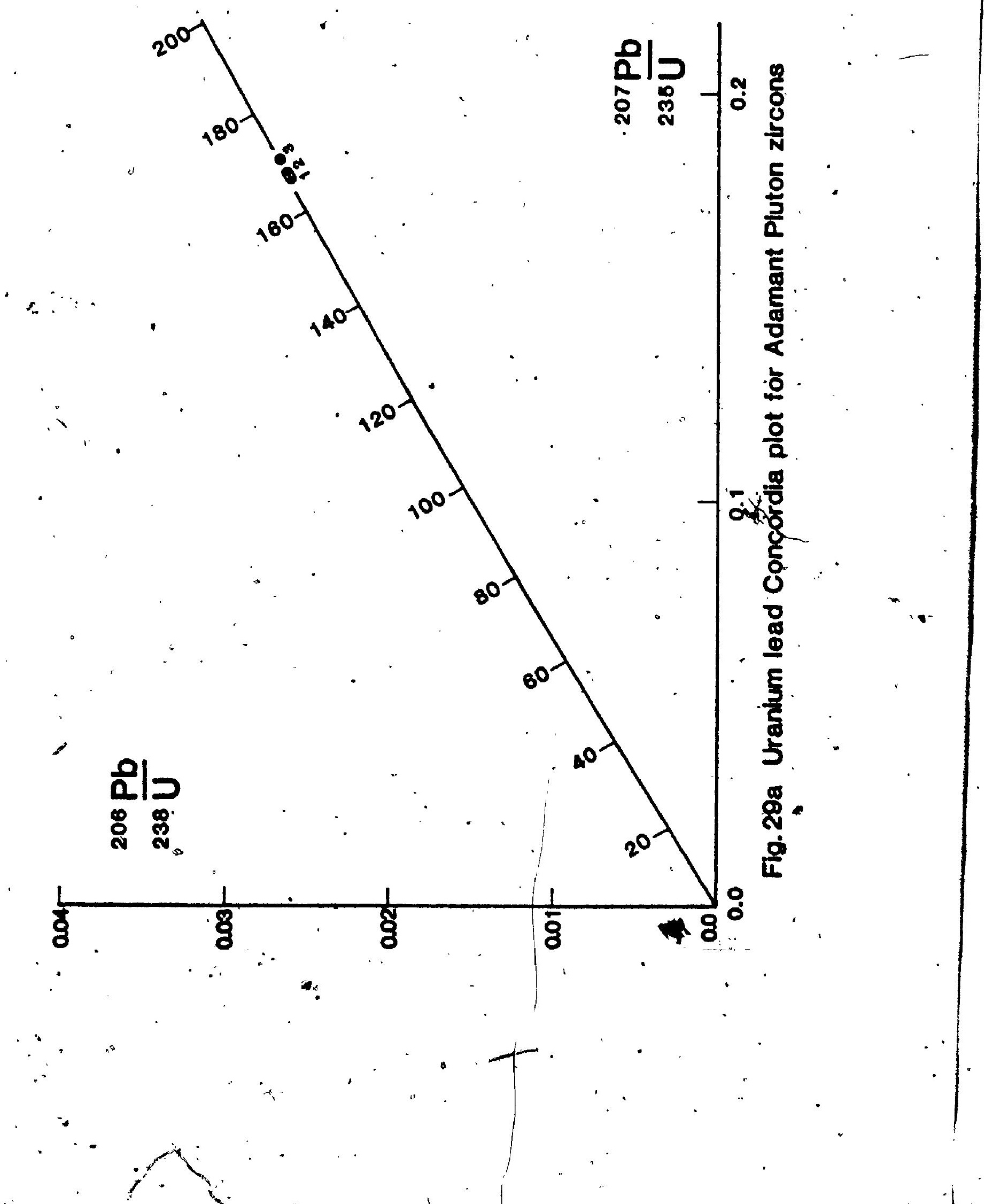


and oxygen to the outer zones of the bodx. The transition from the hydrated outer zone inwgrds to the anhydrous core is a gradual one. Fox (1959) belleved that the pluton crystallized initially as a pyroxene monzontte body, the present petrological variation being secondary'.

The hydration of the body probably occurred during its intrusion to present levels. This event precedes the second phase of deformation because the fabrlc in the outer zone of the body, composed of hydrous mineral phases, has been deformed by second phase folds.

Whilst zircon is absent from the anhydrous core zone of the body, zirconlum is present in very small amounts (Fiqure 27 and Table 2). Samples $C 17$ and $C 18$ yielded $23,1,2$ p.p.m. and 51.58 p.p.m. respectively. Samples C4 and CI2, located in the hydrated part of the body, have zirconium contents of 91.79 and 105.10 p.p.m. respectively. These rotks contain $z i r c o n$, although most zircon bearing rocks have $2 r$, contents of at least, 200 p.p.m. This apparent anomaly may be due in i. part to the low alkali content of the rocks. A high alkali content in the presence of such low'zr values would probably inhibit the formation of zircon ( M.Gorton, pers. Comm.., July. 1980 ). Towards the outer part of the body the amount of zirconium increases rapidly; samples $C_{5}$ and $C h$ contain 199.80 and 377.85 p.p.m. respectibely. 
Table 2. Trace Elemerit Analyses of Adamant Pluton Samples Element Sample

ch C5

C12

C4

C18

$\begin{array}{llllllll}25 & 377.85 & 199.80 & 106.10 & 91.79 & 51.58 & 23.12\end{array}$

$Y . .83 .9$

29.05

16.59

$12.17,14.13$

13.55

Amounts given in parts per million (p.p.m.)

Analyses carried out at University of Toronto by M. Garton.

The abundance of zirconium between the anhydrous core zone and the hydrated perimeter zones differs by a factor of 20, an unusually large, variation for a single intrusive event. variations of up to a factor, of 5 are considered normal (M. Gorton, pers. comm., July 19s0̣).

Such a large and unusual variation may be explained by the foilowing possibilities:-

1. The body is composed of serles of injection phases, 1.e. it is a multiple intrusion.

2. There is an unusual primary distribution pattern of zirconium.

3. The distribution of zirconium has been strongly influenced by secondary activity. Both structurally and chemically "lother than with" respect to zirconium) there is no evidence to suggest that 
the body has had. a multiple intrusive history. This autior agrees with the original, interpretation of Fox (1969), that". the pluton was formed during a single intrusive event.

- Any primary distribution pattern of a major, or trace, element "that exhibits" a variation in abundance within the body shoulds reflect the primary structure of the body. An example of this is the aistribution pattern of tio (figure, 30) which appears to show a definite relationship to the inferred internal structure of the body. The highest values of $\mathrm{TiO}_{2}$ content are in the perimeter zones: présumably this was the first part of the body to crystallize. "Its content decreases progressively until the lowest. values are encountered, in the inferred structural core $8 f$ the body, these rocks presumably being the final ones to crystallize. A distribution pattern such as this is thought to be a primary feature associated with intrusion of the body.:

Any comparision between the distribution patterns of: $\mathrm{TiO}_{2}$ and zirconium is seriously. hindered py the linited number of zirconium analyses avafable. Whilst both species increase in abundance away from the central part of the pluton, they do so in a distinctly differentit manner. Tio 2 does not exhiblt the pronounced perimeter enrichment shown in zirconium (Table 2 and Figure 27.).

From the trace element analyses (Table 2) it appears that the threshold level of zirconium content required to form zircon .lies between 51.58 and 91.79 p.p.m. 
Consequently the presence of zircon within the hydrated rocks immediately adjacent to the western edge of the structural core, implies that the zirconium content is greater than at localities $2 \mathrm{~km}$ to the east, within the anhydrous core zone. Thus the distribution pattern is one of an increase aw from the anhydrous core zone and does not appear to relate to the primary structure of the body. In the western part of the pluton there is another anhydrous core area (Fiqure 29)., a sample from which was found to be devid of zircon. Yet this anggdrous area, as with the larger anhydrous area in the sing part of the body, is surrounded by hydrous, zircon-bearing rock. It is assumed that the zircorifum content of the" unaltered, anhydrous rock is at a primary. Ievel associated with the initial intrusion of the body. The pronouncedienrichment of the outer part of the pluton, especially the perimeter area, with zirconium is interpreted to be due to some secondary activity, the nature. of which is puzzling as zirconium is regarded as a very Immobile element (M. Gorton, pers. comply July 1990).

The most probable time for introduction of the zirconium would have been during the hydration of the body. there beling some type of relationshlp between the hydration and the influx of the element. This would explain why the zirconium is more abundant in the rydrated parts of the body, and why the anhydrous parts of the body contain oniy the low, primary, amounts of zirconium 
It appears that zircon will only"be produced within rocks that have a zirconium content equal orgreater than a certain amount. The primam content level of the body, as evidenced by the hypersthene-augite monzonite, anhydrous core, is.insufficient and consequently there is a loack of zircon within this zone. Outside of the anhydrous core area the hydrated zones, with their increased zirconium content, are able to host zircons. The capacity to do this wovid prestimably increase towards the perimeter where the zirconium content is the hiqhest.

Di scussion

The origin" of zircon and its resistance to regional and contact metanorphic activity has long been debated. The opinions are polarised into two main groups; on the one side are those who belfeve that the growth off zircon is réstricted to envjronments of magmatic consolidation. Alternatively there are those who believe that zircon growth is not restricted solely to magmatic domains and may also be grown as a result of metamorphic or even authigenic activity.

poldervart . (1956) and Larsen and Poldervart (1957) contended that zircons crystallize early. In a magmatic consolidation cycle whereas Gottfried ef al: (1959) silver and Deutsch (1953) and silver (1953b) noted that certain grains of zircon were zoned, Indicating progressive growth dùring maqmatic consolidation. 
Paubeneck (1957), Mertie (1958), Karlsbeek (1952) and Silver (1963a) all were of the opinion that the character of zircons remained unaltered in sediments and metamorphics, the morpholiqical distinctions "surviving selective melting and metasomatisin. Any zircon qrains found in sedimentary or metamorphic rocks were assumed to be detrital, in spite of the fact that overgrowths on zircons within metamorphic ro,ks had long been reçognized.

Such overgrowths usualiy alter the outline of the grains from round to euhedral: Taubeneck (1957) reported that zircons within arg!llaceous rocks that had experienced pyroxene: hornfels Eaçies metamorphism had this form overgrowth. Eckelman and Poldervart (1957) réported similar findings Poldervaart. (1950) noted that " during the ultra-metamorphism of sediments the zircons tend to acquire àn almogt "magmatic" character, whilst Berthelsen (1950) found that in amphibolite, facies metamoriphism a new generation of zircons was produced. The basic assumption of these authors however was that the zircons examined were of a detiltal origin with respect, to their presence in "netamorphic rocks.

As Saxena (1968) pointed out, it is easy to recoqnize vevergrowths but difficult to recognize new grains. The fact. that material may bo added to existing grains was interpreted by him to indicate that it may also be possible to form new grains in a variety of pressure and temperature 
conditions.

Saxena $\left(195^{5}\right)$. Iisted 3 geneticlypes of zircons,along with another ? types:

1 Crystalized from a magma.

2. Formed authiqenically in sediments.

3. Formed under metanorphic conditions.

4. Of authigenic origin, transformed during - metamorphism.

5. Zircons of all types-completely recrystallized under a high qrade of metamorphism.

The authigenic growth of zircons indicates that they may be formed in low temperature and pressure environments; metamorphism would accelerate such a process. From hydrothermal experiments sáxena (195.5) concluded that any zircons present in a decayed state during a hiqh grade of metamorphism should be completely recrystallized.

Armstrong (1922) was of a similar opinion to saxena, and various other authors related zircon growth to authigenic and metamorphic activity. Gillson (1925) reported abundant euhedral zircon as a contact metamorphic mineral in Idaho. Hutton, and Turner $(1935)$ described elongated eutedral. zircons if thé,greenschists of eastern otago, New. zealand. Smithson (1937) and Butterfield (1936) noted aluigenic outgrowtins on detrital zircons in non-metamorphosed rocks; they believed that the growth was in situ.

The work of Krogh and Davis (1972, 1973, 1974 and 1975) 
at the Geophysical, laboratory of the carneglo Institute provided a considerable insight into the behaviour of zligons during metamorphism and the interpretation of $U-\mathrm{Pb}$ ages. Krogh and Davis found that during events of minor metamorphism some zircons were almpst completely unaffected, the zircon $\mathrm{U}-\mathrm{Pb}$ systems being extremely resistant to metamorphism and apparently supporting the concept that they can withstand the effects of reglonal metamorphism. It was also noted that a loss of radiogenic lead may ogcur in the absence of any metamorphism. Tilton (1950) attributed such a loss to continuous diffusion, whereas Goldich, Hedge and "Stern (1970) Invoked the effect of uplift and erosion. Episodic activity was thought by some to account for the disparity (e.g. Wetherill, 1955; Silver, 1953a). Krogh and Davis noted that both the continuous diffusion model of Tilton and the episodic loss theory were supported by data Erom various areas.

To test the effects of reqional metamorphism on zircons Krogh and Davis (1972). performed a detailed study:on samples from the French River granite and adjacent paragneiss south of Sudbury, ontario. It was found that the zircons had been strongly affected by a period of metamorphism 1320 to 1025 Ma. ago. The primary effect was a loss of lead, a lesser effect being the production of new zircons. The formation of the new zircons displaced the U-Pb data points towards the time of the event; the smaller the grains the larger the 
displacement. Also for a given grain size the degree of displacement is proportional to uranium content, an effect similar to that noted by silver (1953a).

Krogh and Davis (1973) pointed out, with respect to the formation of overqrowths, that the smaller grains are more susceptible to projucing an age similar to that of the event because of their laraer surface-to-volume ratio which will result in their having a greater abundance of overgrowth generated during, the event." such qrains are cleaty composed of material of two ages.

In their conclusions. Krogh and Davis (19.73,. . 610) make an illuminating, statement: "The' 'extent of the metamorphism is indicated by the production of zircons in. the imobilizates, the overgrowths on the zircons in the paragneiss,... Each of these products is able to withstand minor reheating (unlike micas) and the determination of a time of intense metamorphism rather than cooling can be made."

Krogh and Davis (1974) found that the migration of lead and possibly uranium, such activity, giving rise to discordant aqes, is enhanced during, and perhaps after, the zircon qrain has experienced alteration. This alteration is of a specific type and has botryoldal form, similar in appearance to hydration diffusion fronts-in volcanic glass: The mechanism of loss of lead, or gain in uranium, at this time was still a controversial issue, the two main-theories 
being those of diffusive loss as opposed to episodic loss. The observations of Krogh and Davis have shown that chemical reaction is a major contributing factor to this loss and resulting discordance in $U-\mathrm{Pb}$ system's.

The exact nature of the chemical change that occurs during boEryoidal alteration was not determined by kroqh and Davis, however a slight decrease in both $s i$ and $z r$ were observed. This supports an assumption made by B.0. Mysen (personal communication to Krogh and Davis, 1974) that hydration may be the major chemical change. An observation by - Gruenenfelder et al.(1955) that the $H$ - OH ratio decreases with the amount of lead loss further suoports the possibility of hydration. Medenbach and El Goresy (In Krogh and Davis, 1975) found that the sum of the oxides in.the botryoidal, zones of alteration was $10 w^{\circ}$ by 58 to 128 . The apparent age of the Adamant pluton. zircons - an interpretation. Observations:-

1. The emplacement and hydration of the Adamant pluton is known to have occurred before the second phase of deformation.

2. The peak of treqional metamorphism occurred after the second but before the third phase of deformation. . . 
3. Sample group $c$ of $z\lfloor$ rcon's collected from the outer. zone of the Adamant pluton produced. a very concordant ${ }^{206} \mathrm{~Pb} /{ }^{238} \mathrm{U}-{ }^{207} \mathrm{~Pb} /{ }^{235} \mathrm{U}$ plot. This suggests that the zircons. have not experienced any bydration, such a reaction being thought to affect the ratios' and consequently negate the possibility of producing a concordant plot.

4. There are no overgrowths on any of the grains. The temperature and pressure conditions that are thought to have prevailed during the peak. of regional metamorphism would probably have been, conducive to the formation of overgrowths on existing zircon girains along with the generation of new grains. Okulitch (pers. comm., June 1980) reports the presence of, overgirowths on zircons collected in the - Cordillera - of southeastern British Columbia. An apparent Devonian age was yielded by the cores. of the grains; the formation of the overqrowths is attributed by Okultich to the same thermal peak that affected the Northern selkirk Mountains in Middie Jurassic time. The fact that overgrowths are absent from the Adamant pluton zircons sugaests that there were no zircon grains before the thermal event. 
Interpretation:-

The Adamglefijton zircons are believed to have been formed during the peak of regional metamorphism, - consequently the apparent age derived from them determines a time of intense metamorphism, corresponding to the peak of regional metamorphism, and it does not indicate a time of. plutonic emplacement.

s to 
7. THE BEHAVIOUR OF AN ELLIPTICAL BODY IN A DEFORMING MATRIX

7a. Introduction

In plan view the long axis of the elliptical Adamant pluton trends east-west, while regional trends of fold axial planes and associated fabrics are northwest-southeast.

The following discussion attempts to resolve the question of whether or not this oblique attitude dates from the original emplacement of the pluton or is due to deformation induced rotation after emplacement.

Two methods are used in an attempt to answer this. question. In the first, finite element analysis is omployed. to produce the strain pattern around an elliptlcal body during uniaxial compression. Two separate orlentations:of the body are modelied, for each orientation the body has the properties of a fixed, rheologically, rigid mass. Each orientation produces a unique strain pattern, these patterns are then compared to straln fabrlc data collected in the field.

The second method involves physical and mathematical models of non-rooted, elliptical inciusions in a deformable matrix. The parameters pertaining to each model are. precisely" known and/or contrólled. Results derived provide constraints upon. the iotation of eiliptical bodies in a varlety of situations. Also lllustrated is the manner in. which the strain elifpses in the matrix adapt, to the 
presence of a rotating, rigid inclusion.

7b. Finite Element Modeling of the stress field Around the Adamant Pluton

7bI. Purpase

The purpose of this study is to derive the stress field" produced around a rigid body when the material surrounding the body is compressed. Such a model is applicable to that of a pre-tectonic pluton during reglonal deformation.

For a general background into the finite element method (at stress analysis the reader is referred to the following texts:

- BOVES, William H., and RUSSELL, Leslie T., stress analysis by the finite element method for practicing engineers. (Toronto: Lexington Books, 1975).

zIENKIEWICZ, o:c., The finite element method in engineering science (New York: McGraw-Hil1, 1971 ).

The following are an integral part of this section:Fiqure 9: Diverqence zone locations 31: Distribution of elements, Layout 1 32: Key to Nodes, Layout 1 33: Principal stress components, Layout 1 34: Frend of principal stress $2 \%$ layout 1 35: Distribution of elements, Layout 2 ., 35: Key to Nodes, Layout 2 
37: .Principal stress components, Layout 2

38: Trend of principal stress 2, Layout 2

39: Adamant pluton potentlal rotation directions.

40: Finite element analysis results

7bII. Definition of Terms

Element

Nodes

Centroid

Mode 1
- 2 di-mensional, triangular shaped body. The outline is defined by 3 nodes.s

- point at which 2 converging sides of a t triangular element meet. Each element has 3 nodes.

- point lociated in the centre of an element.

- rectangular outione, 2 dimensional shape which contains all of the - elements.

Principal stress 1 - the larger stress produced, within the model when a specific set of , $\quad \vdots$ ,. ." Principal Stress 2

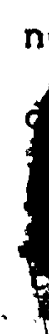
are displaced a speciffc nce in a specific direction. leviated to PSI.

he smaller..stress produced at the same time as PS1. Principal stress 2 is orientated in the same plane. as PS1 but trends at 90 degrees. to it. Principal stresi 2 is always less than PSi, abbrevilated to PS2. 
7bIII. Deformation,

The matrix in both models is stralned when those nodes that lie on both of the sides of the rectangular model that are parallel to the $Y$ axis are displaced 0.75 units inwards in a direction paraliel to the $x$ axis. This displacement and resulting strain occur as one instantaneous action, $1 . e$. there is no incremental accumulation of strain.

The cumulative shortening in the $x$ direction is 0.75 units plus 0.75 units for a total of $1.5^{\circ}$ units, a percentage shortening of 10 .

Deformation is two dimensional and occurs as plane strän, any displacement in the third dimension being zero. 7b IV. The Models

Models I and 2 are enclosed in rectangles with inltial length dimensions of $Y=10$ units and $X=15$ units. Within each rectangle a rigid body is located with its central point superimposed upon the centre of the rectangular frame (Figures 31 and 35 ).

The matrix in each model is divided into a number of trlangular elements. Precision of results is improved by the use of three techniques. Firstly, for each model there is an optimum number of elements. This number can be arrived at by elther calculation or by trial and error graphics. Secondly, each element should be as equilateral as possible. Results for each Individual element are arrived at by an averaging equation based on an equilateral element 
shape. Finally, where there is a need for a concentration of results and a relatively greater degree of precision the areal extent of the element is important. The smaller the element the greater the degree of precision. However this latter technique is 1 imited by the capabilities of the computer programme. Within each model the critical area is the zone bordering each rigld body, a concentration of small elements is located therein (Figures $3 i$ and 35 ).

The rigid body in each model is a straight edged approximation of the outline of the Adamant pluton, modelied at a scale of $0.46 \mathrm{~cm}=i \mathrm{~km}$.

In model 1 the long axis of the rigid body is aligned at 046-246 degrees and is defined by 20 nodes (Figure 28). In the second model the east-west aligned rigid body is defined by 21 nodes (Figure 35 ).

Nodes that are located around the rigld body, except for those on the perimeter of each model, are free to move an unlimited distance in either the $X$ or $Y$ directions.

7b v. Boundary Conditions

1. Those nodes that $11 \mathrm{e}^{\prime}$ on the rectangle "sides parallei to the $Y$ axis, excluding the nodes at each of the 4 corners, are free ta move an unlimited distance in the $Y$. direction but can only. move a pre-determined distance in the x direction.

23 Those nodes that lie on the sides of the rectangle parallel to the $x$ axis, excluding the nodes at each of, the 4 
corners, are free to move an unlimited distance in the $x$ direction but are fixed with respect to moverient in the $Y$ direction. 2

3i- Those nodes at each of the four corners canionly move a pre-determined, distance in the $x$ direction and are fixed with respect to movement in the y;airection.

4. Those nodes tbat lie on the outline of the Adamant pluton, centrally located within each model, are fixed and cannot move in elther the $X$ or $Y$ direction.

.7b VI. Assumptions made in the modeling

No major phase of deformation has been recognized in the study area, or elsewhere in the Northern selkirk Mountains, that postdates the third phase of deformation. It is assumed that the present day orlentation of the long axis of the Adamant piuton, with respect to the structural trends in the surrounding metasediments, was also the orientation prevaling in the final stages, if not earlier. of the third deformation phase.

The present day orientation of the long axis of the pluton is east-west. Planar fabrics that wereformed during the third phasé of deformation strike northwest-southeast. Assuming that there were no components, of rotation.or shearing such a fabric orientation implies that the principal". "compressive." stiess", was "aligned northeast-southwst.

Model 2 is based on the probable east-west orientation 


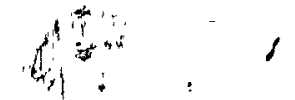

of the Adamant pluton during the thicd phase of deformation and the northeast - southwest trend of the principal compressive stress axis.

The planar fabrics produced in the Northern belkirk Mountains during the second and first phases of deformation also strike northwest-southeast where they are not.visibly reorientated by later phases of deformation. If it is again assumed that there were no components of rotation or shearing involved in either of these phases of deformation then the principal compressive stress axis, during each of them was orientated northeast-southwest.

Any rotation of the pluton in the horizontal plane during one or all of the three major phases of deformation will have occurred in either a clockwise or counter-clockwise direction. Speculation concerning possible rotation of the pluton is 1imited by the present day orientation of the body being known and the regional principal stress orientation for all three major deformation. phases being assumed.

With these two constraints it is very improbable that the pluton rotated in a counter-clockwise direction. It would have had to pass through, or away from, the plane of maximum elongation, aligned, northwest-southeast, in order tó arrive at its present day east, west orientation.

"The maximum amount of clockwise rotation that the pluton could have accomplished is restricted to an amount 
that can be calculated. The direction of maximum shortening, parallel to the princlpal stress direction, is àligned northeast-southwest. If the pluton were inltially aligned in this orientation compression of the body, as opposed to rotation, would have occurred.

The direction of maximum shortening is northeastsouthwest, the direction of maximum elongation is northwestsoutheast, the two lines being mutually perpendicular to one another (Fiqure 39). An, initial long axis orientatión that lies within the northern and southern quadrant formed by the two lines would rotate in a counter-clockwise difiction durirg compression. Such a rotation direction has already been discounted. An initial orientation within the eastern and the western quadrants would place the body in the field of clockwise rotation and enable it to achieve the present day east-west orlentation

Model one is based. on the latter orientation and a principal stress direction of northeast-southwest. The long axis of the body is aligned within the eastern and western quadrants and has the coordinates 046 - 226 degrees, this allows the maximum possible rotation of 44 degrees in order for the body to be aligned in its present day east-west trend.

7p VII. Approximations used in the Modelliag.

In order to model the stress environment of the Adamant pluton the following approximations were necessary. It is 


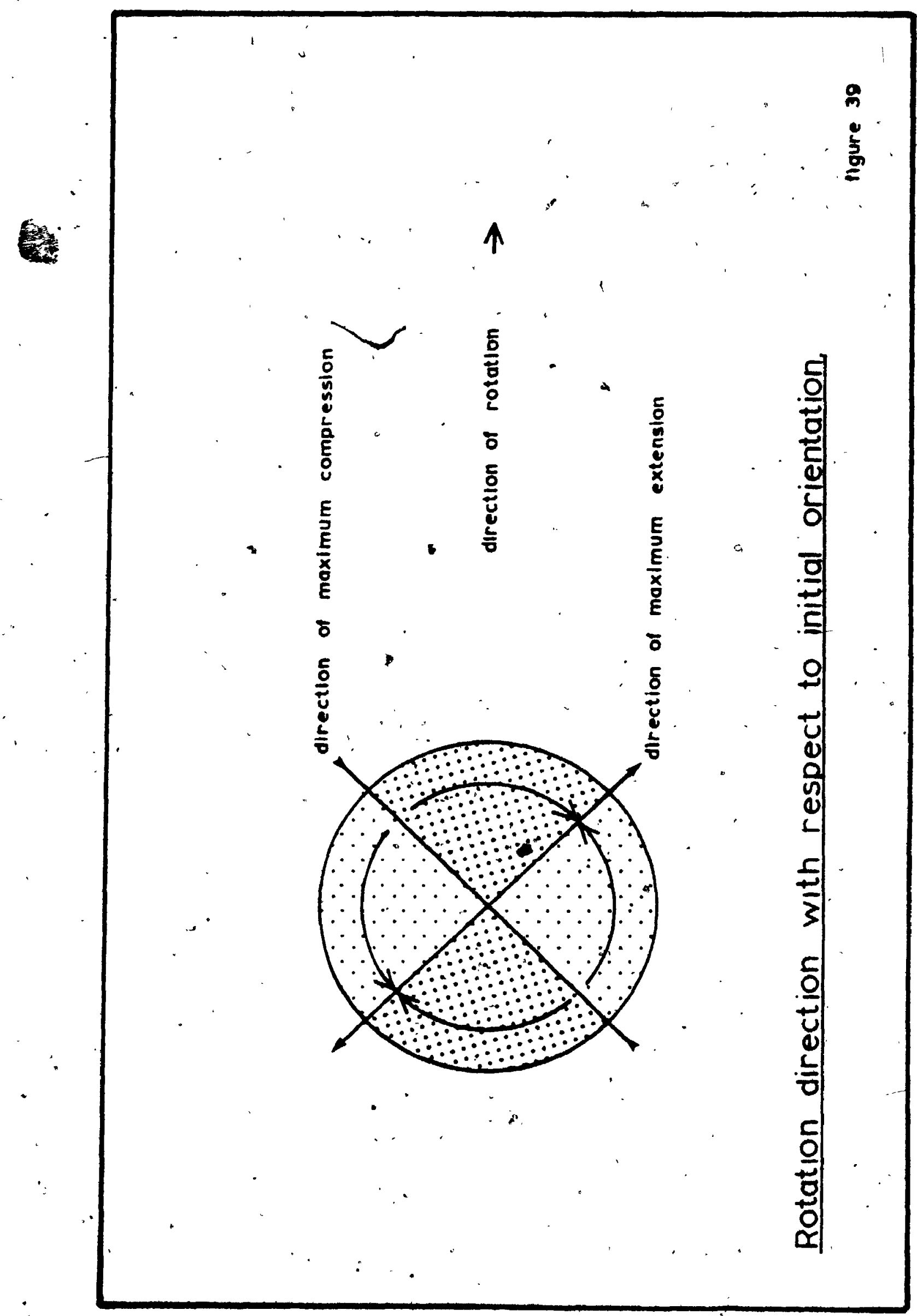


realized that therse approximations over-simplify the real case and the results derlved can only have a qualitative significance.

1. The physical character of the Adamant pluton is approximated to be that of a rigld body; it can neither be deformed nor rotated, any strain applied to it being abruptly terminated at its perimeter.

This approxlmation contrasts with the field evidence of both" folds and a tectonlcally induced, axial planar, mineral fabric in the outer zones of the body. The presence of such features imply that when the pluton was subjected to the high temperatures and pressures associated with midale amphibolite grade metamorphism, it behaved as a ductile rather than rigid medium in the perimeter zones. Whilst the folds and planar fabric are recognized in the outer zones they are absent from the inner zones. This change from ductile to apparently rigld behaviour is transitiohal.. However the areal extent of the region where folding is recognized is, small in comparison to the total area of tite pluton.

Both the ductile and rigid zones were presumabily affected by the same temperature and pressure conditions during regional metamorphism. Whilst the rocks in the outer zone are hydrous, those in the inner zone are anhydrous. This difference in water content probably influenced the rheological behaviour of the rocks during regional 
deformation.

2. The rheological contrast between the Adamant pluton' and the surrounding metasediments is simplified in the modelling. The matrix of the rigid body is assigned a uniform rheological character, that of a linear elastic medium. A wide range of rheologies is present in the various rock types that constitute the cpuntry rock of the Adamant pluton. Rheologically the country rocks are inhomogenous and anisotropic.' Such a complex geometry cannot be accurately detailed, therefore, assigning the mass a uniform rheological property is no more, or less, inaccurate than attempting to represent only a portion of the inhomogeneities.

It is realized however that the country rocks adjacent to the Adamant pluton will not behave in a linear elastic manner during deformation, a non-linear plastic rheology is more probable.

3. Nodal displacements that are applied to each model produce a total shortening of 108 , this is approximately one fifth of the regional shortening estimated In the Northern Selkirk Mountains as a result of successive phases of deformation.

strain patterns generated by a shortening of 108 will obviously differ from those generated by a shortening of 508. However, the general trends will be qrossly similar. Even a percentage shortening as small as 10 generates 
very large stresses within the matrix of each model. This is because imposed boundary conditions constrain the matrix within the rectangular frame and prevent it merely bulging around the rigid body during compression. The stresses are large' also because the body is considered purely elastic i.e. there is no stress relaxation.

Stresses in the actual deformation were probably low, in the order of hundreds of bars.

7bvIII, Results.

When the nodes are displaced and internal deformation ensues the presence of a rigid body modifies the internal stress components. This modification is manifested as a zone of influence or structural aureole (Figures 34 and 38 ). The amount of influence excerted by the rigid body decreases as the distance from it increases.

A structural aureole is generated in each model, within both aureoles there are two zones at which the trend of PS2 diverges to go around opposite ends of the rigid body (Figures 34 and 38): These areas are referred to as zones of divergence.

In both models the mode of deformation and percentage shortening are the same, as are the rheologies of the respective components. Consequently, the trend of PS2 outside of the structural aureoles is similar.

In Model 1 the structural aureole is grossly elliptical in outline with its long axis parallel to that of the rigid 
body. The areal ratio between the structural aureole and riqid body is approximately $15.5: 1$ (Figure 34).

In model 2 the bulge at the northeastern corner of the rigid body is apparent in the outline of the structural. aureole. The long axis of the aureole is sub-parallel to that of the rigid body, the "former being orientated approximately 15 degrees counter-clockwise of the latter (Figure 39). The areal ratio between the structural aureole and rigid body is approximately $13: 1$.

In model 1 the zones of divergence are located at approximately equidistant positions from the perimeter of the rigld body, on elther side of $i t$, one to the north and one to the south (Figure 34 ).

In model 2 the zones of divergence are located adjacent to the porthwest and southeast corners of the rigid body (Figure 38)

As the pliton is rotated in a clockwise direction from its northeast - southwest prientation in model 1 to an east-west. alignment in model 2 the zones of divergence - migrate from their central location to a position adjacent to the ends of the body. Thus a 44 degree rotation of the rigid body induces., the zones of divergence to migrate a distance equivalent to $12 \mathrm{kms}$ paralle? to the perimeter of the rigid body (Figure 40).

7bVIII. Discussion.

The trends of PS2 around the rigid body produced in 


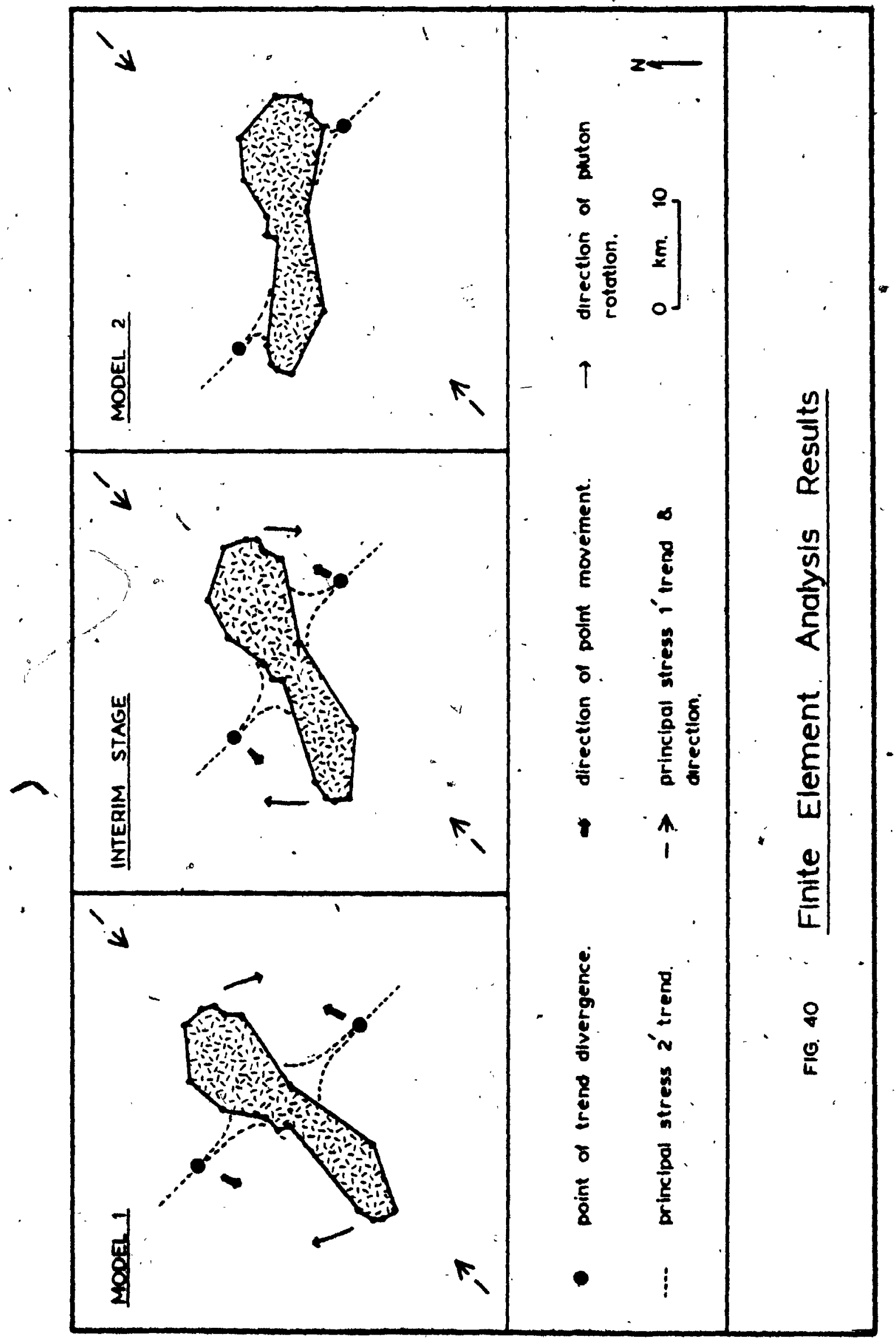


model 1 do not correspond to the pattern of any planar fabrics mapped in the field. There are two obvious explanations for this disparity. Firstly the Adamant pluton may never have had a northeast-southwest or lentation, hence a strain fabric relating to such an orlentation would never have been produced. Secondly if the pluton was previousily in such an orientation any fabric generated around it at that time may have been completely transposed by the action of later deformation(s).

In model 2 the rigid body has been rotated clockwise 44 . degrees, the major axis aligned east-west corresponding to the present day orientation of the Adamant pluton. The trend map of PS2 is very similar to the axial surface trace maps of zones $A$ and $B$ (Figures 13 and 17). Computer derived zones of divergence are located in the same general area as the zones of divergence recorded in the field, or inferred on the basis of fleld data (Figure 9). The major change in phe location of the zones of divergence, with respect to the perimeter of the rigid body, between models 1 and 2 is achieved by rotating the rigid body through an angle of 44 degrees. The zones of divergence recorded in the field, or Inferred, whllst having separate positions are in fact quite closely located, thus indicating that the amount of rotation involved is substantially less than 44 degrees.

Using the theoretical results as a control, the total amount of pluton rotation required to change a, divergence

$$
C^{-}
$$


zone position from that formed during the final part of the first phase of deformation to that 'formed during. the final part of the third phase is approximately 9 degrees. In order to produce such a change in positions, the pluton has to rotate 5.5 degrees during the second phase and 3.5 degrees during the third phase.

The areal ratio between structural aureole and rigid body in model 2 is 13.0: 1 , the areal ratio between the structural aureole as mapped in the fleld and the pluton is approximately $13.75: 1$. The areal ratio between aureole and rigild body in model 1 is higher than both of these, 15.5 : 1. This is to be expected as in model I the rigid body is aligned more discordantly than in model 2 and in the field situation. The smallest. ratio would be achieved when the rigid body, or pluton, was aligned parallel to elther pS 2 or to the reqional structural grain.

The areal ratios listed above are large when compared with deformation aureoles attributed to post tectonic emplacement of igneous bodles: Pltcher (1979) noted that such aureoles usually extend, almost as far as the thermal recrystallization aureoles associated with such bodies. The areal ratio between a thermal aurole and the igneous body is usually quite low when compared to the Adamant plutón structural aureole ratio. eq.

1. thermal aureole : Tono (Japan) granodiorite.

$$
0.15: 1
$$


2. thermal aureole : Santa Rosa (Nevada) granodiorite

$$
0.7: 1
$$

3. thermal aureole : Sulan (Korea) granodiorlte

$$
0.8: 1
$$

4.: thermal aureole : Granite Peak (Montana) granite

$$
0.5: 1
$$

(The above ratios are approximations, data derived from Turner, 19581:

The major disparity between the Adamant pluton ratio, both that derived from model 2 and the ratlo derived from field data.. With those derived from the post tectonic igneous bodies is a further indication of the pre-tectonic origin of the Adamant body.

7bx. Summary and Conclusions

The very strong similarities between the PS2. trend map of layout 2 . (Figure 38 ) and the axial surface trace map of zones $A$ and $B$ (Figures 1.3 and 17) indicate the presence of the Adamant pluton prior' to the third, second, and possibly the first, phases of deformation.

Comparison of calculations with fileld data suggests that during the second and third phases. of deformation the p'luton rotated approximately 9 degrees:

The areal extent of the structural aureole associated with the body is many times larger than deformation aureoles associated with post tectonic bodies. It is however comparable to experimentally. produced structural aureoles 
which are formed around pre-tectonic inclusions.

7c. Mathematical and Physical Models

7cI. Introduction"

The second approach that attempts to resolve the problem involving the discordant trend of the Alamant pluton is a literature review in which the results of published theoretical studies, oaling with the behaviour. of an elliptical inclusion in a. less viscous matrix, áre compared to field observational data. Any comparisons made are solely qualitative as the models assume that the groundmass has the properties of a linear, homogenous, isotropic medium. Such an assumption, discussed in the previous section, limits the extent to which comparisons may be drawn.

- The Eigures pertinent to this section are as follows:Figure 41 : Swerving of A-axes in the matrix around a rigid inclusion.

42 : Relationship between schistosity. and deformed pebbles.

43. Ranges of orientation for forward and backward rotation of inclusions.

44 : Pure shear deformation pathis.

45 Total strain in an elliptical cylinder v. applied total strain.

46 : Notation for definition of $\mathrm{drag}$. 47 : Types of drag patterns of passive 
markers around rigid, elongate incluslons.

7cII. Rigid inclusions in a viscous matrix

: The motion of a rigid ellipsold in a viscous matrix has been dẹtalled in various publications - Gay (1958a, 1973), Ghosh and Sengupta (1973). Ghosh and,Ramberg 71976 ).

Gay (1958a) takes a quantitativg approach and has developed two formulae which describe the motion of an elliptical particle in a viscous matrix deforming by pure shear. The motion of the particle in the matrix is of primary, importance here, the stresses in the matrix are onily considered indirectiy.

The long axis of the particle is projected onto a plane containing the axis of compression and the axis of maximum. extension. The amourit of rotation of the long axis is qiven by:-

In $\cot \phi_{f}=$ In $\cot \phi_{1}+\left(a^{2}-b^{2} / a^{2}+b^{2}\right)$ In $\sqrt{h / h_{k}}$. Eqn. I

where. $\phi_{i}$ - the Initial angle between the projection of the long yaxis onto the plane mentioned $\therefore$ above, and the axis of compression. $\phi_{f}$ - the finali angle analogous to $\phi_{1}$ $a, b-$ the long and short axes of the ellipsold of rotation.

$\lambda_{1}$, $\lambda_{2}$ - the quadratic elongation of the strain in the matrix,i.e. $\sqrt{\lambda_{1}}$, and $\sqrt{\lambda_{2}}$ are the major and 
minor semi-axes of the strain ellipse in the matrix. where there is no perturbation from the inclusion.

To apply this equation to the Adamant pluton two basic assumptions are required.

1. The apparent long axis of the pluton is parallel to the maximum dimension of the outline of the pluton and is therefore aligned at 90-270 degrees.

2. The regional compressive stress trends at 45-225 degrees. 1.e. at ninety degrees to the plane of maximum shortening associated with the youngest phase of deformation which strikes at $135-315$ degrees, this- is similar to that * inferred for the first and second phases of deformation.

\& is 90 minus, 45 degrees, ot 270 minus -825 degrees

$$
\phi_{f}=45 \text { degrees }
$$$$
=
$$$$
a=4
$$$$
\therefore b=1
$$

$$
\begin{aligned}
& \sqrt{\lambda_{2} / \lambda_{1}}=.48 \text { (508 shortening assumed) } \\
& \text { substituting these values into equation } 1
\end{aligned}
$$$$
\check{\phi_{1}}=28 \text { degrees }
$$$$
\phi_{\mathrm{f}}^{-} \phi_{\mathrm{q}}=17 \text { degrees }
$$

Consequently. the formula derived by Gay (1968) - predicts that the Adamant pluton would experience a rotation $\because$. of 17 degrees in a clockwise direction, in the horizontal plane, if the matrix has been shortened by 50 .

Gosh and Sengupta (1973) constructed laboratory. models. 
to investigate the motion of a riqid ellipsold in a viscous matrix. "The models involved a rigid body composed of modeling cluy embedded in a viscous matrix of painters putty. Compression of the model was achieved by moving two plates towards each other.

It was found that away from the inclusion the major axes of strain ellipses were essentlally perpendicular to the direction of compression. Close to the inclusion the swerving of the major axes is apparent, this is accentuated with increased deformation and with closer proximity to the - inclusion (Fiqure 41 ).

The major axis of the inclusion rotates in a direction away from the direction. of compresion. The closer the alignment of the major axis of the inclusion with the direction of compressian then the larger the angle is between the major axes of the strain ellipses and the major axis of the inclusion. With further deformation this latter. angle decreases whilst the former increases. "

The larger the axial ratio of the inclusion: the greater ". the degree of rotation for the same amount of total compression.<smiles>[C]1=[C]C=C1</smiles>

A naturally.occurring counterpart to the experiments of . , Ghosh and Sengupta is the occurrence of pebbles in'a schistose matł1x. Gay (1973) studied pebble deformation based on the work of varlous authors (Strand, 1945: oftedahl, 1948, Braçe, 1955; Flinn, 1956; Hossack, 1958; 

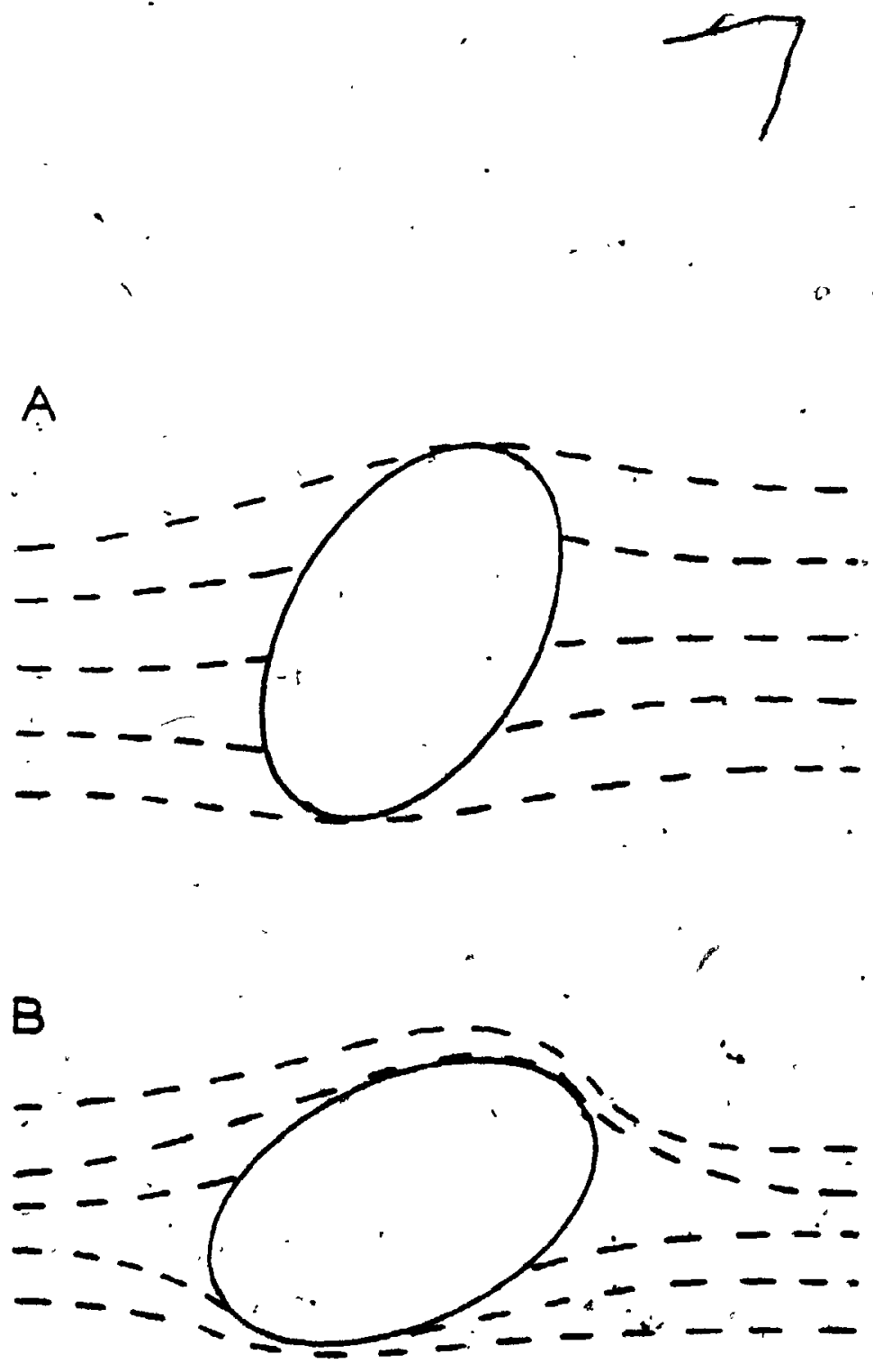

Figure 41 Swaving of A-acos in the matrix aroind a rigid inclusion.

A Partial owrving around a rigid elliption inclunion ubun deformation is mall.

B. Sveriving when dafómation is moderately large.

Eran Gosh, and Sexgreta, 1973. 
Gay, 1969) and concluded that the plane containing the major and mean axes of pebbles is roughly parallel to the schistosity in the matrix. However Gay's use of "roughiy parallel" covers a range from strictly parallel to concordant with respect to schistosity and pebble axis (Eigure 42).

With a smal1 amount of deformation A-axes in matrix strain ellipses will not in general be parallel to the $x$-axes of elliptical inclusions. This contrasts with the common observation referced to above of rough parallelism between schistosity and pebble elongation. This discrepancy is explained by Gay as being related to the amount of deformation that the matrix has experienced. Where deformed conglomerates within a schistose matrix have been described in the field they have commonly undergone moderately strong to extreme deformation. Progressive deformation diminishes the angle between the A-axe's of inclusions and the $x$-axes of matrix strain ellipses (Ghosh and Sengupta, 1973).

A further aid to reducing the angular discrepancy is the viscosity contrast, the greater, it is the larger the angle for the same amount of deformation. Any bowing out of schistosity around pebbles has been shown by experimental and theoretical work to be related to a difference in competency between inclusion and matrix.

Gay cites a number of factors that control the final. orlentation of the deformed pebbles. 
$128^{\circ}$

Figure 42 Relationship between schistocity and and deformed pebbles.

A. strict parallelism between $x$-axis and schistocity.

B Bowing out of schistocity s" concordant relation") around a pebble.

C Partial swerving of schistocity around

$\therefore$ a pebble. 

1. Degree of deformation..

2. Viscosity contrast between pebble and matrix.

3. Initial orientation of pebble with respect to deforming forces.

4. Axial ratio of pebble.

5. Closeness of spacing of pebbles.

Ghosh and Ramberg (1975) combine a mathematical approach with physical modeling in their comprehensive study of the reorientation of inclusions by a combination of pure shear and simple shear.

Their study. highlights the importance off the relationship between the axial ratio of the inclusion and the ratio of the rates of pure shear to simple shear. Also an important factor is the initial oglentation of the inclusion.

According to Ghosh and Ramberg (1975) unlimited rotation of an inclusion will occur during progressive deformation if:-

$$
\begin{aligned}
& R<1+\sqrt{1+4 S_{r}^{2}} / 2 S_{r} \\
& R-a x i a l \text { ratio Eqn.2 }
\end{aligned}
$$

$S_{r}$ - ratio of the rates of pure shear to simple' shear

: The sense of rotation of thimple shear component of the bulk deformation controls the sense of rotation of the inclusion.

When $R>1+\sqrt{1+4 S_{r}^{2}} / 2 S_{r}$ (Eqn.3) there is an orientation at which the inclusion will be stable, this will not change is 
with further deformation. In Figure 43 this orientation is labelled $\phi_{1}$.

An inclusion with an initial orientation $\left(\phi_{0}\right)$ between $\phi_{0}=0$ and $\phi_{1}$ will rotate in a positive sense until it reaches $\phi_{1}$ (Figure 43).

Inclusions initially orientated between $\phi_{0}={ }_{1}$ and $\phi_{0}={ }_{2}$ will rotate backwards (Eigure 43), until stabilized at $\phi_{1}$. Inclusions initlally orientated parallel to $\phi_{2}$ will be stabilized in that orlentation, the rate of rotation at $\Phi_{2}$ being zero. However. $\phi_{1}$ is the only orientation at which rotating inclusions artive at a stable position.

When $\phi_{0}$ is slightiy more than $\phi_{2}$ the inclusion will undergo forward rotation until stabilized at $\phi_{1}$.

If $\phi_{0}$ is less than, $\phi_{2}$ backward rotation occurs until a position at " $\phi_{1}$ is achieved. Consequently $\phi_{2}$ is considered to. be a metastable position.

Ghosh and Ramberg (1967) performed a series of experiments in which rigid blocks of differing axial ratios were placed in a viscous matrix, composed of silicone putty $l_{\mu}=10^{\circ}$ polse), which was then deformed by simple shear. Some of their results are summarized below

1. When the long axis of the inclusion is at a,high angle to the direction of simple shear, inclusions with 'higher axial ratios rotate faster.

2. When the long axis of the inclusion lis at a low angle to. thé direction of simple shear, inclusions with 
132
.$- \quad$

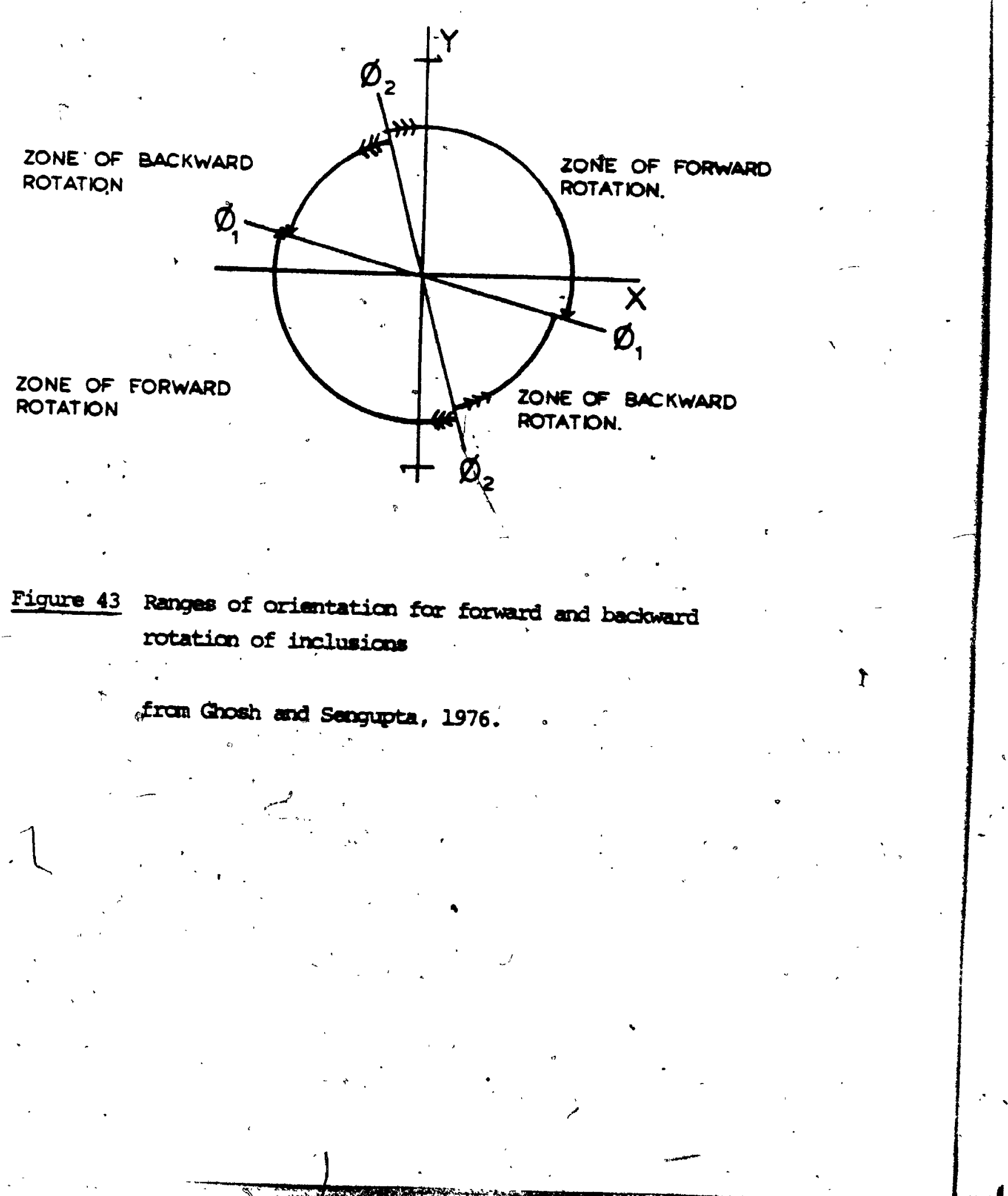


lower axial ratios rotate faster.

3. An elongate inclusion has a maximum rate of rotation when it is aligned at right angles to the direction of. simple shear and a minimum rate when parallel: Ar equant inclusion has a constant rate.

7CIII $\lambda$ viscous ellipsold, rigid core, th a viscous medium Initially the presence of a rigid pucleus, fithin a viscous body, will affect the finite strainelipses in. adjacent, less viscous material. An analysis based on the premise was developed by Tan (1974) to examine-strain in. oolites and other similar objects that have nucleated on a rigid core.

As the outer part of the Adamant pluton has been . deformed, whilst the inner part appears not to have experienced any deformation, such an analysis may be applicable. However the technique developed by Tan' is still in a formative stage and cannot be applied to initialiy elliptical bodies that are not parallel to stress axes. 7cIV. Viscous ellipsoid in a viscous medium Theoretical analyses were developed by Gay (1968b) for two specific occurrences of a viscous ellipsoid in. a viscous med I um.

1. Pure shear deformation of a single, elliptical particle with its axes parallel to the strain axes:

Pure shear is the mode of deformation, consequently the shape of the final ellipse indicates the strain in the 
particle, if the initial shape is known.

Gay arrives at the following equation to determine the change in particle axial ratio during deformation. .

$$
\begin{aligned}
\ln (a / b) & =\ln \left(a_{i} / b_{1}\right)+(5 / 2 R+3) \ln \sqrt{\lambda_{1} / \lambda_{2}} \text { Eqn. } 4 \\
a, b & - \text { long and short axes after deformation } \\
a_{1}, b_{1} & - \text { long and short axes before deformation } \\
R & -(\text { viscosity of ellipsoid)/(viscosity of matrix) } \\
& \text { ratio. }
\end{aligned}
$$

$\lambda \cdot \lambda_{2}$ - quadratic elongation of strain in matrix

The term $5 / 2 R+3$ is the viscosity factor controling the change in particle shape during the deformation. For $R$ values greater than 10 the particle-matrix system has to experience very large strains to achieve a significant increase. in particle axial ratio.

2. Pure shear deformation of an elliptical particle with its axes not parailel to the strain axes.

Deformation in this case results in both a change of particle shape and a rotation of the particle itself.

Where $R=1,1 . e$ no difference in competerice bétween the particle and matrix, the change in orientation is purely geometrical, one ellipse being superimposed upon another.

- Where $R$ is greater than 1, 1.e. the particle has a greater competency, than the matrix; a component of rigid body rotation is introduced when the matrix is deformed. Gay solves this a more complex numerical problem by summing infinitesimal strains to obtain a finite pure shear. 
Equation 4 is rewritten in an exponential form and solved by use of à computer.

There are a few problems with the mathematical procedure used by GaY, consequently the results are in error (Bilby et al., 1975). Gay combines a method of spherical harmontc analysis, developed by Lamb (1932), with a mathematical procedure developed .by Taylor (1932) which determines the deformation of small. drops. of one ilquid in another. Both of these procedures are 3-dimensional. To find the corresponding 2-dimensional solution Gay puts $z=0$. in the formulae developed by Lamb. To obtain the harmonic functions to insert in the formulae Gay again gives $z$ a zero value. Bllby et al.. (1975) re-calculated certain sections of Gay's analyses and noted that by making $z=0$ incorrect numerical coefficlents are generated. Furthermore, merely by making $z=0$ a 3-dimensional harmonic function does not become a 2-dimensional one.

However the qualitative conclusions arrived at by Bilby et al. (1975) regarding the deformation of an elliptical body by pure strain concur with those of Gay. Results from both researches outine. the controliling influence of the $v i s c o s i t y$ contrast when considering deformation (Figures 44 and 45 ):

7cV. Viscous inclusions in a less viscous matrix

Ghosh and Ramberg (1976) experimented with some scale models involving elongate, deformable inclusions in a 
136

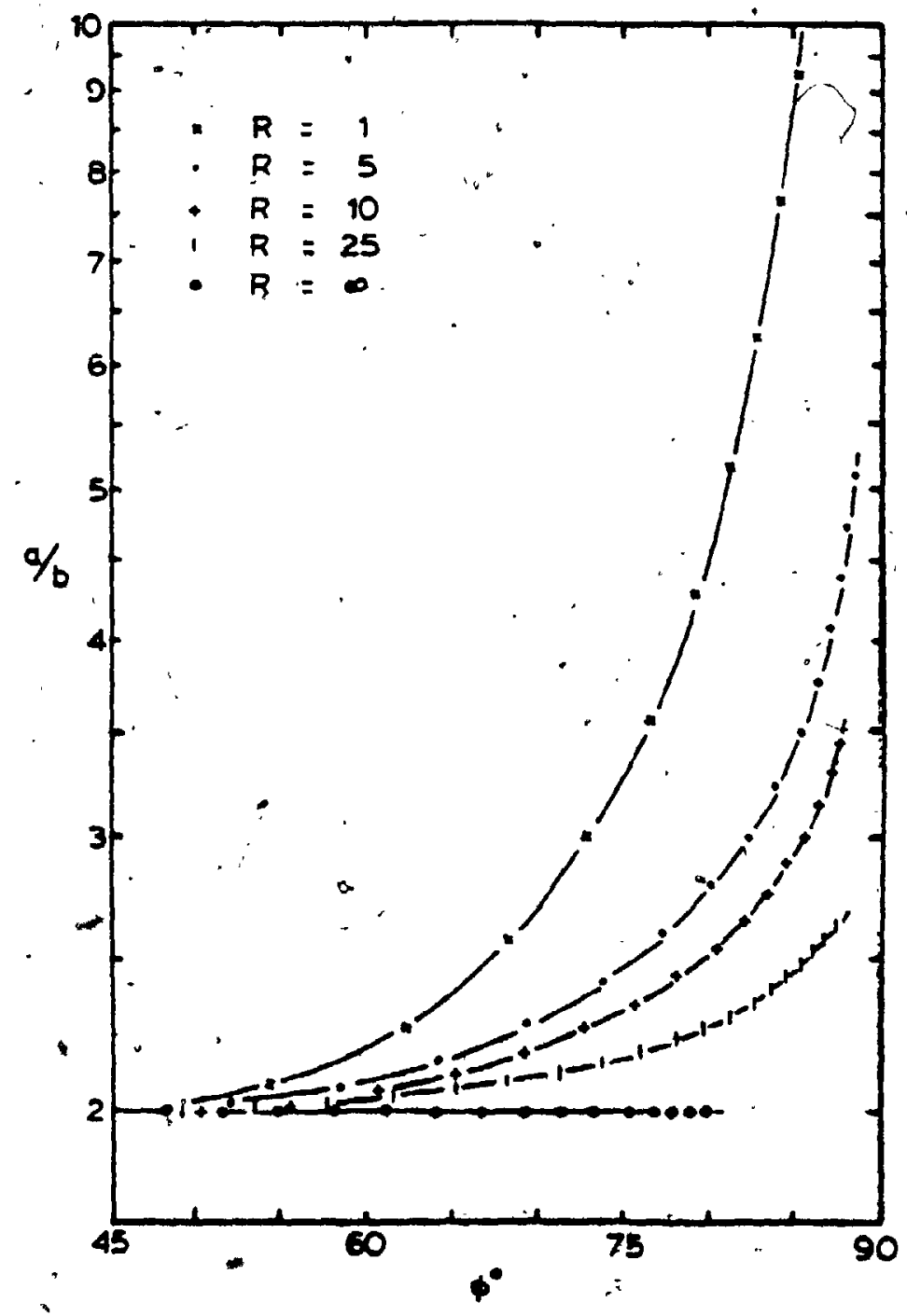

Figure 44 Pure share deformation paths for initially $2: 2$ ellipses alighted at $0=45$ to the $Y^{\prime}$ strain axis. Each point of the carves represents on interval of 0.1 in the pure shear natural strain.

from Gary, 1968. 


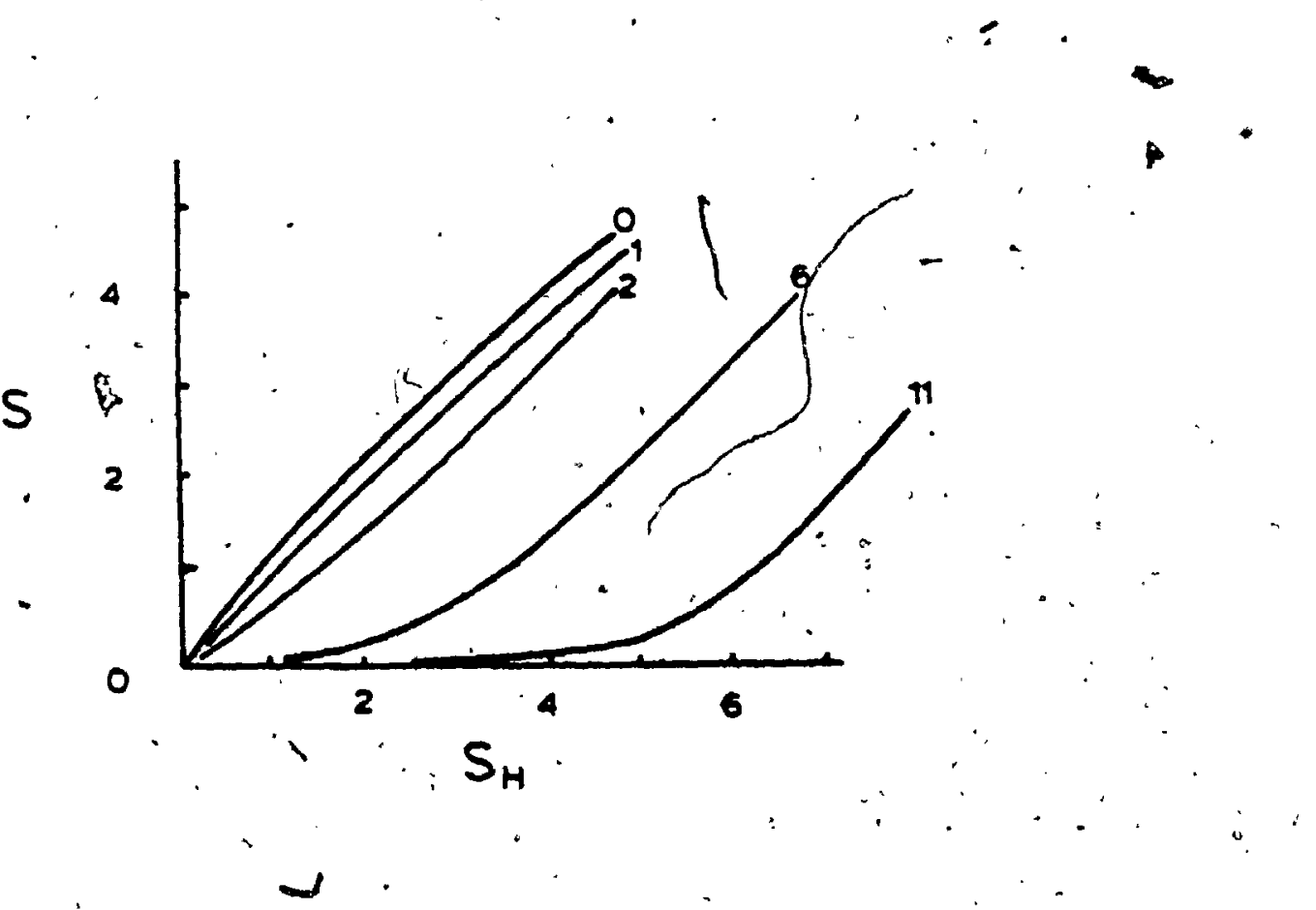

Fiquie 45 Total stiain, S, in an elliptic cylinder versus applied total strain;" s.'

arves labelled with viscosity ratio

from Bilby, Eabelby and Kunct, 197.5.
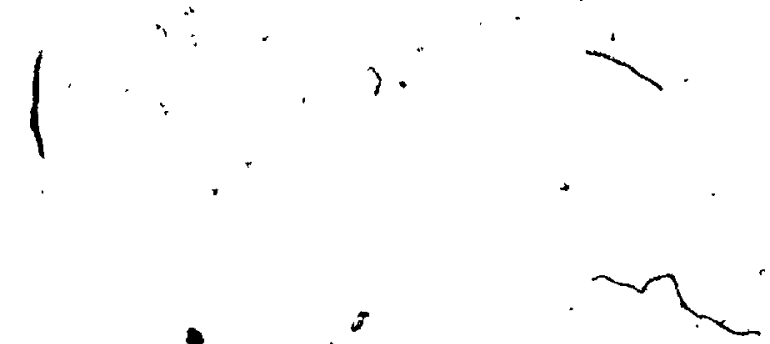
138

viscous matrix deformed by combination of pure shear and simple shear.

The rate of rotation of the inclusions wasofound to vary with:-

1. the axial ratio of the inclusion

2. the orientation of the inclusion,

3., viscosity contrast.

At $\phi<45$ degrees, long. inclusions rotated faster than short inclusions" and soft inclusions rotated faster than. hard ones.

$1 \cdot$ At $\phi>45$ degrees, the reverse of the above occurred.

$\phi$ - angle between $Y$ coordinate axis and artois.

$y$ - parallel to direction of compression of pure $\therefore$ shear and normal to planes of simple shear.

a - major axis of elongate inclusion.

-7cvi. Drag patterns around rigid, elongate inclusions

"During rotation of an inclusion with" a matrix containing a planar fabric t there occurs at the surface of the." Inclusion an apparent dragging of the matrix fabric along the interface of the inclusion:

The following definitions of normal and reverse drag are amended versions of those presented by tosh (1975) and refer to. Figure 45 .

- The point A is located at the edge of a circular body, $\therefore$ centred at point $n$, the 1 line $A E$ is an marker imIne in the groundmass. Without the presence of a rigid, circular 
$\therefore 139$ 
inclusion the, line $A E$, or its extension FE, would change its orientation to. FD by simple shear along the $x$ axis. The presence of the inclusion means that the deformed ine is in fact, only essentially, parallel to, FD at a sufficient distance from. the inclusion. Point $A$ moves to point $B$ assuming rigid body rotation. The angle $A O B$ is the angle of igid body rotation $(\omega)$.

- When $B$ coincides with.c there has been no drag effect on the marker line, $c$ being the point of intersection of the circle arid the line $\mathrm{FB}$.

To define drag the angular distance between points $B$ and $C$ is measured.

The drag of the marker line is defined as:-

$$
\begin{aligned}
& D=\omega-\left(\phi_{0}-\phi\right), \quad=\text { angle BOC in Figure } 46 \\
& \phi_{0}-\text { angle } x O A \\
& \phi-\text { angle xOC } .
\end{aligned}
$$

Nórmal drag occurs when the marker line is,dragged in the same direction as the sense of rotation of the rigid inclusion 1.0. when wis greater than $\left(\phi_{0}-\phi\right)$.

In reverse drag the point $B$ lags behind point. $C$, the markerfline having been aragged in a reverse direction to the sense of rigid body rotation of the rigid inclusion 1.e. $\omega$ is smaller than $\left(\phi_{0}^{\circ}-\phi\right)$.

Ghosh (1975) and Ghosh and Ramberg (1976), examine a variety of experimental cases in which drag effectsare 
produced at the perimeter of elliptical inclusions. They categorize the patterns produced into four main groups (Figure 47), these patterns being generated if the deformation is small and if the bulk deformation is in the Eorm of simple shear.

In type. A (Figure 47) the direction of shear is parallel to the initial marker line. The amount of drag in the periphery varies in all types, except for the first.

The pattern of drag gives an approximate idea of the nature of the bulk deformation, if that deformation is known t.o be rotational or irrotational.

The patterns produced vary, with the initial orientation of the inclusion; the axial ratio of the inclusion; the ratio of the rate of natural strain in the $x$ direction to the strain rate of simple shear; and the amount of simple shear.

The direction of drag can be opposite to the sense of rigid rotation of the body. Also irrotational bulk deformation may produce an asymmetrical drag pattern whereas simple shear: may produce a symmetrical one. Consequently the rotational, or irrotational, character of the bulk deformation is not specified by the drag pattern produced. 7cvII. DIscussion

The results of Ghosh and Sengupta (1973) which show the swerving of strain ellipse A-axes around tho rigid body (figure 41) are. similar to those produced by the finite 
142

Figure 47 Types of drag patterns of passive markers , around rigid, elongate inclusions.

A symmetrical bowing out of market lines

$B$ asymmetrical bowing in of marker lines

C asymmetrical pattern with same amount of normal drag everywhere.

D asymmetrical pattern with both normal and reverse drag patterns.

from Gosh and-Ramberg, 1976. 
A.

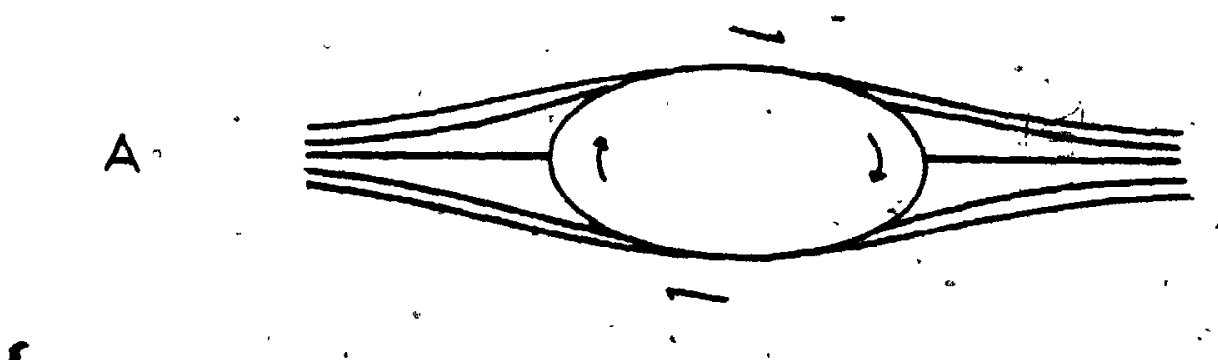

B

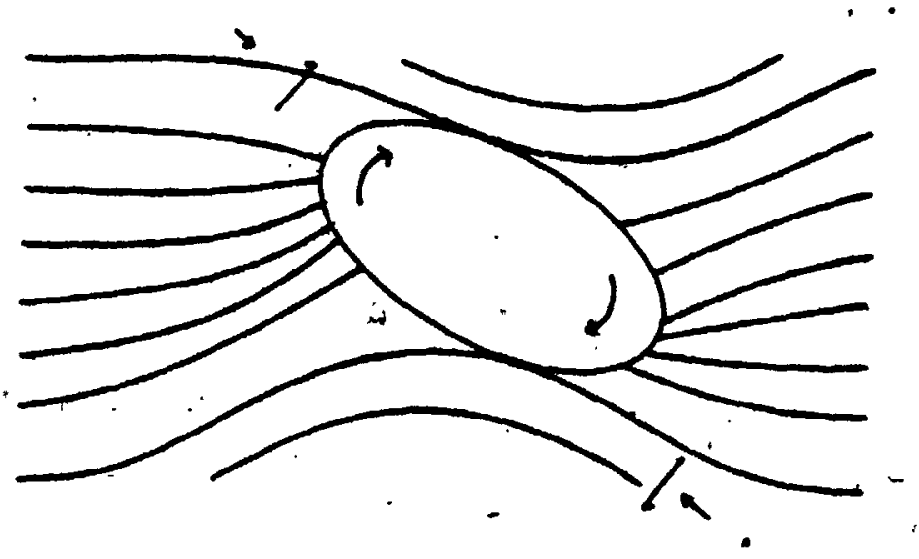

C
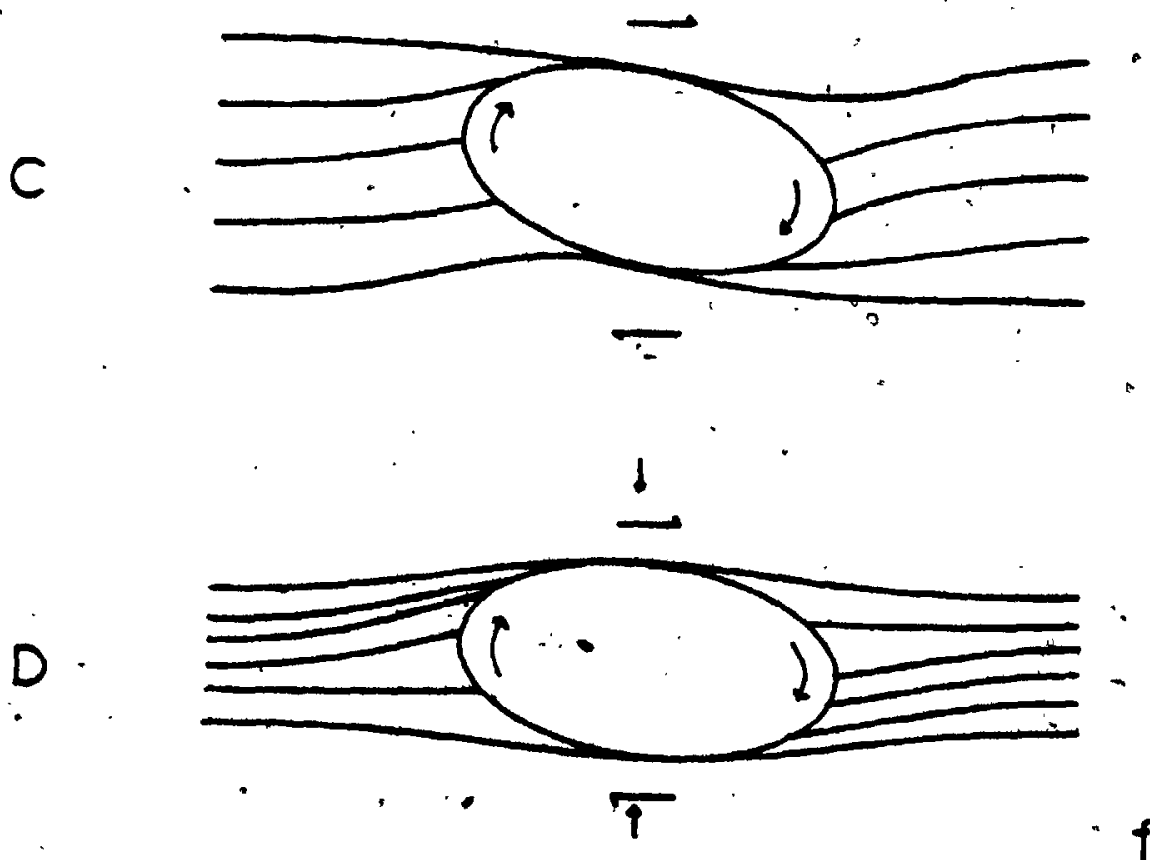

fig. 47

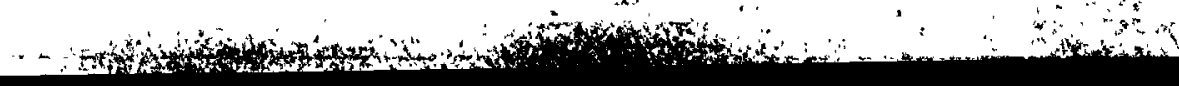


element analysis which in turn are similar to data gathered in the field." In the models of Ghosh and sengupta the rheoloqically rigid body is free to rótate, each set of A-axis orientations will correspond to a particular orientation of the body. As the body rotates so do the A-axes immediately adjacent to it, trying to accommodate to the constantly changing orientations of the rotating body. Both the finite element analysis and the models of Ghosh and Sengupta, in imitating the strain data gathered from the field, assume a pre-tectonic presence of a rigid body. As the orientation of the A-axes are constantly changing, an "old" orlentation being replaced with a "new" one as it were, the patterns produced around the body give no indication of the rotational or irrotational nature of the deformation, unless the "old" patterns are preserved in the matrix with the "new" ones superimposed.

In the field the "new" patterns correspond to the phase three fabric whilst the "old" patterns are those related to the flrst and second phases of deformation. Adjacent to the northwestern margin of the pluton strain fabric associated. with all. three phases is préserved. The difference in orlentation between the Individual fabric patterns is small. indicating that only a minor change in the orientation of the pluton ocurred. between each deformation event (Figure 9).

The pattern produced during each individual phase of 
deformation is presumably related to the findl position of the pluton during that particular phase. Thus the amount of rotation that occurred during the second and third phases of deformation can be calculated; using the results from the finite element analysis as a control an amount of 9 degrees is arrived at. However the amount of rotation that occurred during the first phase of deformation is unknown, only the position of the body at the end of that phase is known. The 9 degrees of rotation is therefore animum estimation with respect to the total amount of rotation that the body may have experienced.

Whether the deformation mode is simple and/or pure shear or 'compressive, 'rotation' of a body within a less viscous matrix that hosts a planar fabric would be expected to produce drag effects, at the surface of the body as outlined by Ghosh (1975) and Ghosh and Ramberg (1976) (Figure 47 ).

No such patterns were. recognized in the fleld adjacent to the pluton or anywhere else. The planar fabric in the matrlx 1.e. the 'sutrounding 'metasediments', is generally concordant with the outline of the pluton, except in the area of the divergence zones, the geometry of which are outlined.in chapter 3 , parts $c$ and $d$.

The absence of any recognizable, form of a drag pattern(s) at the margin of the body may be due to the relatively, minor amount of rotation that the pluton appears 
to have experienced. The cumulative amount of rotation recognized is only 9 degrees whereas the maximum amount. achieved during an individual phase is 5.5 degrees, this having occurred during the second phase of deformation.

An unknown quantity is the amount of rotation that occurred during the first phase of deformation, however, as presumably there were no planar fabrics existing in the country rock prior to the first phase, a drag pattern would not have been produced.

It would appear from the results of the various mathematical and physical models presented that the main controls concerning the behaviour of an ellipsoidal body embedded in a less viscous matrix are the following:-

1. The "viscosity' contrast.

2. The axial ratio of the ellipsoid.

3. The deqree of deformation.

a

4. The inftial orientation of the elipsold.

However, before proceeding to compare experimental results with field data it should be pointed out that the mode of deformation in the models is different to that visualized in the fleld situation. Although the Northern Selkirk. Mountains are bounded by fault zones on all sides there is, no evidence of any simple shearing motion along the discontinuities. Instead regional compression appears to have been the controlling mode of deformation. " The only experimental work to rely solely on compression as its 
deformation mechanism is that of Ghosh and Sengupta (1973).

Despite this difference in deformation mode it is the opinion of the author that the only controlling factor affected in a comparison between experimental and field data would be number 3 , the degree of deformation. The extent to which it is affected is not apparent. The other three controlling factors will remain as important paraméters whatever the deformation mode.

1. The viscosity contrast of the Adamant pluton with its matrix during deformation cannot be accuratley determined. However, it is quite probable that the temperature and pressure conditions prevalent during regianal dynamothermal metamorphism served to reduce the contrast in, viscosities across the margin. Both the outer zones of the pluton and the adjacent metasediments were deformed in a similar manner during the second phase of. deformation. At this time the rheological character of the outer zones of the pluton must have approached that of the matrix. However with an increasing distance from the perimeter and, towards the core of the body fold and fabric evidence suggests that there was a gradual transition from a ductile character to a rigid one. It seems most likely that the greatest, viscosity contrast occurred not at the margin of the body but at some point within it. Berqer and pitcher (1970) noted that there is often as great, or greater, ductility contrast between limestone and adjacent quartzite 
than there is between intruding granite and its country rock.

The peak of regional thermal activity passed prior to the onset of the third phase of deformation, however the outer zone of the pluton was still sufficiently ductile during the third phase to be compressed with the adjacent metasediments. The third phase folds in the outer zone of the body are more open than those developed during the second phase of deformation and they do not penetrate as far into the body as the earlier structures. This suggests that either the body was less ductile during the later phase or that the applied'stress was lower.

The effect of the outer zone being auctile, along with, the surrounding metasediments, would be to reduce the viscosity contrast across the margin. This would reduce" the potential. of the body to rotate during the application of either compressive or shear stress. If the greatest viscosity contrast was located within the body itself then it is possibile that Internal rotation, rather than rotation of the entire body, would be more likely in the event of there being any rotation at ail: This prospect is somewhat unlikely though as the change in the viscosity within the body is one of gradual transition and is not seen as a distinct and rapid change across a. narrow zone:

2. The axial ratio of the pluton is $4: 1$, with respect to experimental modeling this is a relatively hiqh ratio and as such would be a positive contribution towards 
any potential rotation.

3. The percentage shortening in the Northern Selkikk Mountains is. in the region of 508, this degree of deformation would be expected to contribute in a positive way to any potential rotation.

4. The initial orientation of the pluton is constrained by field data, an aspect that is discussed in the finite element analysis section. To briefly refterate, the pluton can only pave rgtated in a clockwise direction if it has rotated at all. Furthermore, the amount of rotation that it may have experienced is approximately 44 degrees or less. If in fact it did rotate the full 44 degrees then it would have had an Initial orientation of 46 - 246 degress. If it is assumed that the principal axis of compression was aligned northeast southwest during the regional phases of deformation then both the preserit day orlentation of the body and the possible initial orientation arediscordant with respect to the direction of elongation. Such discordant trends would prake the body highly susceptible to rotation during regionaf, compressive deformation. 7cVIII. Summary and Conclusions

Experimental and theoretical results imply that preservation of major angular discordance such as that observed for the Adamant piuton would not be expected.

Fleld observations clearly. demonstrate that the pluton 
was emplaced at least prior to the second phase of deformation. Field observations coupled with the results from modeling indicate that the pluton, was emplaced prior to the first phase of deformation. A clockwise rotation of -9 deqrees during the second and third phases of deformation has been interpreted, this being a minimum value for the total amount of rotation experienced, the amount of rotation accomplished during the first phase being unknown:

A. cumulative rotation, of 9 degrees during two major, régional events of compressive stress does not initialiy: appear to be of much consequence. This somewhat-restricted movement may bé explained by the following factörs:-

1. It is quite probable that the Adamant pluton is a keeled body, such a structure will be inherently more stable than a body with a flat base, such as those, used in the experimental models. The presence of a keel will impart a stabilizing force. to the body that will opposer,-. any rotational couple acting upon 1 t.

2. The outline of the Adamant pluton is ellipsoidal only in an approximation. Unilike the experimegntal bodies it : does not possess a smooth outline, rather it has embayments along its perimeter.. This lack of a smooth profile may I increase the frictlonal resistance of the body to rotation. 
8. MODE OF EMPLACEMENT

8 8a. Introductión

According to pitcher (1979) the average areail gxtent of Intermediate, granitic bodies is $150 \mathrm{~km}$; the Adamant plutop is approximately $120 \mathrm{~km}$. The most common outiline of such bodies is, circular, there sometimes,being a certain degreef of elongation parallel to the structural grain of the country rock. The shape of the body is probably an expression of the contrast in ductility between the intrision and its envelope. As the viscosity of the body increases.so does the potential for it ta be discordant. 1.

There are two aspects: concerning the present-day orlentation of the Adamant pluton that constrain any Interpretation of the mode of emplacement. The flrst is the discordant alignment which probably indicates that the body was emplaced as a viscous mass. The relative lack of veining and reaction at the contactifurther suggest that the outer part of the body at least was a semi-solid crystal mush, skin of viscous monzonite beling visualized.

The second constraint is the orientation of the metasediments around the body: They dip towards and below the body and increase in age away from 1t.' To accommodate such an orlentation the form of the pluton has to be that of a body with some lateral extent, similar to that of a sill or laccolith. At a certain tectonic level further vertical movement of the magma, must have been-haited, to be replaced 
by extension of the body in a horlzontal/sub-horizontal direction.

Consequentiy during emplacement :the. imagina must have" been. sufficiently viscous to accout for lts discordant. trendfbut sufflolently moblle to be able to flow lateraliy. 8b. Discussion

It is guite probable that the majority of magmas asgend through the crust at sub-liquidus temperatures and are therefore 'likely to be crystal-bearing to some degreed This erystal proportion will iricrease by precipitation untll the magma evolves' to a crystal mush. As buch they may behave as Binghl bodies. (Shaw it al.; 1968; Shaw, 1965, 1959, 1972; Boţtinga and we111;1972; Mufase and McBleney, 1973.) having well defined yleld strengths and much higher 'apparent viscosities. This non-Newtonian character is in accord with the contlusions of Nickel et al. (1967) and others who found that flow liayers were not producedo in viscous media containing crystal-ike particles untll high rates of flow were achleved. Such high rates are not considered to be likely in grantelc plutons, and Indlcate that the pbserved fabrics in grothitic plutóns have been formed outside of the Newtonlan flow domain when crystillization was near completion.

A high degree of crystallization does not necessarliy mean that the granite is immoblilzed, various chemical and physical factors that are present may serve to induce and/or 
lengthen the period of mobility. Tectonic squeezing /cf. Rast, 1970), which commonly enhances buoyancy as the drifing, mechanism, is viewed by pitcher (1975) as the most effective of these factors. Where the intrusion of magina is via a pre-determined Iineament, heat will be conserved by successive intrusions, and the country rocks may also it as an insulating medium with the "magmas being fluxed by the water suçked back. into the pluton", (PItcher." 1975). However reaction with the country rocks can also increase the viscosity of the magma quite drasticaliy icf. Nelson and sylvester, 1971).

- In order to. spread laterally, once vertical agcent has ceased, the magma" has to exert a force upon the enclosing rocks. This force is a combination of doming the overlying strata upwards, shouldering aside the strata in front of the advancing magma and compressing, to a minor degree the materlal below.

In assolciation with the shouluring aside mechanism of: emplacement a deformation fabric is commonly superimposed upon the country rocks eg. the Ardara and Main Donegal granites "(Pitcher and Berger,' '1972)." 'the Rogart-Granite Complex (Soper, 1963), the Vradaligranlte (Sylvester, 1964). The strain impased on the country rocks during the expansion of these" bodies is recognized as a. set of folds and fabric that Increase in Intensity towards the body and are not recognized beyond a certain distance from:1.t. Pitcher (1979) 
noted thaf with respect to expanding diapirs in Donegal, "the superimposed deformation aureoles extend almost as'far as the thermal recrystallization aureoles indicating that plastic deformation/depended upon the pre-heating of the envelope".

Al1. of the above examples presumably occur where the magma, having ascended in a narrow pipe, is halted in the relatively ductile crust and thén expands outward by continuous, or a series of, injection(s), of magma into the hot core. The resulting pluton not only has a deformed periphery but also has a deformed envelope. Pitcher (1979) explains the lack of a deformed envelope around some plutonic bodies eg.: Ploumonac'h (northern France), as being due to the magma remaining sufficiently moblie to enter the brittle, upper crust where it possibly deforms its own periphery but not the rigid envelope.

8c. Inferred Emplacement Mechanisms

Añ obvious mechanism of emplacement to producé án east -west alignment of the Adinant pluton is to have a linear conduit aligned east-west ( due to the chemical homdgeneity and Inferred internal sitructure of the body it is assumed that there, is only one conduity.
Brown (1980b) shows that the columbla River fault zone dips to the east below the Northern Selkirk Mountains and he contends that easterly drected movement along it hâs emplaced strata of the area as an allochthon from an 
original location to the west. Consequently, it is to the west that one should look for pre-phase two, east-west trends. East-west trends characterize the shuswap teriain. these trends probably originated during or before the onset of regional metamorphsim. The relative timing of events in the Shuswaps and Selkirks is stili not clearly understood.

It is possible therefore that east-west trends were present in the source.terrain of the Adamant pluton and that these trends could have controlied, the orlentation of the pipe. However, the inferied elliptical outinge of the condift does not support this possibility.

The preceding hypothesis presupposes that the elongated outline and present day aliginment of the body are mimary features. They inay however be secondary, the original outline and alignment having been quite different. In order for the body to be elongated and aligned parallel to an east west trend a similariy orientated structural grain, that is presumably, related a north-south compressive stress direction,. must be invoked. Nowhere in the Northern selkirk Mountains has such a structural grain.. or evidence of such a stress direction, been recognized. LFurthermore whilst the outer zone of the pluton was ductile during at least the second and third phases of deformation, the actual area that appéars" to have been' sufficlently moblie to enable a distinct change. In shape to occur was somewhat restificted, and probably insufflcient to accommodate anything other than 
minor changes. In the outiline of the body.

The two" hypotheses outlined above both assume that the present day shape and position of the body were controlled by either pre- or post-emplacement kinematic stresses. In the following hypothesis a controling factor is the nature of the sediment's into which the body was emplaced. The paleo-slope during Hadrynian times was towards the west; it is assumed that the sediments dipped towards the west and had a strike direction that was closer to notth-south than east-west. Such an orientation of planar anisotropies would induce an easterly inclination of the condult, should it be inclined at all.

A distinctive feature of the outcrop pattern around the Adamant platon is the manner in which the Middie Marble member $1 s_{s}$ wrapped around th eastern end and along the northern margin of the body. Whilst the second, and third. phases of deformatión undoubtably have. exerted some influence upon this outcrop pattern it is possible that they have merely, amplified a feature that was formed during the emplacement of the body.

At certain localities within the outer zone of the body, in close proximity to the margin, inclusions of various shapes and sizes are present. These inclusions are invariably composed of marble and/or quartzlte. 'In the central ared of the body, $0.75 \mathrm{~km}$ to the west of the western edge of thie hypersthene-auglte monzonite core zone, Fox 
(1969) reported the presence of a large xenolith of marble with quartzite. This author interprets the xenolith to be a roof pendant assoclated with the emplacement of the body. Inclusions of marble within the outer zone, which only occur. where marble of the Middle Marble member is in close proximity, are also interpreted as being derived during the emplacement of the body.

The trace of the Middle Marble member around the eastern end and along the northern margin is not everywhere continuous, also there is a distinct variation in thickness along strike. At the southeastern corner of the pluton the summit areas of Guardsman Peak and Mount stockmer are underlain by carbonate of the Middle Marble member (Figures 5 and 8 ), the intervening valley of Palmer creek however is devold of carbonate. on both the northern and southern valley sides the competent carbonate can be seen to thin gradually until it has zero thickness in the lower part of the valley.

It is suggested that the Middle Marble member exerted a controlling influence upon the manner in which the Adamant platon was emplaced, 'In the form of the body, and in its resulting orientation. The tectonic level at which magmatic ascent ceased was, above the stratigraphic level of the Middle Marble member: Where, the: latter is in contact with the body, or adjacent to it, it can be seen to dip towards and bengath it. It is expected that in passing through the 
Middle Marble member the hot magma would have precipitated decarbonation of the carbonate rich strata (cf: Nelson ind Sylvester, 1971). Liberated $\mathrm{CO}_{2}$ would have been introduced into the magma causing isothermal crystallization, a viscous skin of magma being formed over and-around the body. The po'ssibility of magma ascending further would be greatly reduced; it would probably spread laterally. Overlying the Middle Marble member is a thick, interbedded succession of quartzite, grit and conglomerate. Th1s competent succession overlying. the crystallizing magma may have acted as a further obstacle with respect to vertical magmatic ascent. The position. of the conduit through which the magma was emplaced is inferred to be adjacent to the hypersthene-auglte monzonite core zone (Chapter 4 and Figure 25). As the magma spread laterally to the east from this aperture it would have been partialiy rimmed by the Middle Marble member. The spreading magmatic front would have exerted a tensional force upon the carbonate strata resulting in thinning ond then rupture of the layers, hence the discontinuous trace across the valley of palmer Creek.

Lateral spreading to the west and southwest does not appear to have been hindered by the presence of the Middle Marble member carbpnate strata, consequently there is a distinct bulge in the southwestern part of the body lFigure 8). Lateral spreading to the northwest was controlled by the carbonate strata, the northwestern margin of the body 
being defined by a linear contact adjacent to the trace of the Middle Marble member (Figure 8 ):

Whilst the perimeter of the plutogn has been folded and the alignment of the body has been altered'slightly, due to an element of rigid body rotation, it is envisioned that the present-day form and orientation of the body are grossly similar to those at the time of emplacement.

Neither Fox (1959) nor this author recognized any folds or fabric in the country rock adjacent to the 'Adamant plutor that may be primarily related to the emplacement of the body: Both the periphery and the envelope are deformed but only by the folds. that can be definitely related to regional kinematic events. Phase 'two folds' in the country rock beconie progressively tighter adjacent to the body; rather than this resulting foom, forceful action by the nagma during .. emplacement of the body it is interpreted to be an accommodation feature related. to the $\because$ presence of a pre-existing rigid body. This aspect is discussed more fully in Chapter. 3 , section $\mathrm{f}$.

As it is unlikely that, the pluton was' emplaced by a passive stoping action, the production of a structural aureole associated with the forceful emplacement of the body would be expected. The present, day absence of such an aureole may be explained invarious ways.

1. The tectonic level to which the pluton was emplaced was sufficiently high that the country rocks were britțle, 
as at Ploumonac!h-(Pitcher, 1979). Whilst the periphery of the body may, or may not, have been deformed during the emplacement, the country rocks were not'.

2. The lateral, extent of the spreading during the emplacement of the body may be much less than is envisioned, the condult having a larger cross-sectional area that has been inferred. Consequently doming of the overlying strata, since eroded, rather than the pushing aside of laterally adjacent strata, would have been the dominant deformation mechanism during emplacement.

3. A fabric associated with the emplacement. of the body was generated by a pushing aside action.' This fabric has since been transposed and/or recrystallized by later thermal and kinematic activity associated with regional events, in much the same manner that $S_{0}$ is interpreted to have been transposed by the action of the second and third phases of reglonal deformation.

The last explanation is the most appealing to this author. 


\section{COMPARISON WITH BELCHERTOWN PLUTON}

The composition and zoning of the pluton are quite unusual, similar bodies within the cordillera are rare.- The Belchertown plution in the Appalachians of Massachusetts however is strikingly, similar to the Adamant pluton in many respects, a fact flrst noted by Ashwal et al. (1979) in a comprehensive description of the syn-tectonic Acadian intrusion.

The comparable features between the two bodies include:-

1. Chemistry and mineralogy; with respect to the major elements' the body is essentially homogenous.

2. Zoning of the body; the core zone is composed of two pyroxene-monzodiölte, which grades outward into pyroxene-free, hornblende-biotite-epidote gneiss. Mineralogical changes were isochemical except for water, and reflect progressive hydration.

3. Interial structure; the core zone contains a foliation composed of plagioclase crystals, the outer zone contains a foliation composed of hydrous mineral phases that is orientated parallel to the contact and to a foliation in the country rock.

4. Ashwai et al. (1979), Interpret the pluton to have been emplaced with a brittle core zone, that did not undergo plastic deformation during regional metamorphism.

5. Inltial crystallization temperature of the magma 
was 950 to 900 deqrees $C$.

6. The interpreted (Ashwal et al.. 1979) form of the body is that of a semi-concordant sill with a pipe like feeder vent.

There are certain physical and interpreted features presented in the work of Ashwal et al. (1979) that differ from the corresponding aspects of the Adamant pluton and the interpretations of this author.

1. The oxidation ratios $\left(2 \mathrm{Fe}_{2} \mathrm{O}_{3} \times 100\right) /\left(2 \mathrm{Fe}_{2} \mathrm{O}_{3}+\mathrm{FeO}\right)$ decrease progressively outward in the Adamant pluton whereas In the Belchertown pluton no such regularity has been recognized.

2. In the outer zone of the Belchertown pluton the foliation strikes parallel to a foliation in the adjacent , bedded rocks; such a trend being generally parallel to the contact. This foliation is interpreted as a syntectonic fabric related to the late stage of the Acadian orogeny.. In the Adamant pluton the fabric: in the outer zone that is generally parallel to the contact is interpreted as being related to flow of the body during emplacement whereas the fabric 'that is parallel. to fabric in the adjacent metasediments is, interpreted. to be related to a post intrusive, reglonal deformation. event.

*. 3. In an earlier paper Ashwal and Hargraves (1977) postulate that the Belchertown pluton has oxperienced 30 to 60 degrees of rotation towards the northwest about a 



\section{SUMMARY AND CONCLUSIONS}

The Adamanit pluton is a club-shaped mass aliqned éast -west. The broader part of the body, at the eastern end, is composed off a series of concentric, petrological zones. Hypersthene-augite monzhnite forms:. the core and is successively enclosed by zones of monzonite with variable amounts of hypersthene, augite, biotite and hornblende; hornblende granodiorite.' and quartz monzonife; biotite-hornblende granodiorite and quartz diorite. The western part of the body" is composed of two pod-shaped, isolated zones of monzonite surrounded by quartz'monzonite: .

The pluton has been emplaced into the strata of the Horsethief. Creek Group, part, of the windermere supergroup of Hadrynian age. Middle amphibolite facies metamorphisin affected these rocks during the Middle Jurassic. Adjacent to the pluton the meta-sediments generally dip towards and belbw the predominantly inward dipping or vertical margin of: the body.

Whilst, the body is chemically homogenous with respect to 'the major elements. the distribution of zirconium is anomalous and shows a strongly pronounced trend of perimeter -zone enrichment. Such a distribution pattern is thought to be secondary and, related to syn/post emplacement activity that occurred during the hydration of the body.

Zircon.' is limited to the hydrated parts of the body. the anhydrous core zone, and transition zone being devold of 
zircon. The distribution of 'zircon "appears to be controlled by the alstribution of zirconium in the presence of a low" alkali content. The zircons gare, thought. to have formed during the regional metamorphlapeak that occurred in the Middle Jurassic .

The three-dimenstional form of the body is interpreted to be similar to that of a slli or laccolith, the congult being centrally located.

On the basis of data "collected in the field the piuton is at least as old as the second phase of deformation. The highiy discordant aligment of the body. with réspect to the regional phase two structurgl trend" suggests that rather" than being emplaced synkinematically it was Intruded prior to that deformation phase.

Finite element analysis indicates that the pattern of the strain fabric produced by the first. second and third phases of deformation around the pluton is consistent with the pluton being pre-tectoric to each deformation phase. Furthermore the oxientation of the zopes of divergence about the pluton, when compared to the results derlved from finite element analysis, 'Indicate that tho bogy. has experfenced a Iimited amount of rigid hody rotation.. This consists of approximątely $5.5^{\circ}$ degreesl of íovement in a clockwise direction during the second phase of deformation and approximately 3.5 degrees of movement; also in a clockwise direction, during the thirdphase.. The behaviour of the 
body during the fitst phase of deformation is unknown. Mathematical mateling predicts that the pluton should have experieniced 17 degrees of rotation in a clockwtse direction, giving the body an original long axis aligñment in the horizontal plane of 73 - 25.3 degrees.

The - Adamant pluton: may be: as young as the Middle Jurassic but an older age is equally possible. If the first phase of deformation in the Northern selkirk Mountains. is contemporanious with, the earliest phase of deformation récognized to the south then the plutor was emplaced prior to. or during, the Middle Palleozolc.

4. 


\section{REPERENCES}

AKAAD, M.K. 1955. The Ardara granitlc diapir of County Donegal. Ireland. Q.J. Geol. Soc. London, 112, 263-288.

ARMSTRQNG, P., 1922. 21rcon as criterion of lgneous or

- sedimentary metamorphics: Am. Jour, Scl.. 5th ser., v. 4, p. 391-39.5.

ASHWAL; L.D., and HARGRAVES, R.B., 1977. Palacomagnet $1 \mathrm{c}$ evidence for tectonic rotation of the Belchertown pluton, west-central Massachusetts: Jour. Geophys. Research, V.

.. 82, No. 8, p. 1315-1324.

ASHWAL, LEWIS D., LEO, GERHARD W., ROBINSON; PETER; ZARTMAN, ROBERT, E. . HALL, DAVID J. 1979. The Belchertiown Quartz Monzodiorite pluton, west-central Massachusetts, a syntectonic Acadian intrusion. Amer. J. Sc1.. V. 279, p. 936-969.*

BAEK, R., 1937. (Reprinted 1959). Structural behaviour of Igneous rocks. Mon. Geol. Soc, Am: 5, 177p.

BARRIERE, M. 1977. Deformation associated with the ploumanac'h intrusive complex, BrIttany. J. Geol. Soc. London, V. 134, p. $311-324$.

BERGER. A.R. and PITChER, W.S. 1970. Structures in granitic rocks: A commentary and critique on granite tectonics. Proc. Geol. Assoc., V. 81, P. 441-461.

BERThELeON; A., 1960. Structural btudice in the Precambrian' of western Greenland. II. Geology of Touquisap Nuna. Gronlands feol. Undersogelse, Bull, v. 25, p. $1-223$.

BILBY, B.A.: ESHELBY, J.D. and KUNDU, A.K. 1975.. The change of shape of a viscqus elilpsoldal region embedded in a slowly deforming matrix having a different viscosity. Tectonophysics, v. 28, p. 265-274.

BOTTINGA, $Y$. and WEILL, D. $\vec{F}$. 1972. The viscosity of magmatic silicate 11qutds: A model for calculation. Am. J. Sc1..
$v 272$, p. $438-475$.

BOWES. WILLIAM, $H .$, and RUSSELL, LESLIE, T. 1975. Stress analysis by the finite elenent method for practicing. * engineers. Lexington Books, Toronto.

BROWN, R.L., 1978. Strutural evglution of the southeast Canadian Cordiliera, A new Uypothesis. Tectonophysics., v. 48, p. $133-151$. 
BROWN, R.L. 1980a. Frenchman Cap Dome, Shushlap Complex, British Columbia. A progress report, Pap. Geol Surv. Can. 80-1A.

BROWN; R.L. I980b. Metamotphic complex of S. E. Canadian Cordiliera and relationship for foreland thrusting. In: Thrust and Nappe Tectonics, Geol. Soc. London, Pergammon Press (in press).

BRONN, R.L., PERKINS, M.J. and TIPPETT, C.R., 1977.

- Structure and strathraphy of the Blg Bend area, British Columbia; Report of Activities, Pt. A; Canada Geol. Survey Paper 7.7-1A, p. 273-275:

BROWN, R.L.' and TIPPETT, C.Ro, 1978. The Selkirk Fan structure of the Southeastein Canadian Cordlliera. Bull. Geol. Soc.

. Am. . V. 89, P. 548-558x

BROWN, R.L. and TIPPETT, C.R. and LANE, L.S., 1978. Stratigraphy facies and correlations in the Northern Selkirk Mountains, Southern Canadian Cordilleria. Can. J. Earth sci.. v. 15; p. 1129-1140.

BROWN, R.L." and READ; P.B. 1979. Basement cover Interaction: Shuswap Metamorphic Complex and the Kootenay Arc - Northern Selkirks. Evolution of the Crateic Margin and related mineral. deposits. Abs. Geol. Assoc. Can. Cordilieran Section, Prog. and Abs. 9.

BROWN, R.L. and PSUTRA, J.F., 1979. Stratigraphy of the east flank of Frenchman Cap Dome, Shuswap Complex, British Columbia, Pap. Gool. Surv. Cari., 79-1A, 35-6.

BUTTERPIELD, J.A., 1935. Outgrowths on zircons: Geol. Mag., V. 80. P. 155-155.

CAMPBELL, R.B., 1973. Structural cross-section and tectonic model of the southeastern Carfadian Cordillera. Can. $J$. Earth Sci., V. 10, p. 1607-1619.

CHAPPLE, W.M., 1978. Mechanics of thin-skinned fold and thrust belts.' Geol. Soc. Am., V. 89, P. 1189-1198.

Cloos, E., 1933. Structure of the "Ellicott City granite", Maryland, Proc. Nat. Acad. Sci., Wash., V. 19, p. 130138 .

CLoos, E., 1934. The Loon Lake pluton, Bancroft area, Ontarlo, Canada; J. Geol. V. 42, p. 39.3-399.

DE VRIES, C.D.S., 1971. Metamorphism and structure of the Esplanade Range, Brttiah Columbla, unpub. M.Sc. thesis, Univ. of Calgaxy, CaIgary, Alberta, $113 p$. 
DE VRIES, C., GHENT, E. . JONES, J. and SIMONY, P. 1971. Metamorphism and structure of the Esplanade Range and northern Dogtooth Mountains, British Columbia. Geol. Soc. Am. Abstr. Prog., V. 3, P. 378.

DOUGlas, R.J,W., Gabrielse, H., WhEElER, J.o., STOTT, D. F. and BELYEA, H.R., 1976. Geology of Western Canada. In: Douglas; R.J.W. (ed.) . Geology and Economic Minerals of Canada. Geol. Surv. Can. B. p.,357-546.

DUNCAN, I.J. 1978. Rb/Sr whole-rock evidence for thiree Precambrian events in the shuswap Complex, southeast British Columbla (Abs.) Prog. with Abe. Geol. Assoc. Can., -v. 3, . 392-393.

DUNCAN, I.J., PARRISH, R.R. and ARMSTRONG, R.L., 1979. $\mathrm{Rb} / \mathrm{Sr}$ geochronology of post-tectonic intrusive events in the Omineca Crystaline Belt, Southeastern British Columbla.Abs. Evolution of the Cratonic Margin and related Mineral Deposits. Abs. Geol. Assoc. Can. Cordilleran section, Prog. and Abs. p. 115.

ECKELMAN, F.D. and POLDERVAART, A., 1957. Geology and evolution of the Beartooth Mountains, Montana and Wyoming. Bull. Geol. Soc.' Am.., V. 65,.p. 947-948.

ELLISON, A.H., 1957. The Hamill Group of the Northern Dogtooth Mountains, British Columbia, Canada, unpub. M.Sc. thesis, Univ. of Calgary, Calgary, Alberta.

FAURE, G., 1977. Ṕrinciples of isotope geology, pub. John Wiley Sons.

FLINN, D., 1955. On the symmetry principle and the deformation ellipso1d, Geol. Mag., V 102, P. 36-45.

FOX, P.E., 1959. Petrology of Adamant Pluton, British Columbia," Geol. Surv. Can., Paper 67-61, 101p.

FRANZEN, J.P. 1974. Structural analysis in the Selkirk. Fan Axis near Argonat Mountain, southeastern British Columbia. unpub. M.Sc. thesis, Carleton Univ., Ottawa, Ontario,.55p.

FYLES, J.T.. 1964. Geology of the Duncan Lake area, Lardeau district, British Columbia: British Columbia Dept. Mines and Petroleum Riesources, Bull 49.

GAY, N.C., 1968a. The motion of rigid particles embedded in a viscous fluld during pure shear deformation of the.

- Eluid. Tectonophysics, v. 5(2), p. 81-88. 
GAY, N.Q., 1968b. Pure shear and simple shear deformation of inhomogenous viscous fluids. 2. The determination of the total finite strain in a rock from objects such as deformed pebbles. Tectonophysics 5(4), p. 295-302.

GHENT, 'E. , 1975.' Temperature, pressure and mixed volatile equilibria attending metamorphism of staurolite-kyanite bearing assemblages, Esplanade Bange, British Columbia. Geol. Soc. Am. Bull., v. 85, 'p. 1654-1660.

GHENT, E.D., JONES, J.W.. and NIÇHOLLS, J., 1970. A note on the significance of the assemblage calcite-quartz plagloclase-paragonite-graphite. Contí. Mineral. and Petrol.. v. 28, p. 112-116.

GHENT, E.D. and DE VRIES, C.D.S., 1972. Plagloclase-garnetepidote equilibria from the Esplanade Range, British Columbla. Can. J. Earth Sci.., V. 9, p. 618-63.5.

GHENT, E.D. and MCKEE, E.H.., 1975. K-Ar dates for metamorphic. minerals from the Esplanade Range, B.C.. Can. J. Earth Sei.. V. 12, P. 1593-1595.

-GHOSH, S.K., 19.75. Distortion of planar structures around rlgid spherical bodies. Tectonophysics, V. 28, p. $185-208$.

GHOSH, S.K. and SENGUPTA, S., 1973. Compression and simple shear of test models with rigid and deformable inclusions. Tectonóphysics, v. 17, p. 133-175.

'GILLSON, J.L., 1925. Zircon, a contact metamorphic mineral in the Pend oreille district. Idaho: Am. Mineralogist, v. 10 , p. 187-194.

GOTTFRIED, DAVID, JAFFE, H.S. and SENFTLE, F.E., 1959. Evaluation of the iead-alpha (Larsen) method for determining ages of Igneous: "U.S. Geol. Surv. Bull. 1097A, 63p.

GOLDICH, S.S., HEDGE, C.E. and STERN T.W., 1970. Age of the

Morton and Móntevideo gnelsses and related rocks, southwestern Minnesota, Geol. Soc. An. Bull, v, 81., p. $3571-3599$.

GRUÉNENFELDER, M., HANSON, G.N, , BRUNNER, G.0. and EBERHARD, E. 1965. U-Pb discordance and phase unmixing in zircons (abstract). Geol. Soc. Amer. Spec." Pap, v. 101, p. $80-81$.

HOLDER, M.T., 1978. Granite emplacement models. In: Upton, B.G.J: Emplacement and crystalilization of minor intrusives J. .Geol. Soc. London, V. 135, Pp. 459. 
HOY, T., 1974. Structure and metamorphism of Kootenay ArC rocks around Riondel, B.C. Ph.D. thesis, Queen's Univ.., Kingston, Ontario, $202 p$.

HOY, T., 1975. Geology of the Riondel area: British Columbia Dept. Mines and Petroleum Resources, prelim, Map 16.

HOY T., and MCMILLAN, W.J. 1979.- The geology in the vicinity of Frenchman's Cap gneiss dome. In: Geologlcal Fleldwork 1978, British Columbia Dept. Mines and Résources.

HUTCHINSON, R.M., 1955. Struature and petrology of the Enchanted Rock batholith, Llaca and Gillesple counties, Texas: Geol. Soc. Am. Bull.. †. 67, p. 763-806.

HUTChINSON, R.M. 1960. Petrotectonics and petrochemistry of late precarabrian batholiths of central Texas and the north end of pikes peak batholith, Colorado, 21st Int. Geol. Congr. Norden, v. 14, p. 95-107.

JONES, A.G.,-1959: Vernon map area, British Columbia, Mem. Geol. Surv. Can., V. 296, p. 1-186.

JONES, J.W., 1959. Low grade metamorphism of Proterozolc rocks from the Esplanade Range, British Columbia. unpab. M.Sc. thesis, Univ. of Calgary, Calgary, Alberta:

JONES, J.W., 1972. An almandine garnet isograd in the Rogers Pass area, British Columbla: The nature of the reaction and an estimation of the physical conditions during 1 ts formation. Contr. Mineral and Petrol., v. 37, p. 291305.

KARLSBEER, F.e 1962. Petrology and structural geology of the Berlanche Valloire area, Belledonne Massif, France, Thesls, Rijksuniversiteit, Leiden, 136p.

KROGH, T.E. and DAVIS, G.L., 1972. The effect of regional metamorphism on U-Pb systens in zircons and a comparison with Rb-Sr systems in the same whole rock, In: Annual Report of the Director, Geophysical Laboratory, Carnegle Institution, 1971-1972.

KROGH, T.E. and DAVIS, G.L., 1973. The effect of reglonal metamorphism on U-Pb systems in zircon and a comparison wi.th Rb-St systems in the same whole rock and its constituent minerals. In: Annual Report of the Director, Geophysical Laboratory, Carnegie Institution, 1972-1973. 
KROGH, T.E. and DAVIS, G.L., 1974. Alteration in zircons with discordant $U-P b$ ages. In: Report of the Director, Geophysical Laboratory, Carnegle Institutuion, 1973-1974.

KROGH, T.E. and DAVIS. G.L., 1975. Alteration of zircons and differential dissolution of alterted and metamlct.zircon. In: Annual Report of the Director, Geophysical Laboratory, Carnegie Institution, 1974-1975.

LAMB, H., 1932. Hydrodynamics. Cambridge University Press, $738 \mathrm{p}$.

LANE, L.S., 1977. Structure and stratigraphy, Goldstrean River-Downie Creek area, Selkirk Mountains, British Columbia. unpub. M.Sc. thesis, Carleton Univ., Ottawa, Ontario, 140p.

LARSON, L.H. and POLDERVAART, A., 1957. Measurement and distribution of 21 rcons in some granitic rocks of magmatic origin: Mineralog. Mag. v. 31, No. 238, p. 544-564.

LEATHERBÁRROW; RoW., and BROWN, R.L., 1978. Metamorph1sm of the Northern Selkirk Mountains, British Columbia; Current Research, Part A., Geol. Surv. Can. Paper 78-1a, p. 81-82.

LEECH, G.B., LOWDON, J.A., STOCKWELL, C.H., and WANLESS, R.K., 1953. Age determinations and geological studies; Geol.

Surv. Can., Paper 63-17.

LOWDON, J.A., STOCKWELL, C:H., TIPPER, H.W. a a WANLESS, R.K., 1963. Age determinations and geological studies. Geol.

Surv. Can. Paper 62-17.

MACKLIN, J.H., 1947. Some structural features of the intrusions in the Iron Springs district. In: Guldebook to the Geology of Utah,. V. 2, 52 p.

MERTIE, J.B., Jre, 1958. Zlirconium and hafnium in the southeastern Atlantic states: U.S. Geol. Surv. Bull. $1082-A$, p. 3-5.

MURASE, T., and MCBIRNEY, A.R., 1973. Properties of some common igneous rocks and their melts at high temperatures. Bull. Geol. Soc. Am... V. 84.' p. 3553-3592.

NELSON, C.A., and SYLVESTER, A.G. 1971. Wall rock decarbonation and forcible emplacement of Blrch Creek pluton, southern White Mountaing california. Bull Geol. Soc. An. V. 82, p. 2891-2904: 
NICKEL, E., KOCH, H. and NUNGASER, W., 1957. Modellversuche sur Flieszregelung in Graniten. Mitt. Schweiz. Mineral. Petrol. V. 47, p. 399-498.

O'NEILL; J.R. and GHENT, E., 1975. Stable isotope study of co-existing metamorphic minerals from the Esplanade Range, British Columbia. Geol. Soc. Am. Bull. V. 85, P. 17081712.

PIGAGE, L.C., 1976. Metamorphism of the Settler Schist, southwest of Yale, British Columbia, Ca. J. Earthisciences, v. 13, p. 405-421.

PITCHER, W.S., 1975: On the rate of emplacement of batholiths. Journal of Geol. Soc., v. 131, p. 587-591.

PITCHER, W.S., 1979. The nature, ascent and emplacement of granite magmas. J. Geol. Soc., V. 136, part 6, p. 627-652.

PITCHER, W.S. and BERGER, A.R., 1972. The geology of Donegal: a study of granite emplacement and unroofing. Wiley. Interscience, London, $435 p$.

POLDERVAART, A., 1950. Statistical studies of zircons as a criteria in granitization. Naturé, V. 165, P. 574-575.

POLDERVAART, A., 1955. Zircons in rocks, Part 1, Sedimentacy rocks: Am..Jour. Sci., V.-253, P: 433-461.

POULTON, T:P...1970. Gtratigraphy and sedimentology, Horsethief Creek Formation, northern Dogtooth Mountains, British Columbia. unpub. M.Sc. thesis, Univ. of Calgary, Calgary, Alberta, 97p.

POULTON, T.P.. 1973. Upper Proterozolc "Limestone Unit". northern Dogtooth Mountains, British Columiba, Can. J. Earth Sci.., V. 10, p. 292-305.

PRICE, R.A., 1955. Flathead Map-area, British Columbia and Alberta. Mem. Geol. Surv. Can. p: 335.

PRICE, R.A. and MOUNTJOY, E.W., 1970. Geologle structure of the Canadian Rocky Mountalins between Bów and Athabasca Rivers a progress report in t wheler, J.0. (ed.) : Structure of the Southern Canadian Cordilfera. Spec. Pap. Geol. Assoc. Can., V. K. p. 7-39. 
PSUTKA, F.J., 1978. Structural setting of the Downle slide northeast flank of Frenchman. Cap gnefss dome, Shuswap complex, southeastern Britlsh Columbla; unpub. M.Sc. thesis, Carleton Univ. Ottawa, Ontario, 7.0p.

RAMSAY, J.G., 1967. Folding and Eracturing of rocks. McGraw- HIl Book Company, London, 568p.

RAST, N., 1970. The inltiation, ascent and emplacement of magmas. In: Newall, G. and Rast: N. (eds.) Mechanism of Igneous Intrusion. Geol. J. Spec. Issue 2, p. 339-352.

READ, P.B., 1975. Lardeau group, Lardeau map area, west half, British Columbia, Pap. Surv. Can. 75-1A, p. 28.

READ, P.B., 1976. Lardeau map-area (82 k west half), British Columbia. Geol. Surv. Can. Pap. 77-1A, p. 95-95.

READ, P.B., 1979. Relationship between the Shuswap Metamorphic Complex and Kootenay Arc, Vernon east half, southern British Columbla. Geol. Surv. Can:.Pap. 79-1A, p. 37-40.

READ, P.B., 1980. - Stratigraphy and structure: Thor odin Frenchman Cap dQmes, vernon east-half, southern British Columbia: Geol. Surv. Can. Pap: 80-1A.

READ, P.B., and WHEELER, J.0. 1975. Lardeau west half geology: Canada Geol...Survey Open file map 288.

REESOR, J.E., 1970. Some aspects of structural evolution and regional tectonic setting in part of the Shuswap Metamorphic Complex. In: Wheeler, J.O. (ed.) structure of the southern Canadian Cordillera. Spec. Pap. Geol. Assoc. Can. V. .6, p. 73-85.

REESOR, J.E., 1973. GeQlogy of the Lardeau map ared, east half, B.C., Geol.. Surv. Can. Mem. P. 359.

ROBBINS, D.B., 1975. Structure and the relationshdp between deformation and metamorphism in the Encanpment Creek area, British Co.jumbia: Geol. Assoc. Canada Ann. Mtg.. Edmonton, Abs. V. 1, p. 59:

ROSS, J.V. 1970. Structaral evolution of the Kootenay arc, southeastern British Columbia, In: Wheeler, J.P. (ed.) structure of the southern Canadian Cordillera: Geol. Assoc. Canada.. Spec. Paper, p. 53-66.

SAHA, A.R., 1959. Emplacement of three granitic plutions in southeastern Ontar10, Canade. Bul1. Geol. Soc. Amer. v. 70, p. 1293-1325. 
SAXENA, S.K., 1965. Evolution of zircons in sedimentary and metamorphic rocks. Sodimentology, v, 6, p. 1-33.

SAXENA, S.K., 1968. Evolution of zircons in sedimentary and metamorphic rocks: A reply. Sedimentology, v. 10, p. 145146.

SHAW, D.A. 1980. A concordant uranium-lead age for zircons in the Adamant pluton, British Columbia. In: Loveridge W.D. 1980, Rubidium-strontium and uranium-lead isotopic age studies, Current research part c, Geol. Surv. Can., paper 80-1C, in preparation.

SHAW, H.R, 1965. Comments on viscosity, crystal settling and convection in granitic magmas. An. J.Sci.. v. 263, P. 120152 .

SHAW, H.R., 1969. Rheology of basalt in the melting range, J. Petrol.. V. 10, P. 510L535.

SHAW, H.R., 1972, Viscosities of magmatic silicate liquids: an empirical method of prediction. Am. J. Sci., V. 272, p. 870-893.

SHAW, H.R., WRIGHT, T.L., PECK, D.E. and OKAMURA, R., 1968. The viscositybof basaltic magma: an analysis of field measurements in Makaopuhi lava lake, Hawal1. Am. J.. Scl., V. 266, P. 255-2\%:

SILVER, L.T., 1953a. The relation between radio-activity and discordance in zircons: Nuclear goophysics, Natl. Research Council Pub. V. 1075, p. 34-42.

SILVER, L.Ti. 1963b. The use of cogenetic uranium-lead isotope. systems in zircons in geochronology: Radioactive Dating, Internat. Atomle Energy Agency,Proc. (Athèns) . p. 279-287.

SILVER, L.T. and DEUTSCH, S. 1963. Uranium-lead isotopleic varlations in zircons: A case study. Jour. Geology, v. 71, p. 721-758.

SIMONY, P.S.. 1975. Stratigraphy and structure between Rockies and Shuswap gneiśses near Big Bend of the Columbia. Geol. Soc. Am. Abstr. Prog.'v. 7, p. 859.

SIMONY, P.S. and WIND, G., 1970. Structure of the Dogtooth Range and adjacent portions of the Rocky Mountain Trench. In: Structure of the southern Canadian Cordillera. (Wheeler, J.0.,ed)..Geol. Assoc. Can., spec. paper 6 , p. 4 \}1. 
SOPER, N.J., 1963. The structure of the Rogart Igneous complext Q.J. Geol. Soc. London, V. 119, p. 445-478.

SMITHSON, F., 1937. Outgrowths on zircons in the Middle Jurassic of Yorkshire: 'Geol. Mag., V. 74, p. 281-283.

SYLVESTER, A.G., 1954. Geology of the Vradal granite. Nor. Geol. Tiddskr, V. 44, p. 445-482.

TAN, B.K., 1974. Deformation of particles developed around rigid and déformable nuclei. Tectonophysics. V. 24, p. 243-. 257.

TAUBENECK, W.H., 1957. Zircons in the metamorphic aureole of the Bald Mountain batholith, Elkhorn Mountains, northeast Oregon (Abstract). Geol. Soc. Am. Bull. V. 8, p. 18031804.

TAYLOR,.G.I., 1932. The viscosity of a fluid containing small drops of another fluid. Proc. R. Soc. London, Ser. $A$, 138: P. 41-48.

THOMPSON, R.I., 1972. Geology of the Akolkolex River area near Revelstoke, British Columbla: Ph.D. thesis, Queen's univ.. Kingston, Ontario, $125 \mathrm{p}$.

TIPPETT, C.R., 1976. A structural and. stratigraphic crosssection through the Selkirk fan axis, SeIkirk Mountains, southeastern British Columbia, unpub. M.Sc. thesis Carleton University, ottawa, Ontario, 147p.

TÍlTON, G.R. 1960. Volume diffusion as a mechanism for discordant lead paths, J. Geophys, Res. V, 65, p. 2933-2945.

TURner, F.J. Metamorphic Petrology, McGraw-Hill Book Company. New York, 1968, 403p.

VAN DER LEEDEN, J., 197.6. Stratigraphy, structure and metamorphism in the northern Selkirk Mountains, southwest of Argonaut Mountain. southeastern British Columbia. - unpub. M.Sc. thesis, Carleton Univ., Ottawa, Ontario, $105 p$.

WANLESS, R.K. STEVENS, R.D., LACHANCE, G.R. and RIMSAIT R.Y.H., 1974. Age determinations and geological studies, Geol. Surv. Can., Paper 64-17 (part 1).

WANLESS, R.K. and REESOR, J.E. 1975 Precambrian zircon age of orthogeneiss in the Shuswap Metamorphic Complex. British Columbia, Can. J. Earth Sci. v. 12, p. 326-332. 
WETHERILL, G.W., 1955. Dlscordant lead ages, I. Trans. Amer. Geophys. Union, V. 3, p. 320-326.

WHEELER, J.0., 1963. Rogers pass map-area, British Columbia and Alberta ( $82 \mathrm{~N}$ west half): Geol. Surv. Can. Pap. $62-32,32 p$.

WHEELER, J.0., 1955. Big Bend map-ara, British Columbia (82M east half). Geol. Surv. Can. Pap. 64-32, p. 1-3.7.

WHEELER, J.0. 1970. Structure of the southern Canadian Cordillera. Geol. Assoc. Canada, Sp. Paper 6.

WHEELER, J.O. CAMPBELL, R.B., REESOR, J.E, and MOUNTJOY, E.W., 1972. Structural style of the southern Canadian Cordillera: Internat. Geol. Cong. 24th, Montreal 1972, Guldebook for -

- fleld excursion XOl-AOL.

WHEELER, J.O. and GABRIELSE, H., 1972. The Cordllleran structural province. In: R.A.Prlce and R.J.W. Douglas (eds.). Varlations in tectonic styles in Canada. Geol. Assoc. Can. Spec. Paper 11, p. 9-81.

WHITE, W.H., ERICKSON, G.P., NORTHCOTE,K.E. DIROM, G.E. and HARAKAL, J.E., 1967. Isotoplc dating of the Guichon batholith, B.C. Can. J. Earth. Sclences (4), 1957, No: 4.

WIND, G. 1957. Structural geology of the northern Dogtooth - Range, British Columbia. M.Se. thesis, Univ. of Calgary Alberta. :

ZIENKIEWIC2, 0.C., 1971. The finite element method in engineering science, McGraw-Hill, London.

ZWANZIG, H.V., 1973. Structural transitions between the foreland zone and core zone of the Columbian orogen, Selkirk Mountalns, British Columbia, Ph.D. thesis, Queen's Univ., Kingston, Ontario, 158 p. 
APPENDIX TABLES

Key to Appendix' Tables 1 to 5 .

The format presented here is simflar to" that of Tlppett $(19.75)$.

1. Stratigraphic unit letter..

2. Stratiquaptic distance af the base of the unit from the base of "the member, except where the base of the member is not exposed; in which case the column is left blank.

3. Thickness of the unit. With-respect to thick units the measurements are derlved from cross-sections; for the thinner units the measurements are.those recorded. In the' field. In neither case has any correction been made to ailow for the effects of structural repetition, tectonlc thlekening or thinning. Consequently the accuracy of the thicknesses given is sometimes questionable.

4. Stations at whlch the relevant data.was collected. 5. General description of the unit basedion field data. The data in each individual table reads in an ascending stratigraphic order. Refer to figure 8 for the location of each section. 


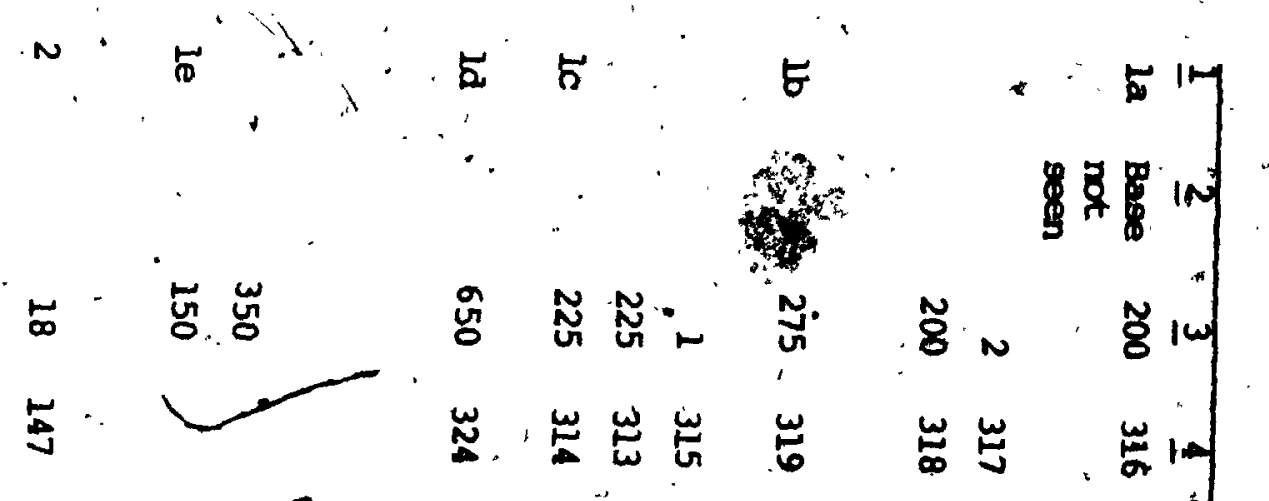

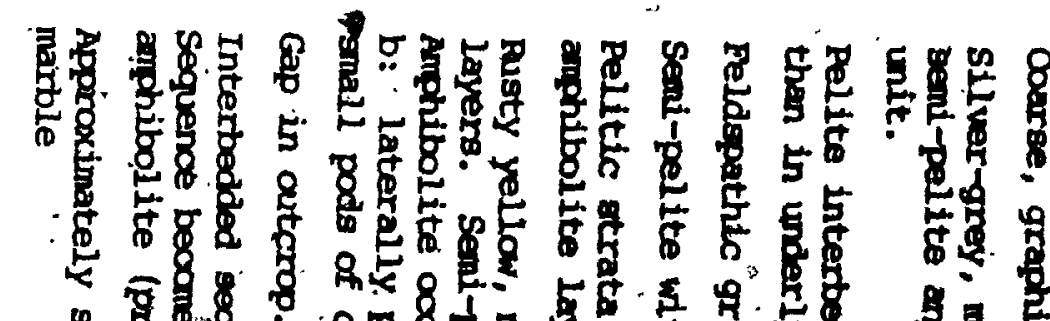

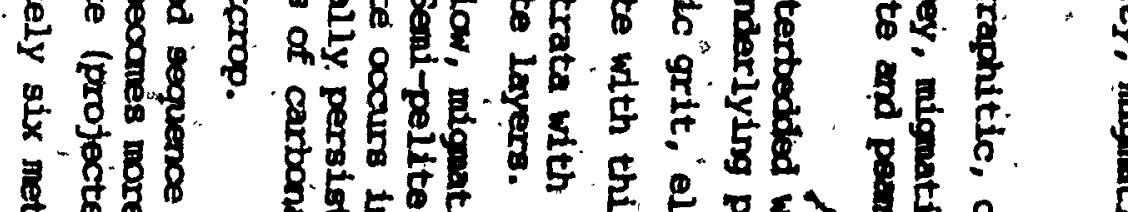

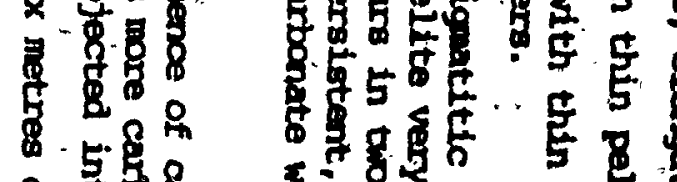

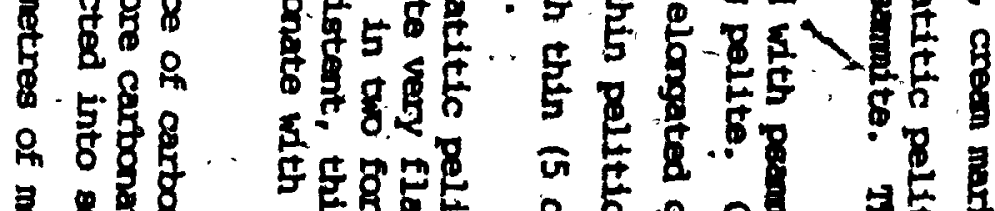

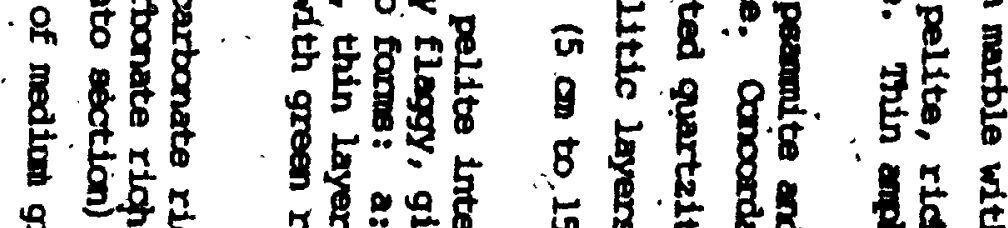

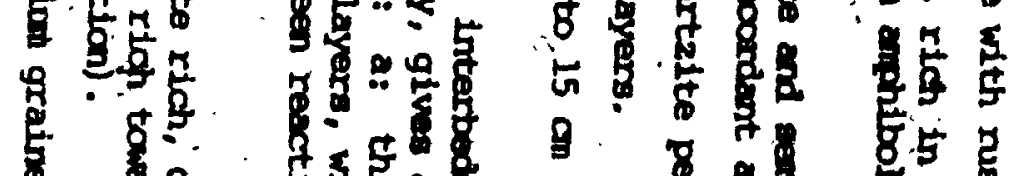

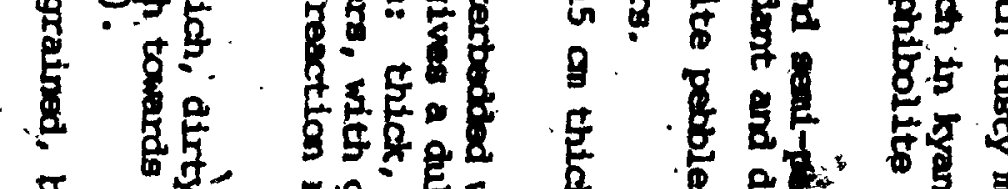

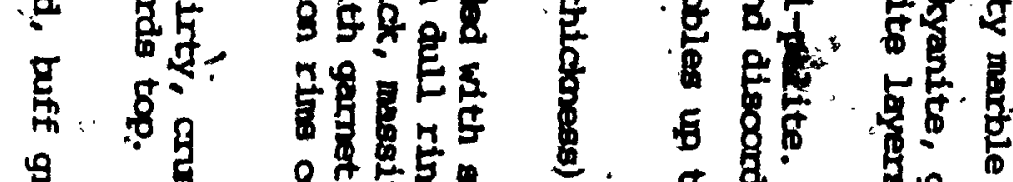

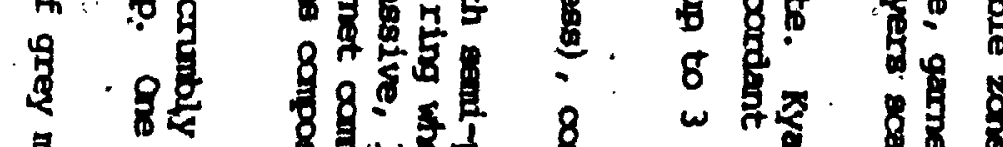

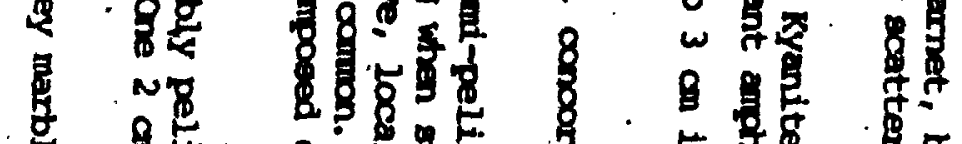
要

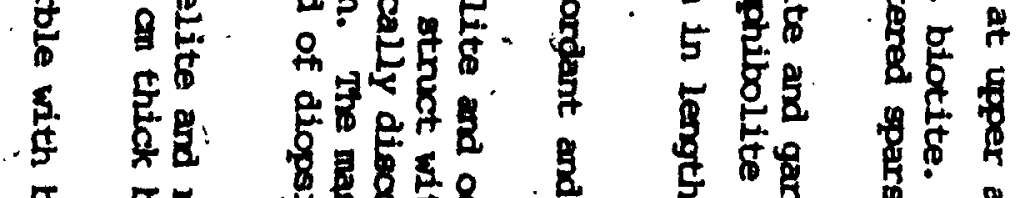

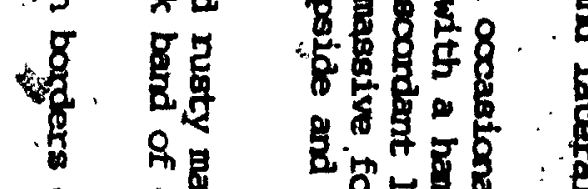
品, 案 .

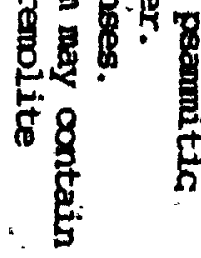

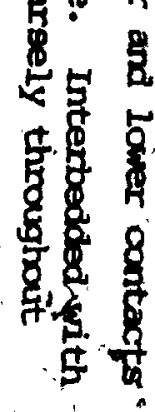
8 in 要

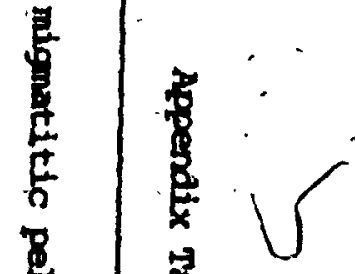


PLATE $M$

(5) F.

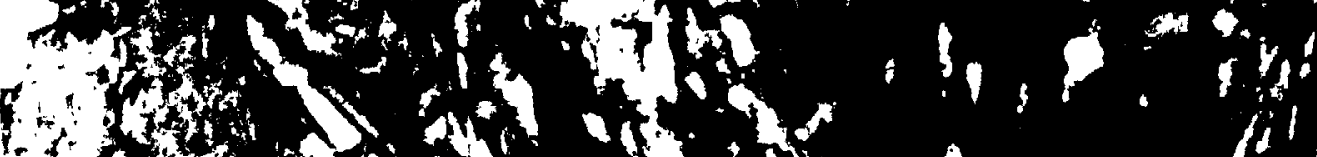

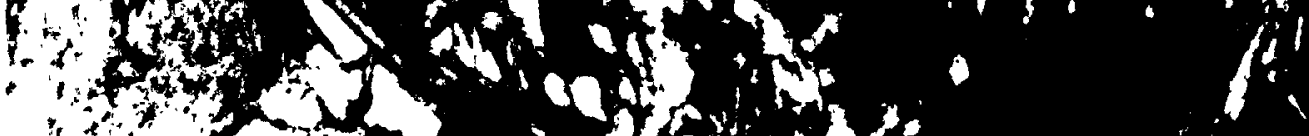
(1)

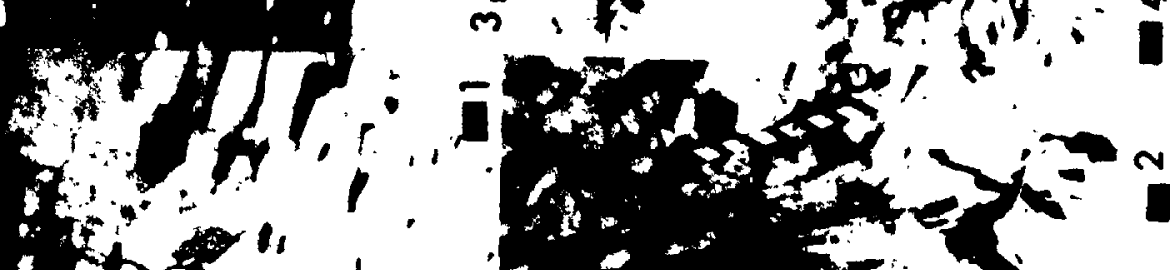

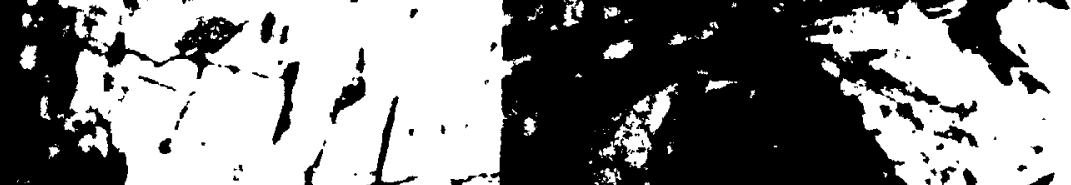

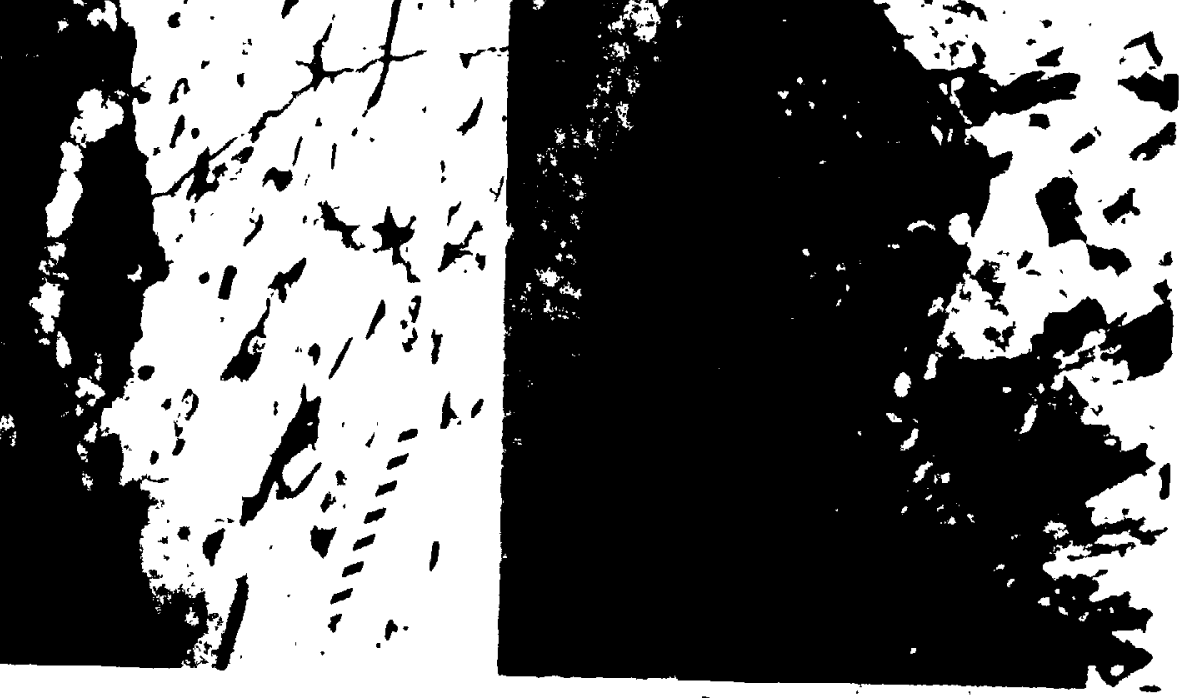





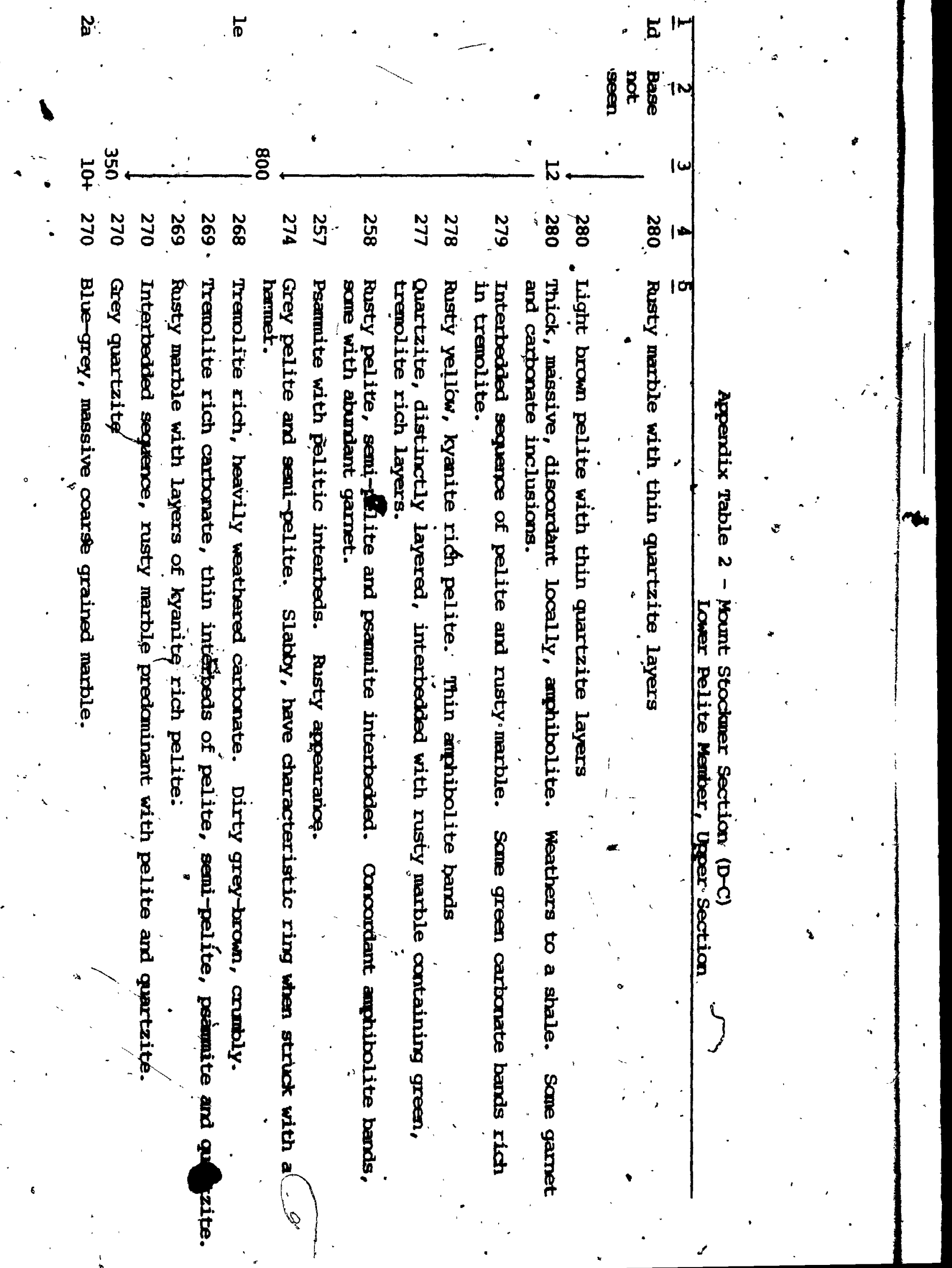


.

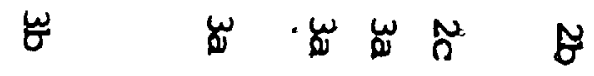

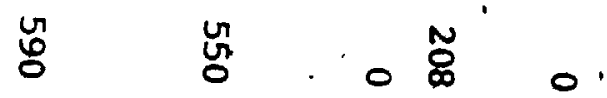

8ㄴ

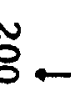

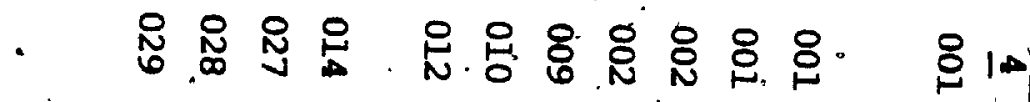
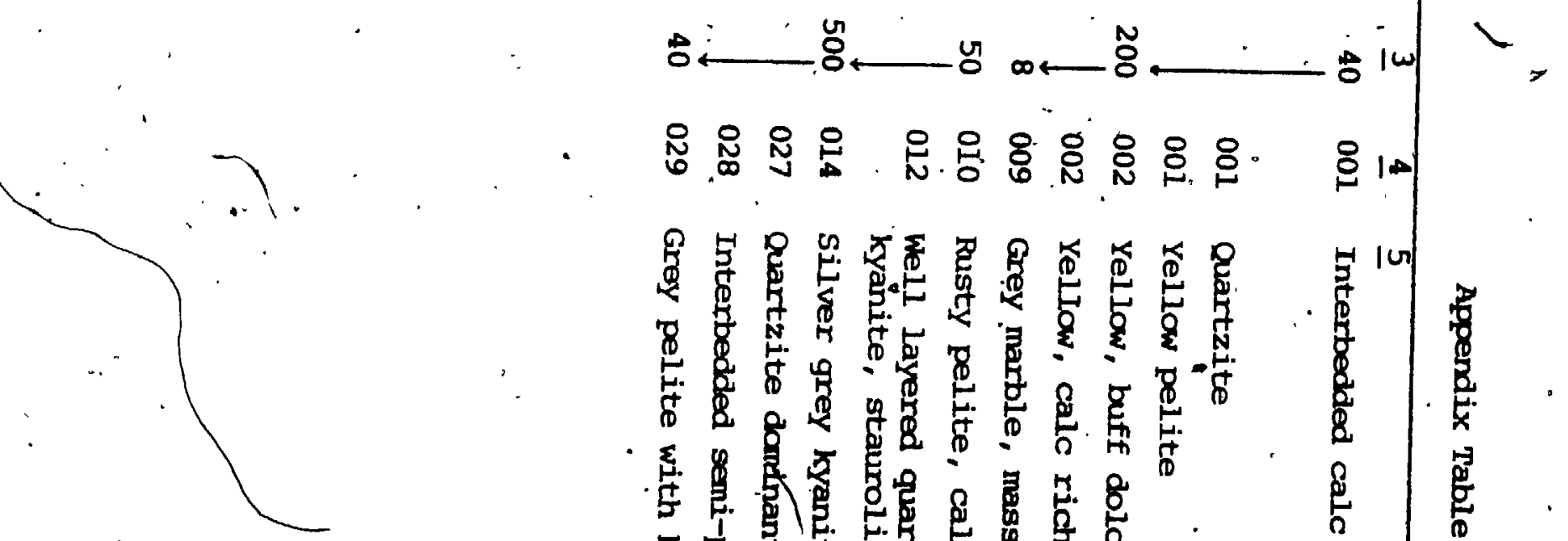

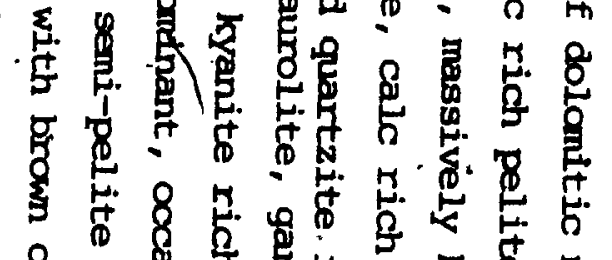

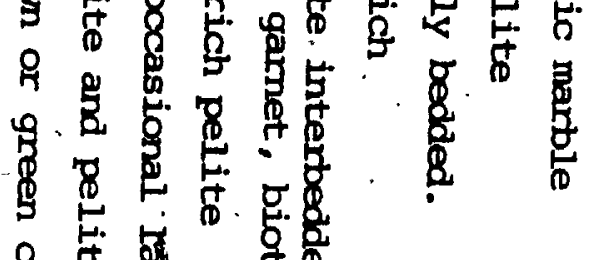

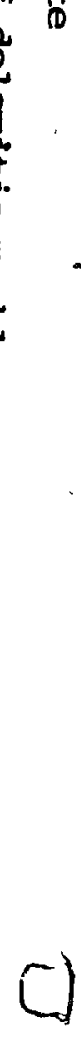

8
8
8
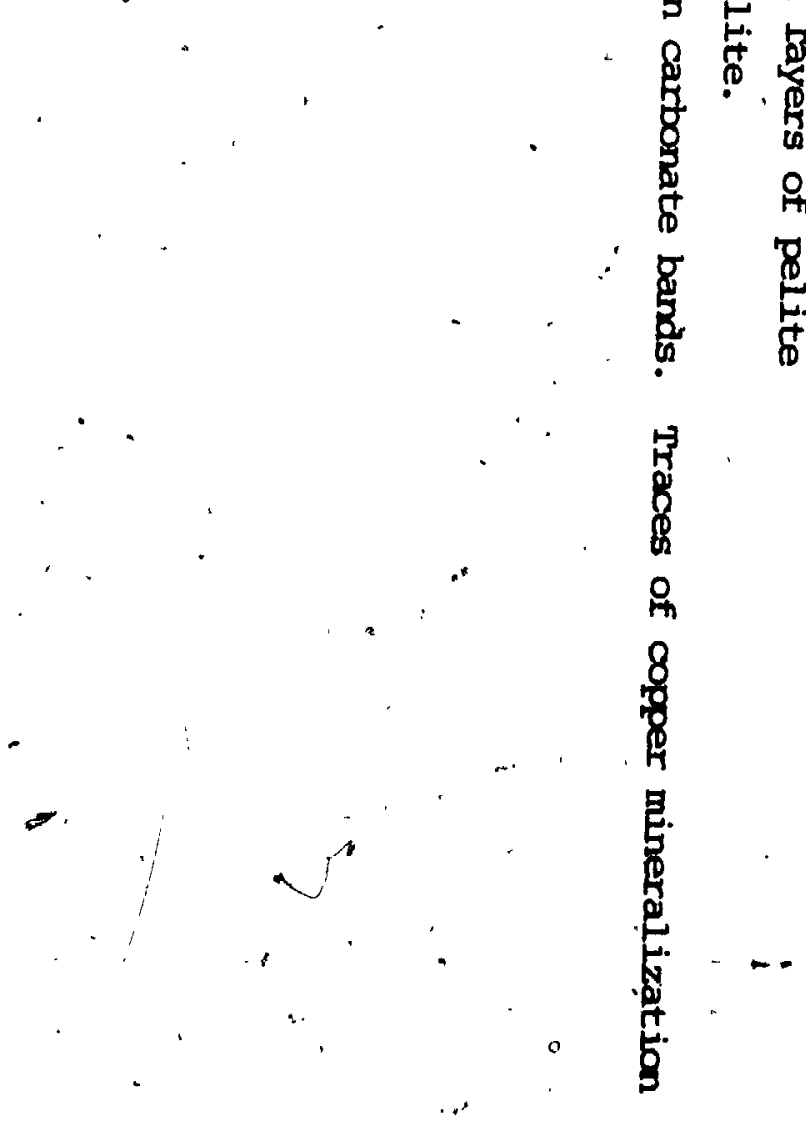

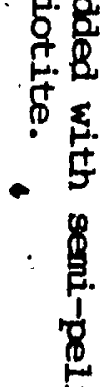
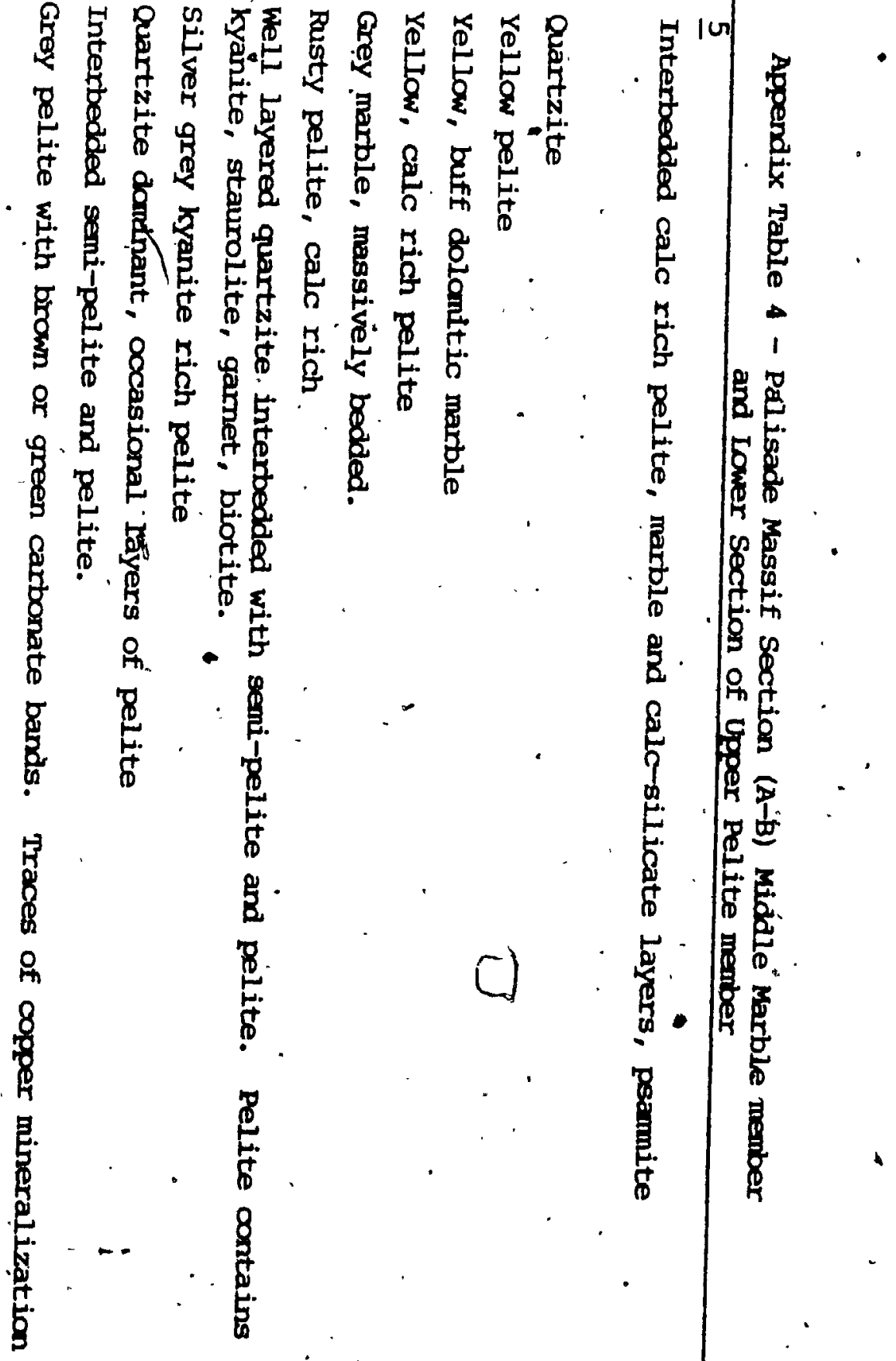


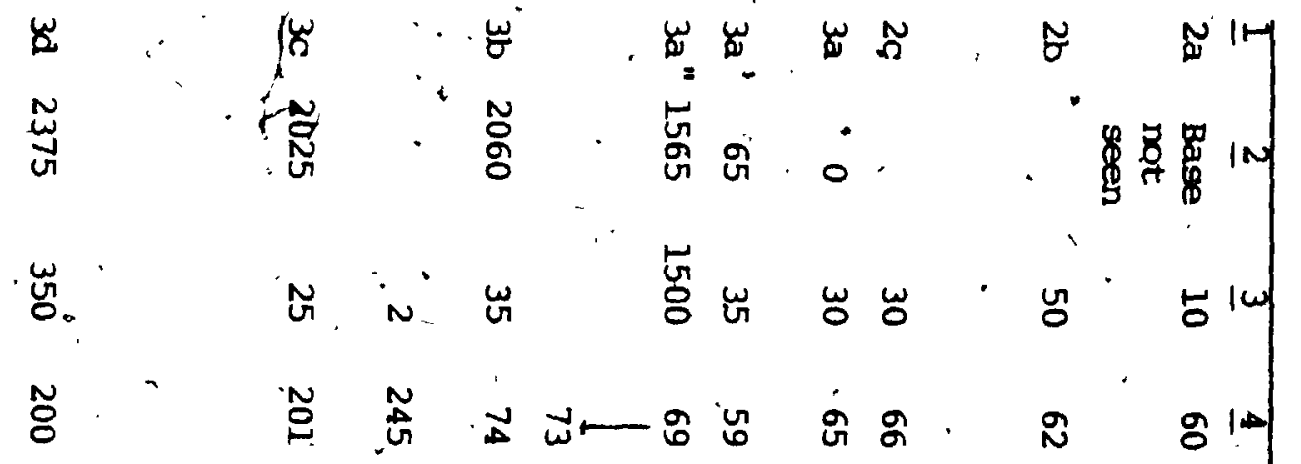

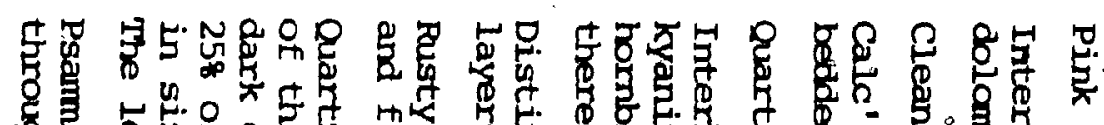

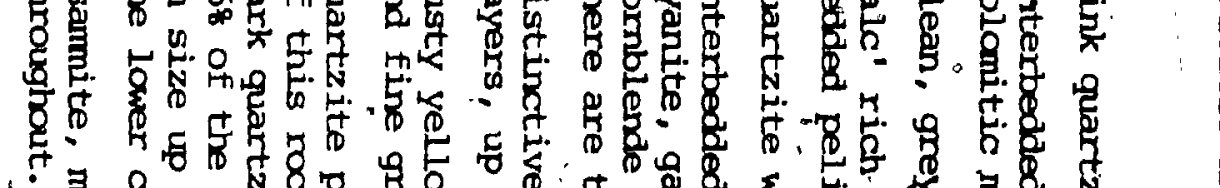

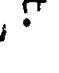

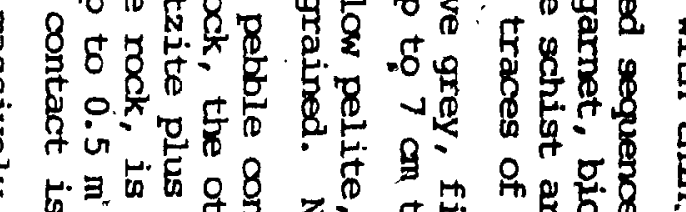

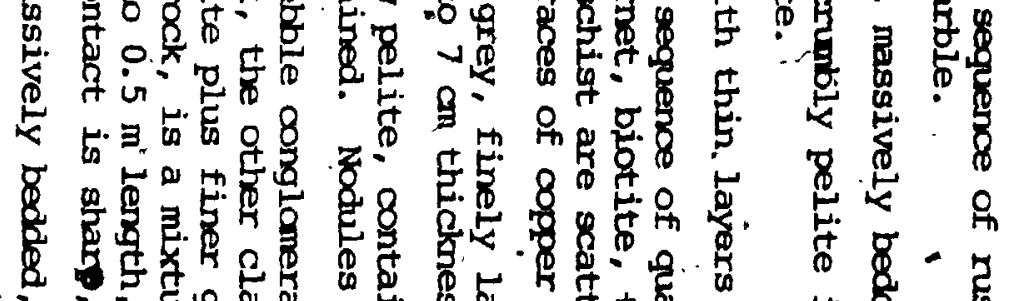

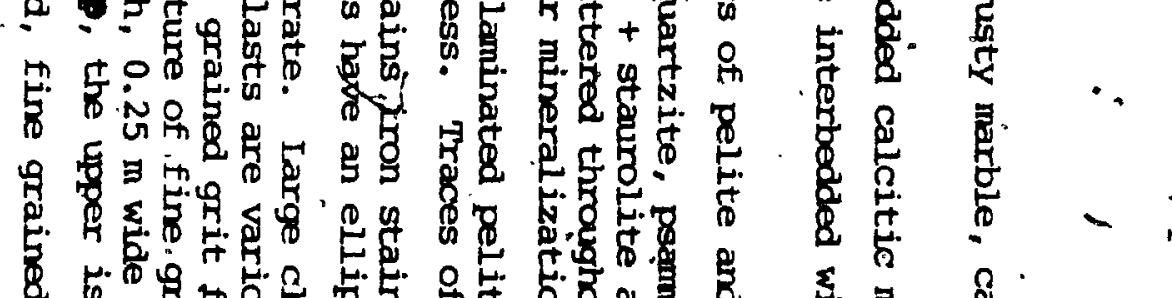
8.

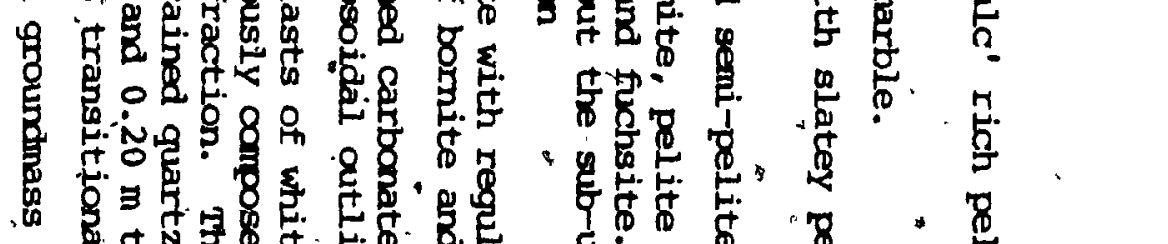

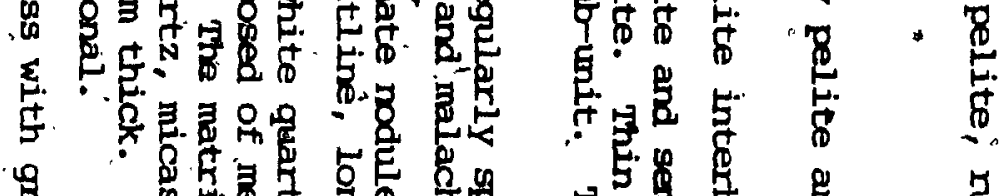

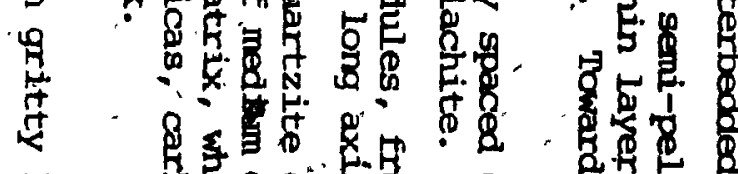

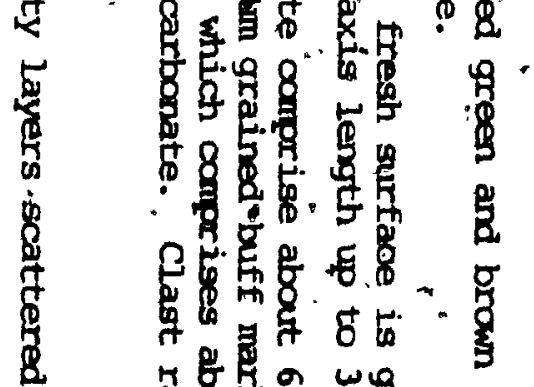

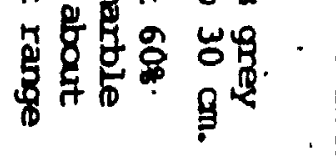

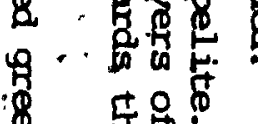

-

最

옹영

क्षे

若.

号 致

t

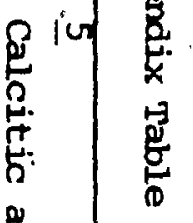

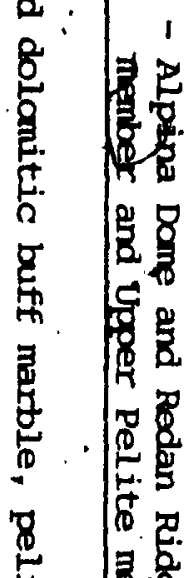

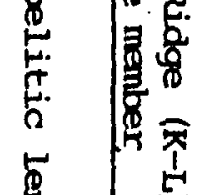

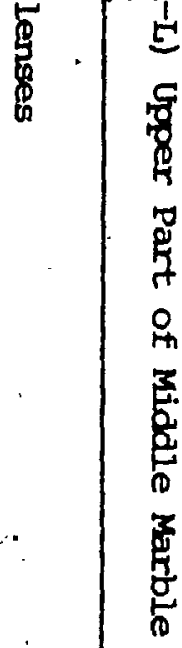



PLATE,

1 .

Looking northwesterly at the pluton-country rock contact along the eastern end of the pluton. (The slopes on the right are those of the western bank of Tabernacle creek.

M:M.m. and L.P.m. strata dip towards, and under the pluton and are structurally located on the western limb of the phase three Golofiver anticline.

2 . Looking westerly at the pluton-country rock contact on the western edge of Granite Glacier. (map reference $432378 / 57353541$.

- M.M.M. and L.P.m. strata are vertically stacked against the margin of the body and structurally lie on : upper limb of the phase three Gold River anticline.

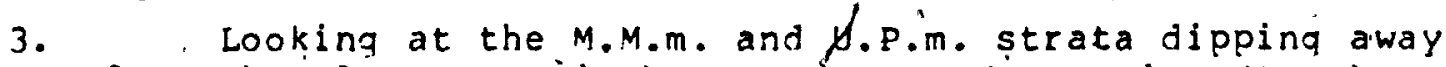
from the pluton margin between Mount Enterprise (to the left l and Mount colossal (left of centre).

4.- M.M.ri. strata vertically stacked against the pluton margin, approximately 3 km west of Austerity Pass. viewed looking northwesterly. 


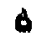

Plate a

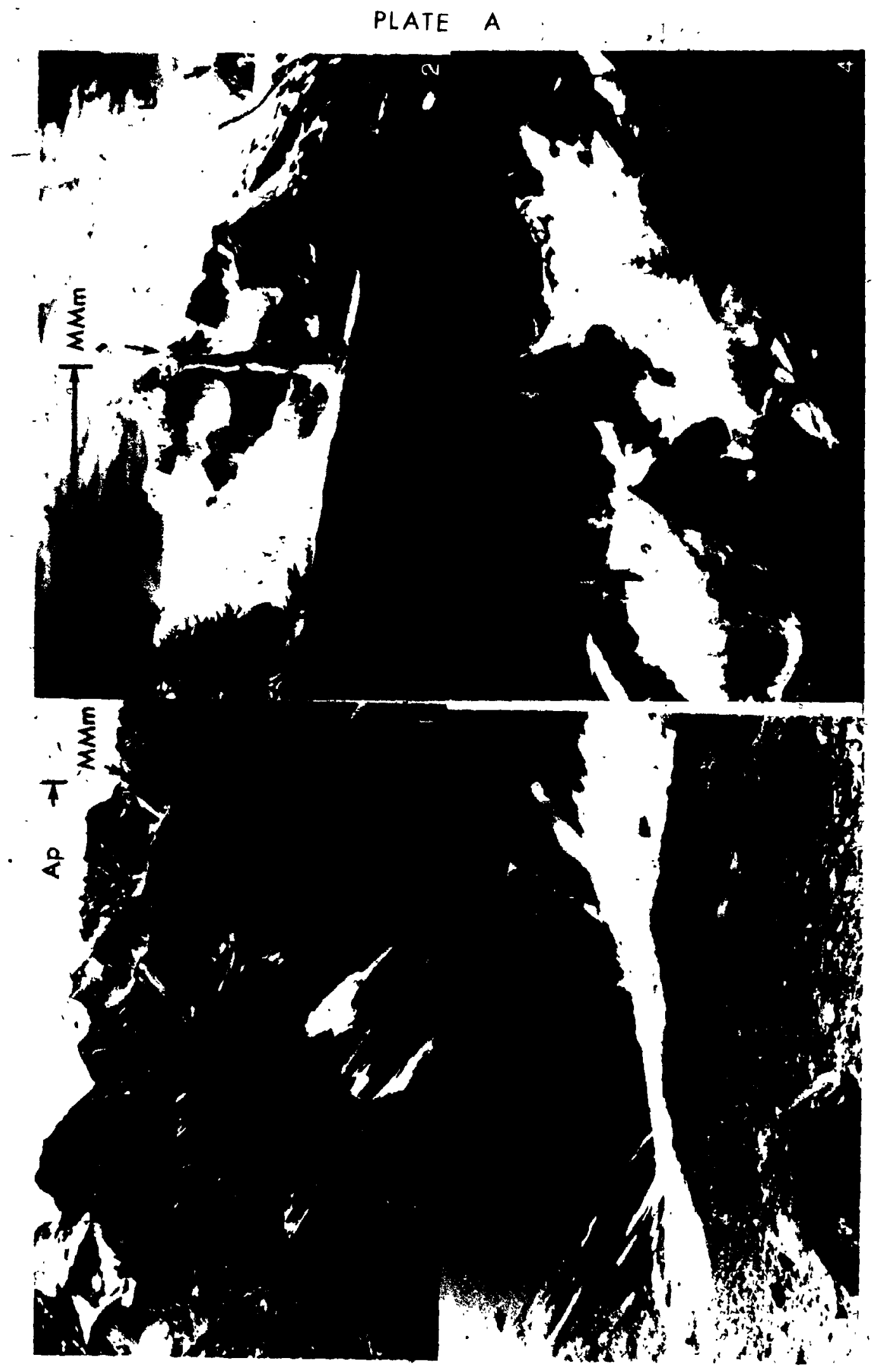


PLATE $B^{i}$

1. The Palisade massif with the Palisade Hook structure outlined by Unit $2 a$ of the M.M.m. The structure is viewed from the southeast, the grey marble peak in the lower right is, Ravelin Mountain.

On the northeastern limb of the palisade anticline (P.A.), the hinge zone of which is shown by a solid line, the Sir Sanford anticline is refolded. The dashed line marked .5.S.a. indicates the hinge zone of the phase two sir sahara anticline.

One of a series of flat-lying phase two minor folds (dotted line) is shown on the crest of the Palisade antiform.

'2. 'A closeup of the Palisade Hook structure viewed from the south.

3. The easterly facing aspect of the Palisade massif (Ravelin Mountain lower slopes are at he lower left). 


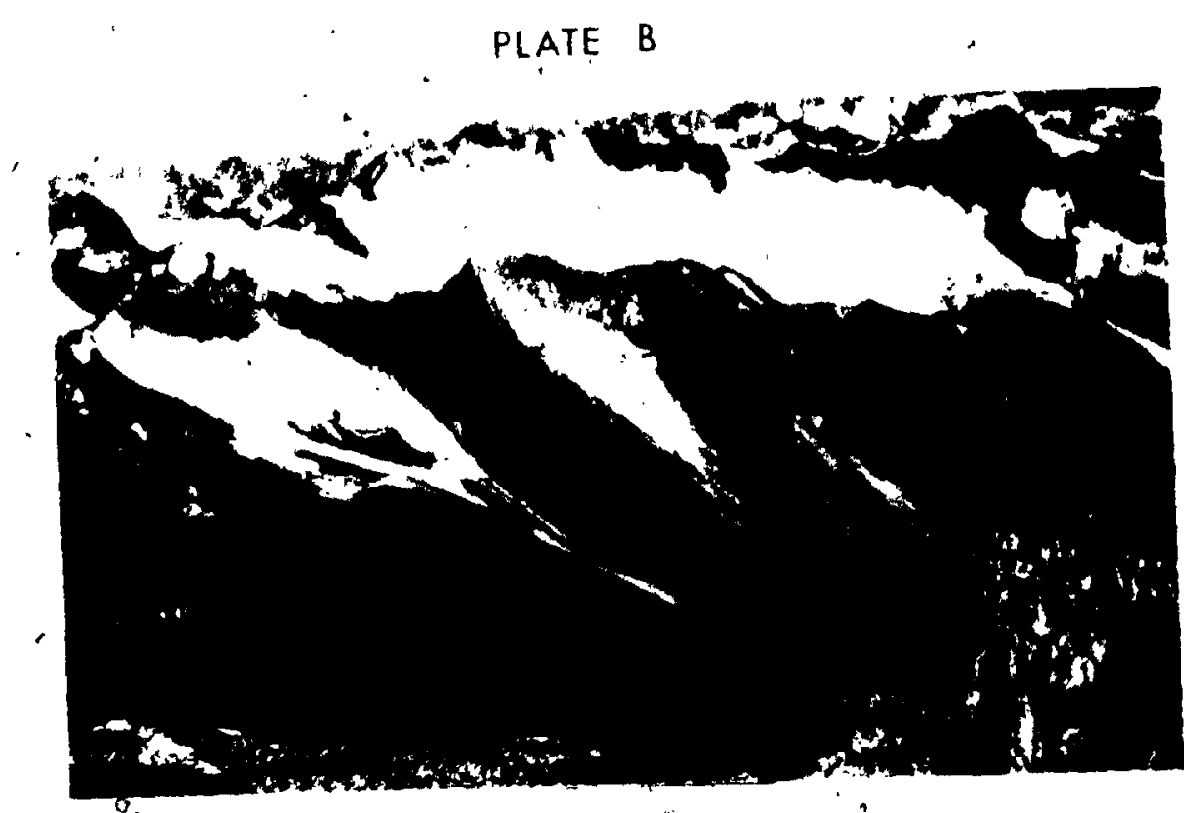

9

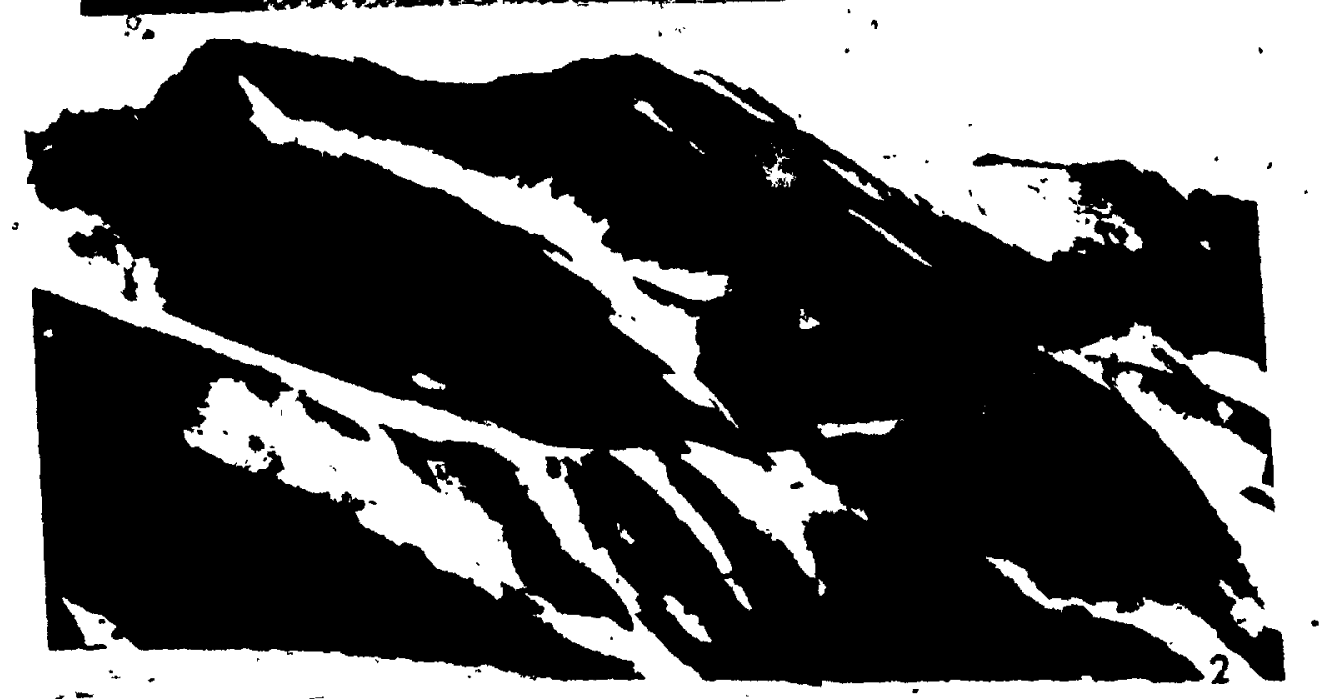

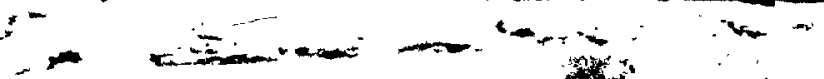

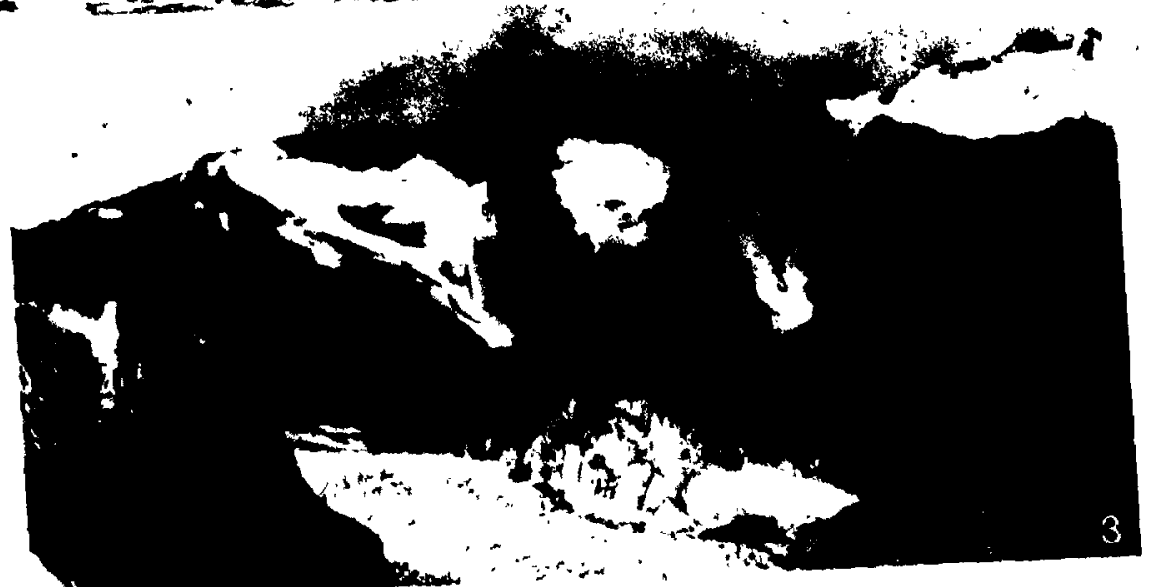


\%:

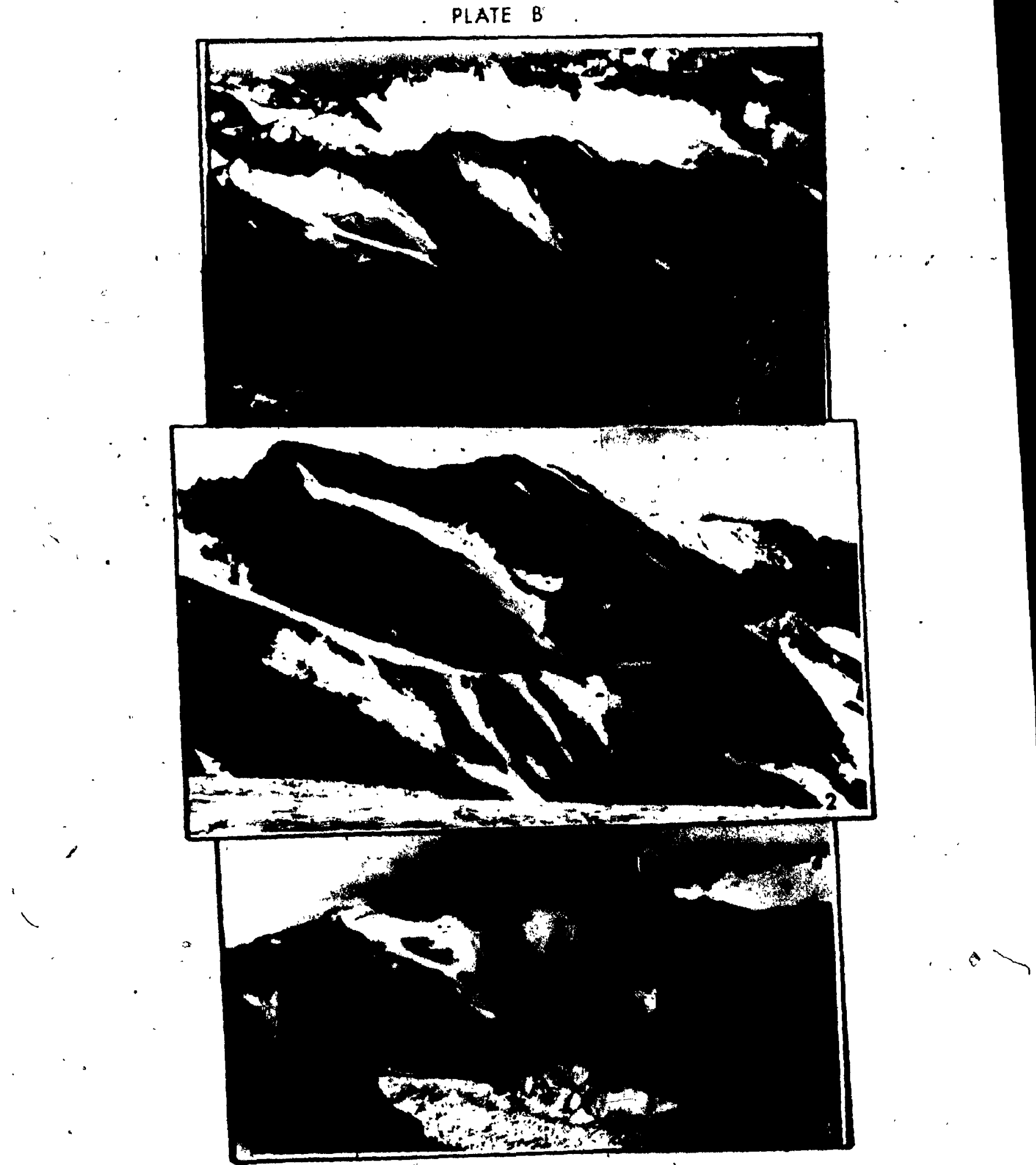


A panorama view of the east-southeast facing slopes of the Guardsman Peak ridge, total length of ridge shown is approximately $1.0 \mathrm{~km}$. The phase three folds are structurally located on the eastern Iimb of the Sir sandford syncline and on the western limb of the Gold River anticline. 


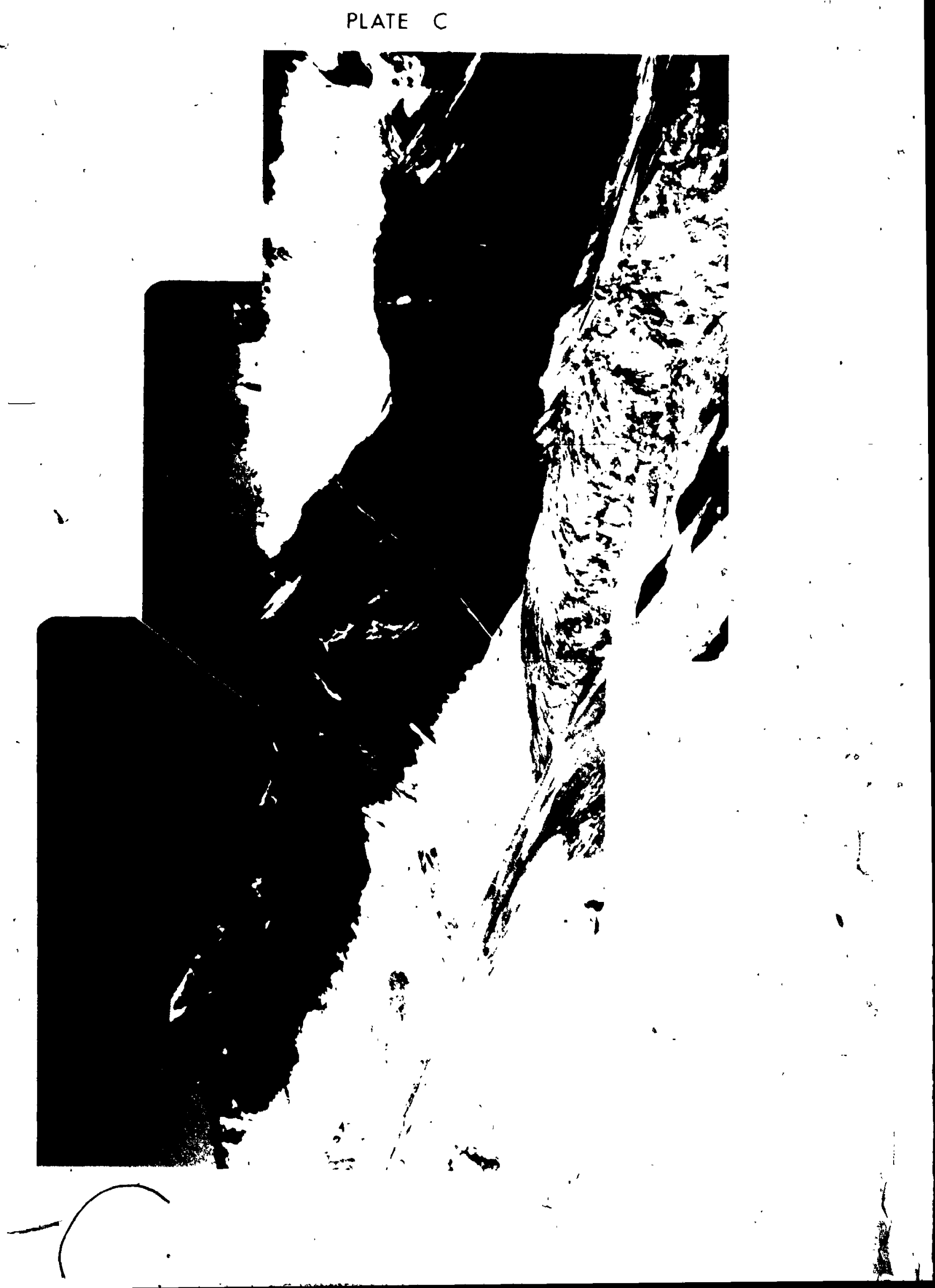




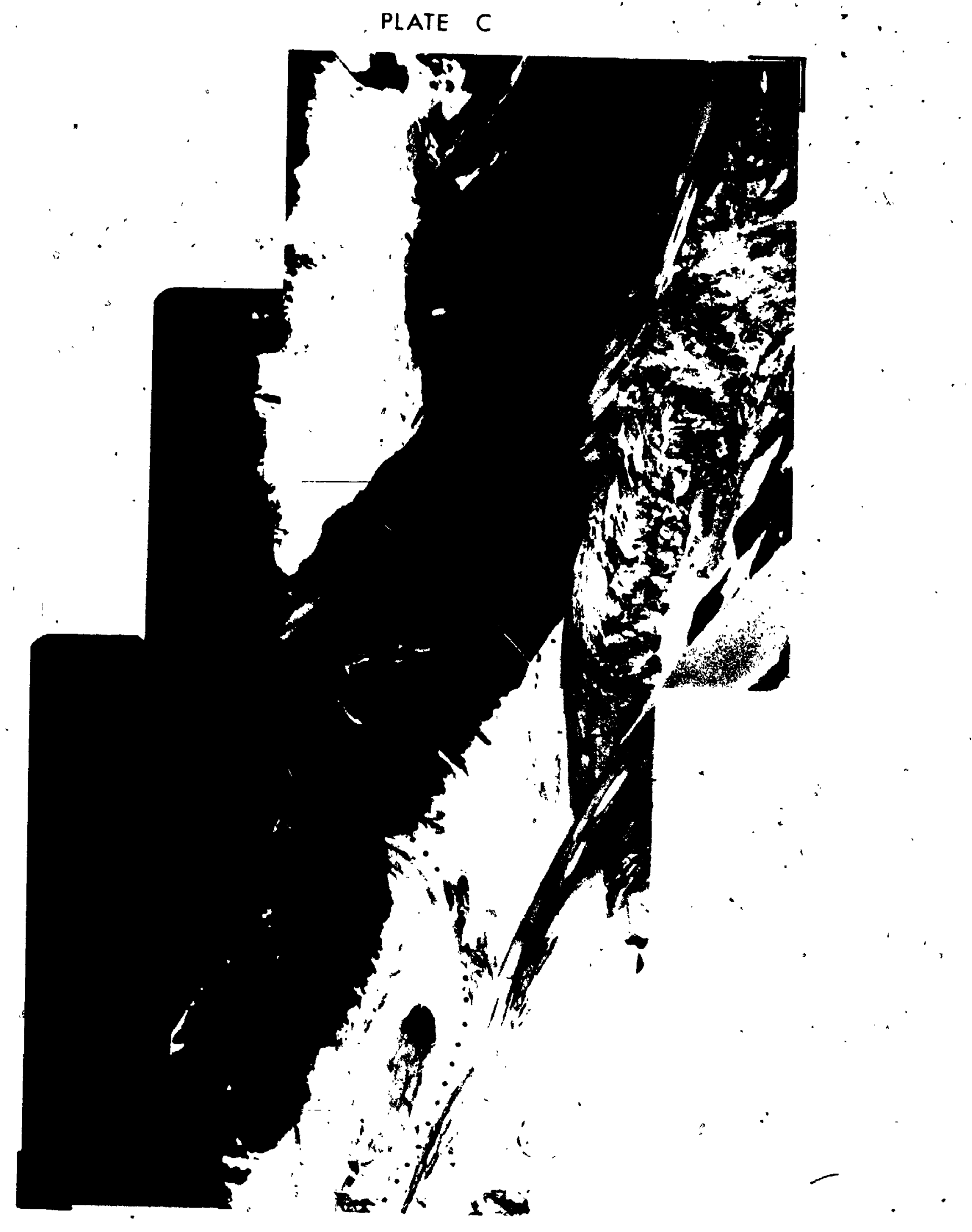


PLATE D

1. Looking southeasteriyothe Mount Sir sand ford syncline, outlined by the M.M.m. Wi th the U.P.M. In the core.

2. Station 132 viewed from the $135 t$. The summit area of Mount Enterprise is composed of W.M.M.m. Which outlines a type 3 interference pattern.

Trace of $S_{0}$ within M.M.m. shown by dotted line. 
Plate D
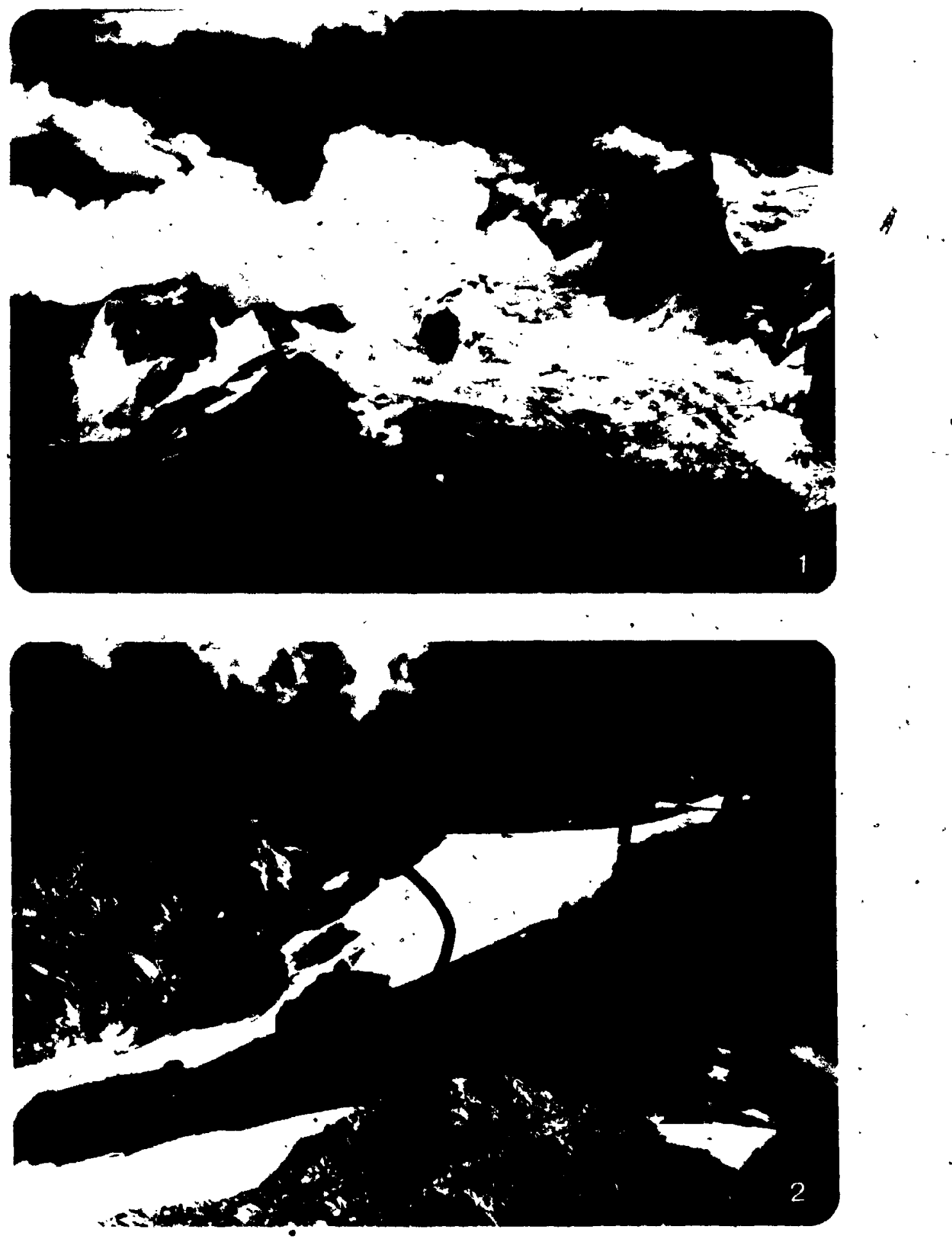


$$
\searrow \text { plate D }
$$


t

PLATE E

1

Amphibolitic lenses within unit $2 a$ of M.M.m. Adjacent to station 223 .

2. Boulder of coarse, quartzite pebble conglomerate, Unit - Ba' of U.P.m. (lens cap diameter $-54 \mathrm{~mm}$ ).

3.1 Quartzite grits, lasts of quartz, quartzite, and carbonate. Unit $3 a^{\prime \prime}$ of U.P.m.

- 4. Looking southeast towards core-zone of phase two Mount Sir. Sandford anticline. M.M.m. strata folded over L.P.m. strata. Station 008 .

8 

1

PLATE F.

1. Looking southeasterly at a flat lying, first phase fold with second phase folds superimposed upon the upper limb. Strata of L.P.m. Station 293.

2. Second phase minor fold in thinly interbedded marble with calc-rich pelite. Fold shows characteristic necked hinge. Station 337.

3. Second phase fold, outlined by a semi-pelite layer, within rigmatitic pelite that is strongly crenulated by phase three deformation. Strata of the U.P.m. Station 385 .

4. Third phase crenulation in migmatitic pelite, $s_{2}$ stromily folded by $D_{3}$ activity. Strata of L.P.m. Station. 330. 

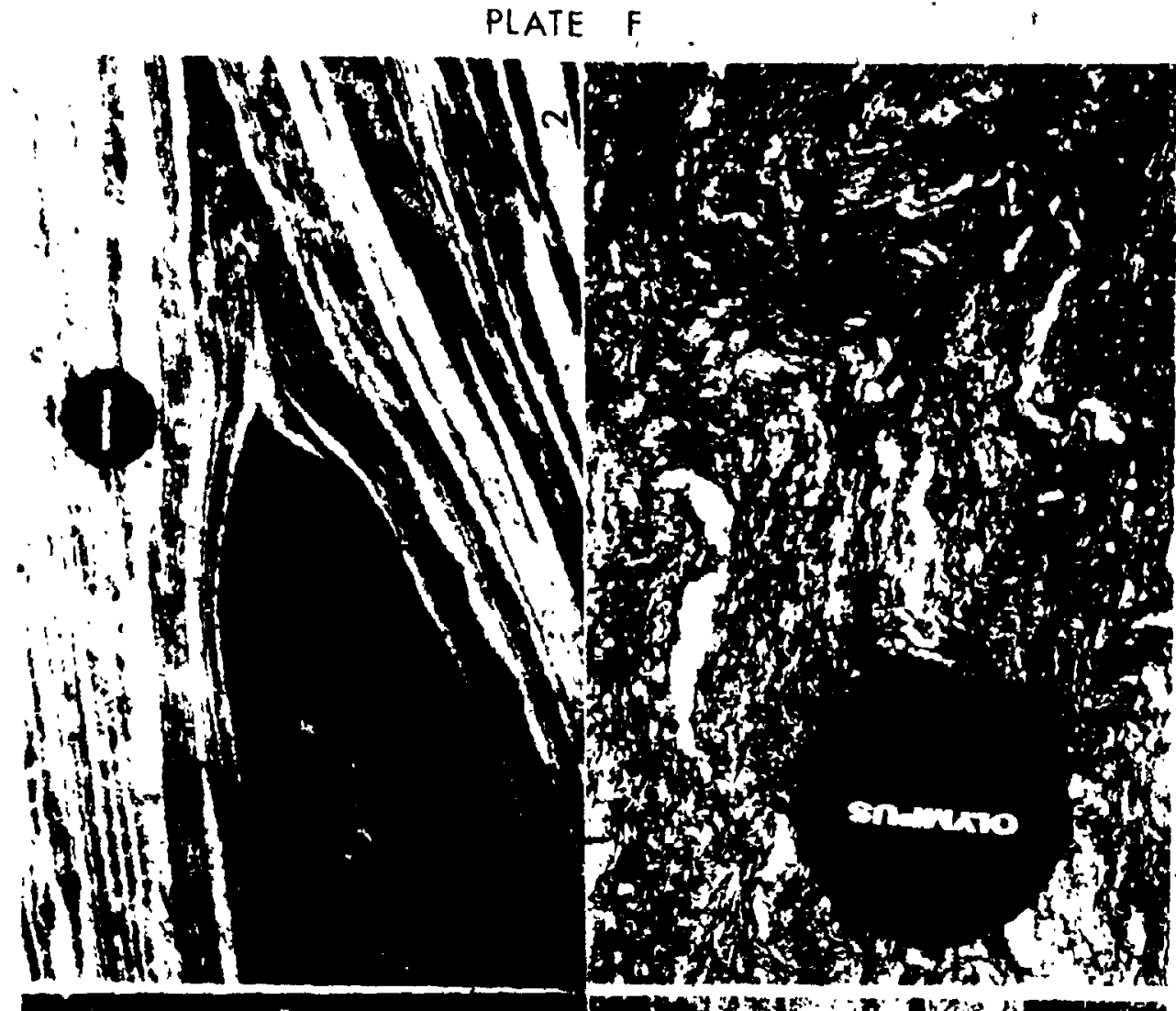

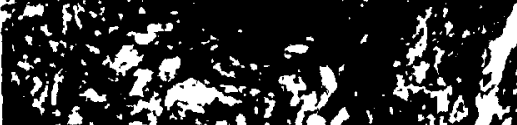

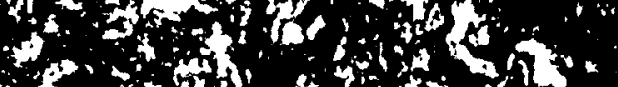
fistond (f)

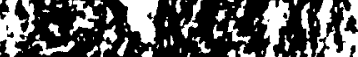

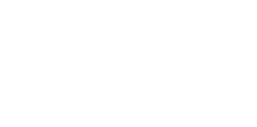

$\infty$
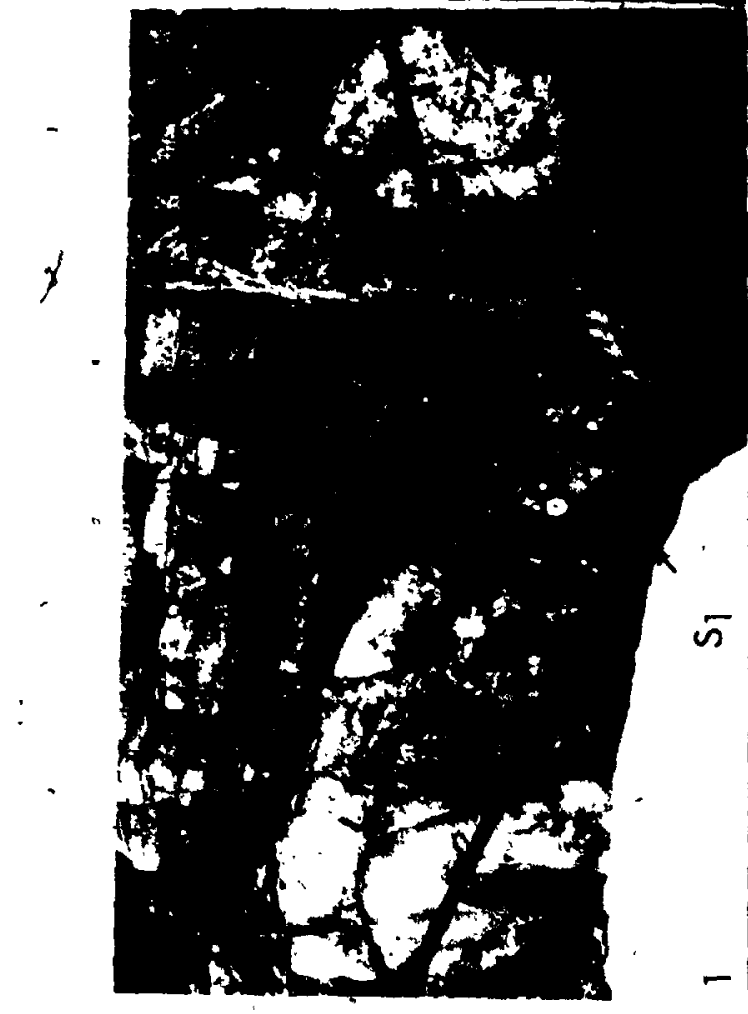

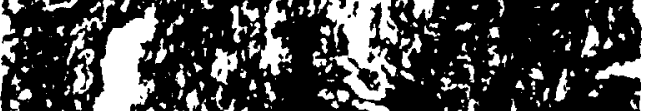

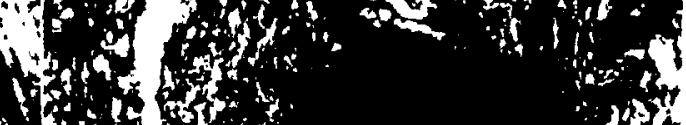
mis

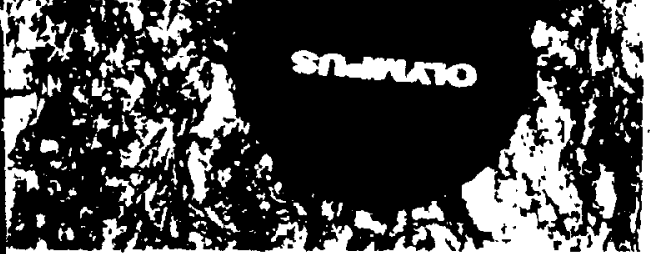

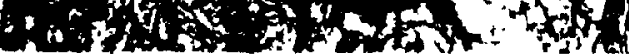

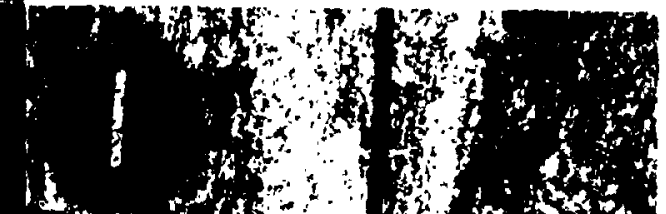

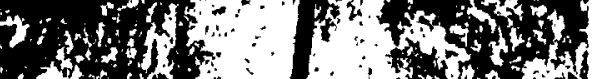
(4)

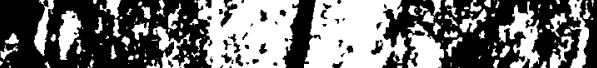

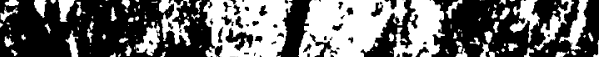
4hts

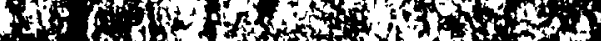

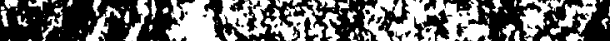

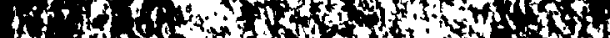
o hat

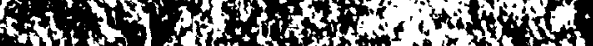

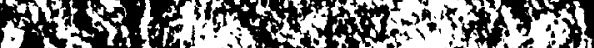

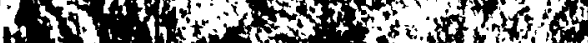

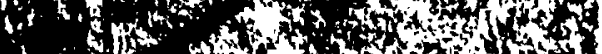
1. $x^{2}$ ? $\rightarrow-4)$ t

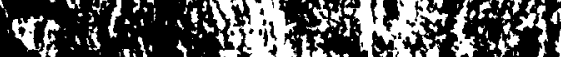

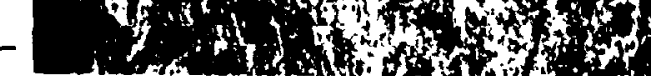


1.

Phase two folds showing characteristic necking in hinge zone; a stronqly developed. mica planar fabric orientated parallel to the axial surfaces of the phase two folds. Some phase three crenulation visible of U.P.m. strata. Station 115 .

2. Close-up of above.

3. Shearing parallel to $s_{2}$ seen in more competent layer within interbedded rusty marble, pure marble and dolomitic marble sequence. Sequence at top of the L.P.m., Im below .lower contact of Unit $2 a$ of the M.M.m. Station 063 .

4. Phase three fold outlined by carbonate conglomerate horizon within Unit $2 b$ of M.M.m. Elongated carbonate clasts orientated parallel to $s_{2}$ and are folded over hinge zone of the phase three fold." Station 354: 
Plate G

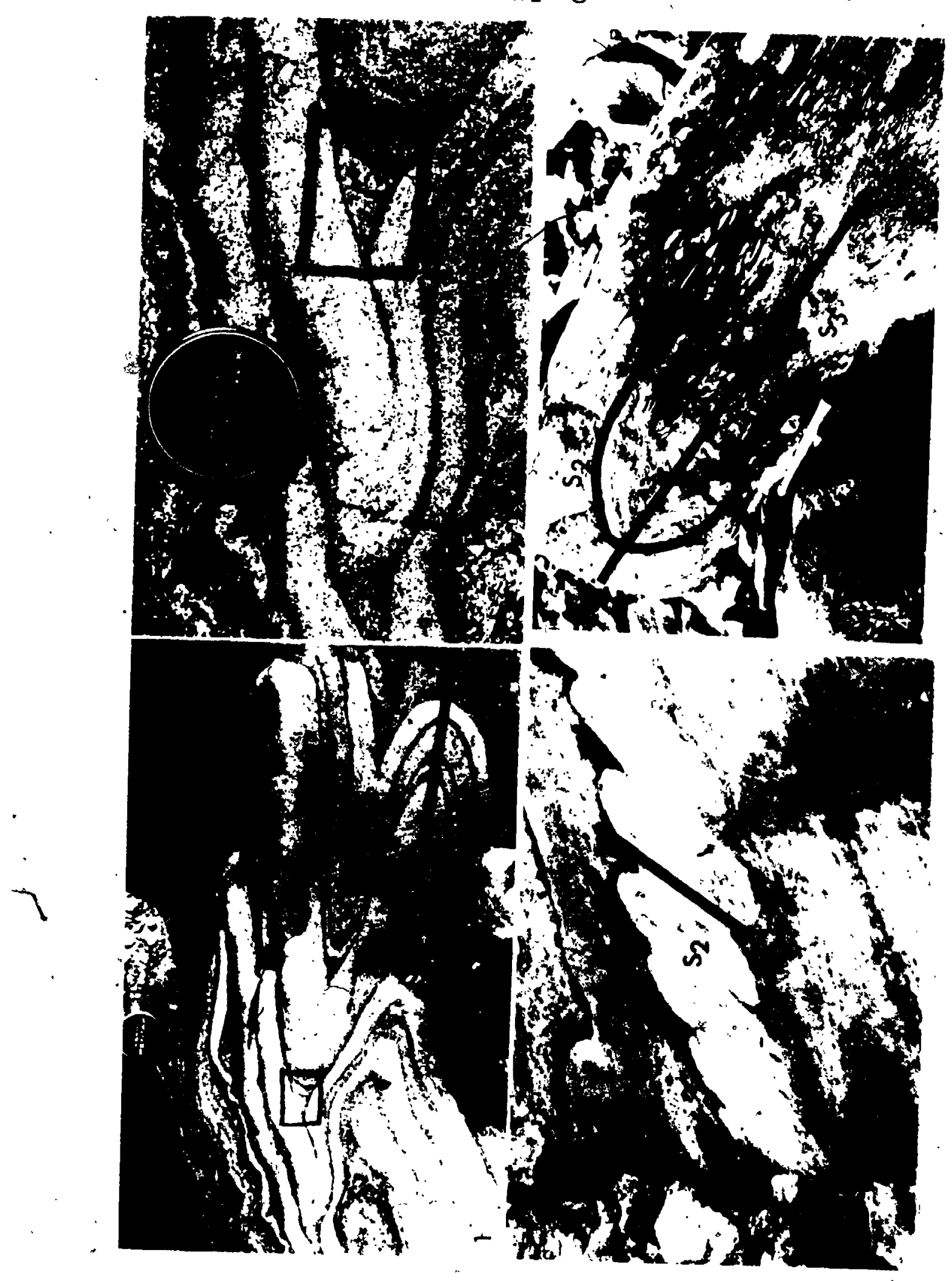


PLATE H,

1. Second phase folds on the limb of a phase three anticline. Unit $2 b$ of the M.M.m. Station 353 .

2. Type 3 interference pattern outlined by a concordant amphibolite layer in the U.P.m. Station 395

3. Unit $2 a$ of the M.M.m. veneering the Mount Sir Sanford massif. Viewed from the northwest, Sir sanford. glacier in the middle ground.

6.

2 
plate $\mathrm{H}$

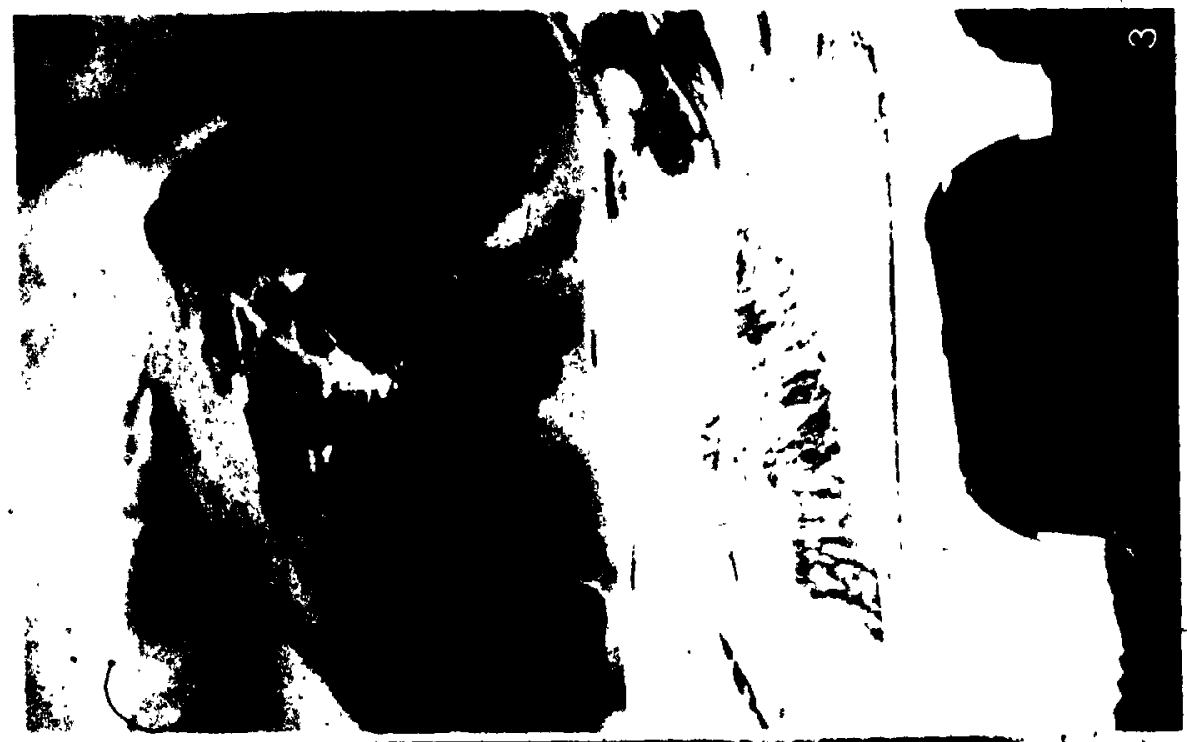

B

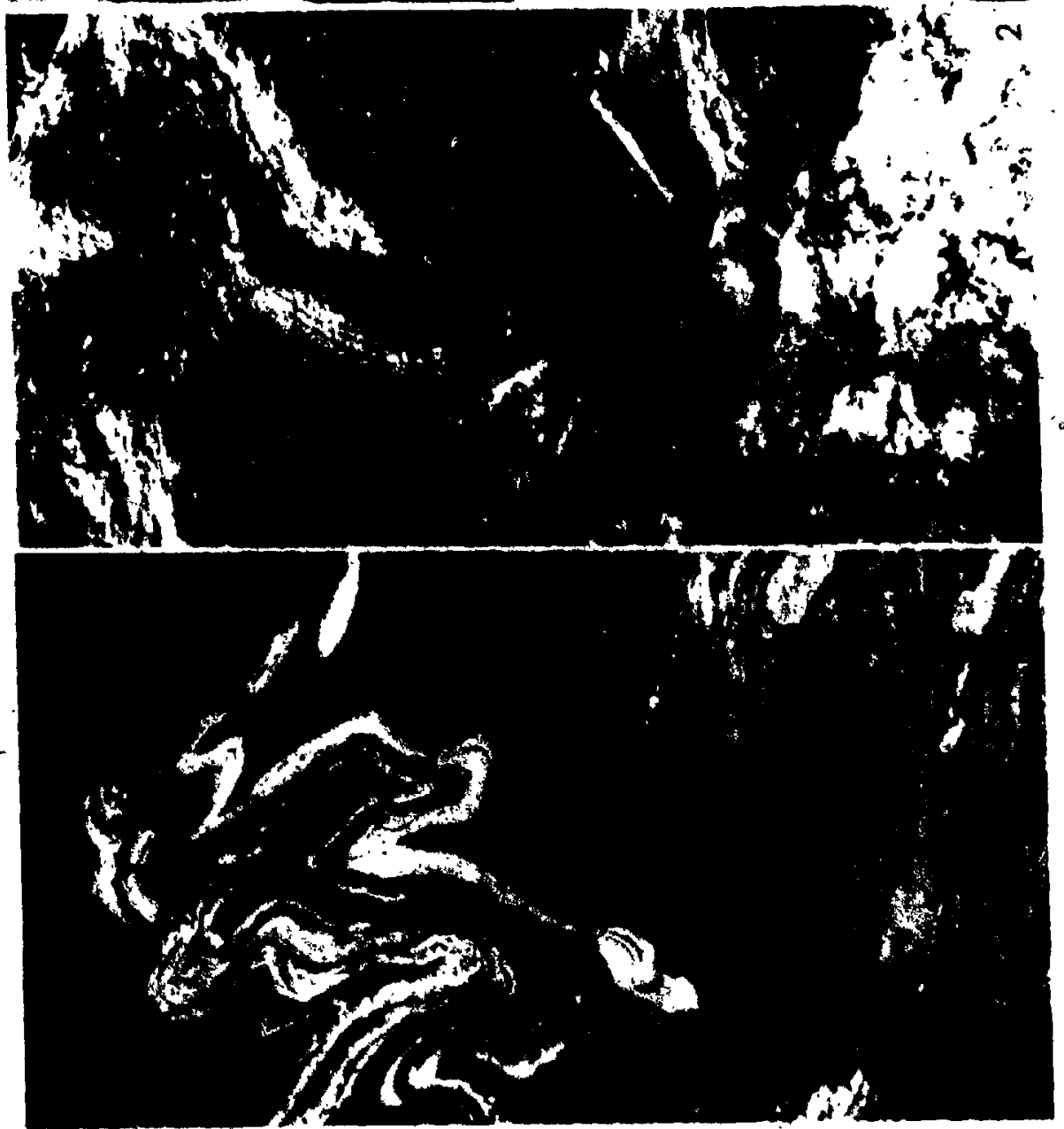

כ

a 
PLATE I

1. Phase two minor folds developedoin thinly layered al ternating bands of marble and "dirty" marble, upper "part of Unit $2 b$ of the M.M.m. Adjacent to Station 068.

2. Type 3 interference pattern developed in petites of the U.P.m. Station 047 .

3. A strongly developed phase three crenulation lineation at a high angle to $s_{2}$.

4. Phase four crenulation lineation developed in very mica-rich pelite, U.P.m. Adjacent Station 11 . 
PLATE I
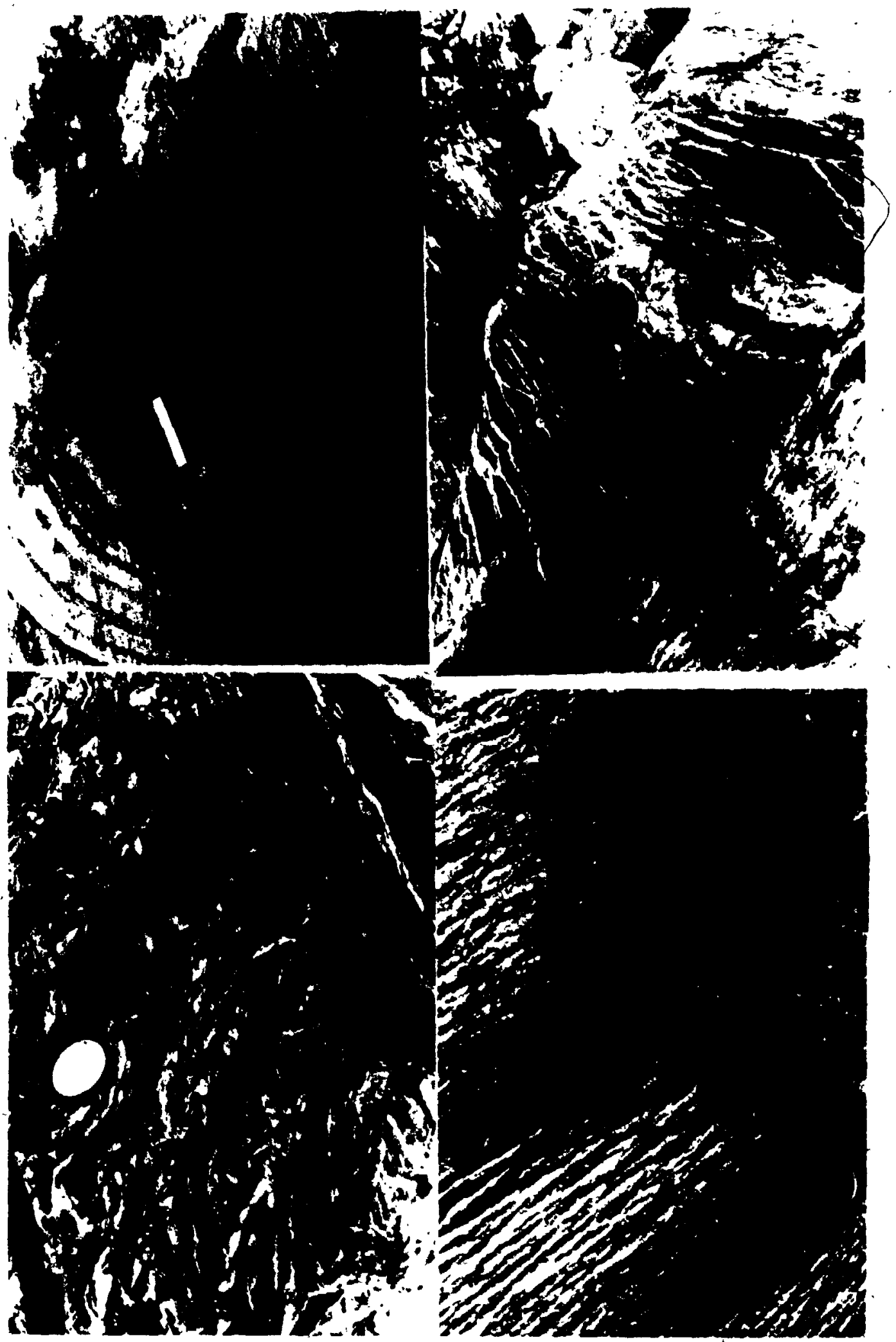


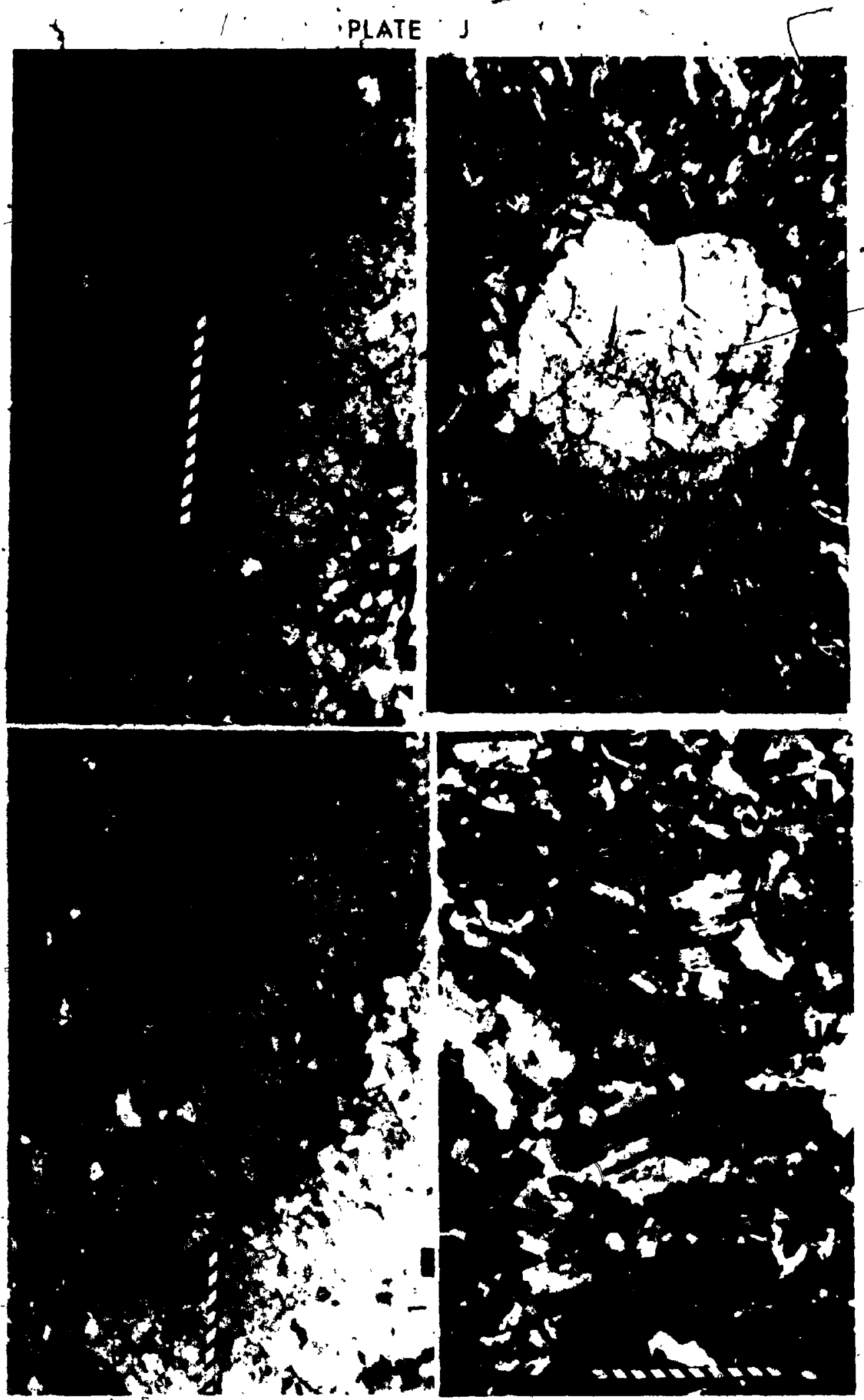
PLATE $K$.

1. Kyanite (some, grains identified by arrows) parallel to $\mathrm{S}_{2}$; posts 2 and $\mathrm{Pre}_{3}-\mathrm{D}_{3}$ growth. Station 430 .

2. Sillimanite (fibrolite), kyanite, fir net, biotite and quartz. Station 288 .

3. $D_{3}$ crenulation cleavage ( $S_{3}$ parállel to striped I line) produced by deformation of $\mathrm{S}_{2}$. station 194 :

4. Hinge, zone of $D_{3}$ crenulation showing formation of alternating quartz-rich and mica-rich layers $\left(. S_{3}\right.$ parallel to striped'linel. Station 394. 


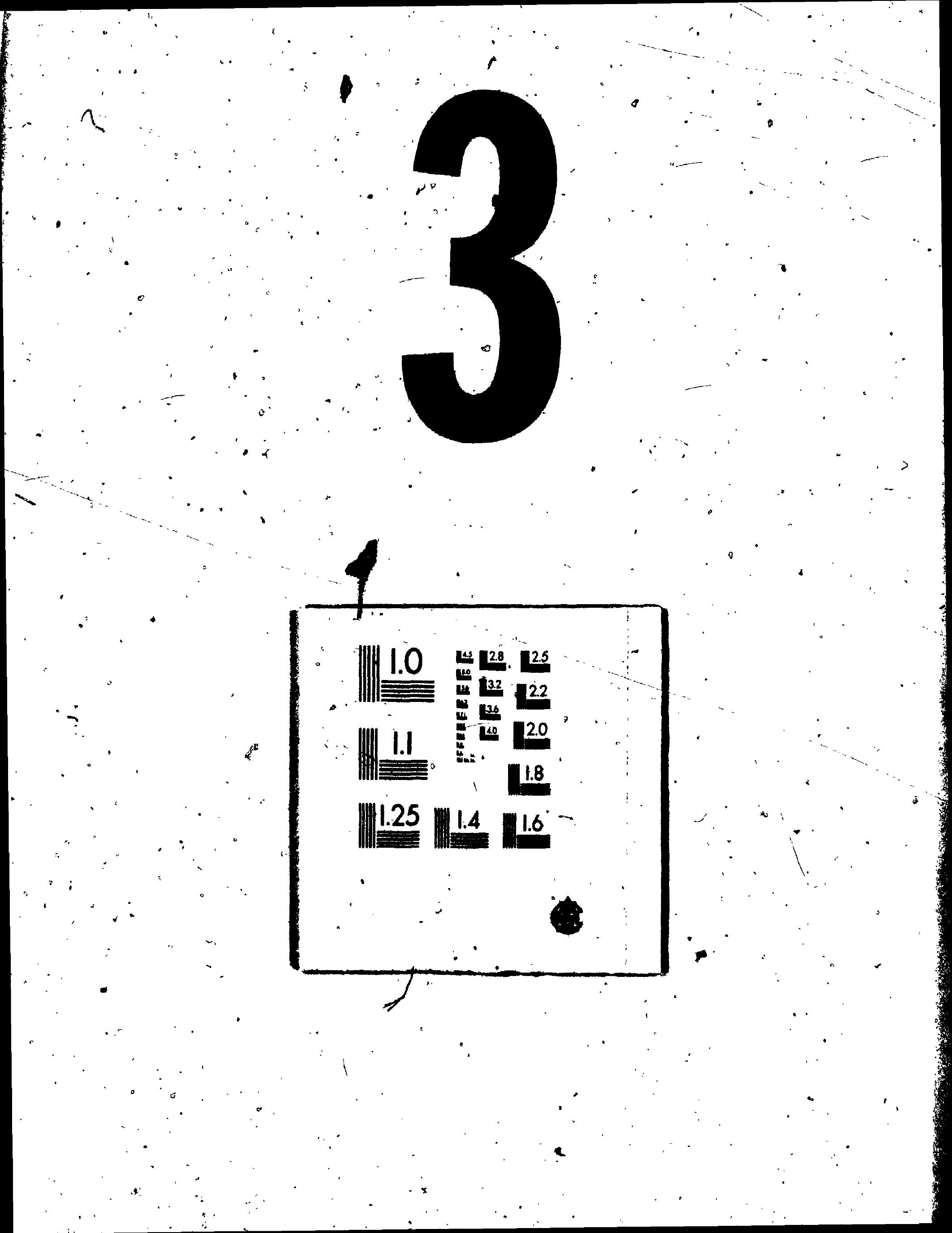


PLATE L

1. Garnet, with straight inclusion trails of quartz a overgrew a straight, $s_{2}$ prior to onset of D3. $s_{1}=s_{e}$ Station

2 .

Garnet, with straight inclusionitrails of quartz, overgrew a straight $\mathrm{S}_{2}$ prior to onset of D3. During D3 the porphyroblast was rotated ar the fabric in the matrix was crenulated. $s_{1} \neq S_{e}$. Station 424 .

3. Garnet porphyroblast with curved inclusion trails of quartz. Growth occurred during initial part of D3, a mildly crenulated $s_{2}$ was overgrown by the garnet. After cessation of garnet growth $S_{2}$ in the groundmass was strongly crenulated. Station 429 . 


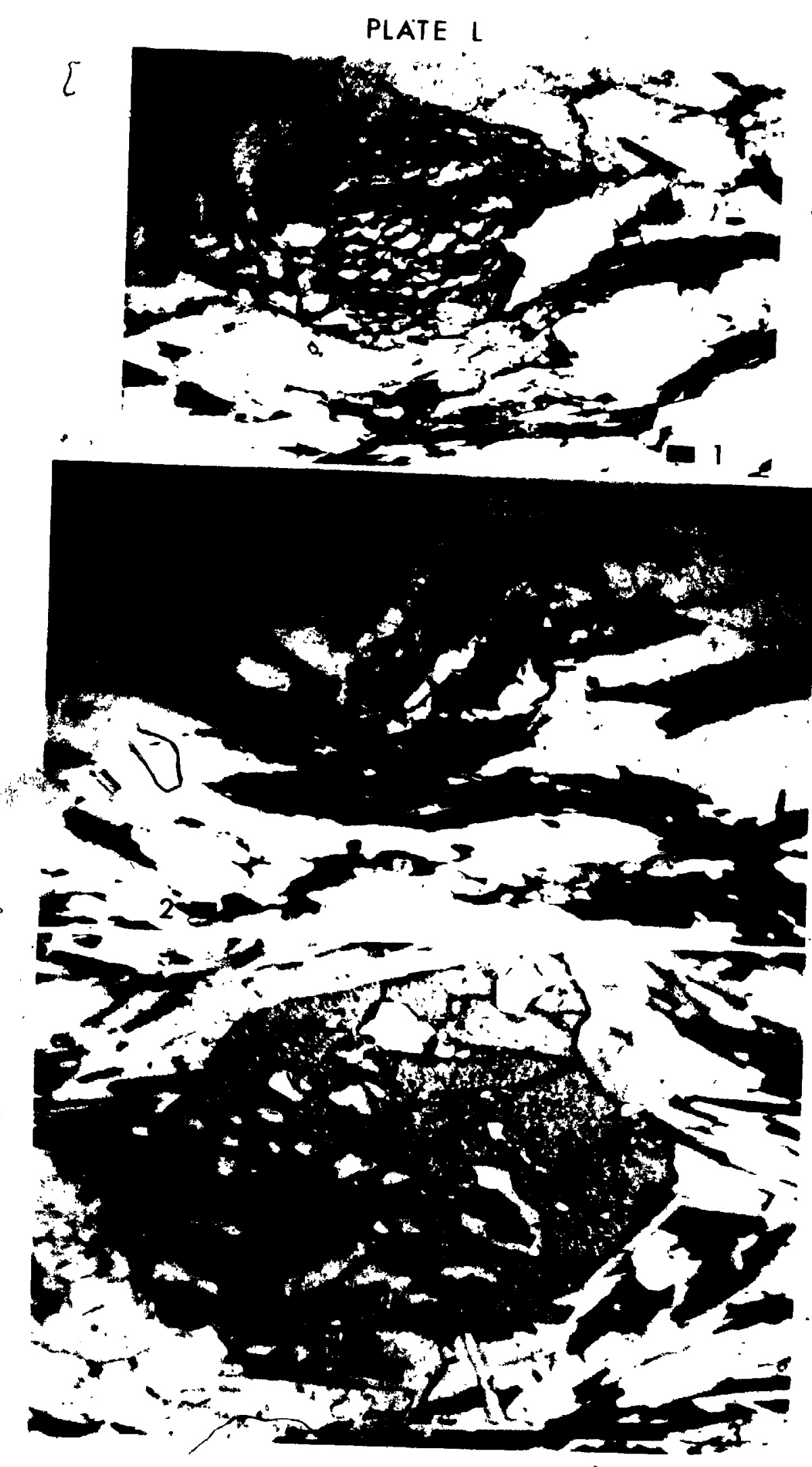


PLATE .M

1 .

Biotite orientated parallel to $s_{2}$ (striped line)

marking a high angle with $S$ o defined by contact between quartz-rich layer and amphibole-rich layer. Station 429.

2 . Faintly curved inclusion trail in staurolite grain, $\mathrm{S}_{2}$ strongly deflected around porphyroblast. Staurolite growth occurred at a very early stage of D3, overgrew a very weakly crenulated $S_{2}$ ( $S_{2}$ parallel to. striped 1 ines). Station 99 .

3. Muscovite, orientated parallel to $S_{2}$, crenulated by F3. Garnet, with straight inclusion trails, overgrew S2 prior to onset of $D 3$. Station 191 .

4. Large prophyroblast of biotite, overgrew a straight $S_{2}$ prior to onset of $D_{3}$. $S_{2}$ in groundmass strongly crenulated around porphyroblast. Station. 191. 
Plate M

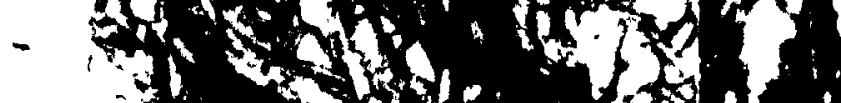

ins

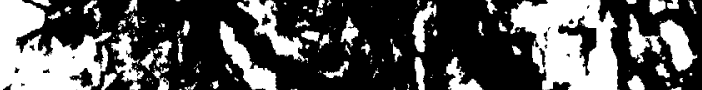

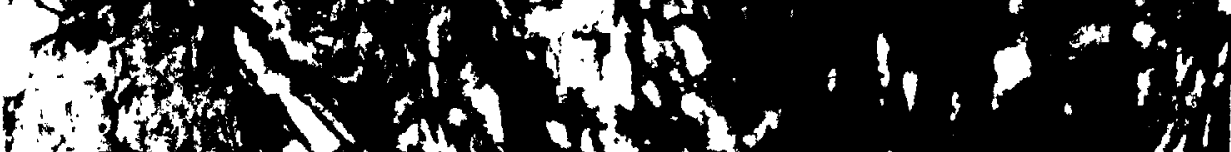

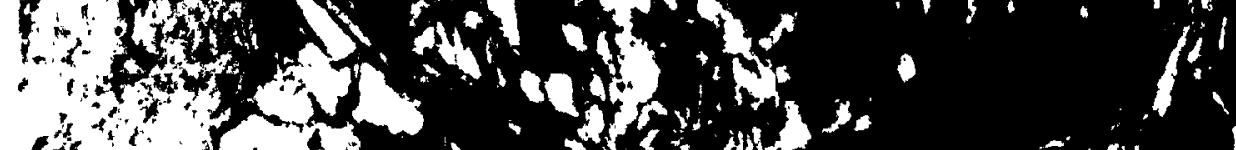

(4), (4)

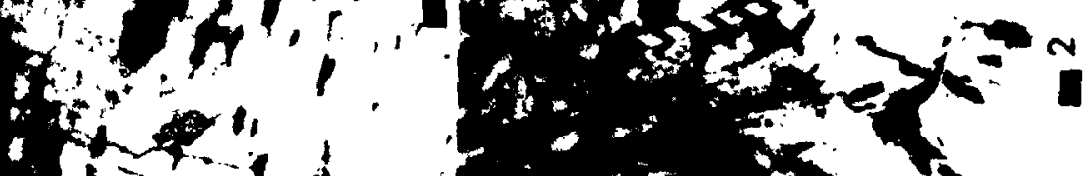
(n)

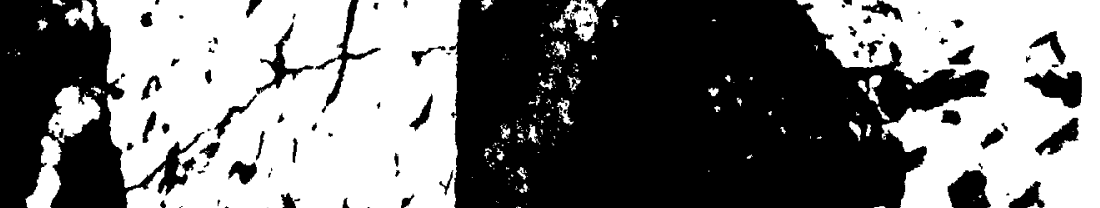

$4+1,4+19$

* af $\div$

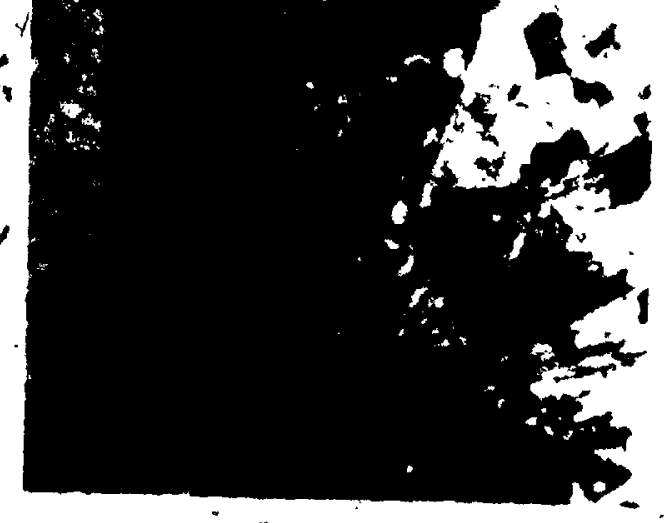


lof

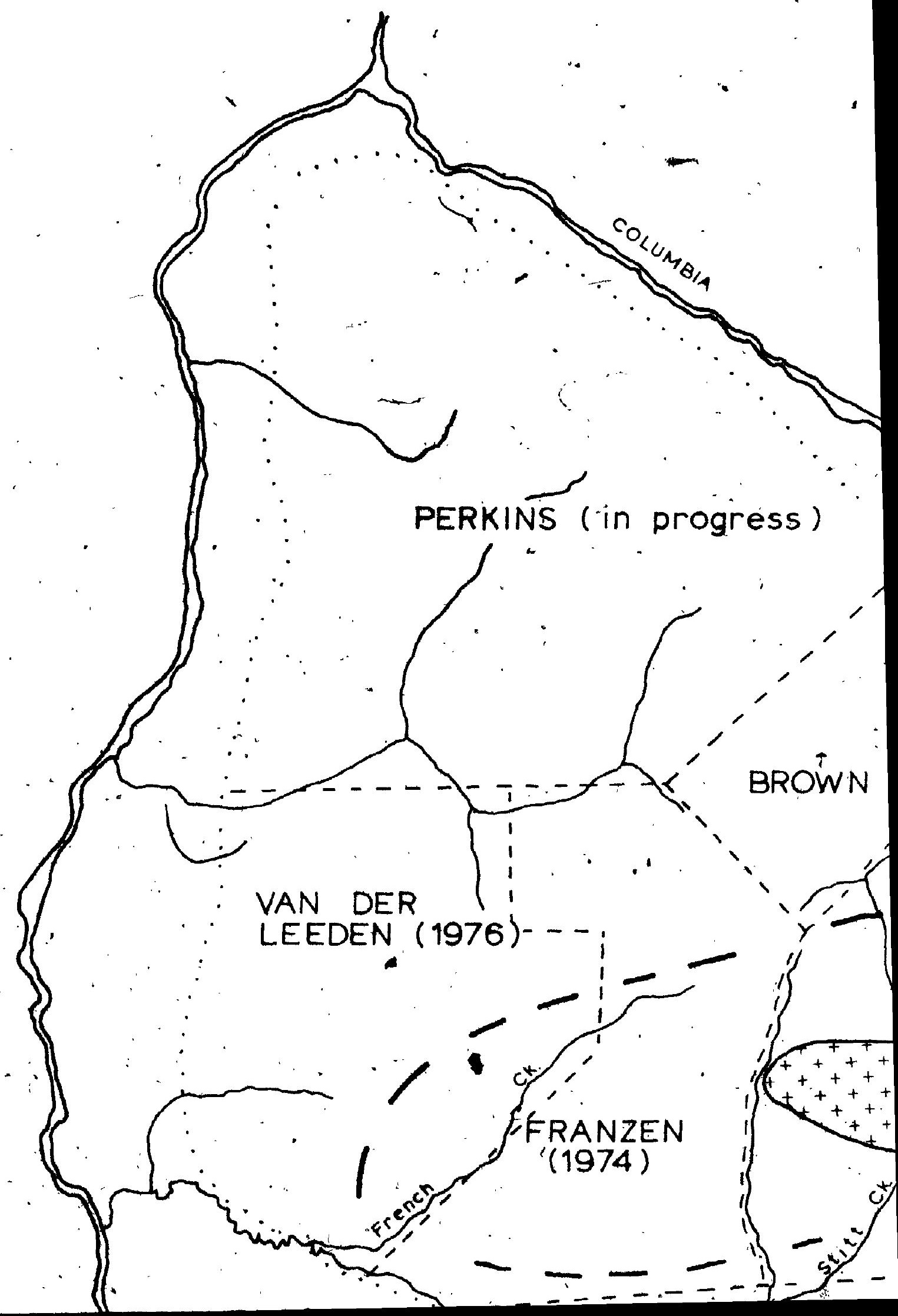



primate boundary of area mapped

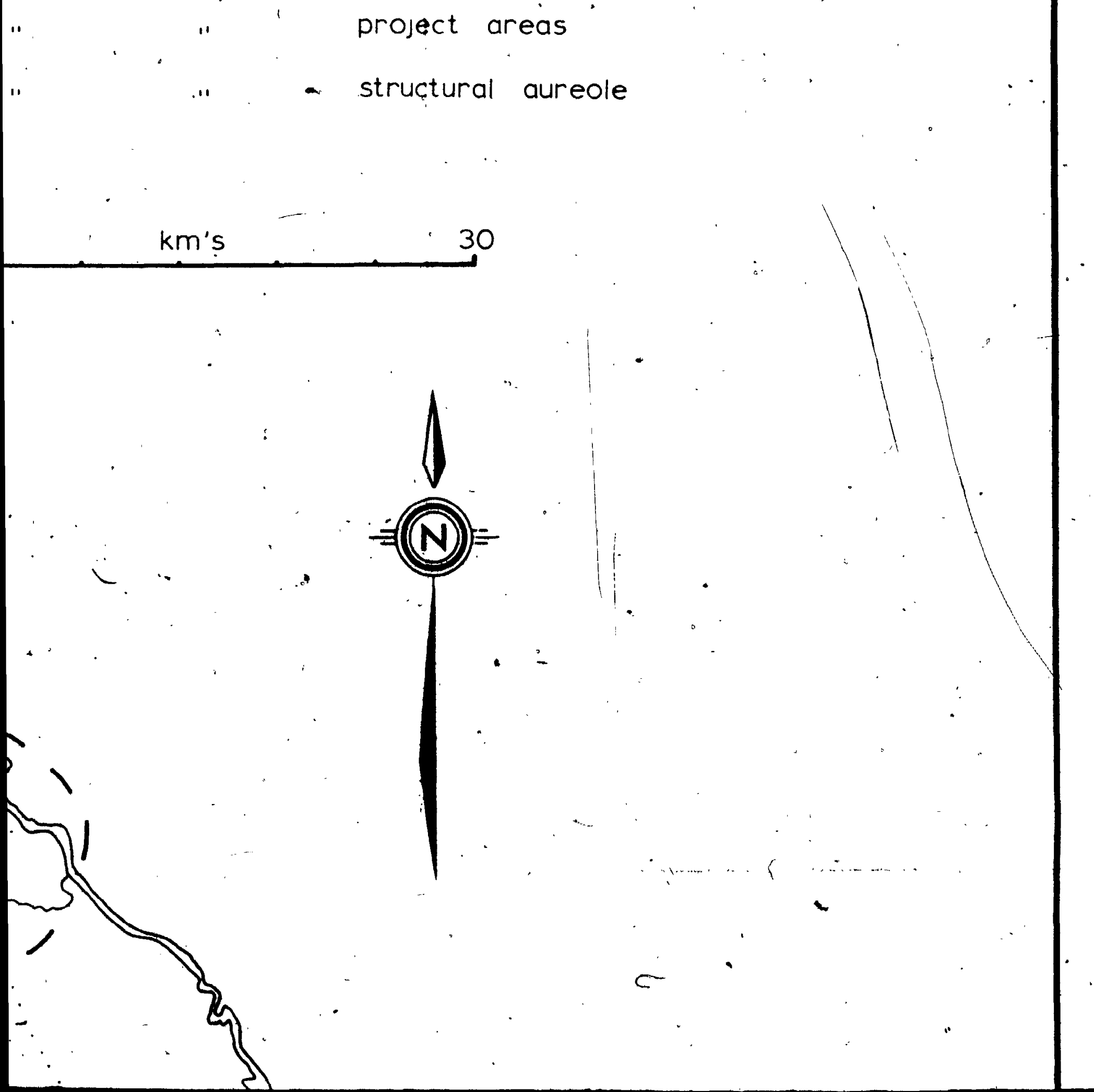




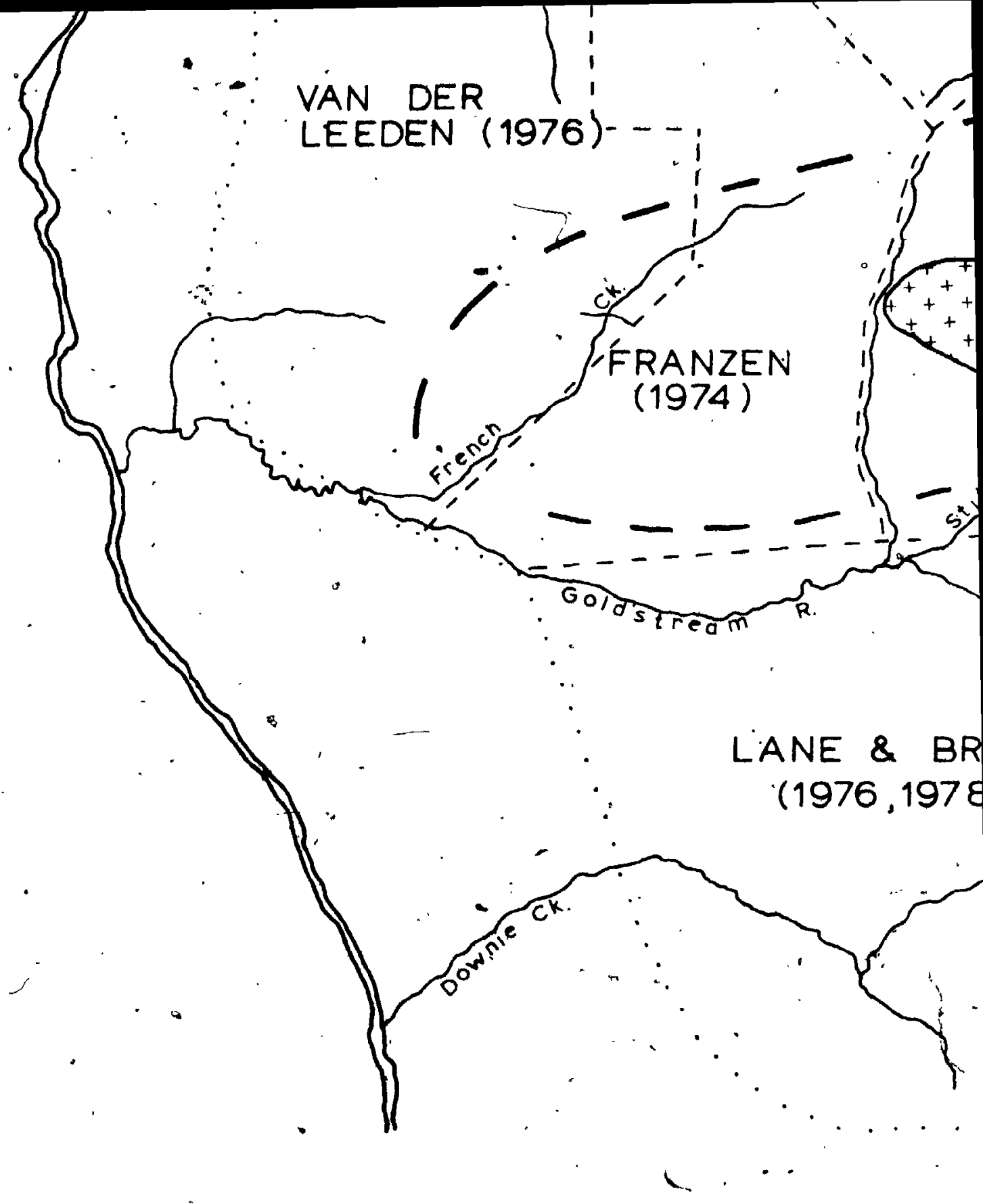





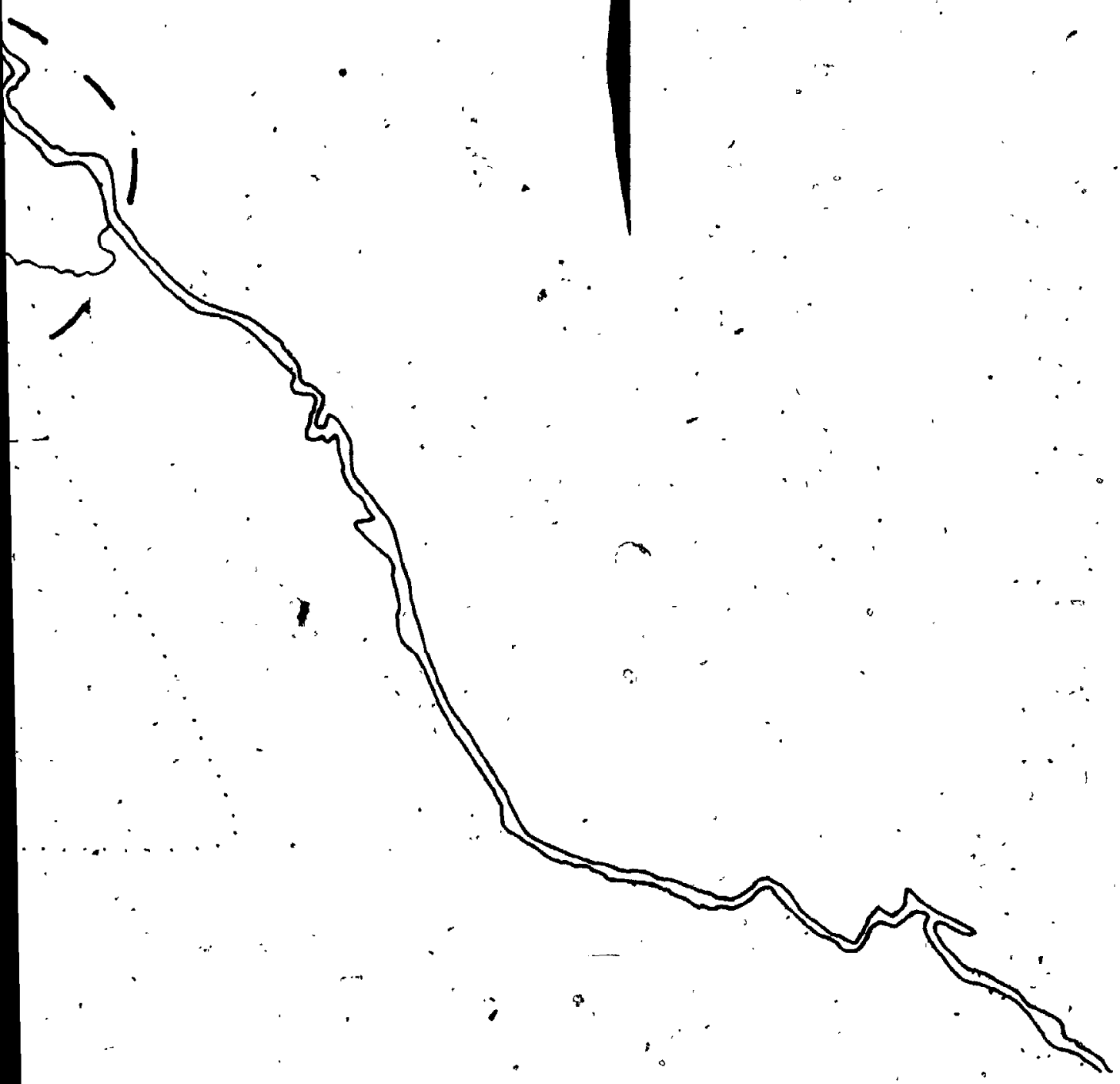






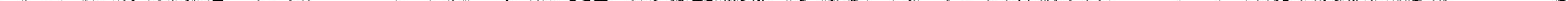


$40 f$

$117^{\circ} 45^{\circ}$

7

FIg. 5. MAJOR PEAKS WITHIN \& ADJACENT

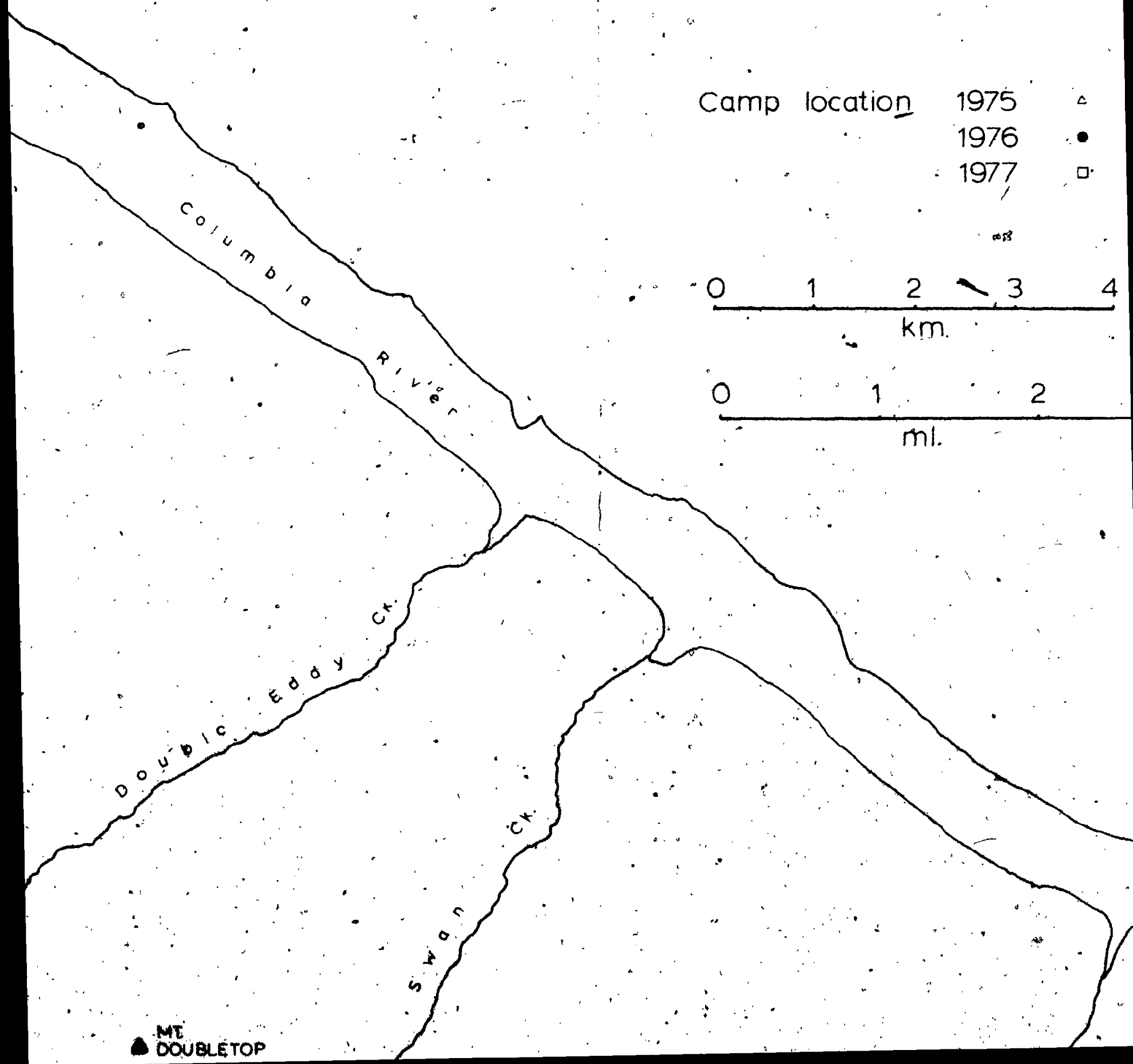




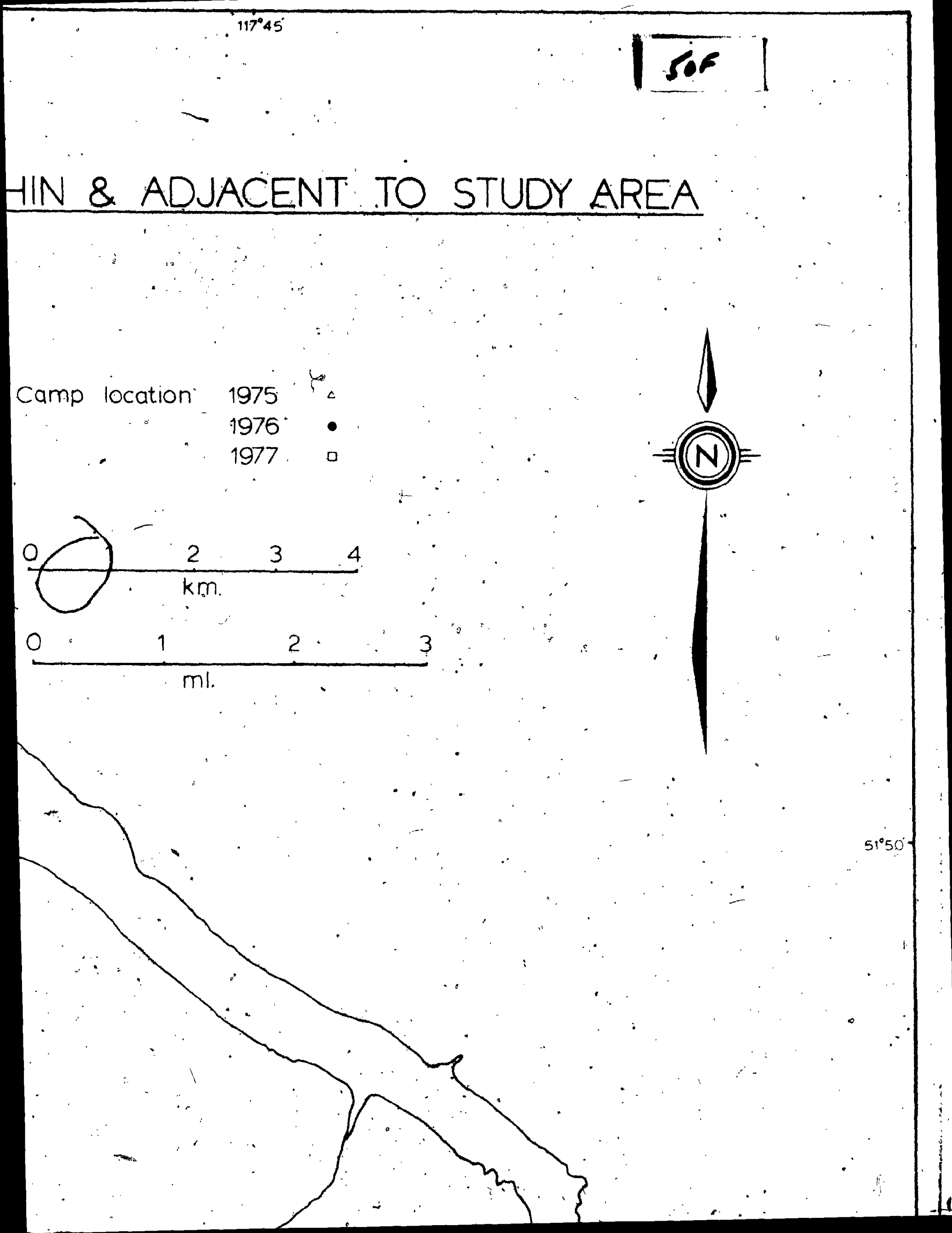




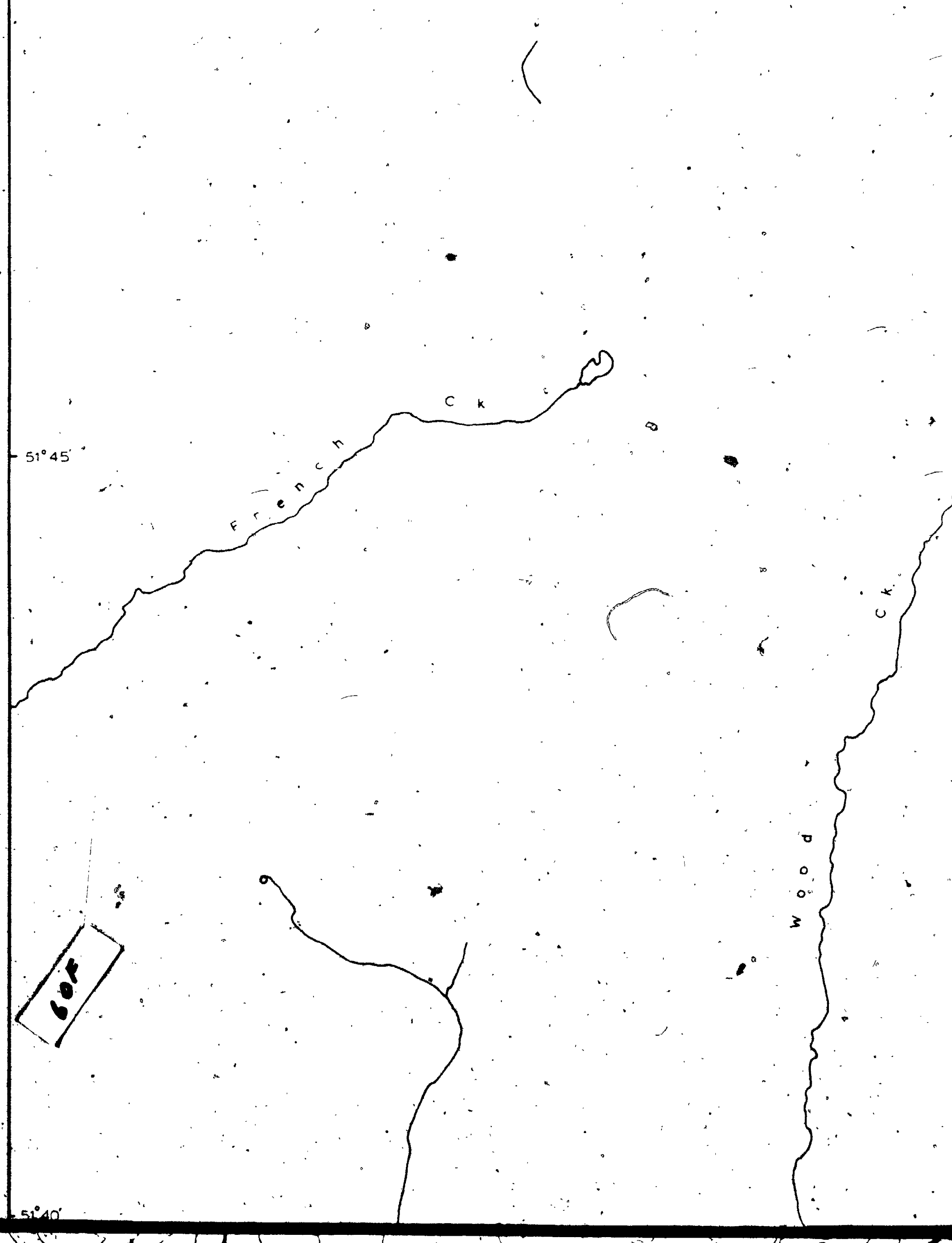




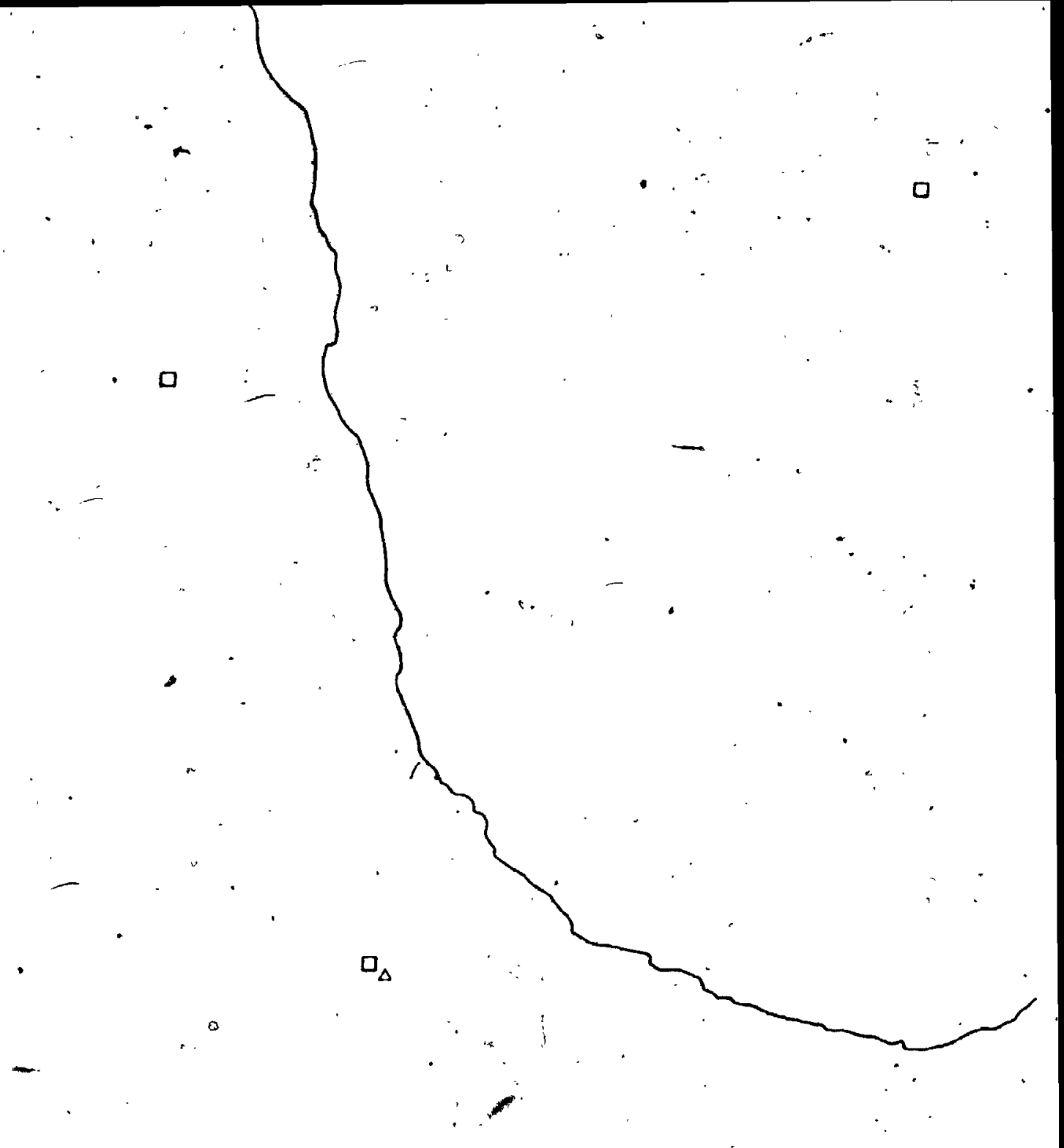




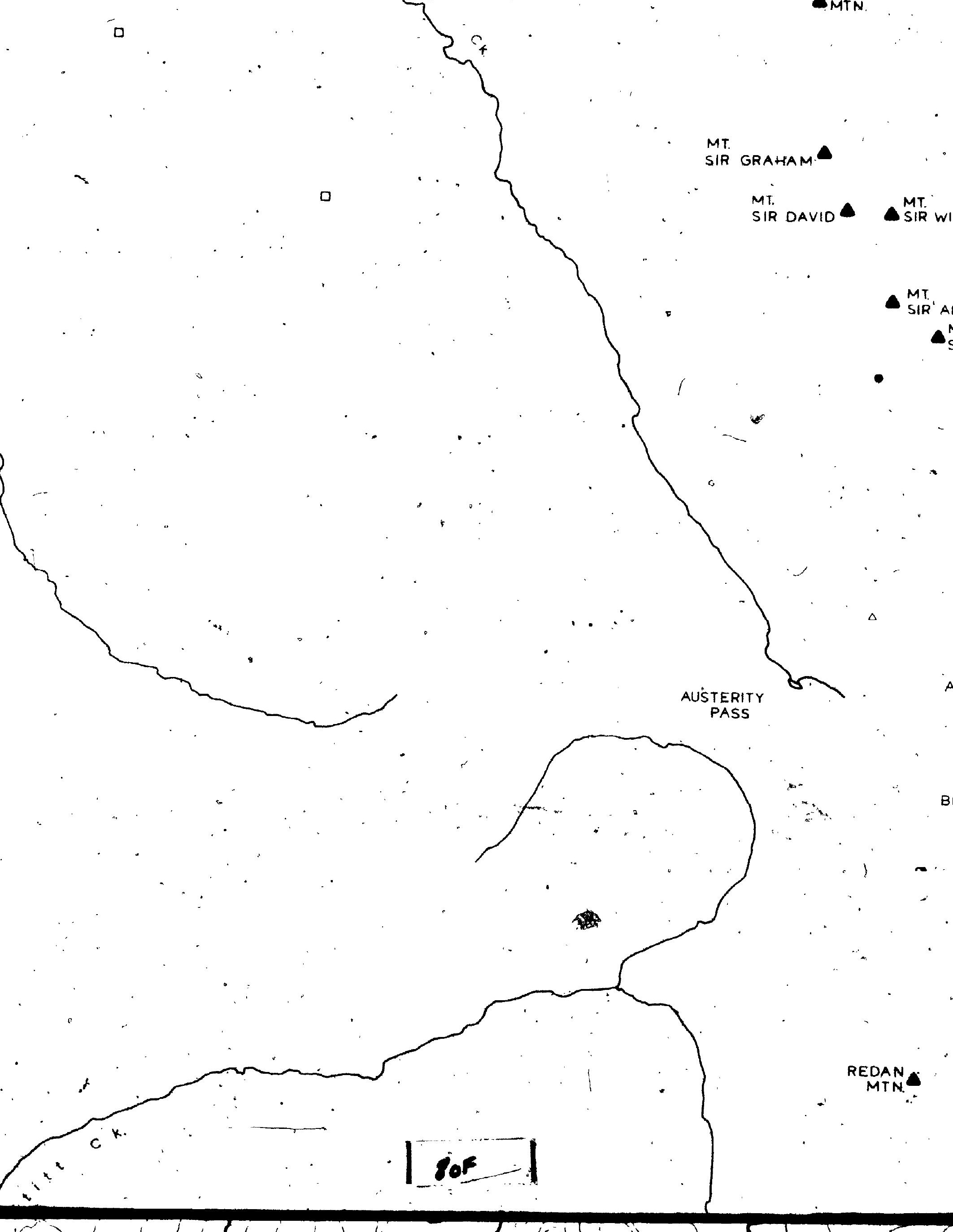




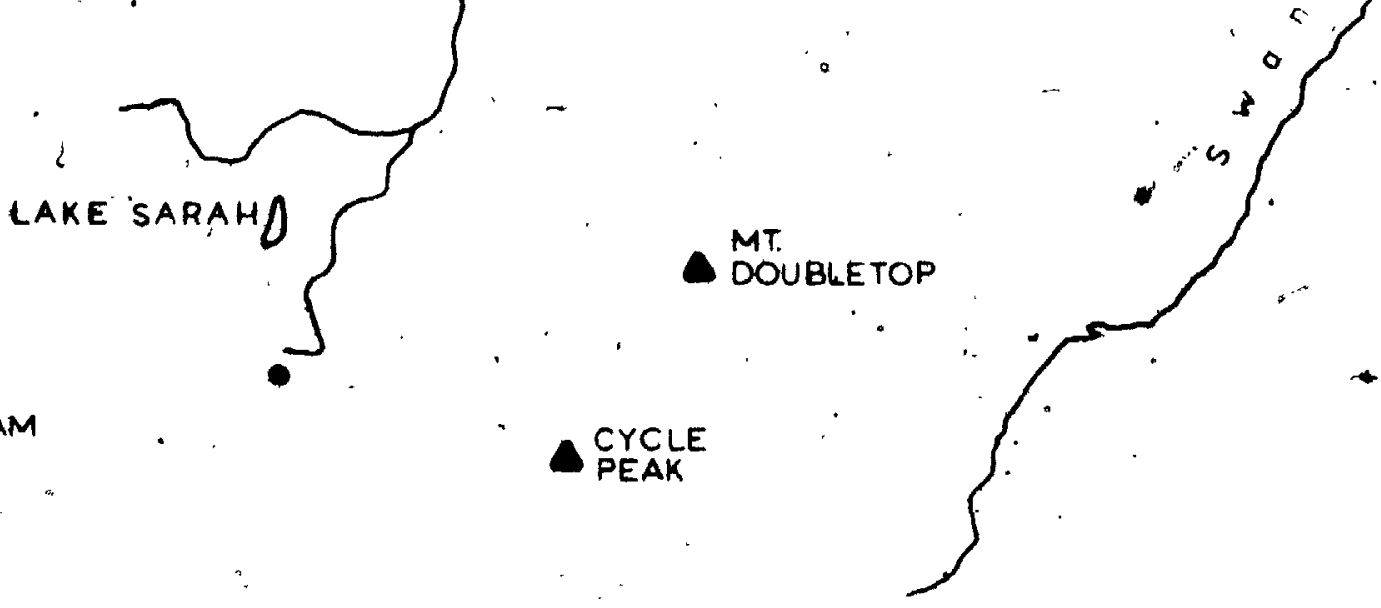

MT. SIR ANDREW

, A MIR HENRY

- $\triangle$ MT. ENTERPRISE

MT. COLOSSAL

QUADRANT MIN.

$\triangle$ HOUDINI NEEDLES

$\Delta$.

UNICORN

SENTINEL

MIN.

PEAK

- THE IRONMAN AUSTERITY MIN.

PIONEER 'PK.

TURRET PK.

ADAMANT MIN.

$\triangle$ GHERGOYLÉ

GIBRALTER PK.

- BLACKFRIARS PK.

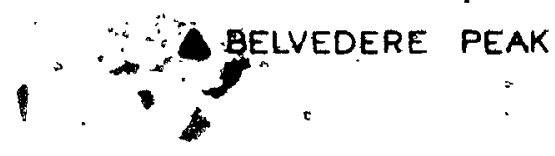

YGDRASIL MIN.

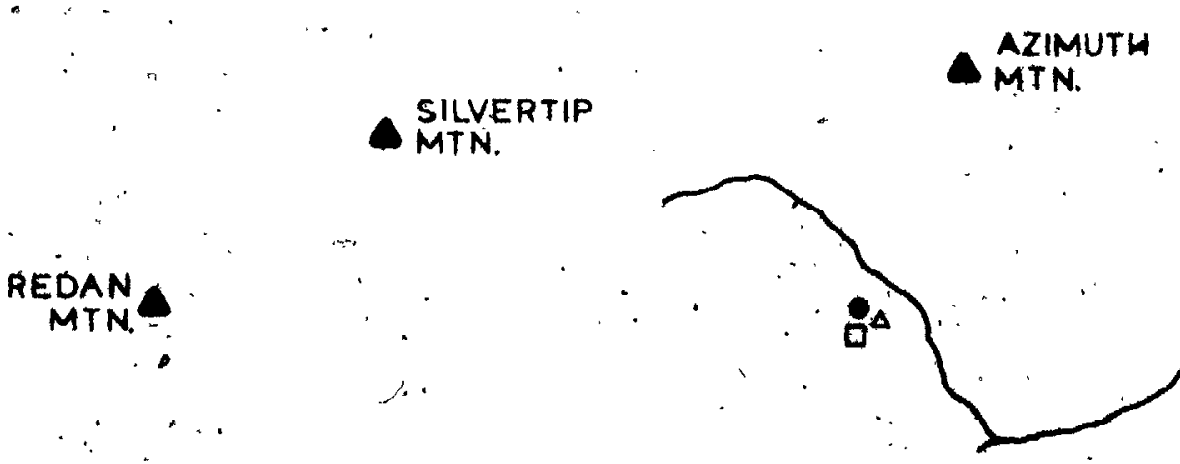




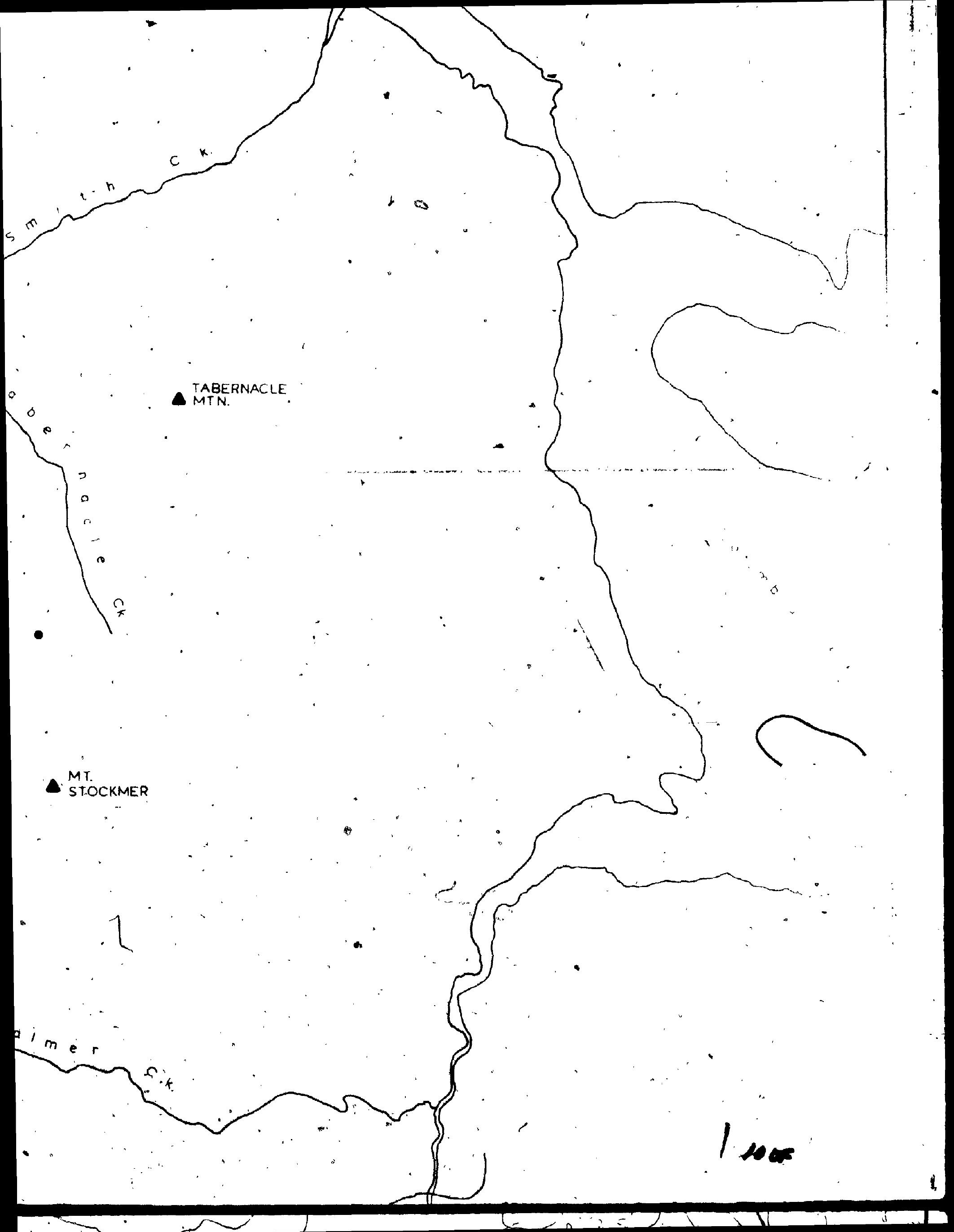




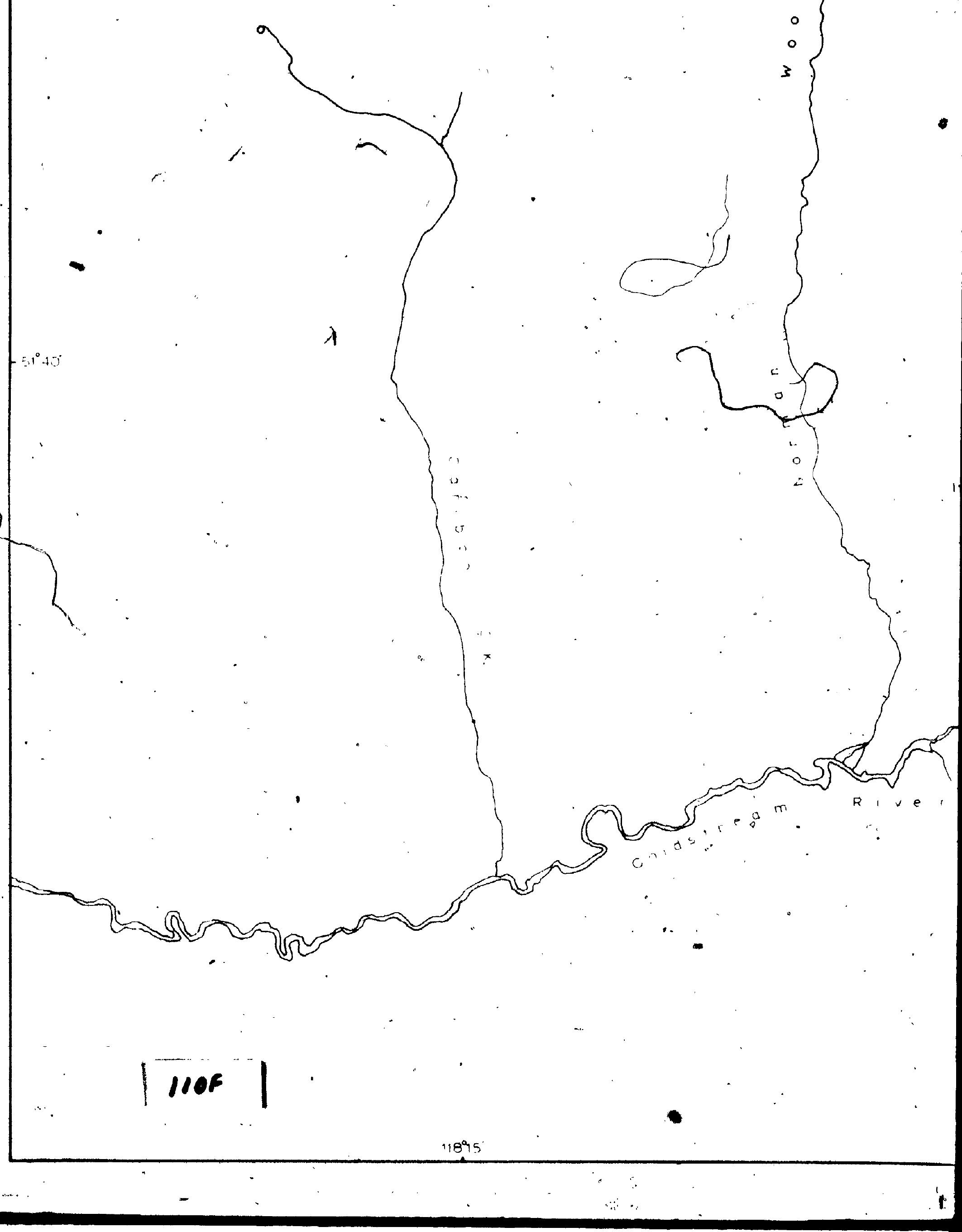




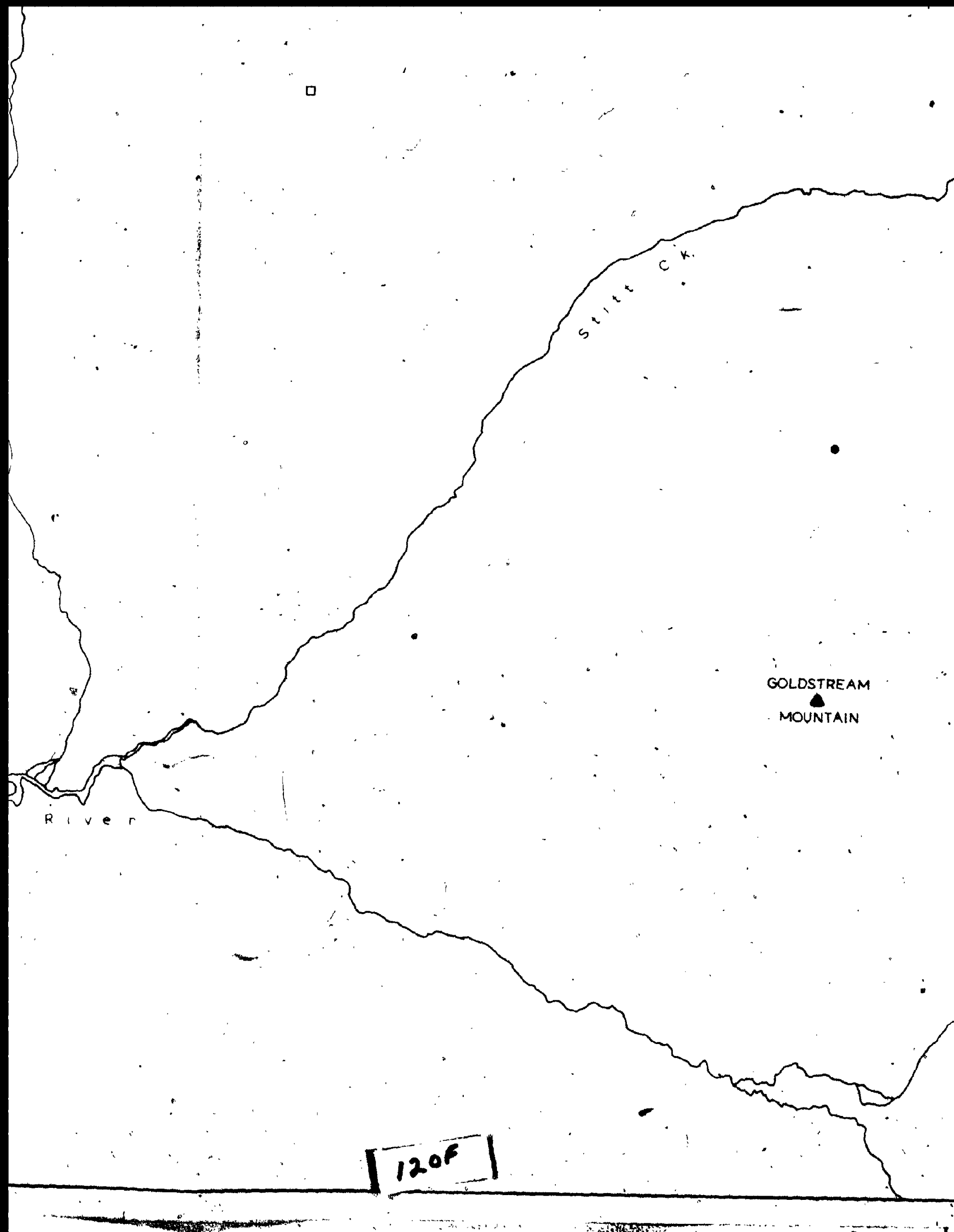



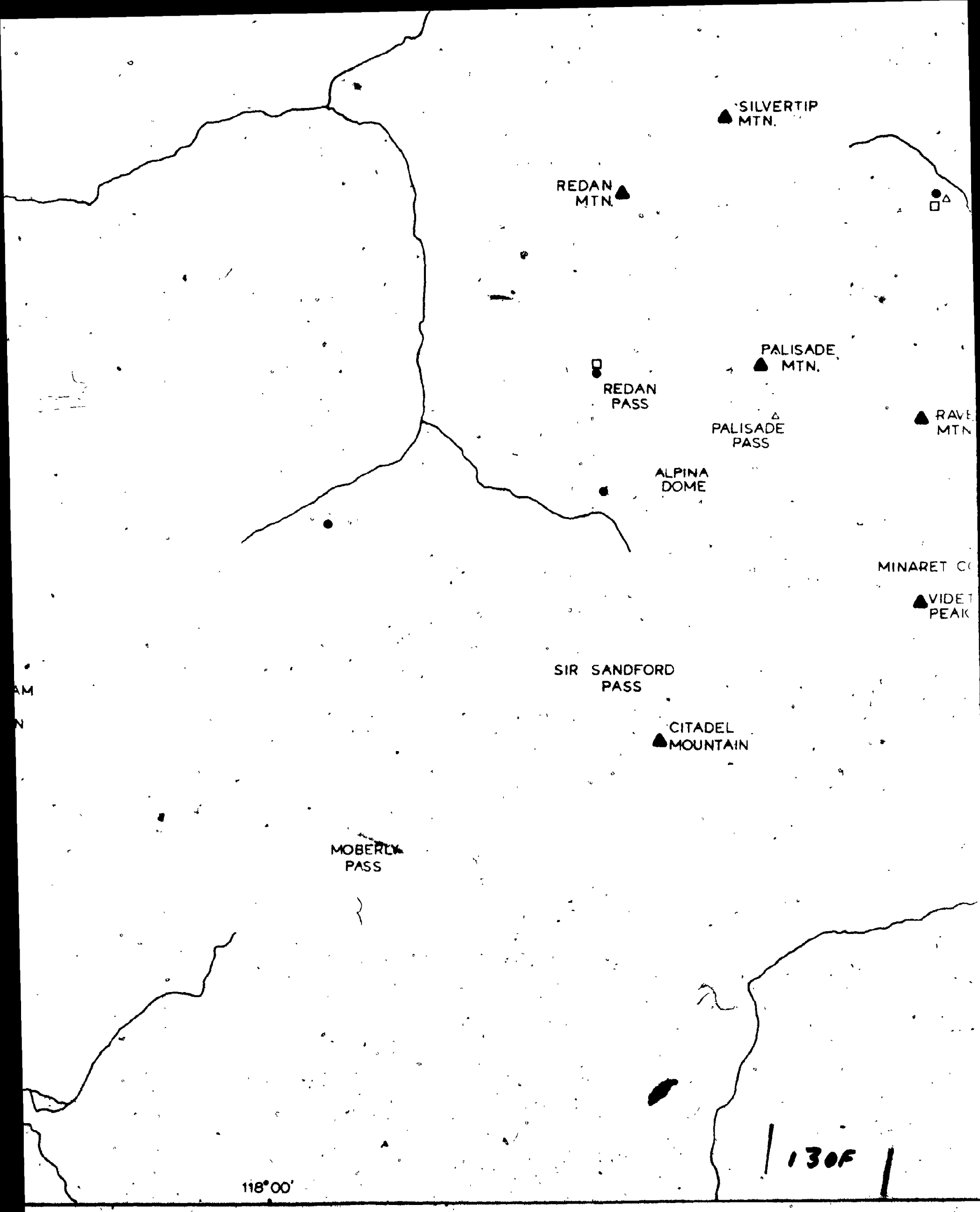


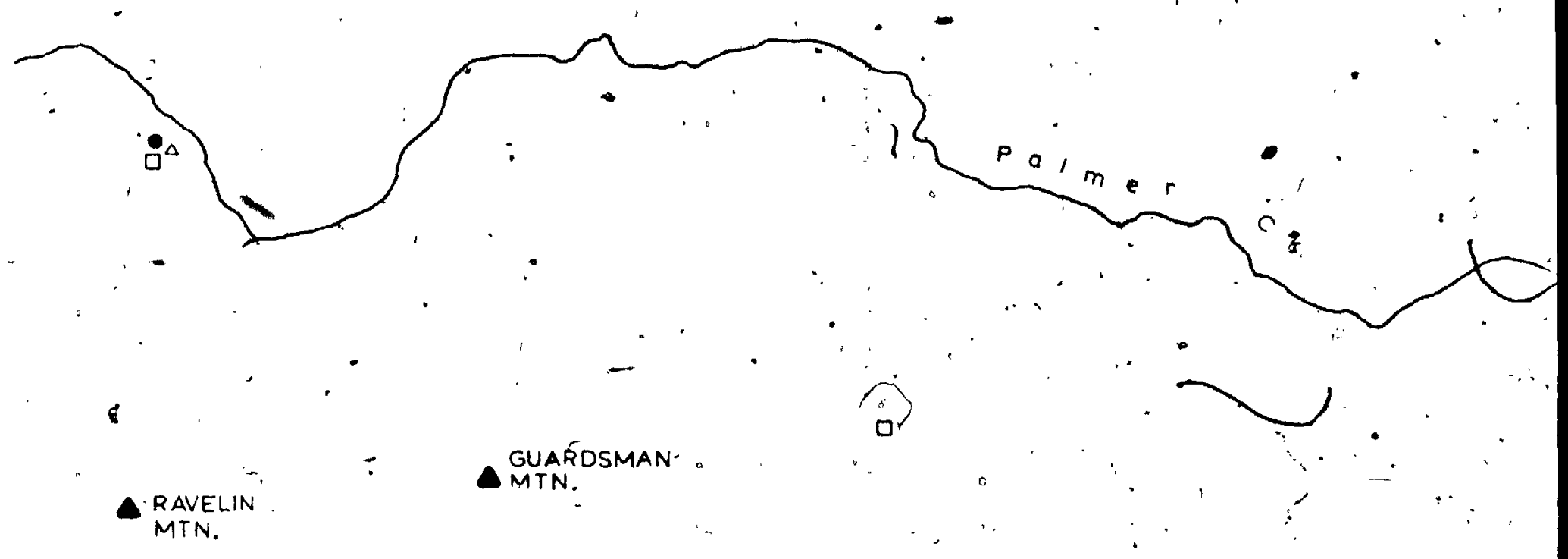

MINARET COL

- videTTE.
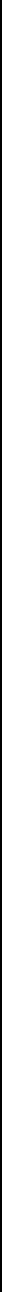


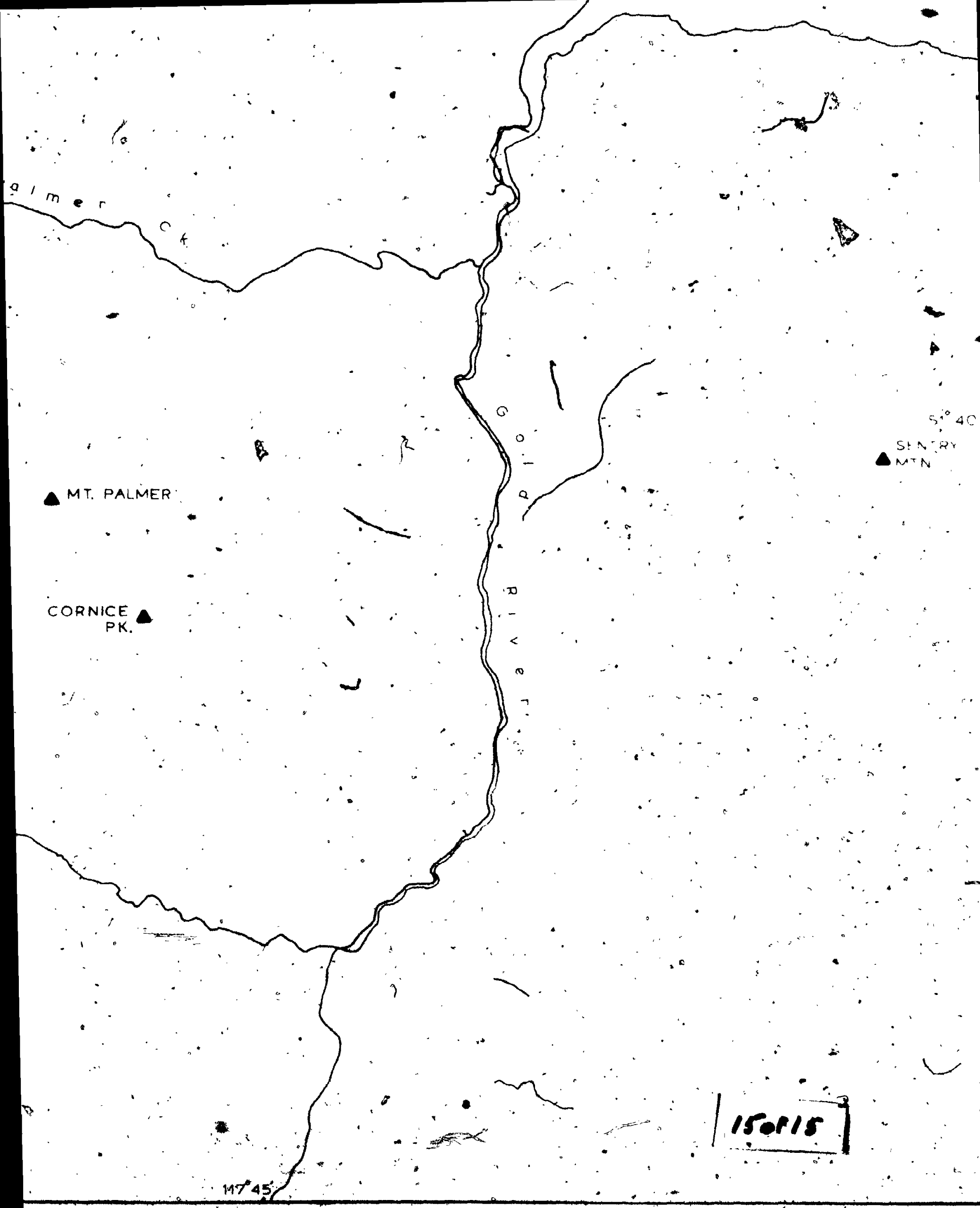




$$
108
$$

fig. 6 TOPOG

Contour interval toe or snow tie

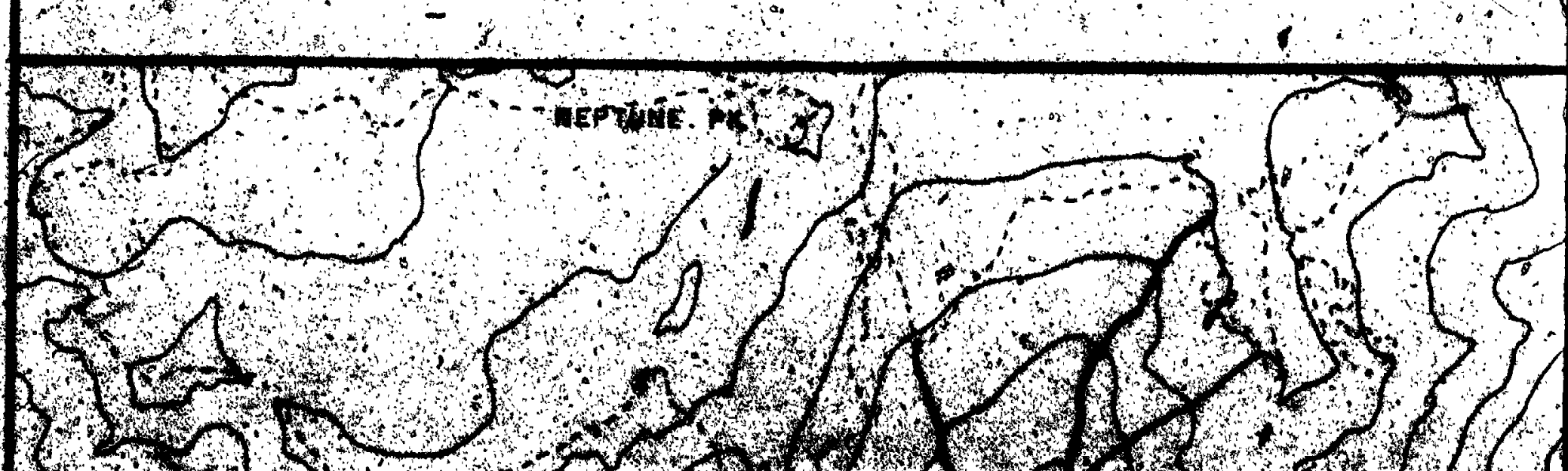




$$
\sqrt{20 \%-1}
$$

POGRAPHY AND DRAINAGE - ZONE A.

val 1000 - feet

field.

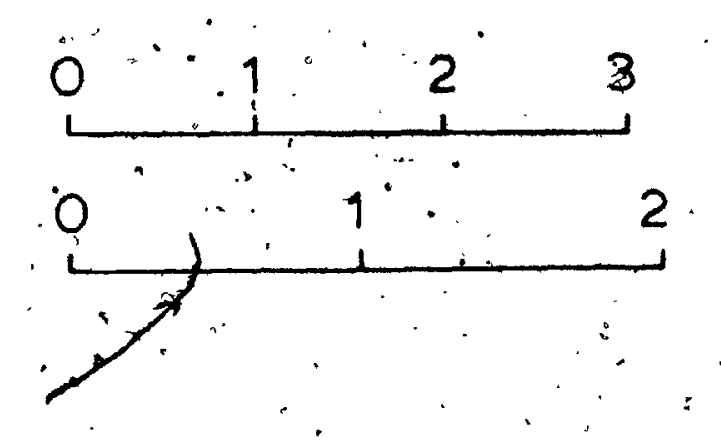




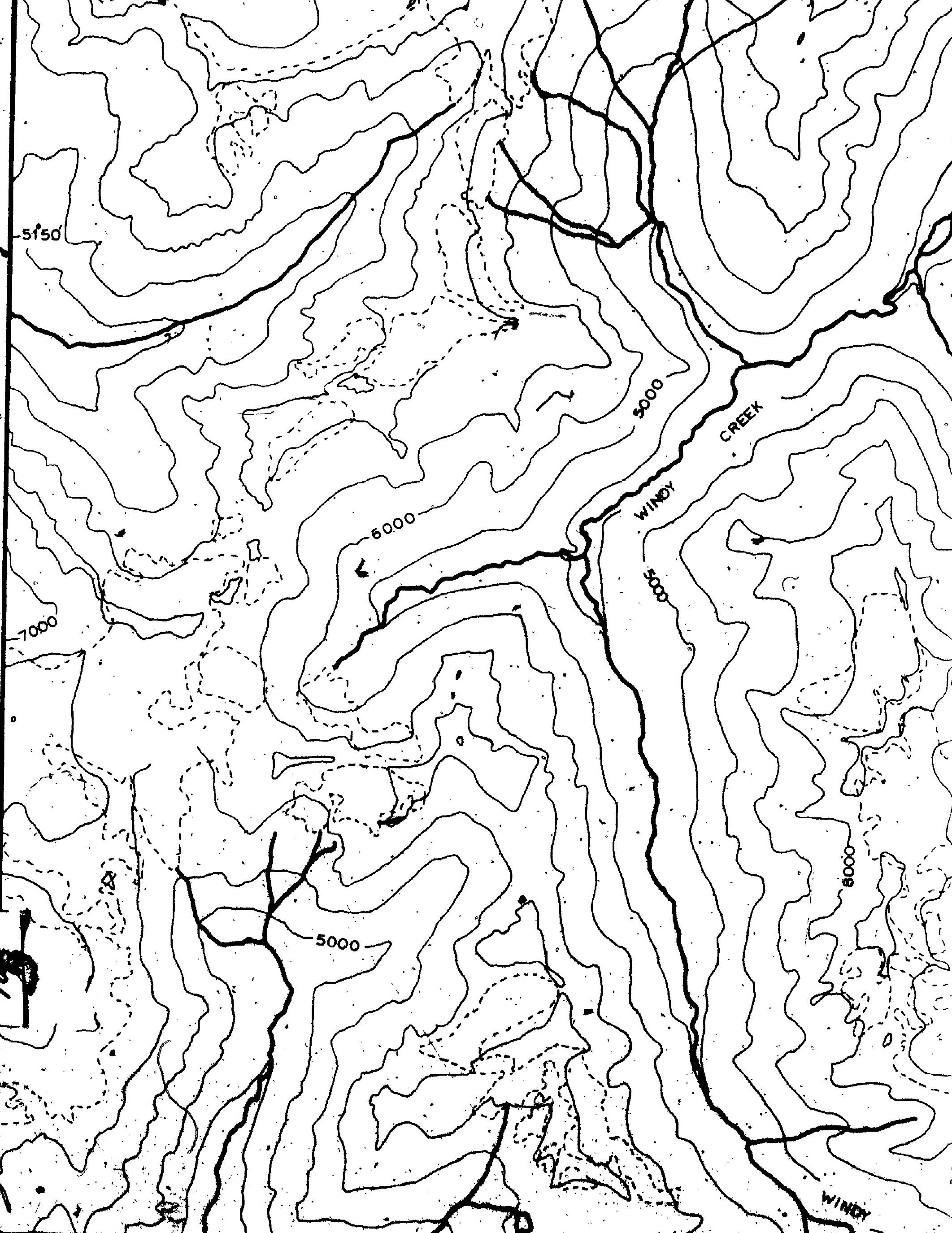




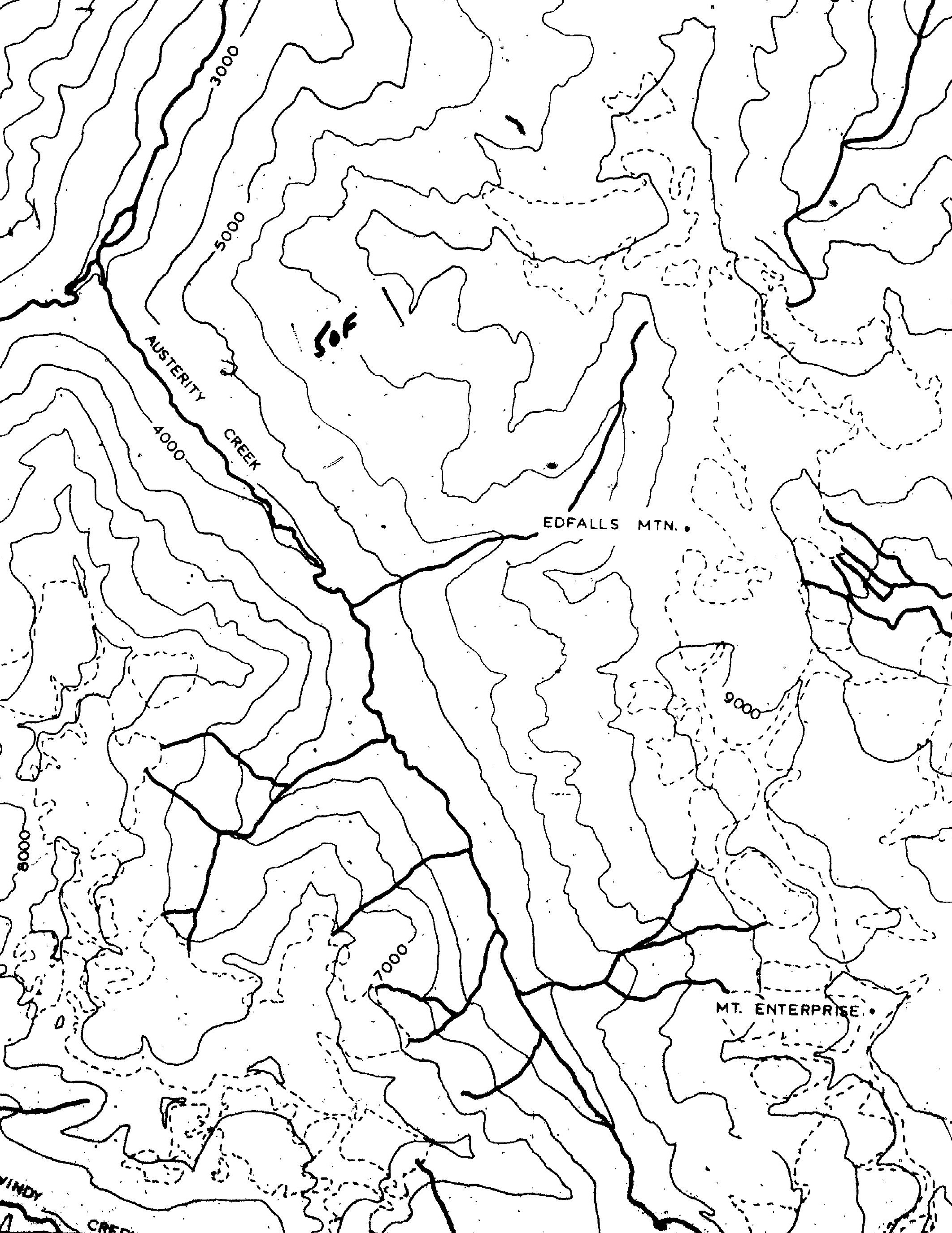




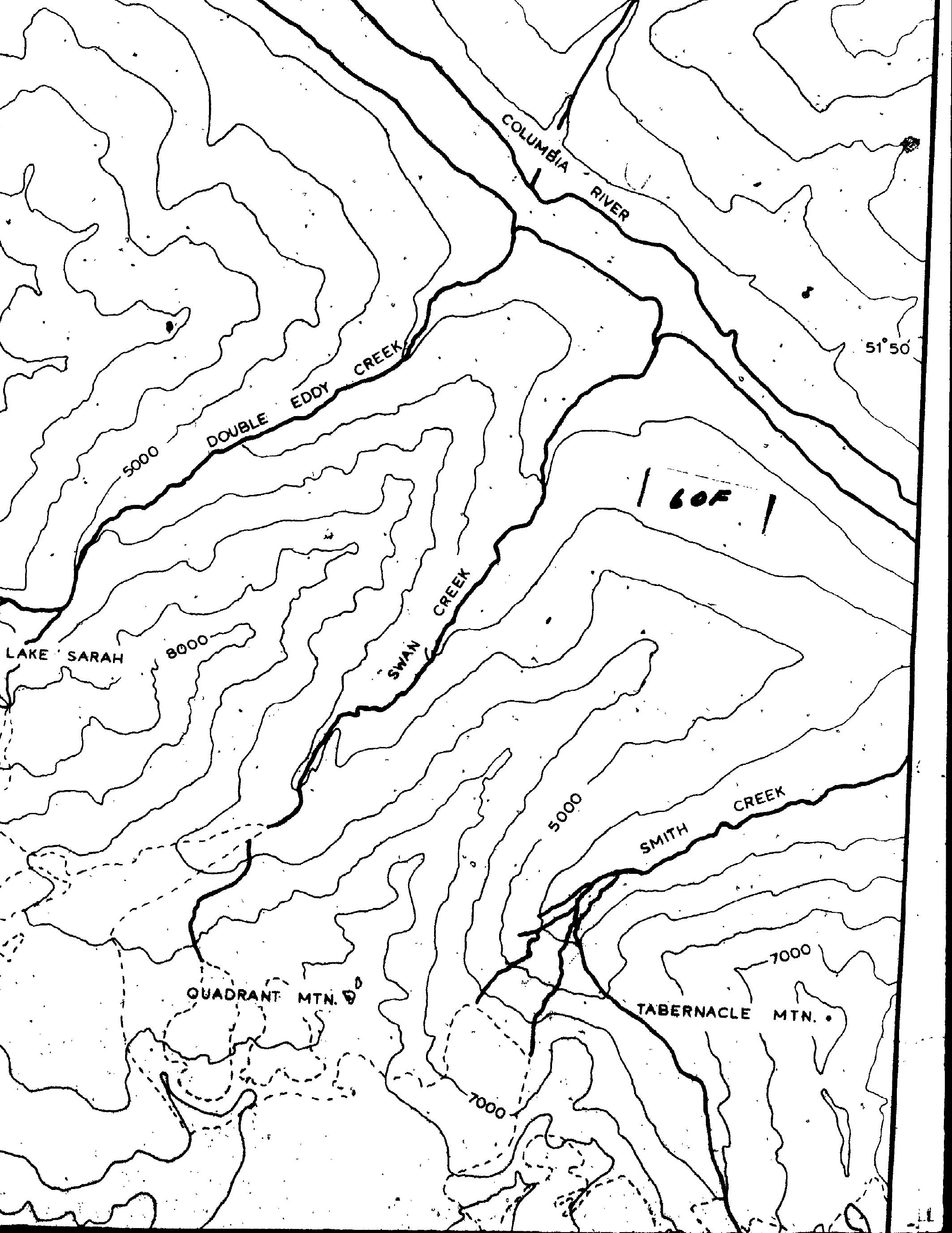




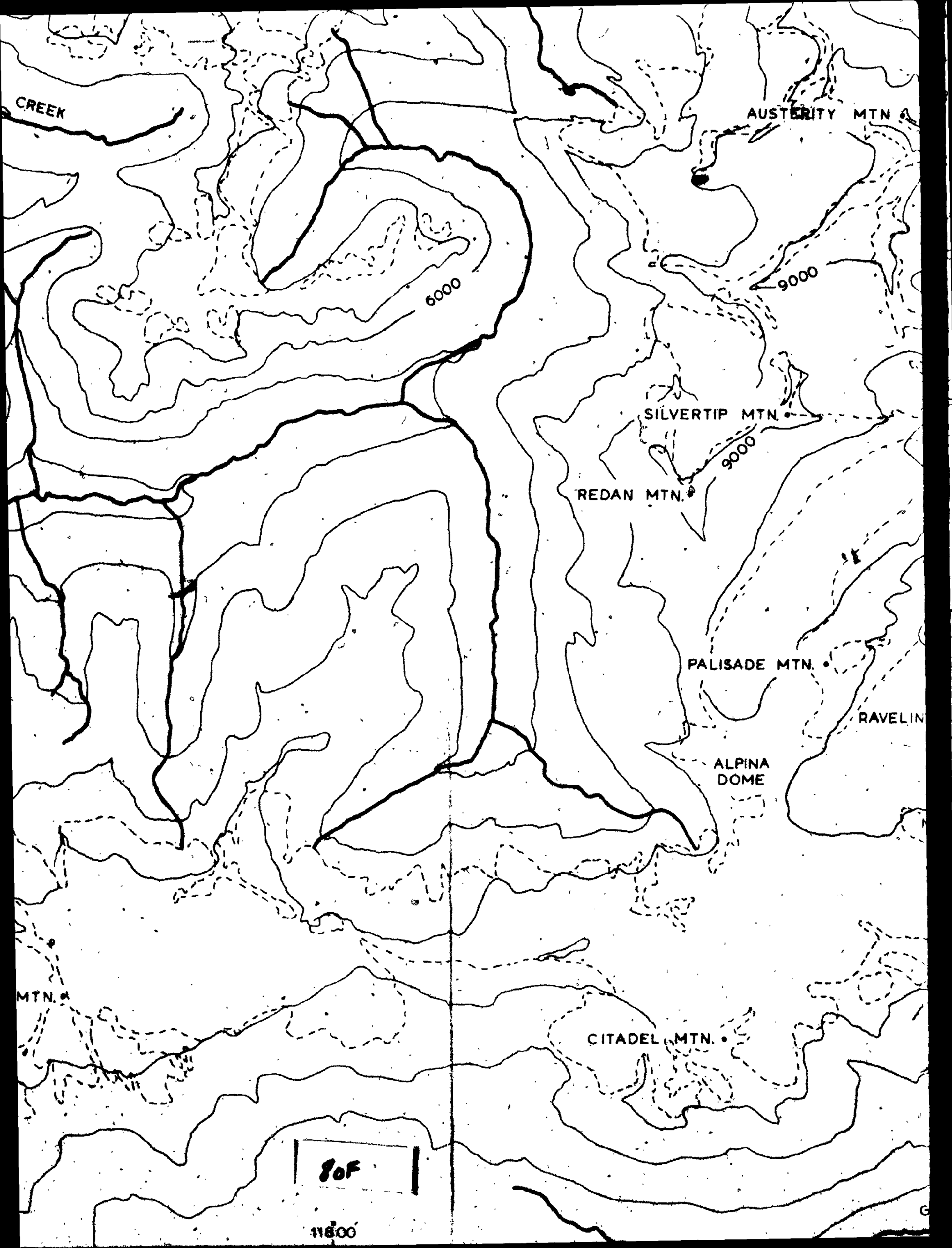




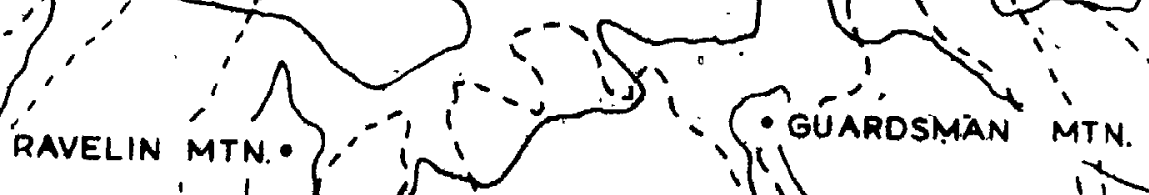

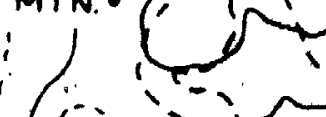

(n)

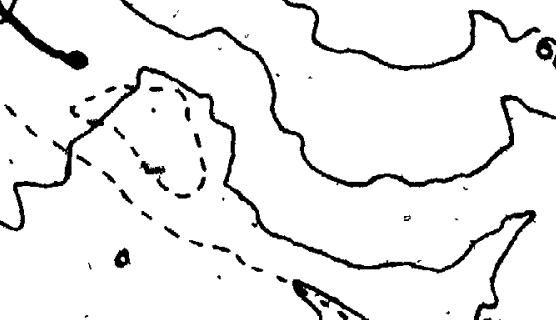

MT. SIR SANDFORD '

MT. sir SANDFORD

8

$\rightarrow r$

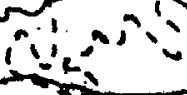


1061 


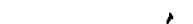




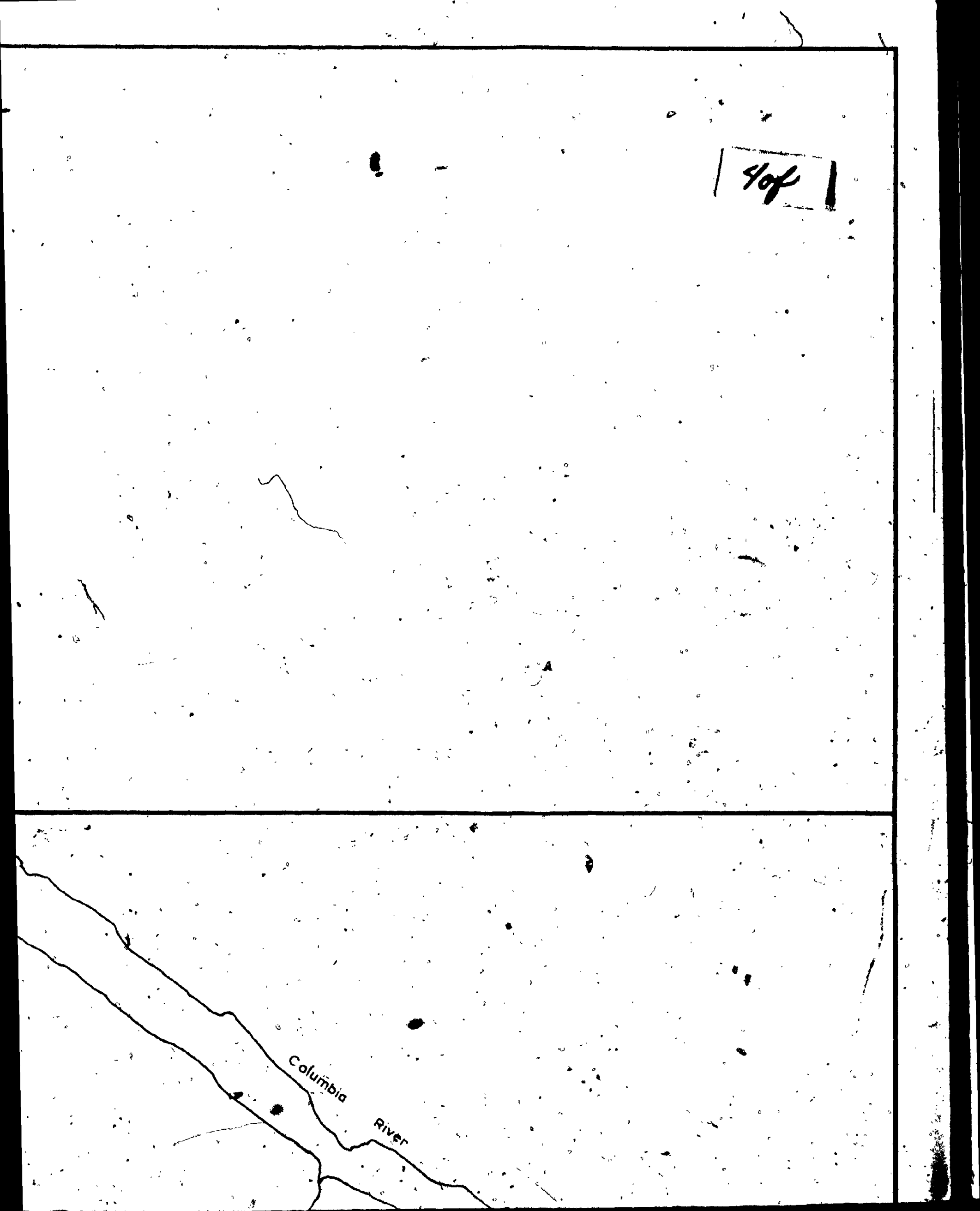




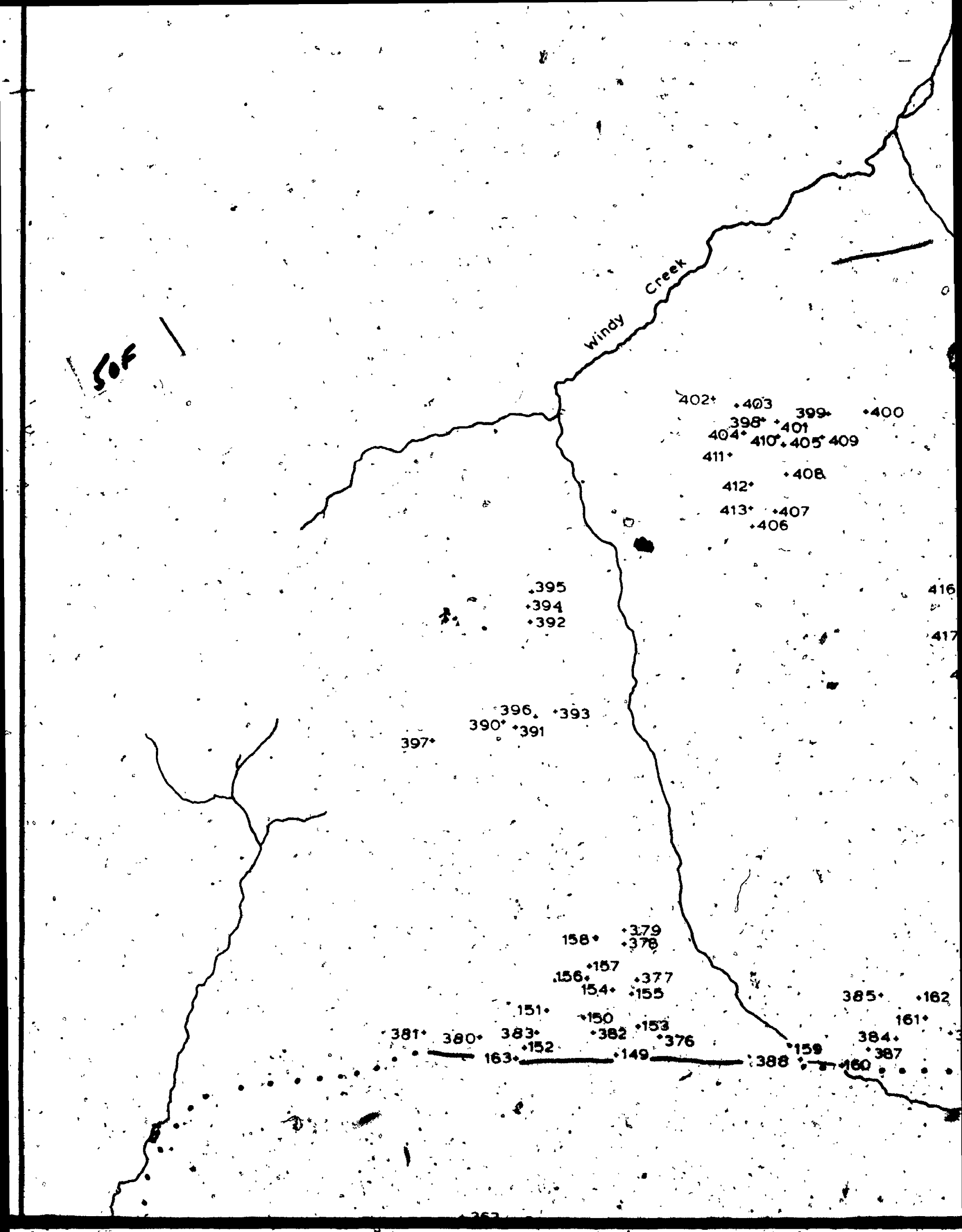




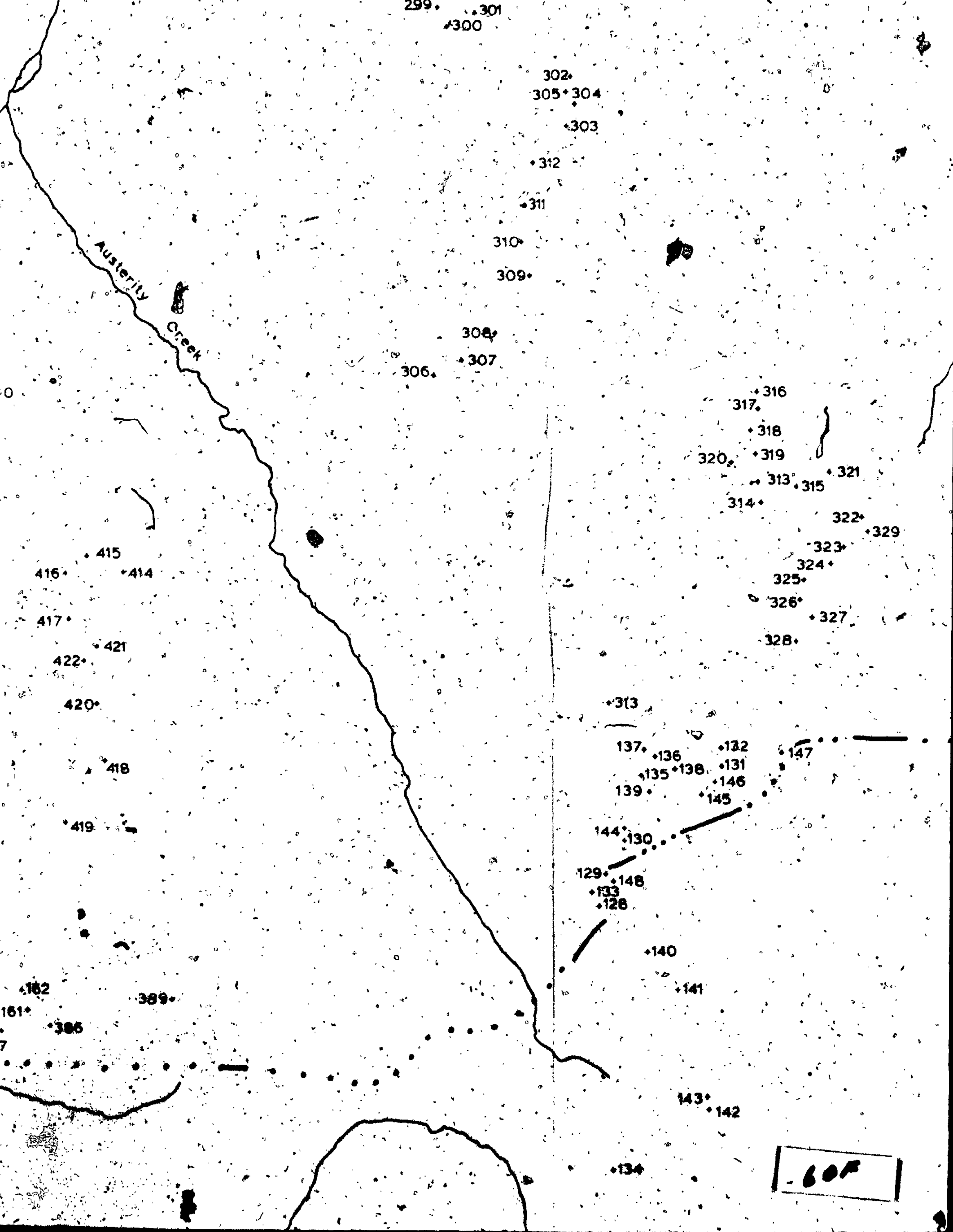




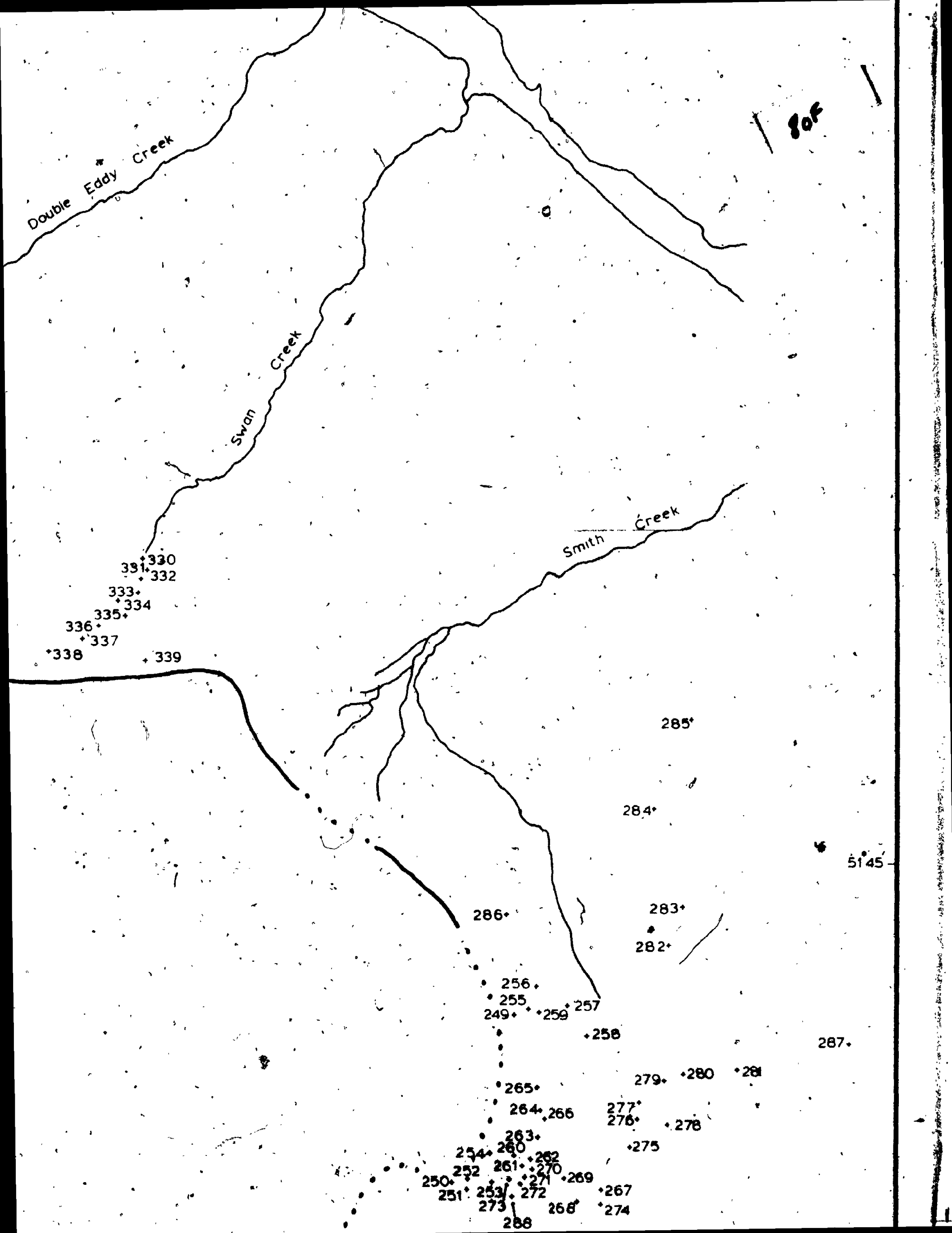




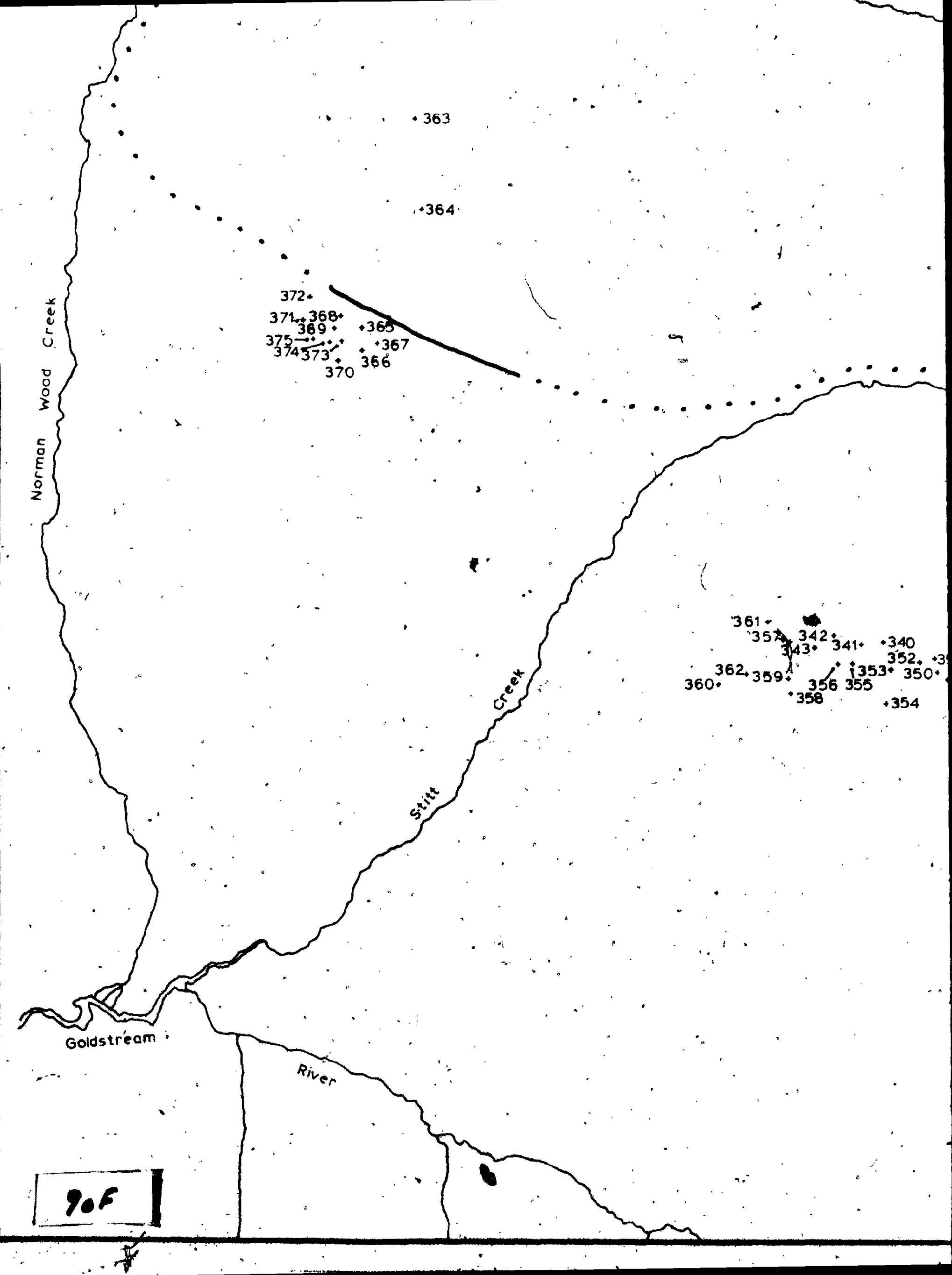




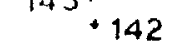




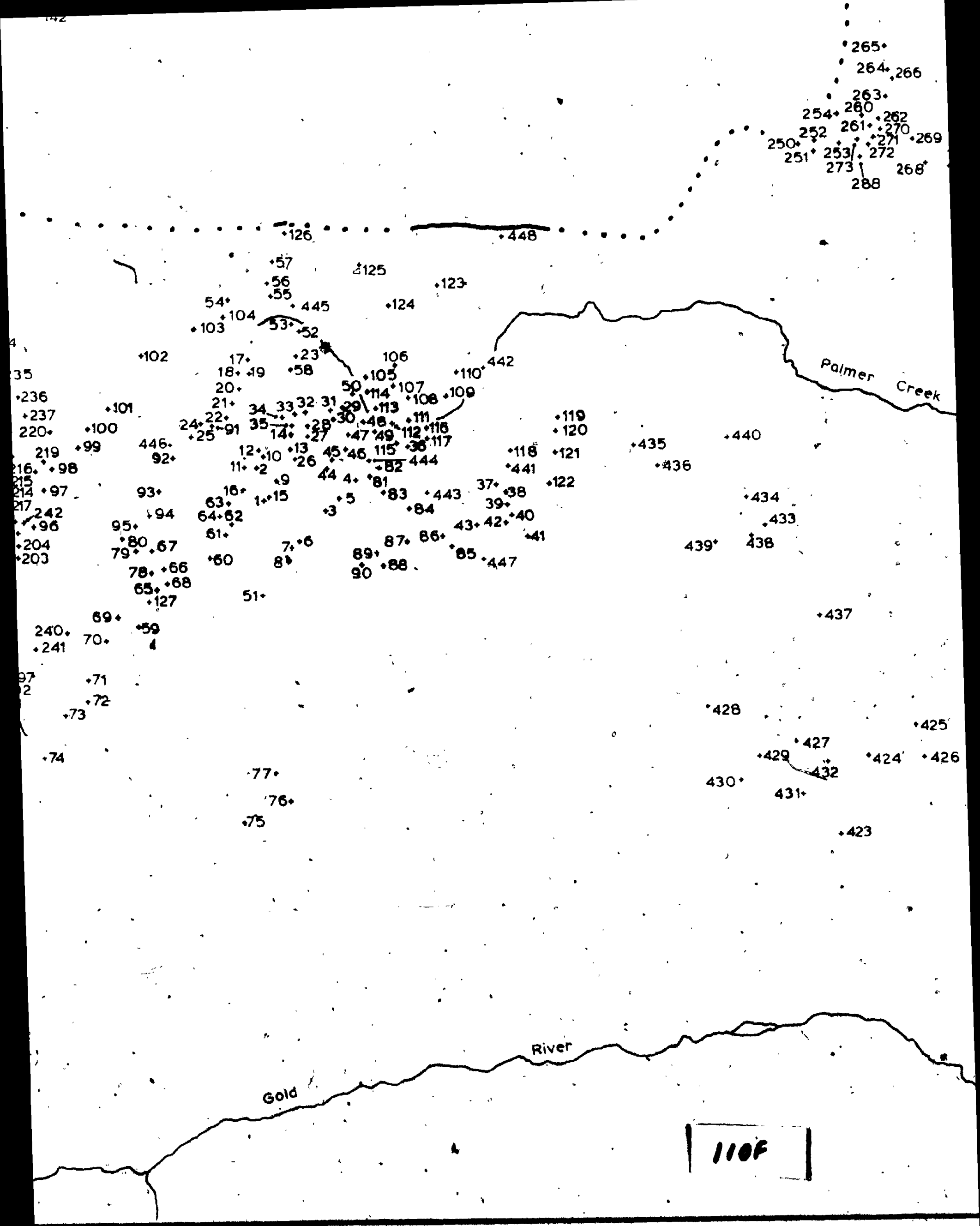


iof 1

LOWER

TOP

$1 e^{\prime \prime} \quad$ Rusty

$1 e^{\prime} \quad$ Rusty

8 trem

.1e Transitid
Pelite.

1d' Mașsive,

1d Amphibd

1c Thin cor

10' Grit bo

ib interbed

1á Marble

$\therefore \rightarrow+\cdots$

10 Pelite

BASE NOT 

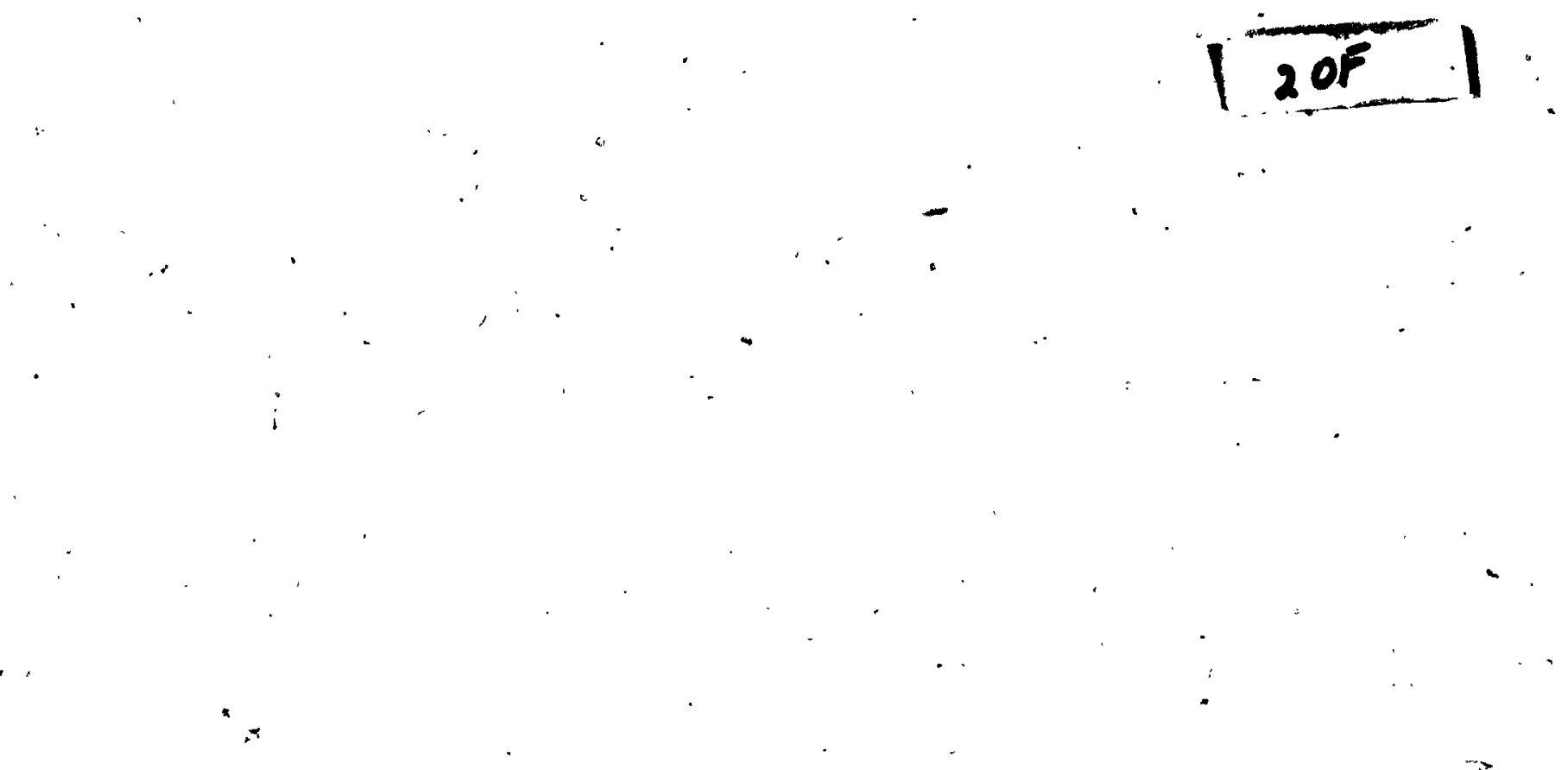

\section{LOWER PELITE MEMBER}
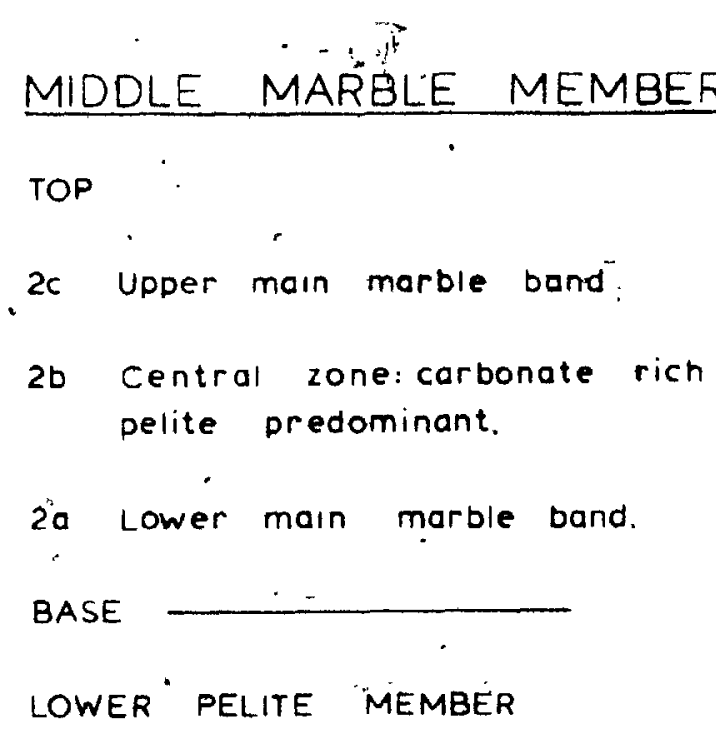

1d Amphibolite of varying types, with rusty pelite.

1c Thin concordant amphibolite bands, with pelite.

$15^{\prime}$ Grit band.

10 Interbedded zone: psammite, semi-pelite, pelite.

1á 'Marble band

10 Pelite witi occasional psgmmite bands.

BASE NOT RECOGNIZED 


\section{fIg 8 LITHOLOGICAL MAP - ZONE A.}

\section{MEMBER}

band

bonate rich

boind

\section{UEPER PELITE MEMBER}

TOP NOT RECOGNIZED

1.

3e Pelutic sequence, metamorphic index minerals common.

$3 d^{\prime}$ Thick sequence of grits

$3 d^{\prime}$ Massive quartzite with thin pelite bands.

3d Quartz rich sequence: quartzite, grit bands, psammite, Delite.

3c Massive, quartz-pebble conglomerate.

3b Grey pelite with brown or green carbonate bonds. Troces of copper? minerals.

$30^{\circ}$ Interbedded sequence of semi-pelite. pelite; psammite, quartzite.

$3 a^{\prime}$ Thin interbeds of psammite, quarfeite, grit.

3a Transition zone: carbonate rich pelite, rusty marble.
IGNEOUS ROCKS

4 Amygdaloidal basal 
1

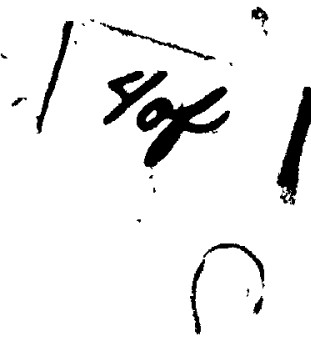

BCKS

\section{KEY TO SYMBOLS}

Limit of outcrop studied.

al' bosalt

Exposed contact.

** Extrapolated or

interpolated . contact.

$\rightarrow$ Sedimentary tops.

Exposed pluton contact.

$\ldots$. Extrapolated or

interpolated pluton contact.

Line of section.

Fault.

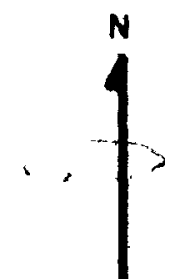

$\because 8 . \frac{1}{4 m}$

2

? 

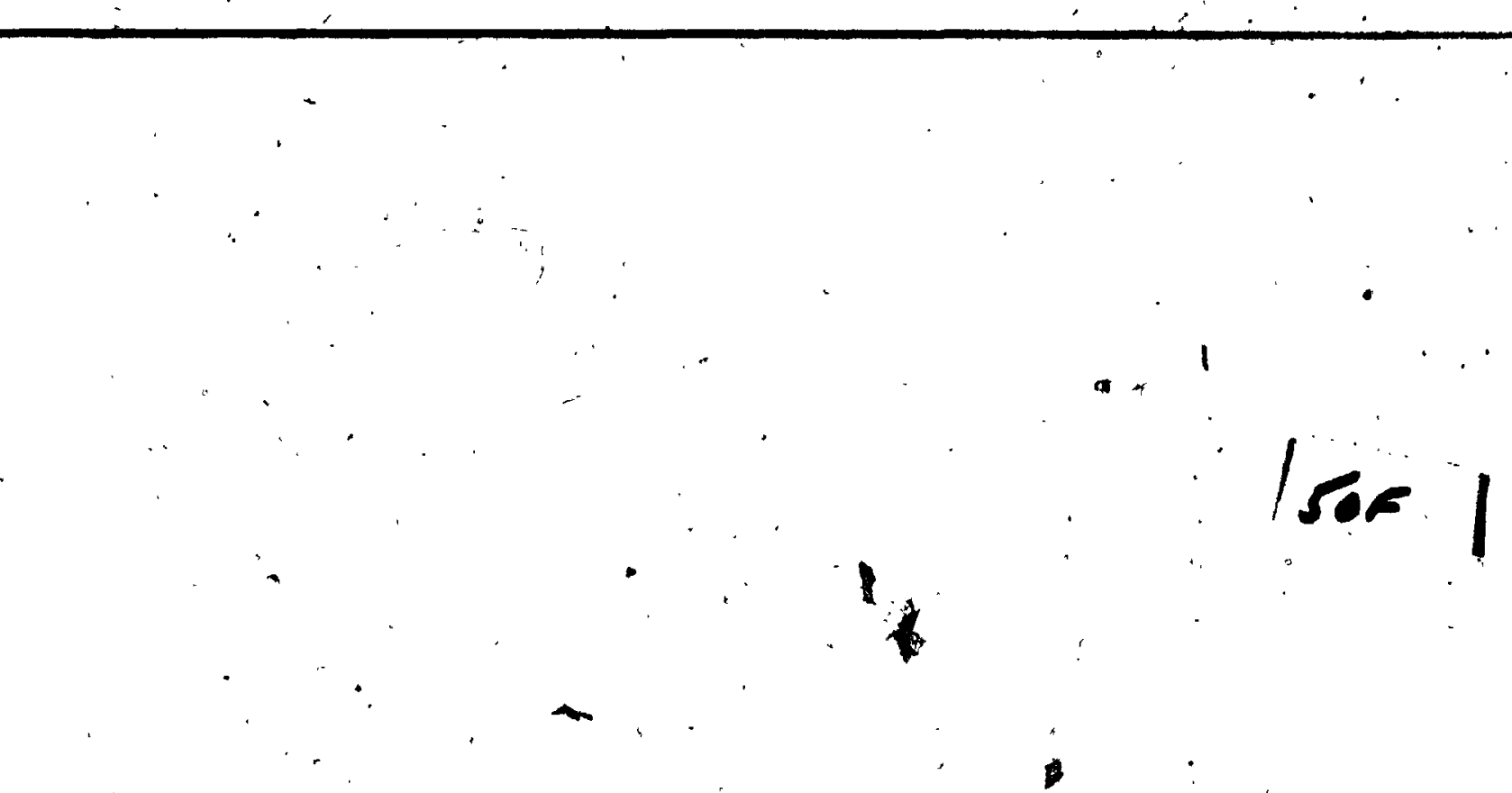

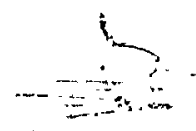

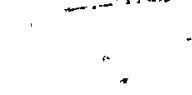

$+4$

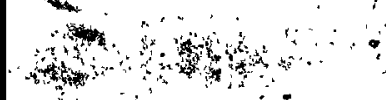



<smiles>C#CCC(C=CCCC(C)C)CC</smiles> 



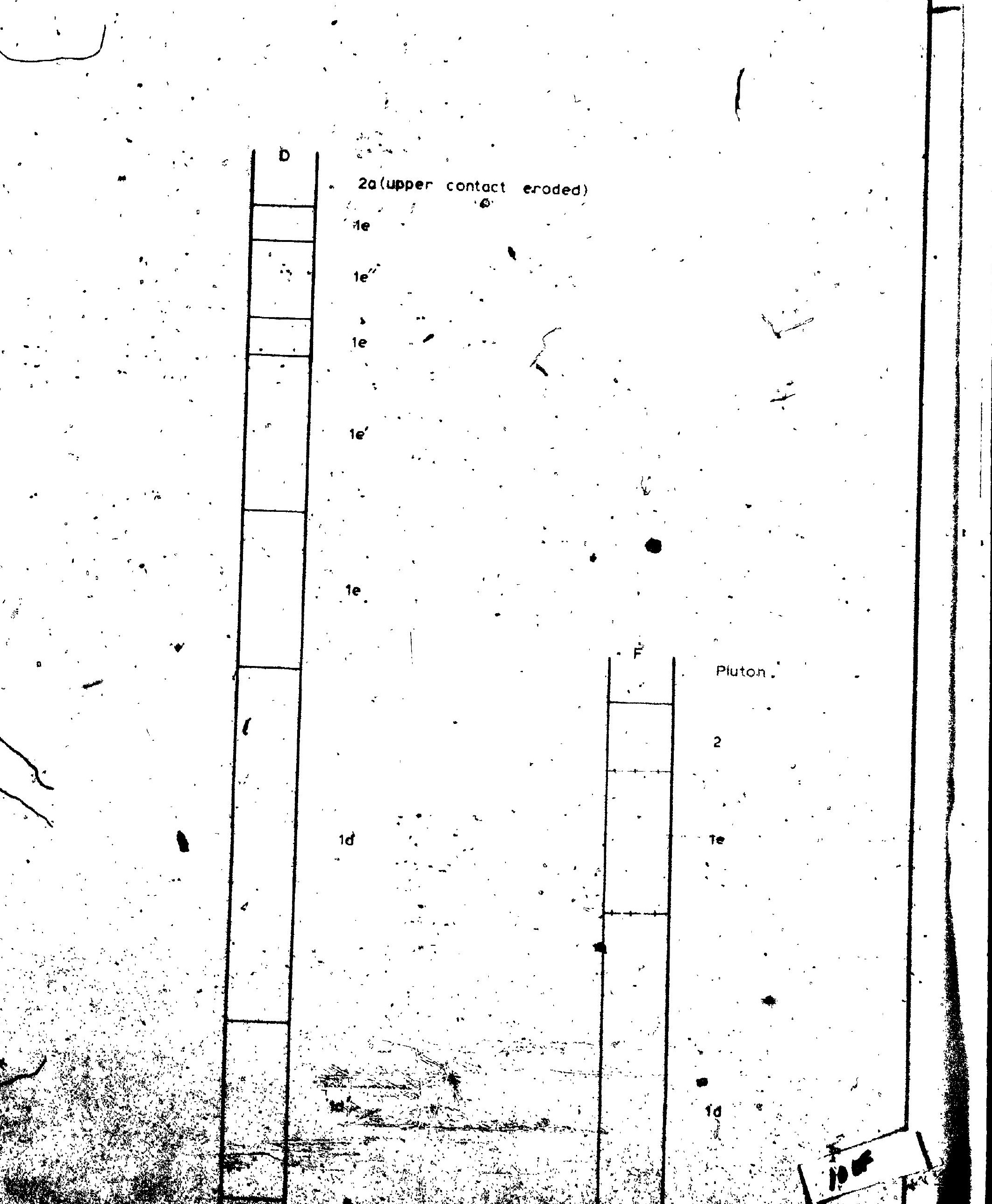





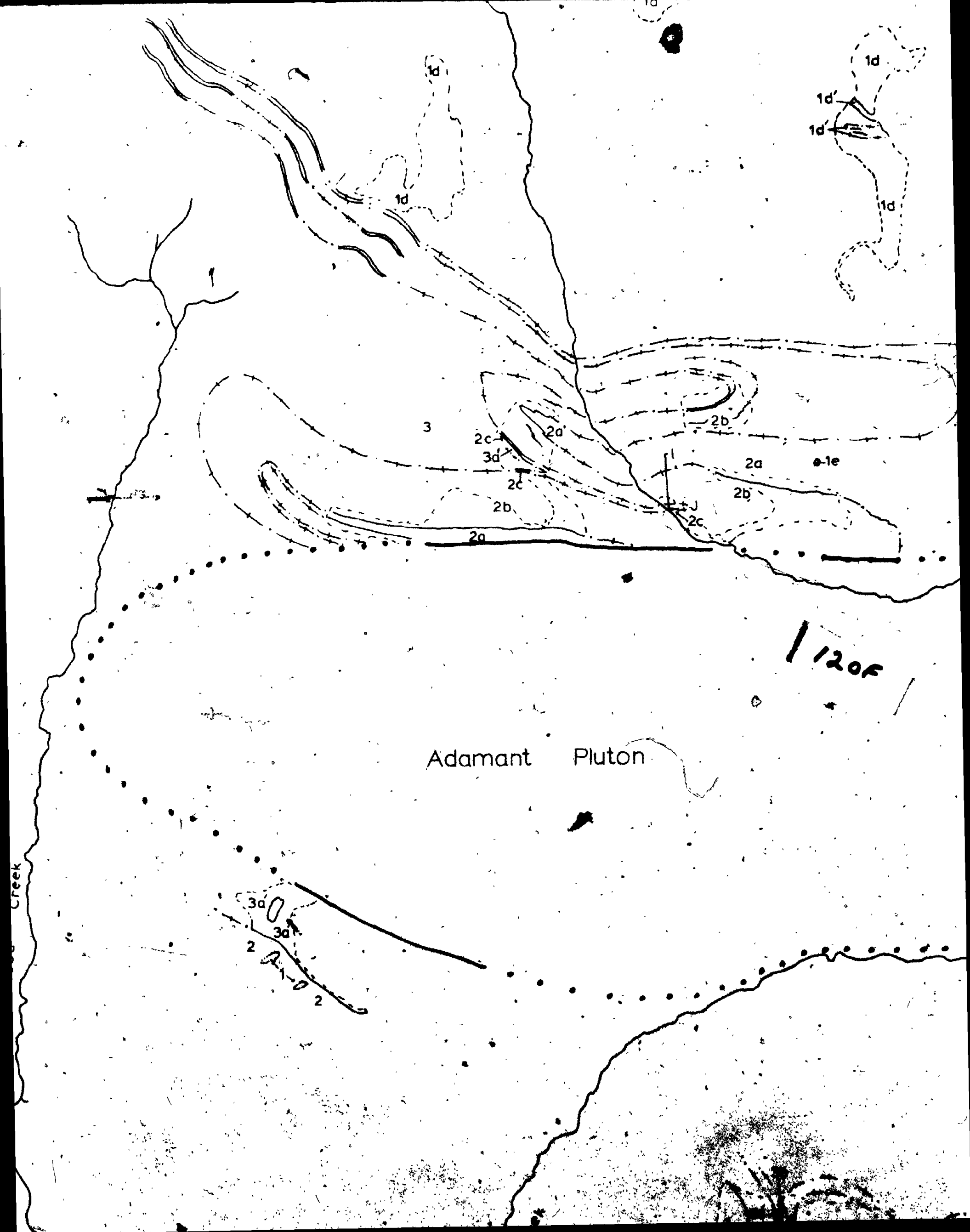




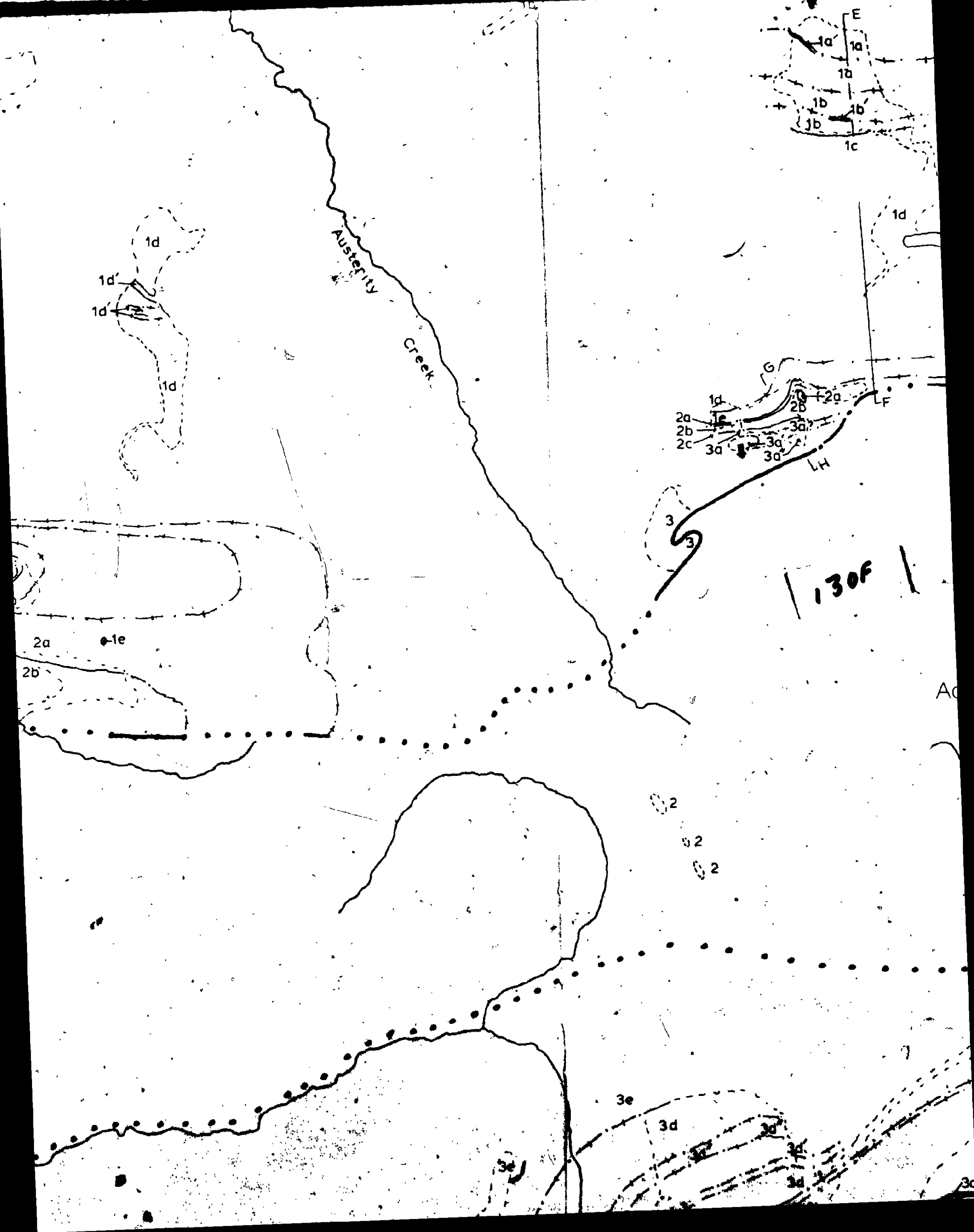






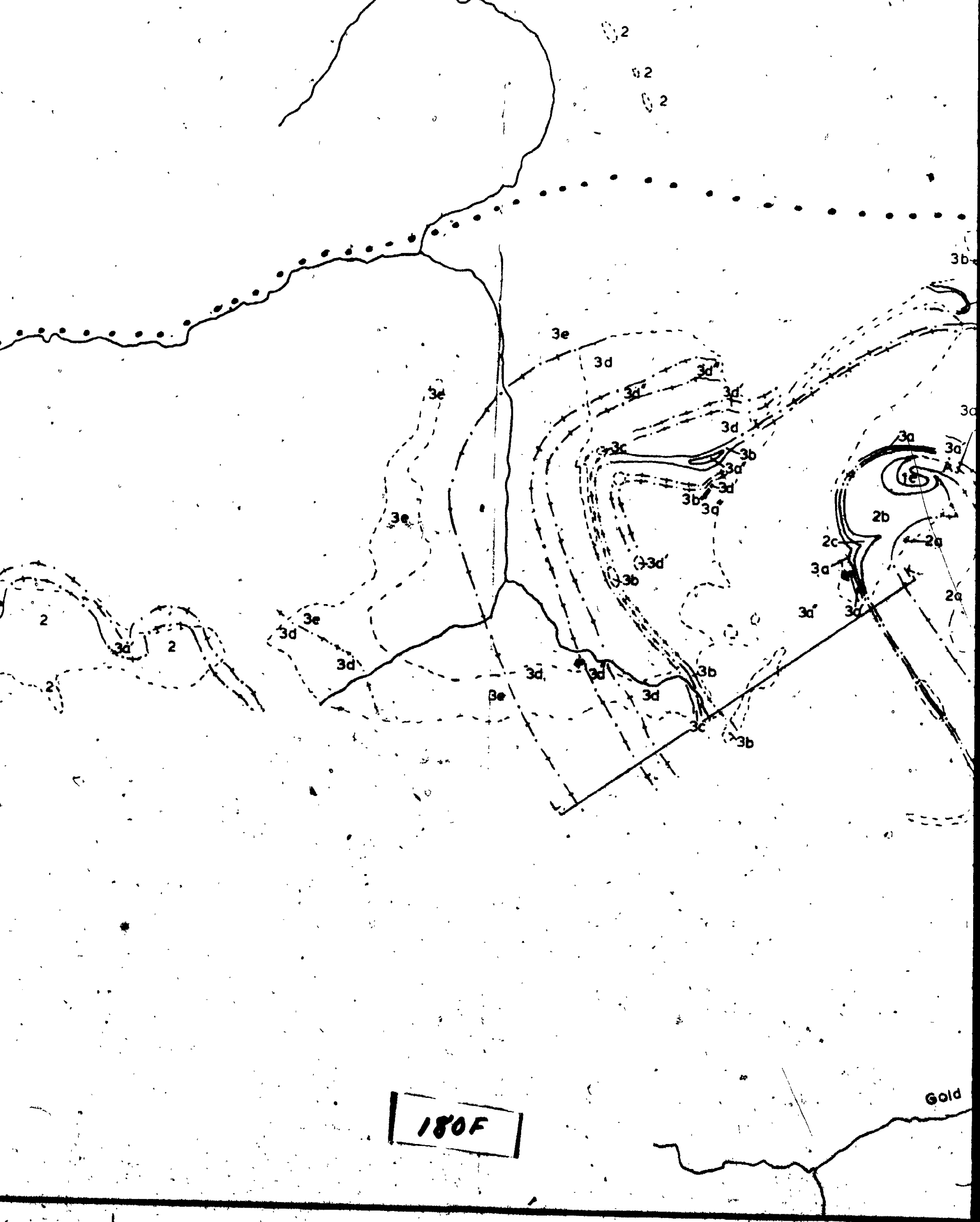



$+, \quad+\infty$

oof

STRIKE \&' DIP OF BEDDING \& . OF MINOR FÓlD aXIAL PLANES, CLEAV',

- PLUTON CONTACT.

$\because \quad \because \quad \therefore$ ASSUMED OR

4

$1 *$ 

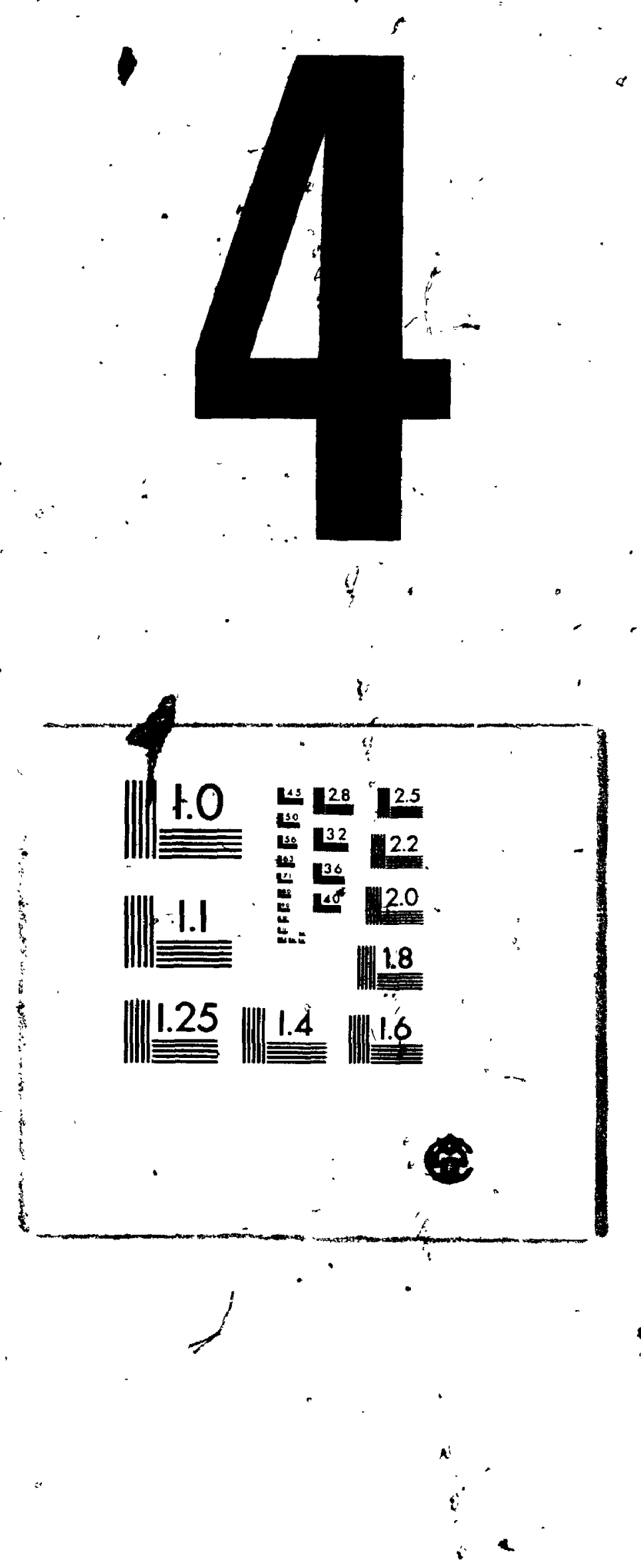


\section{fig. 10 \\ ORIENTATION OF $S$ \\ 85$$
1-\mathrm{ZON}
$$

$D_{1}$

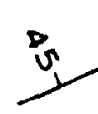

VAGE.

INFERRED.

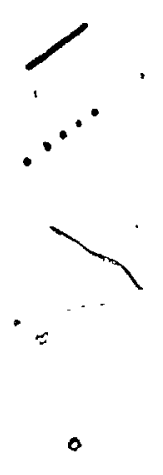

$\theta$

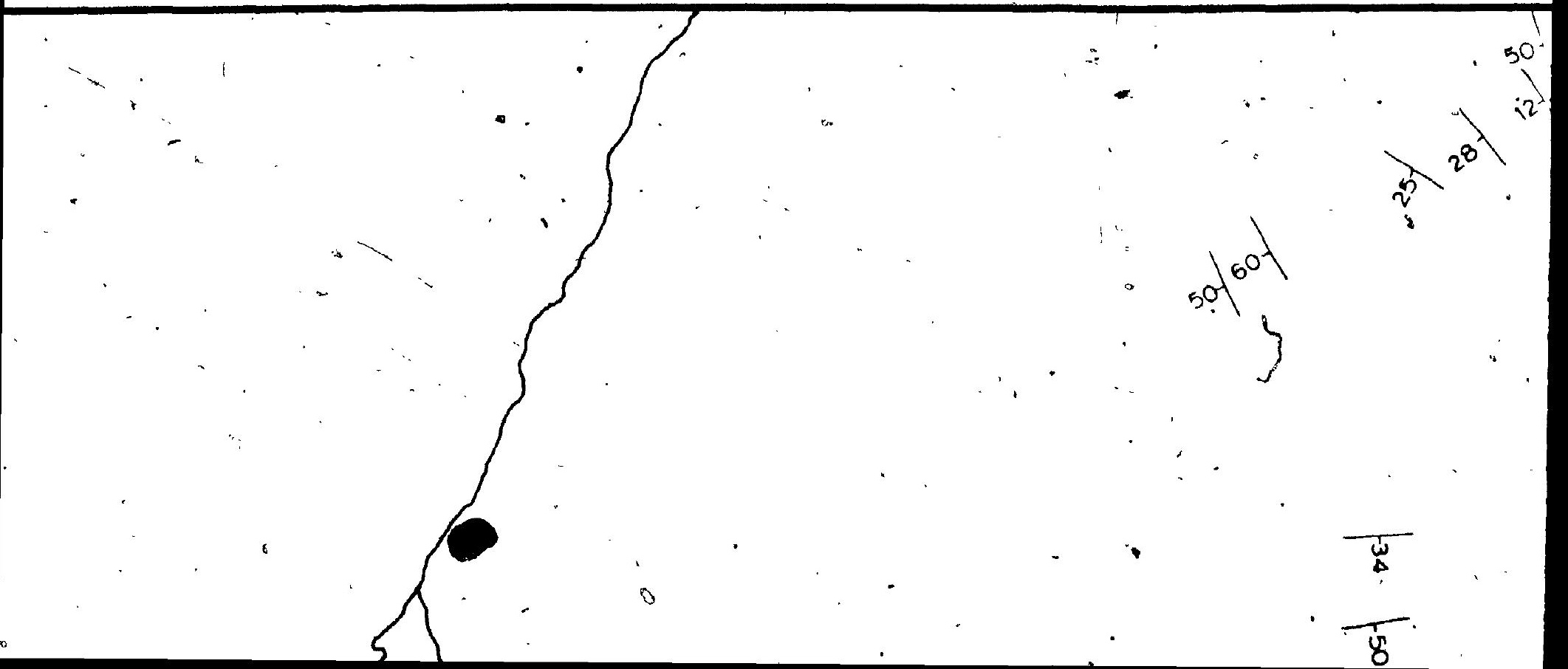




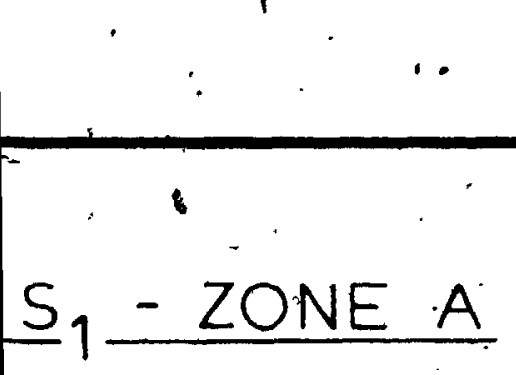

13051

(.

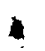

$\rightarrow$

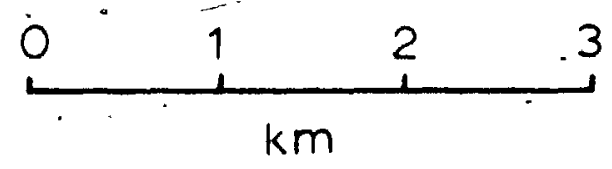<smiles>C[14NH2]</smiles>

$\because$

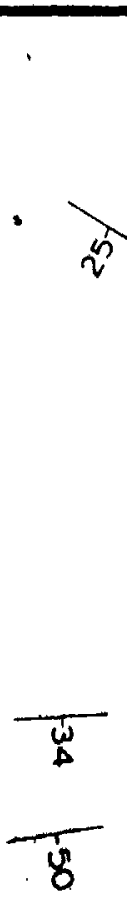



$\overline{⿱ ㇒ ⿻}$

8

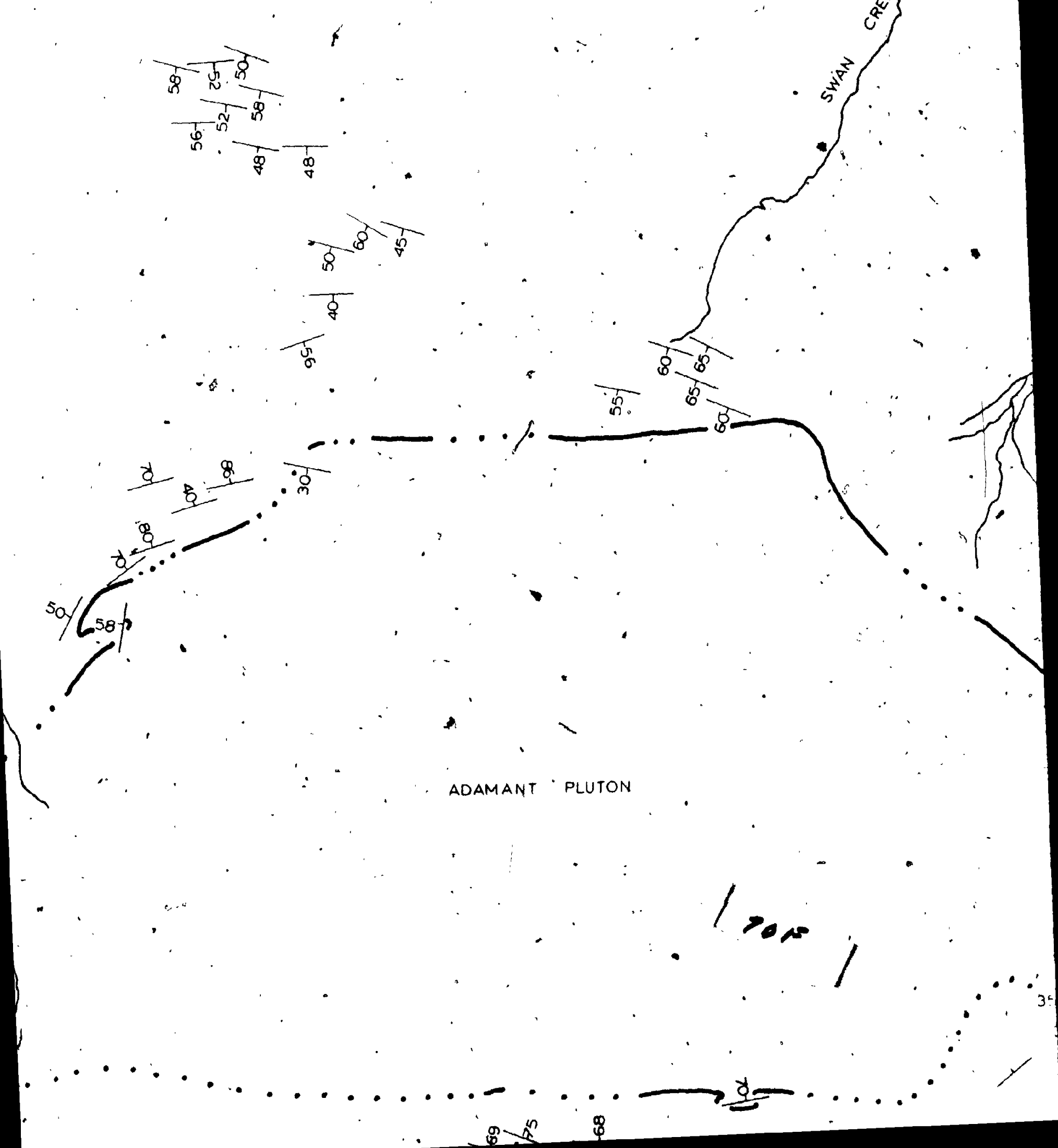





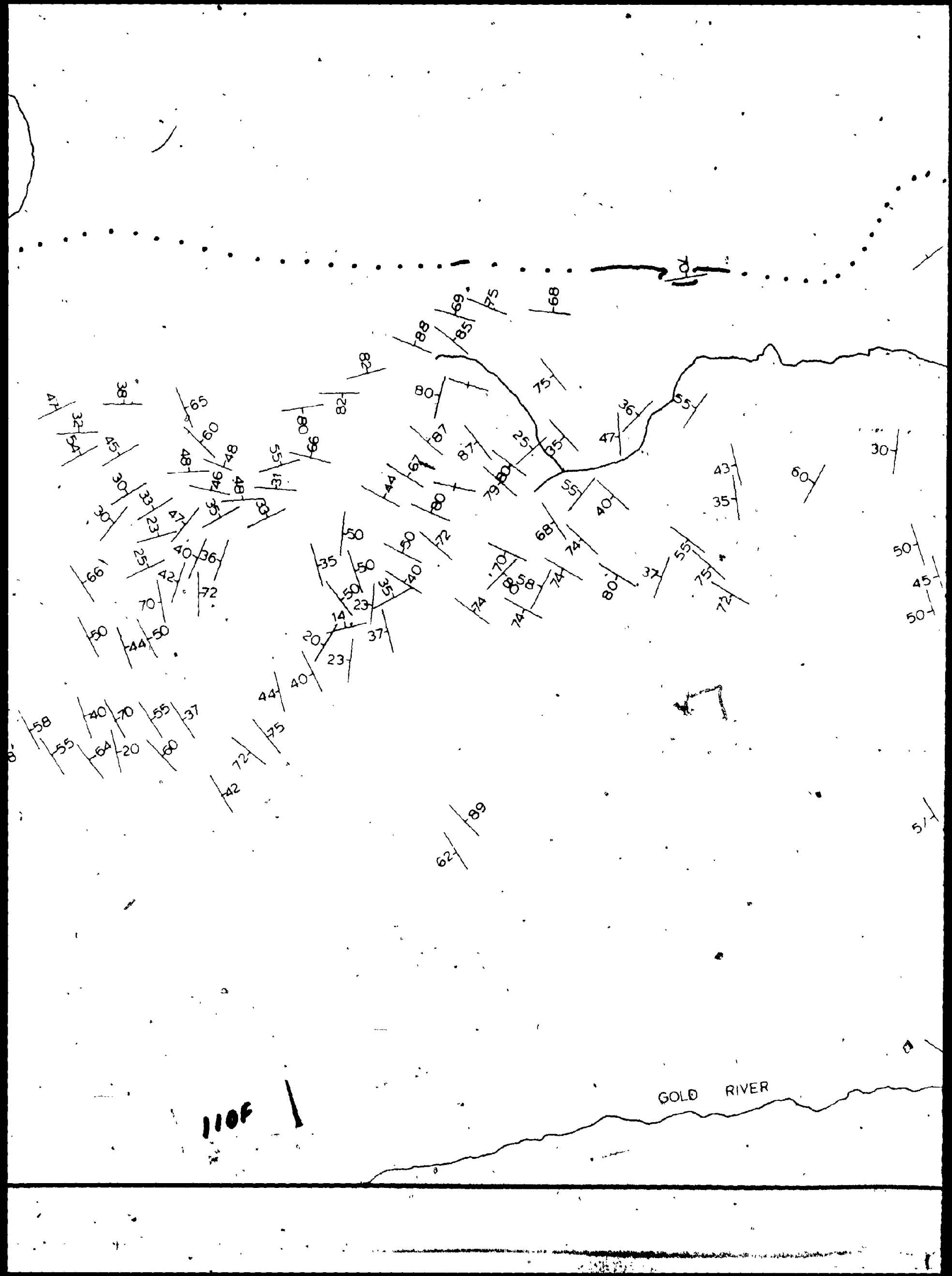




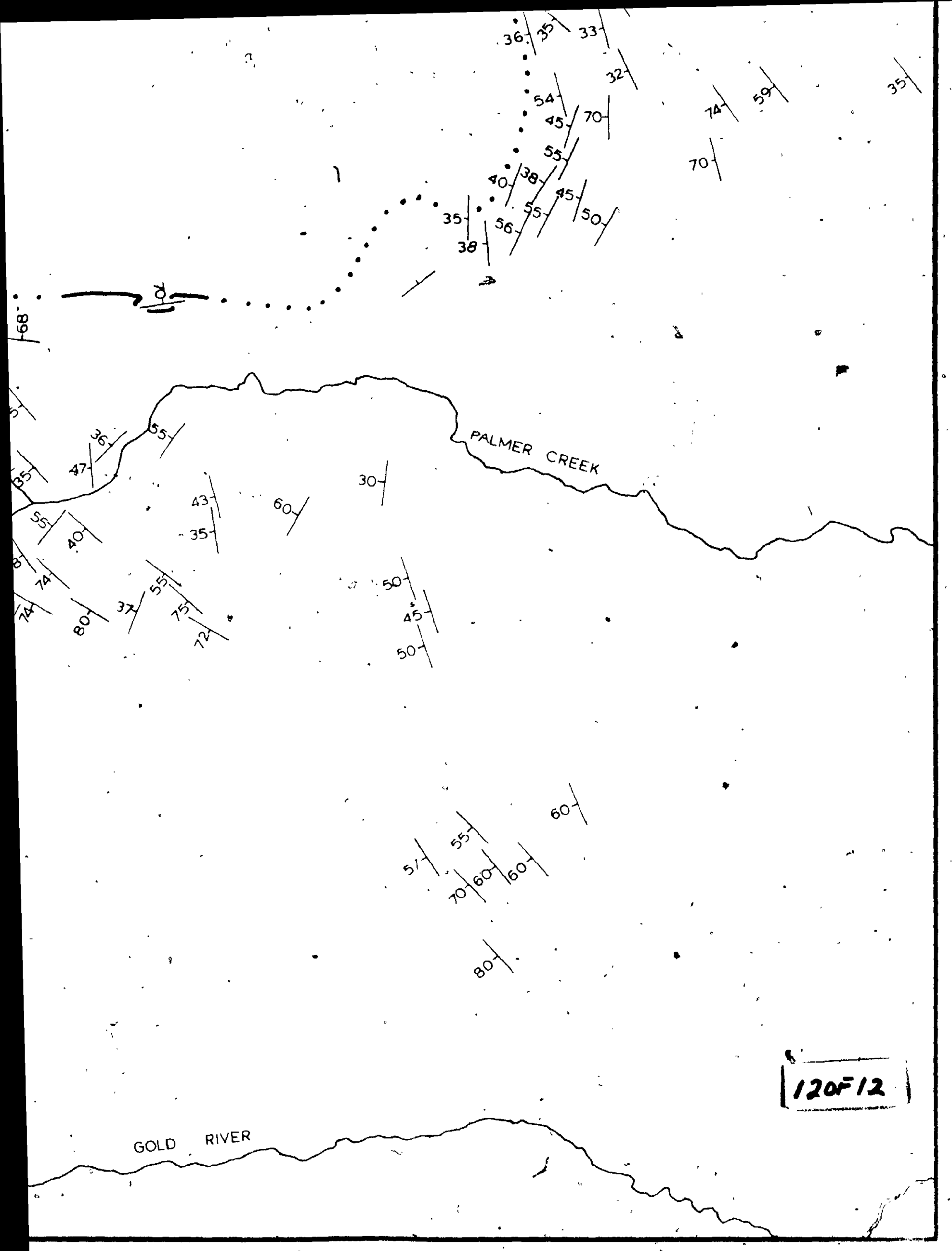





$$
2 \text { of }
$$

fig.11 STEREOPLOT OF $D_{O / 1}-D_{-}$ 
$\therefore \mathrm{D}_{2} \stackrel{\text { \& }}{\mathrm{D}_{3}}$ FABRIC ELEMENTS - ZONE A. 



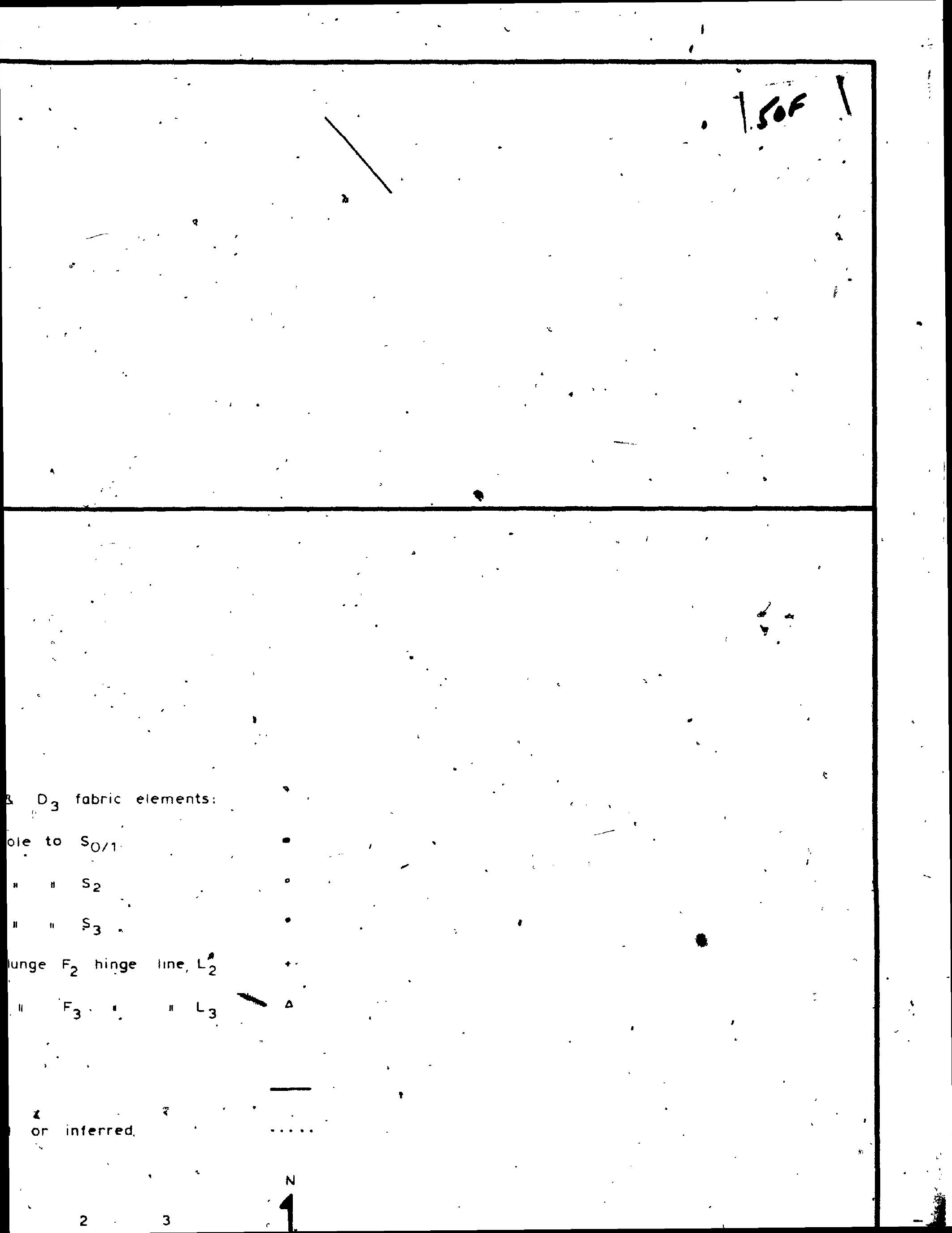




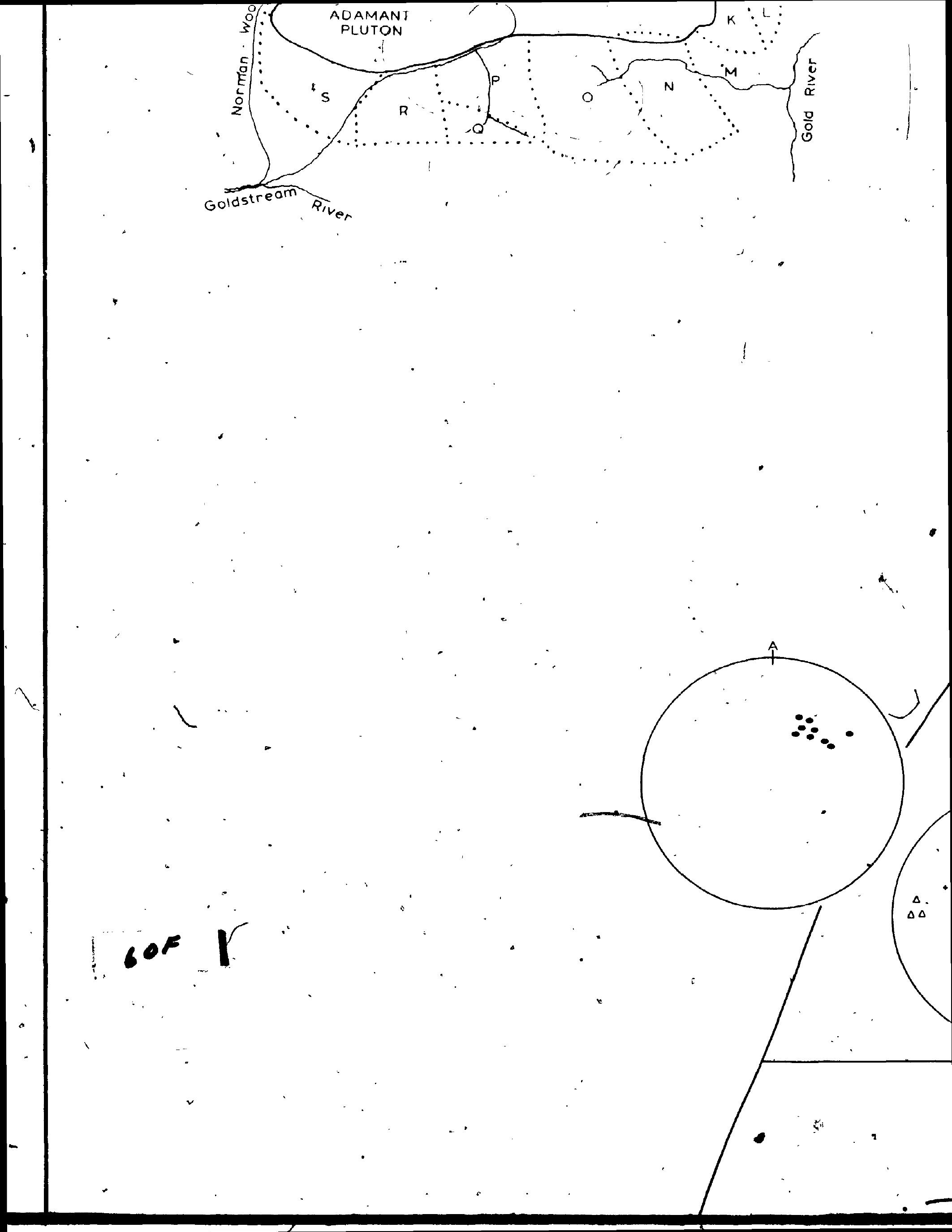




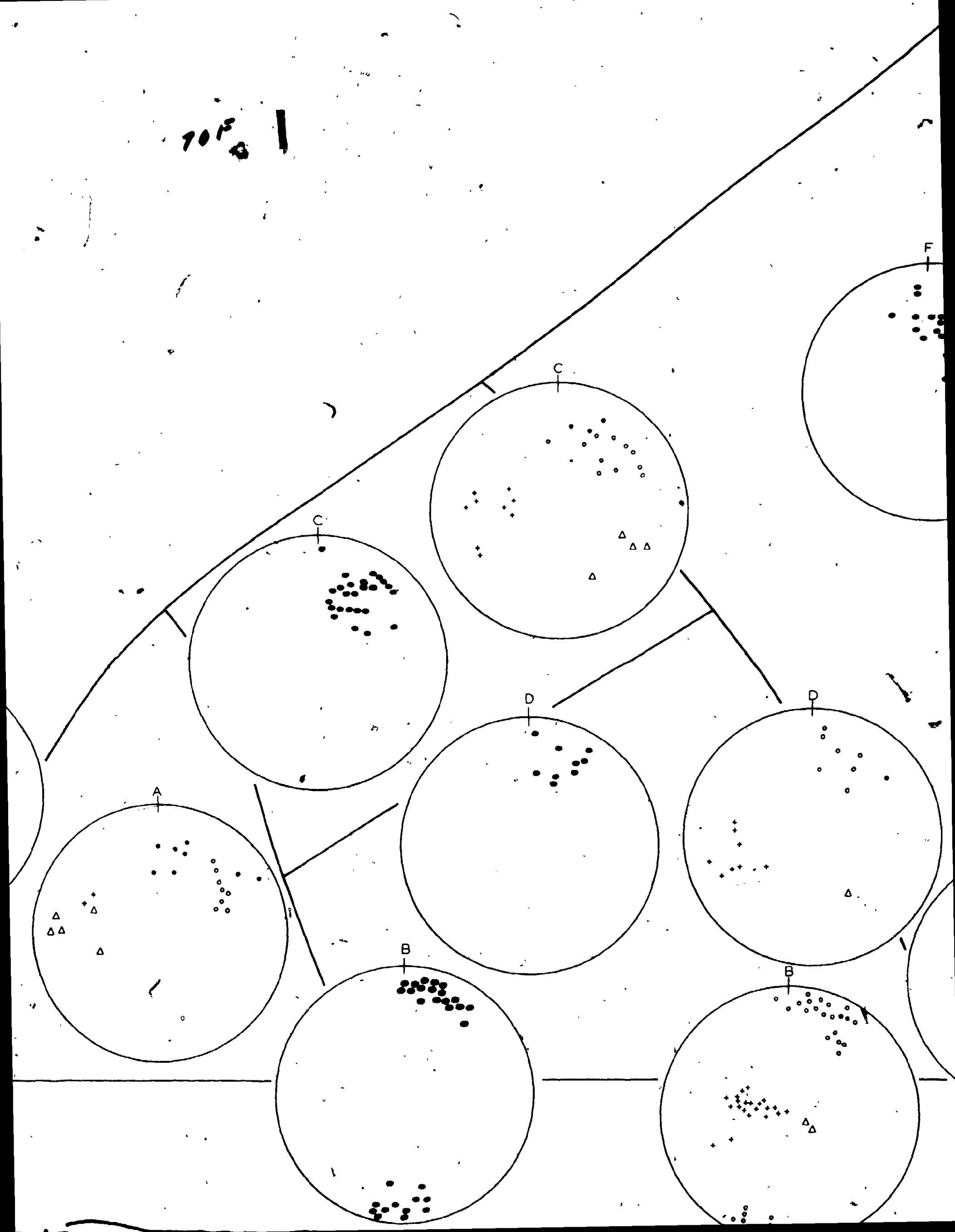




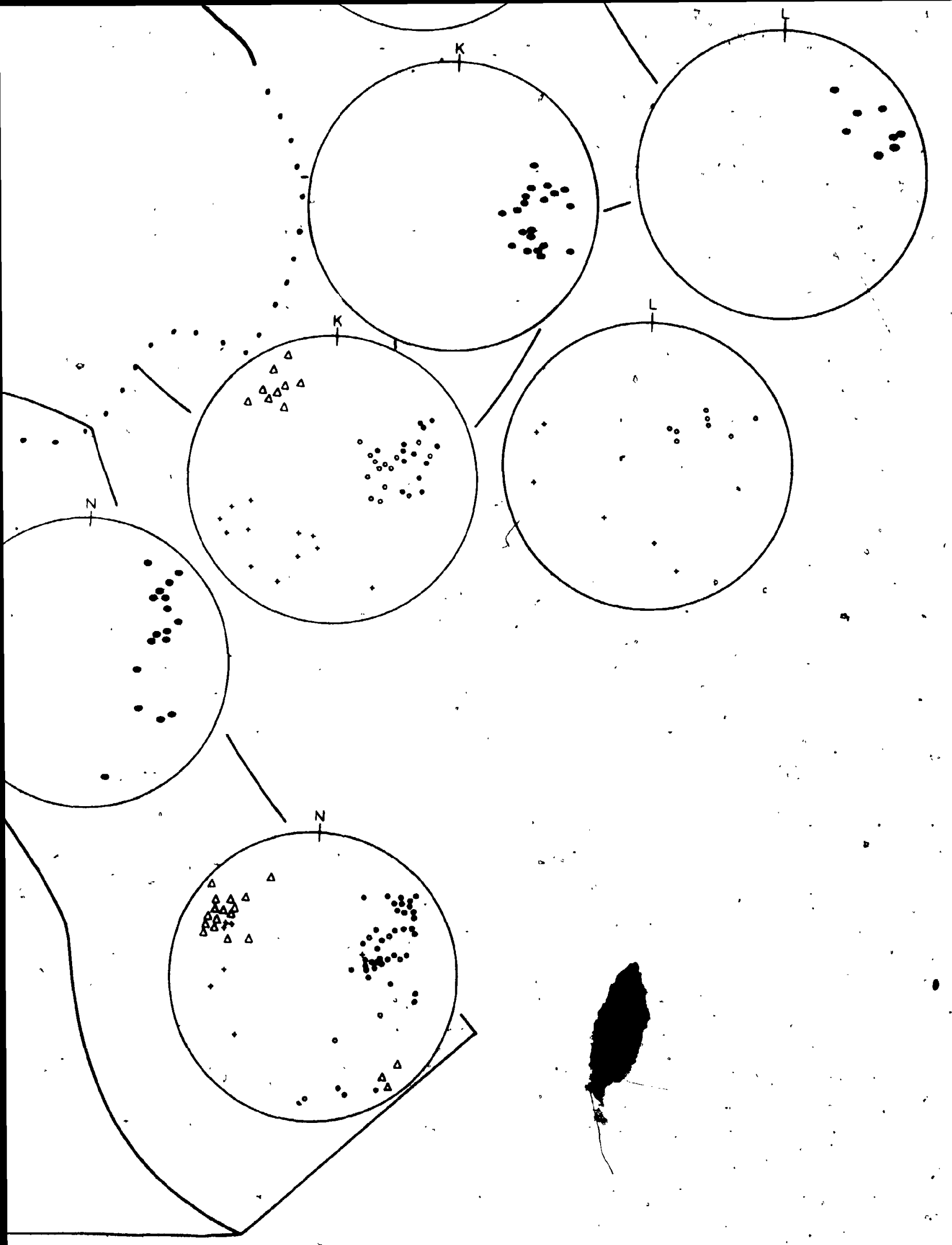


of

STRIKE \& DIP OF $D_{2}$ MINOR FOLD AX TREND \& .PLUNGE OF $D_{2}$ MINOR FOLD INTERSECTION LINEATION. SO /SO

PLUTON CONTACT.

$\therefore \quad$ ASSUMED OR INF 
fig. $12 \underline{D}_{2}$ MINOR STRUCTURES - ZN

2 of

i:

Lld axial plane, cleavage.

年

FOLD HINGE LINE, $\mathrm{S}_{\mathrm{O}-1} \mathrm{~S}_{2}$

2

$\circ$

R INFERRED.

$\backslash$ 
1 
$a$ 


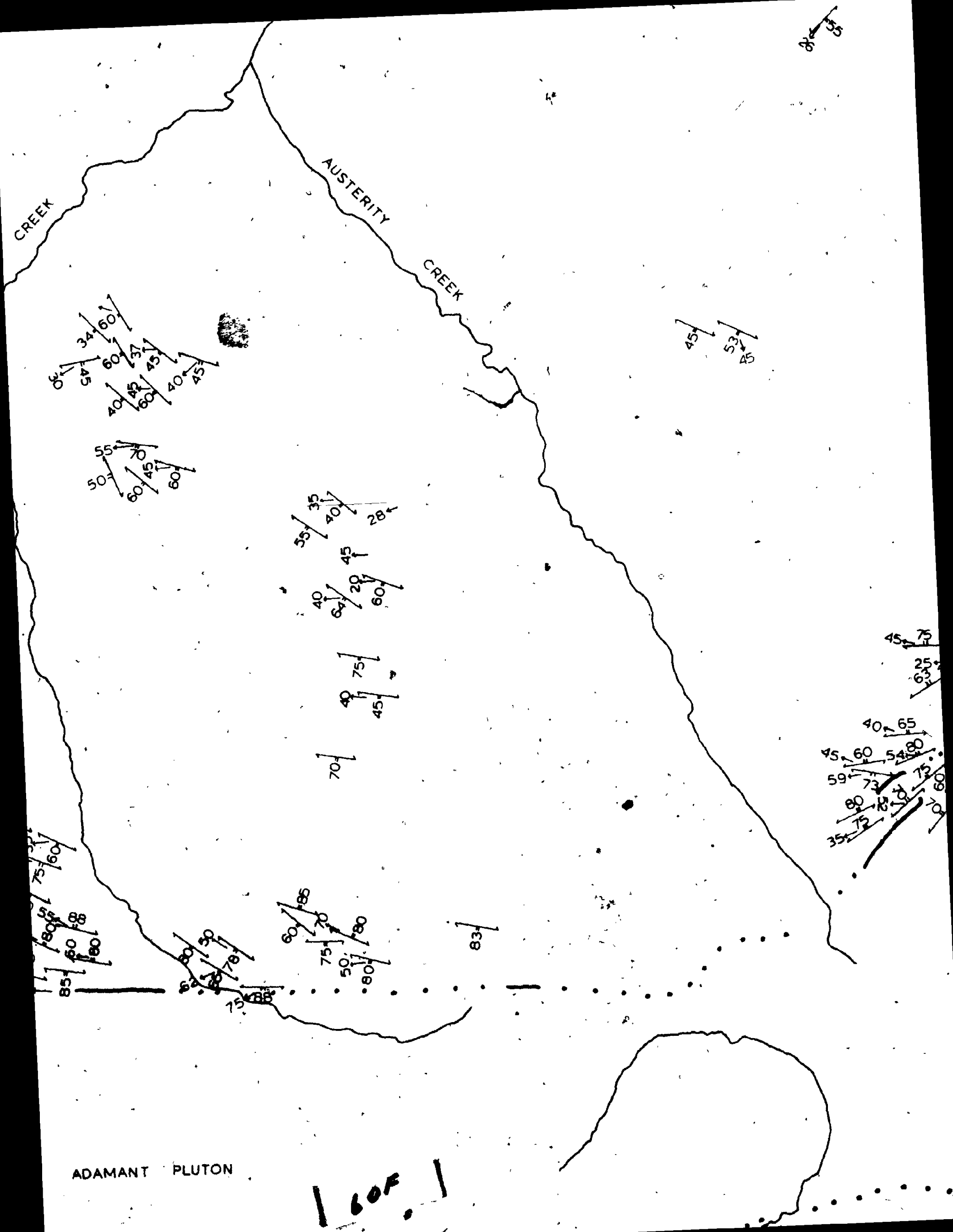




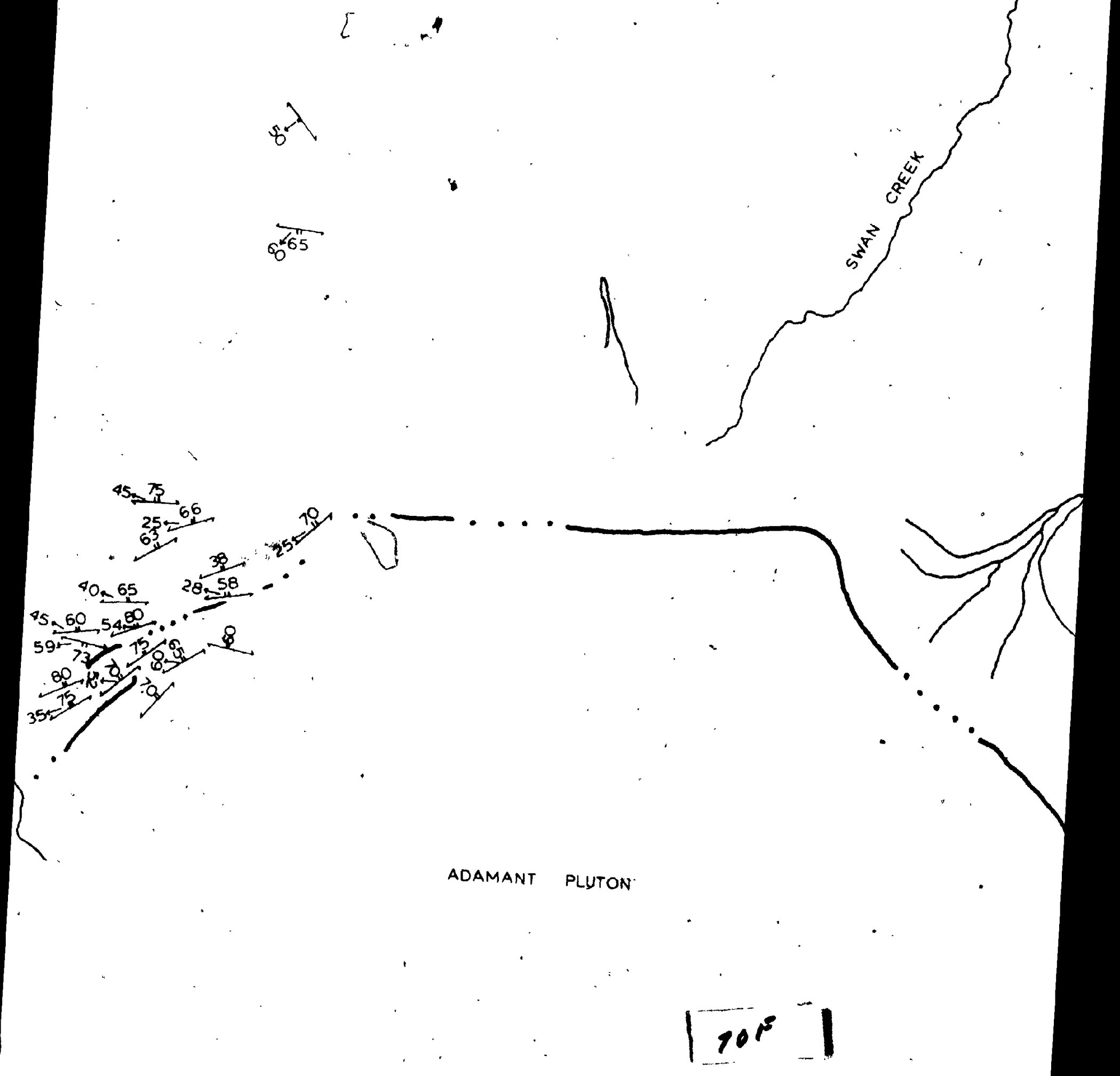




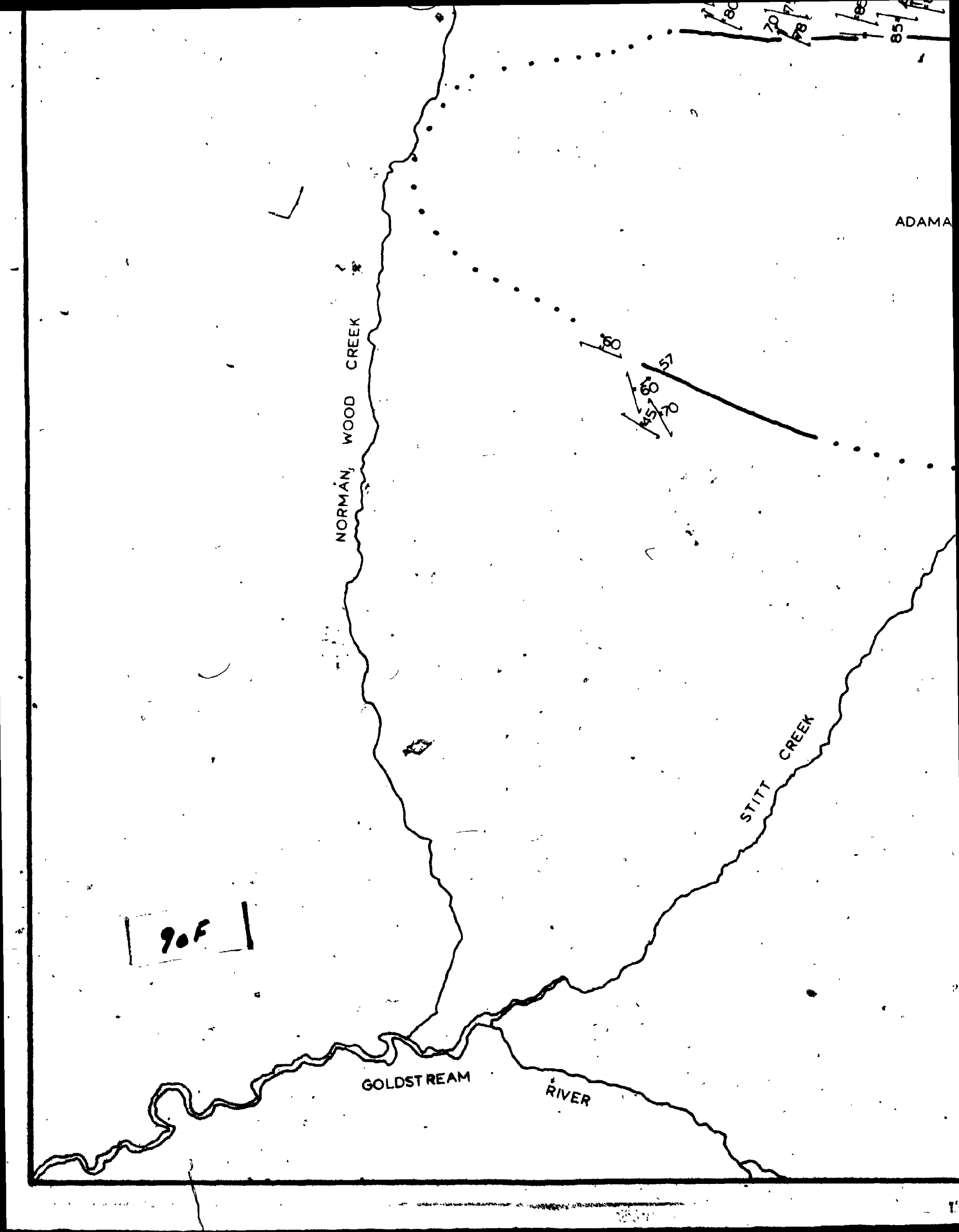




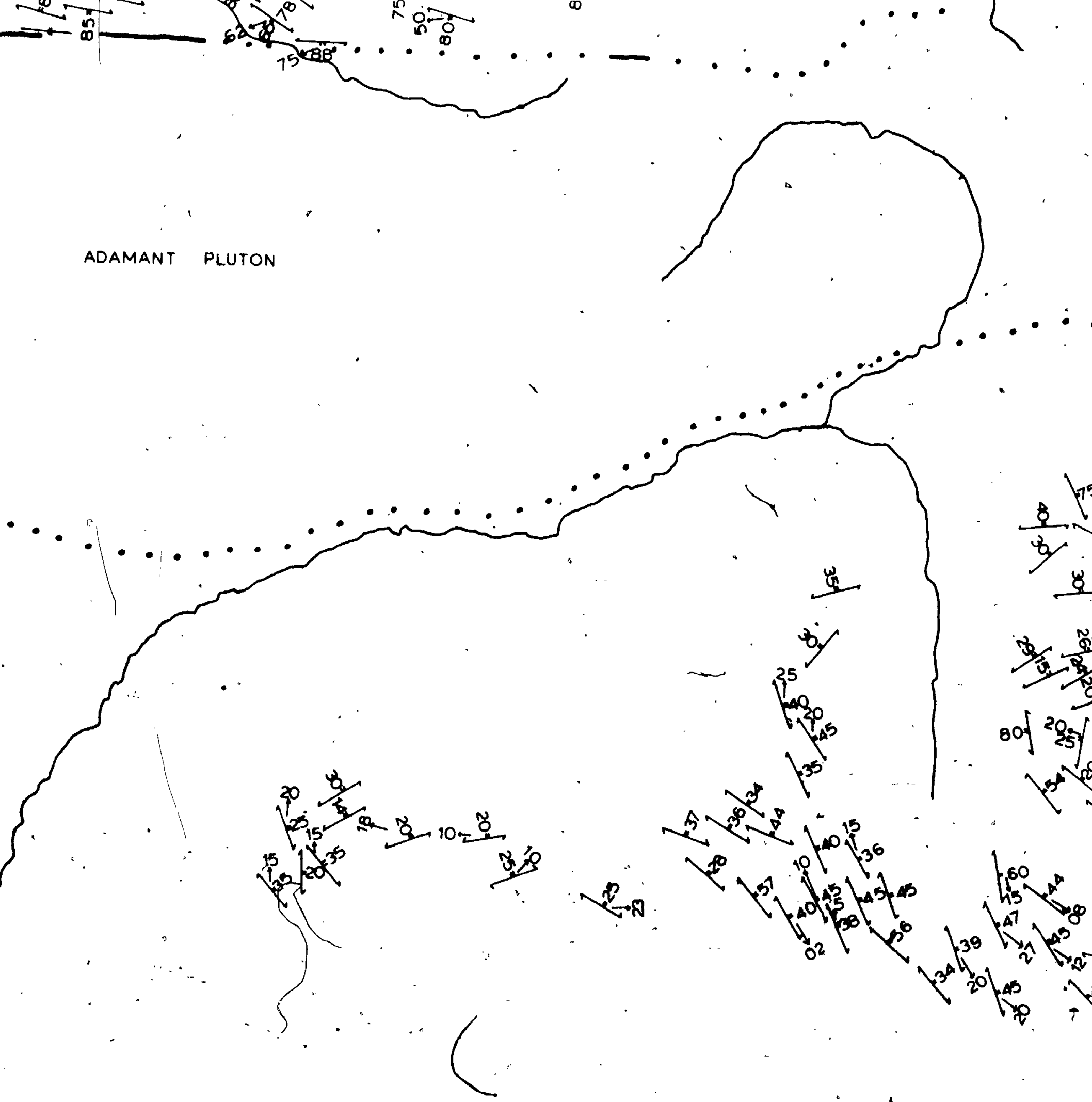




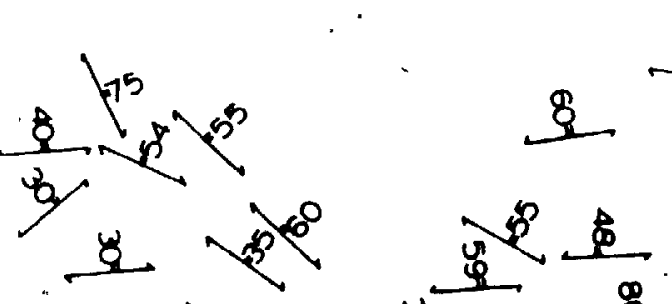

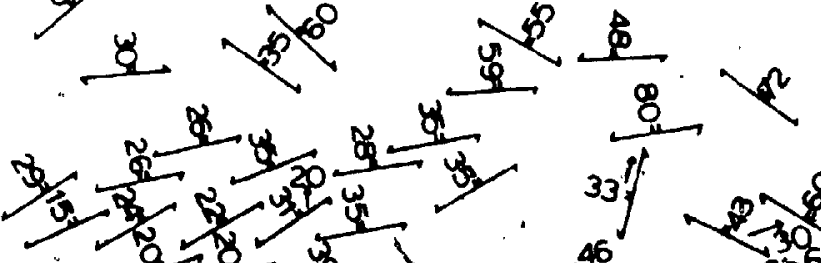
of 2053 ,

1 (1)

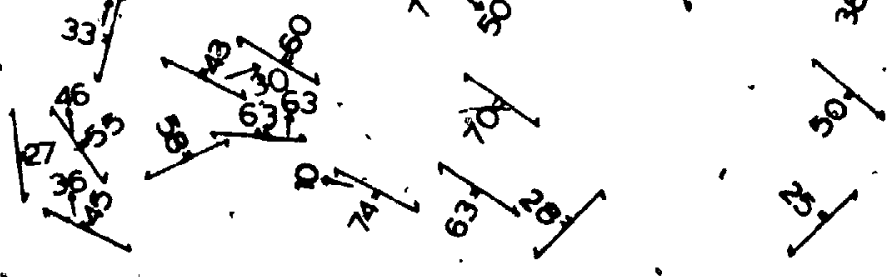

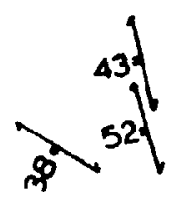
$0^{2}$
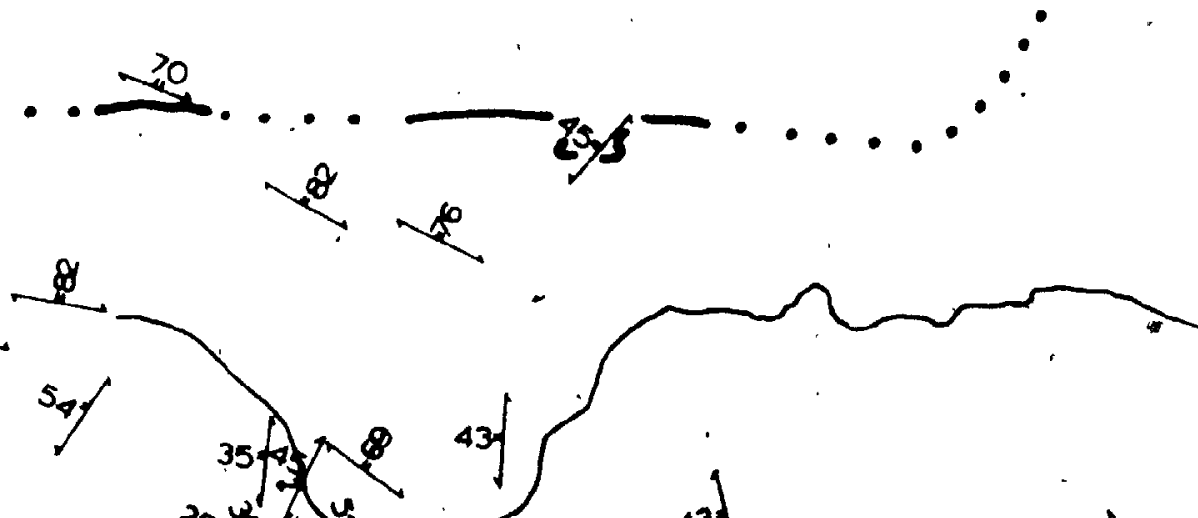


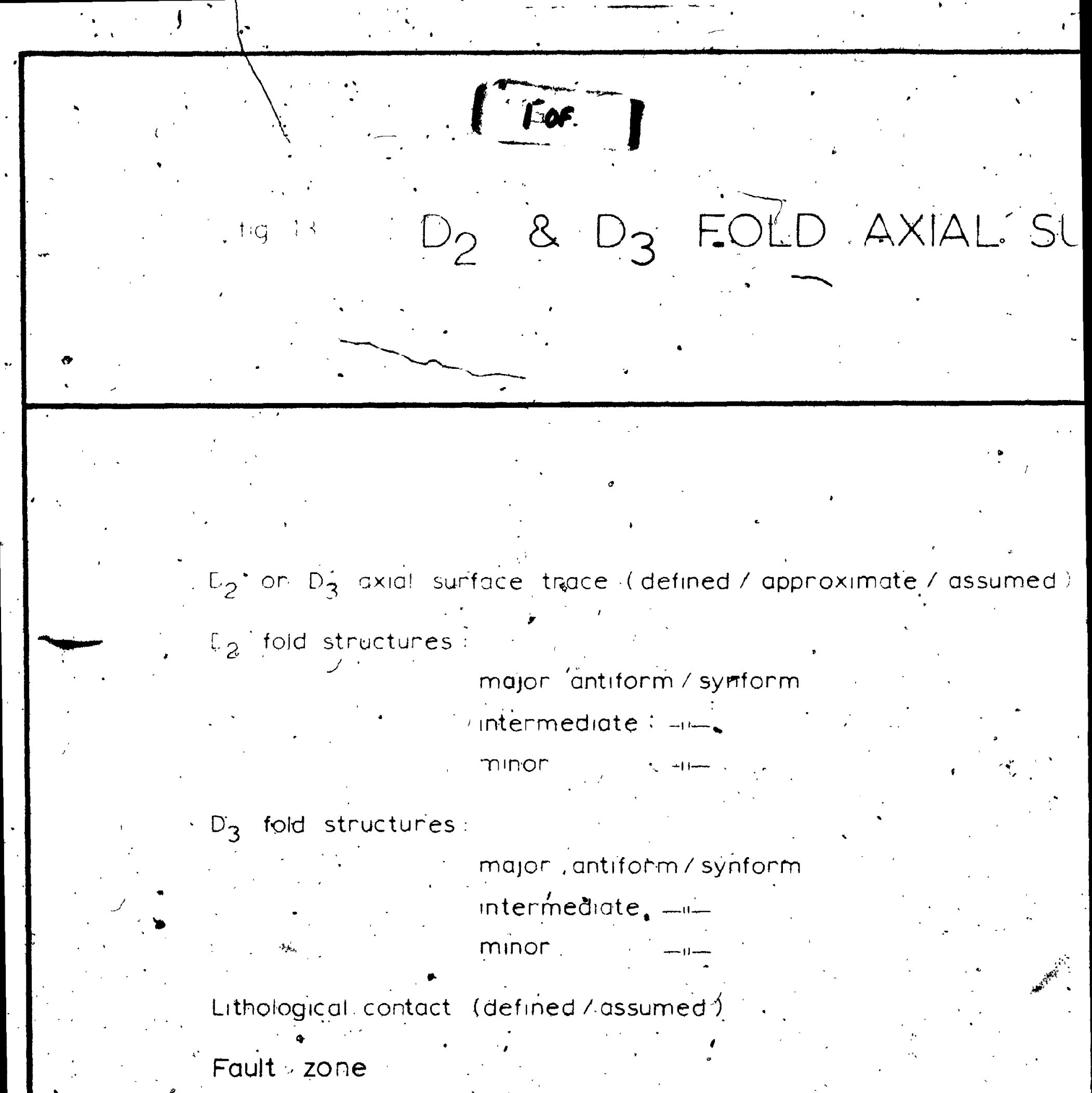




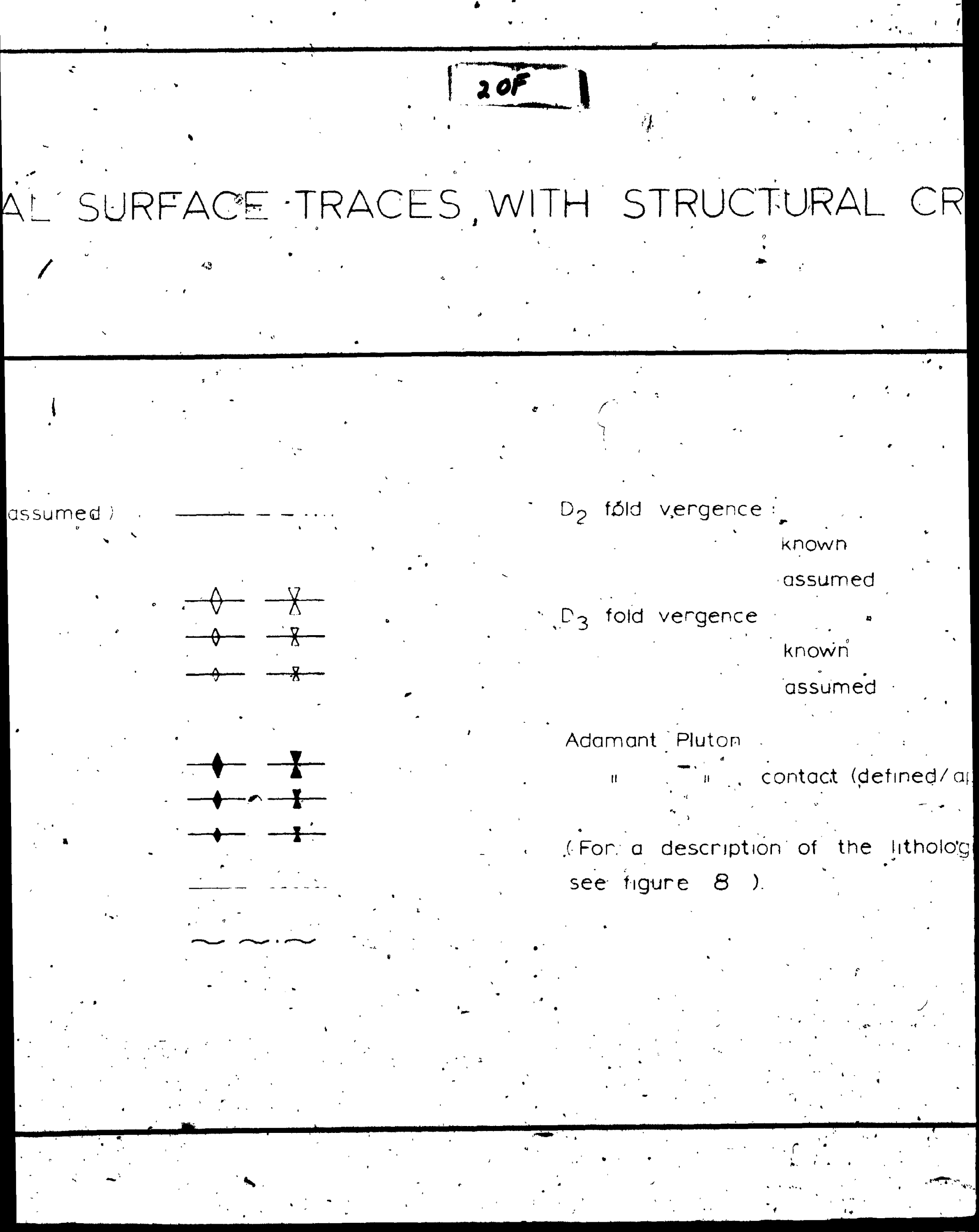


AL: CROSS-SECTIONS - ZONE A.
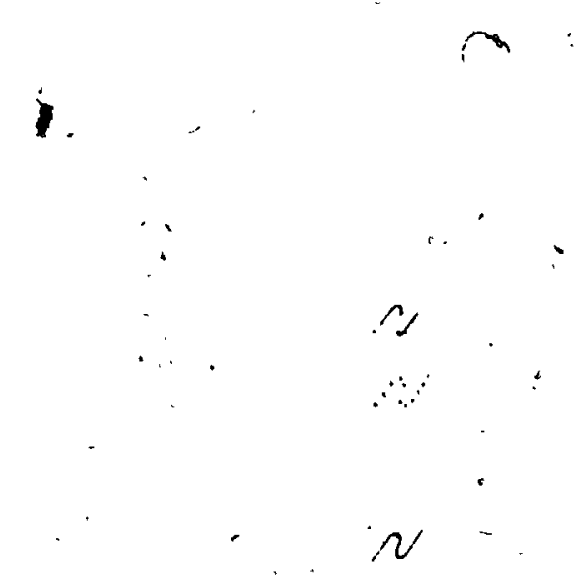

Gefined/ approximate)

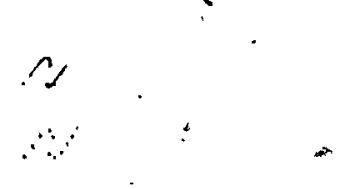
med.

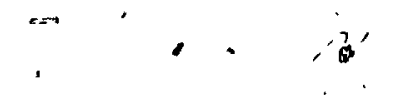

the lithological units
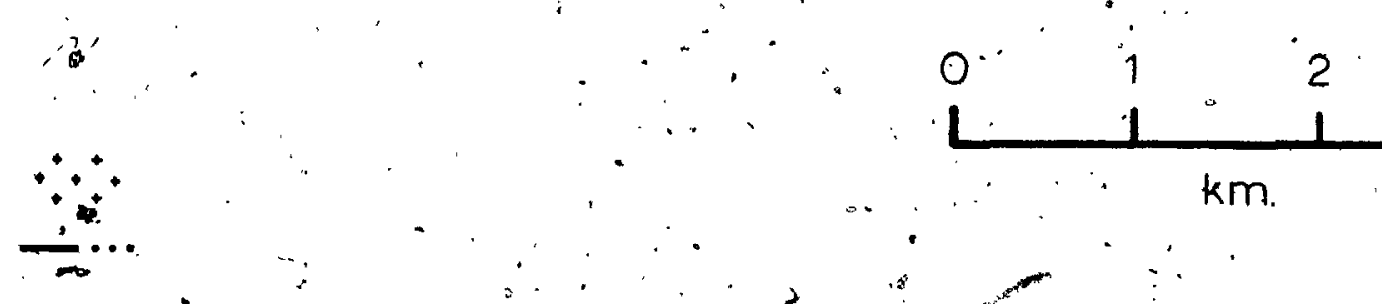



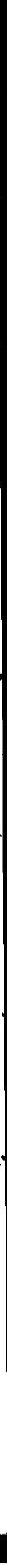




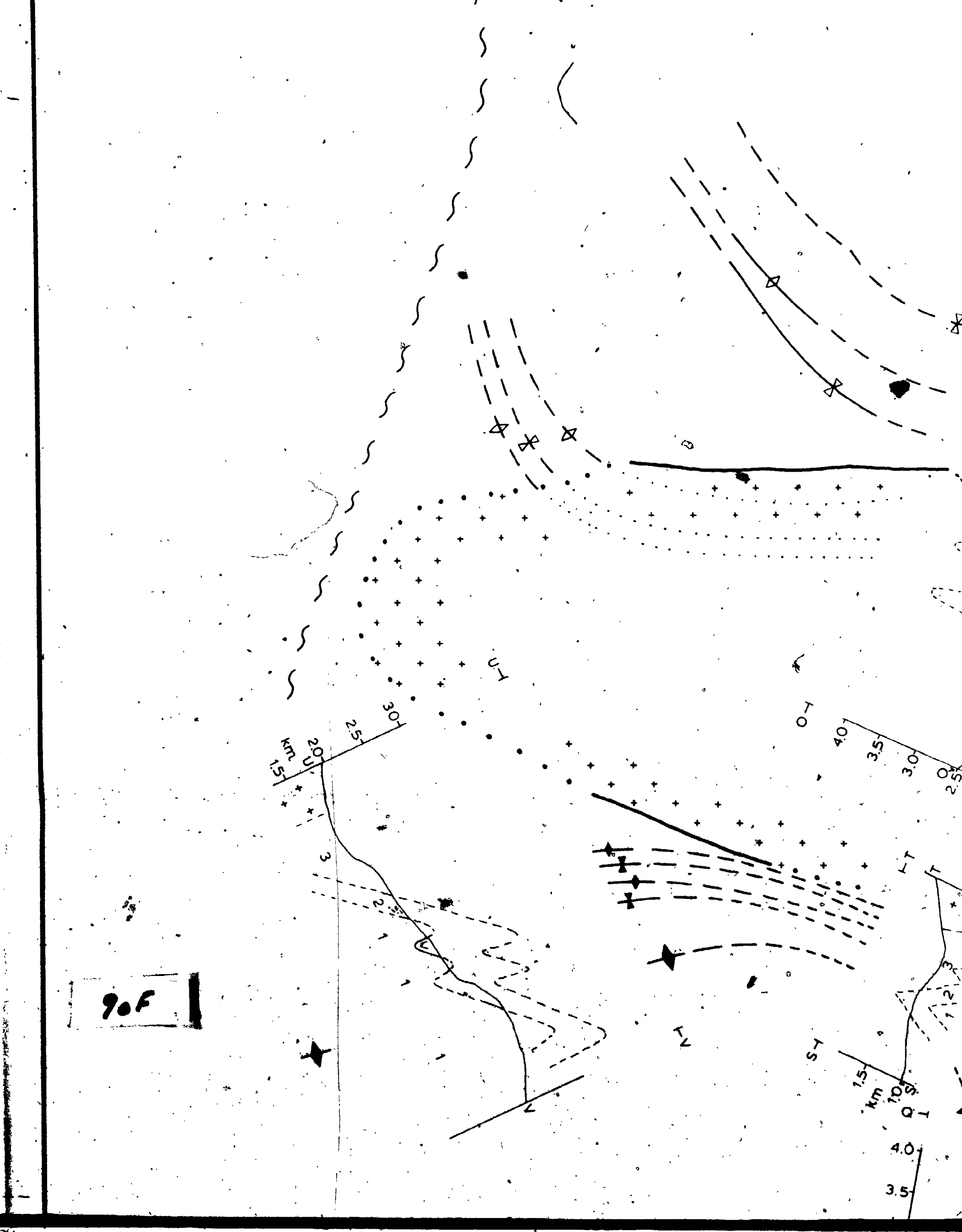




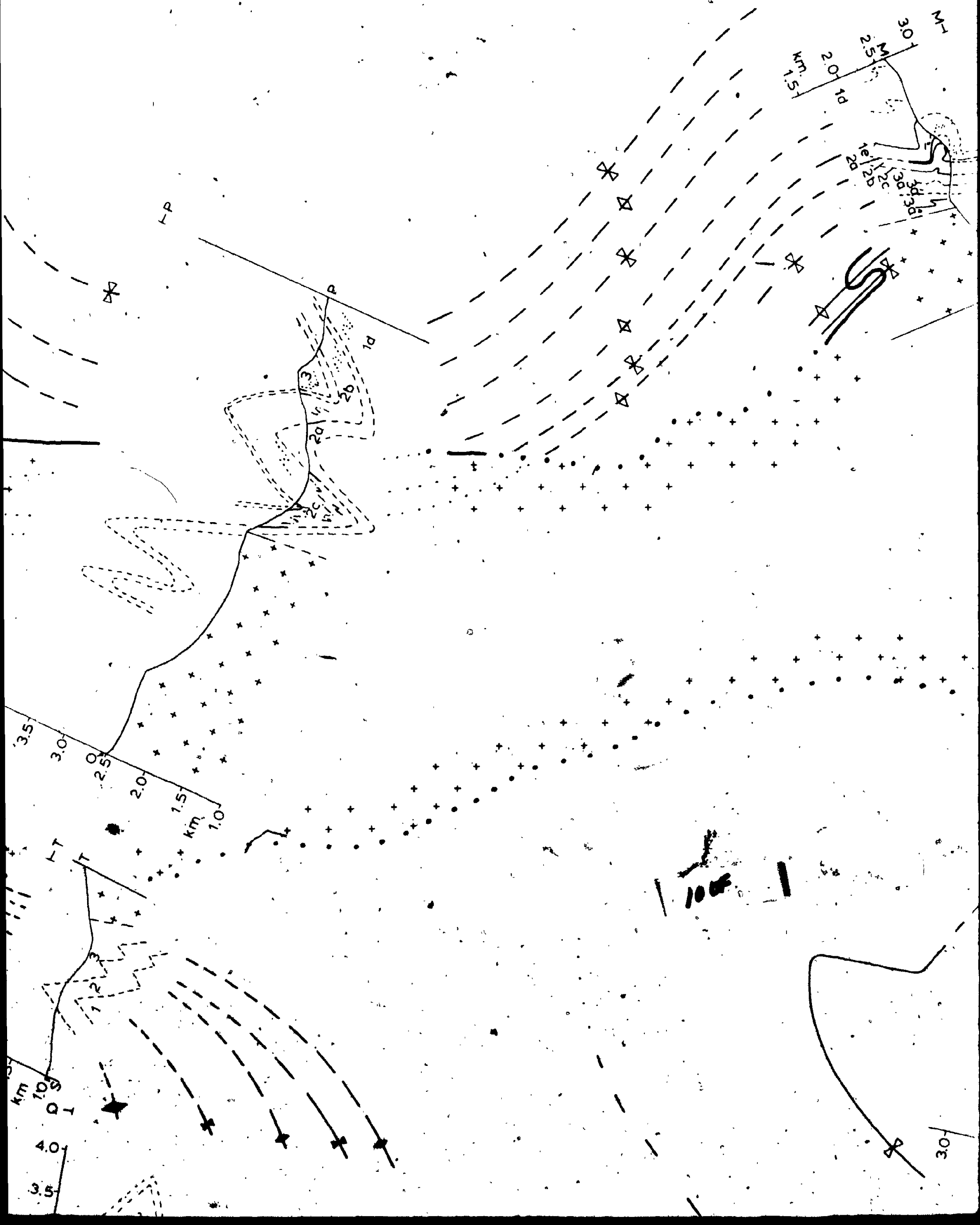



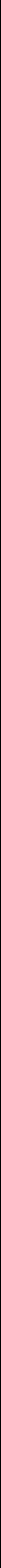


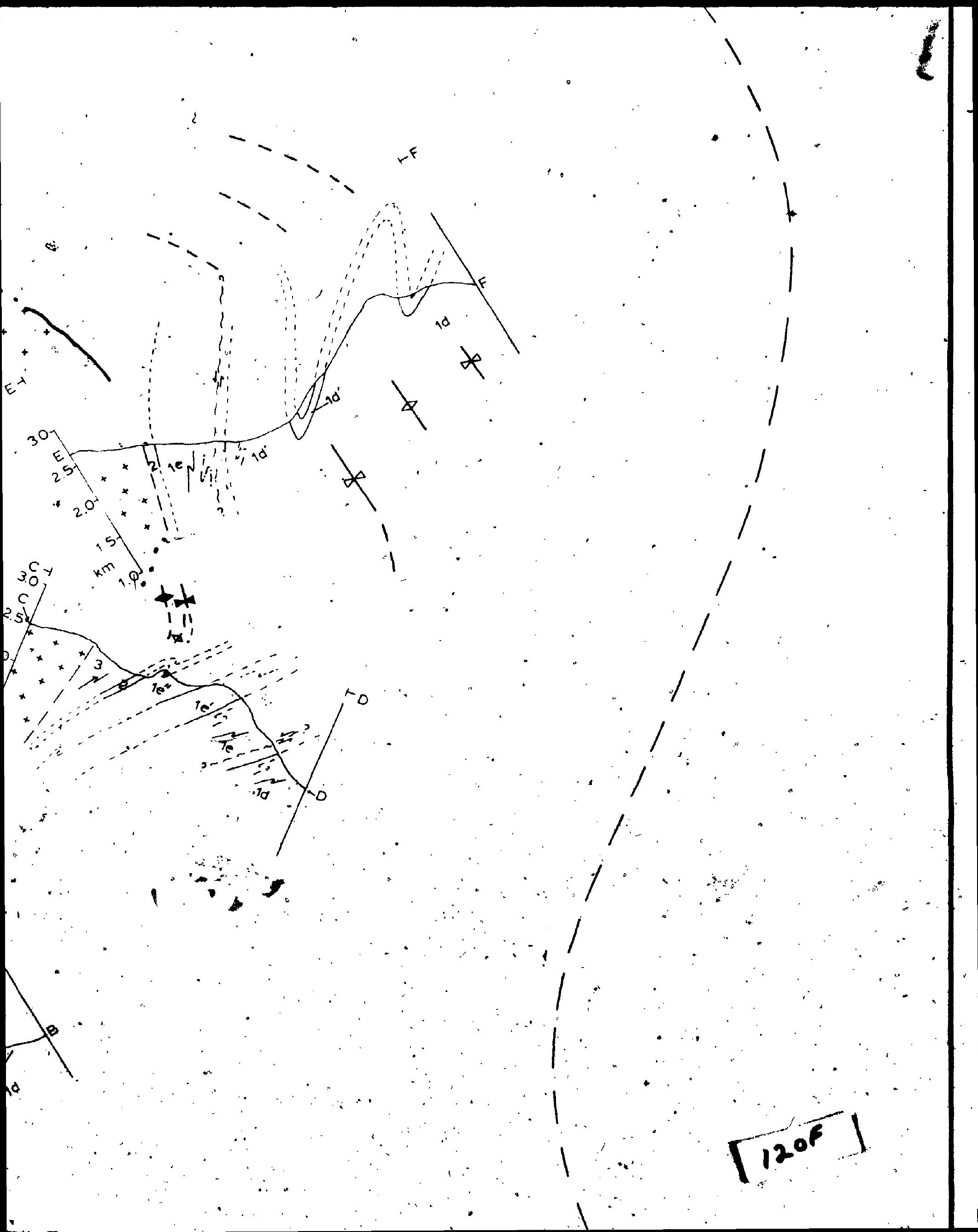




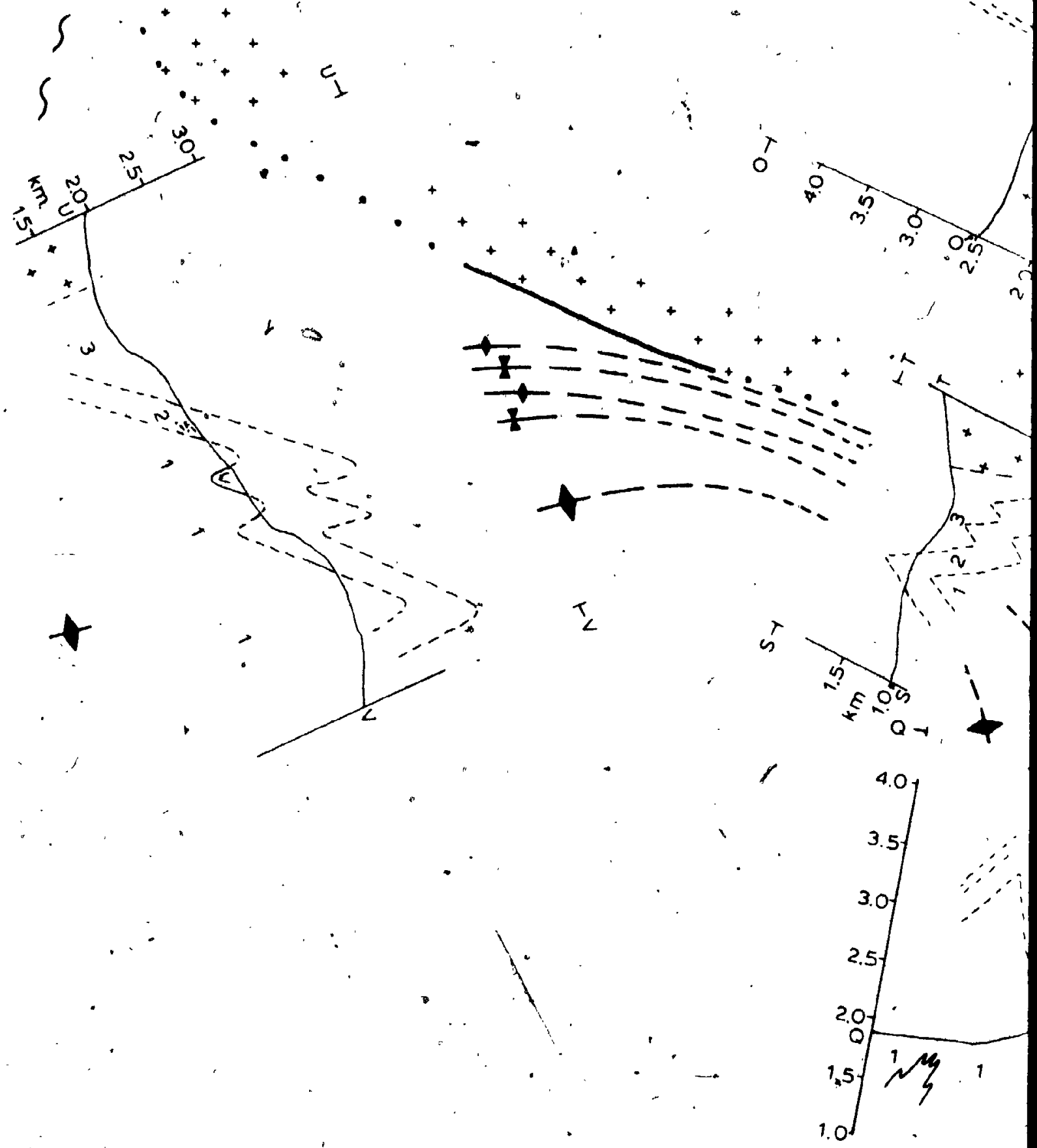




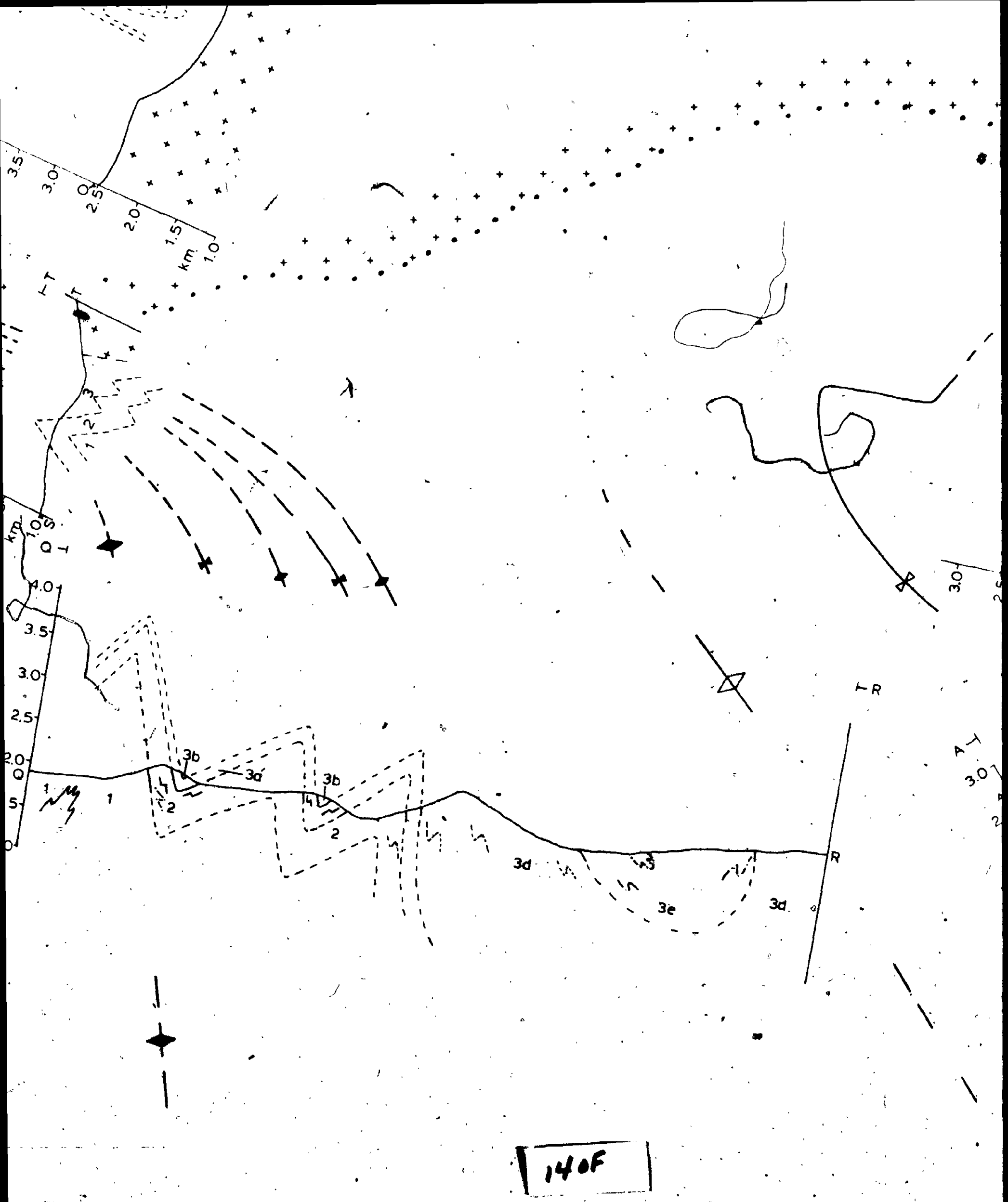




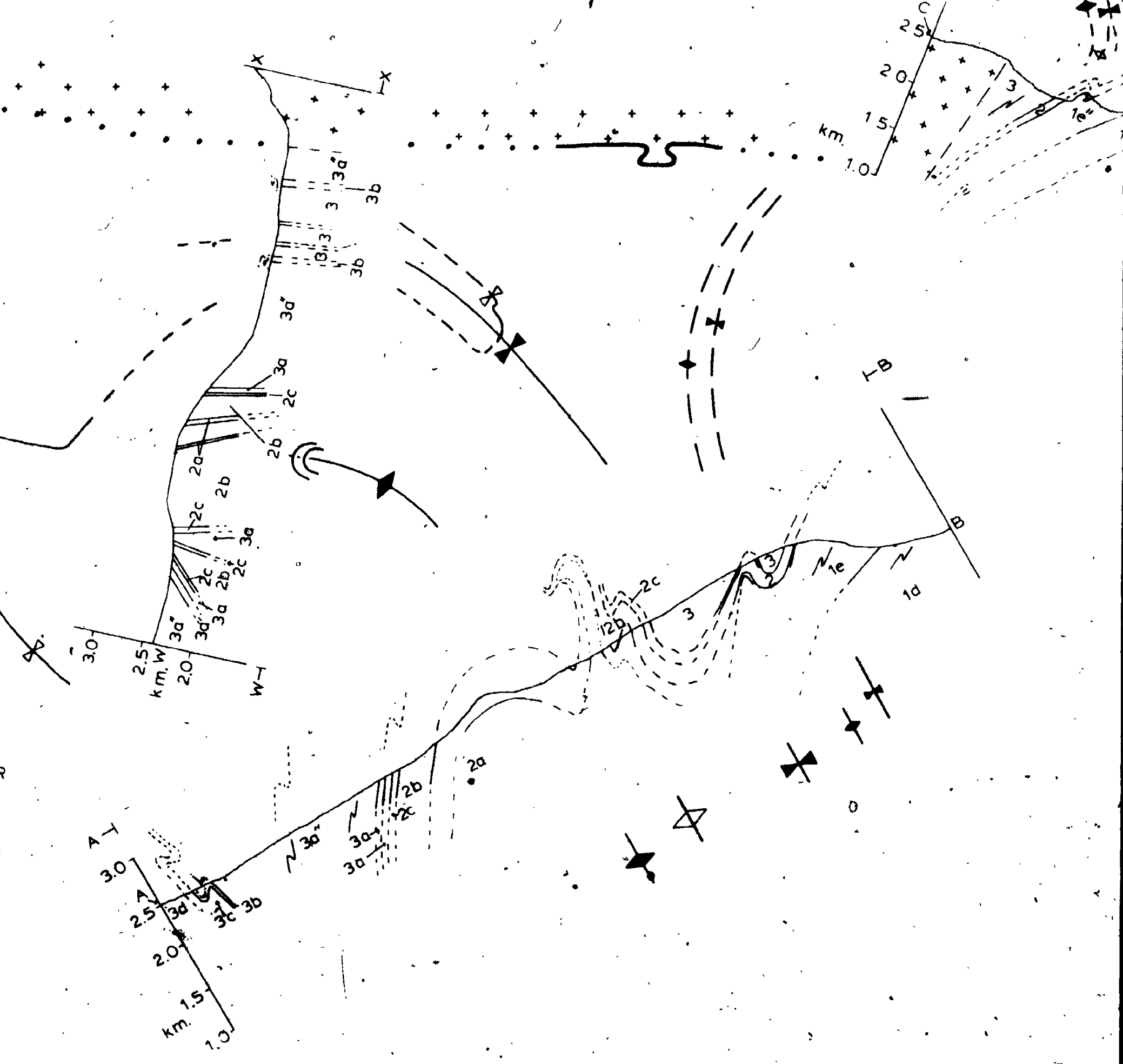



1 of

i.

-STRIKE \& DIP.) OF $D_{3}$ MINOR FOLD AXIAL TREND \& PLUNGE OF $D_{3}$. MINOR FOLD. HIN INTERSECTION LINEATION:

- NORMAN WOOD CREEK. FAULT. ZONE 
4

1

fig $14 \quad D_{3}$

3 MINOR STRUCTURES ZONE A

d axial plane, cleavage.

OLD HINGE LINE, $\mathrm{S}_{\mathrm{O}-1}-\mathrm{S}_{3}$

$\nabla_{s y}$ 
<smiles>C1CCCC1</smiles>

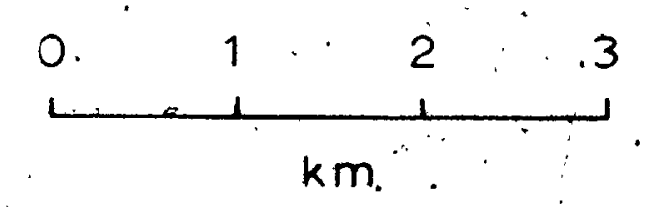




\section{पक}

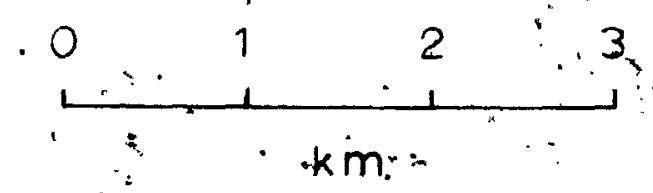
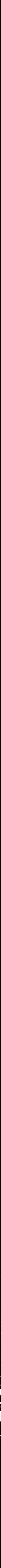


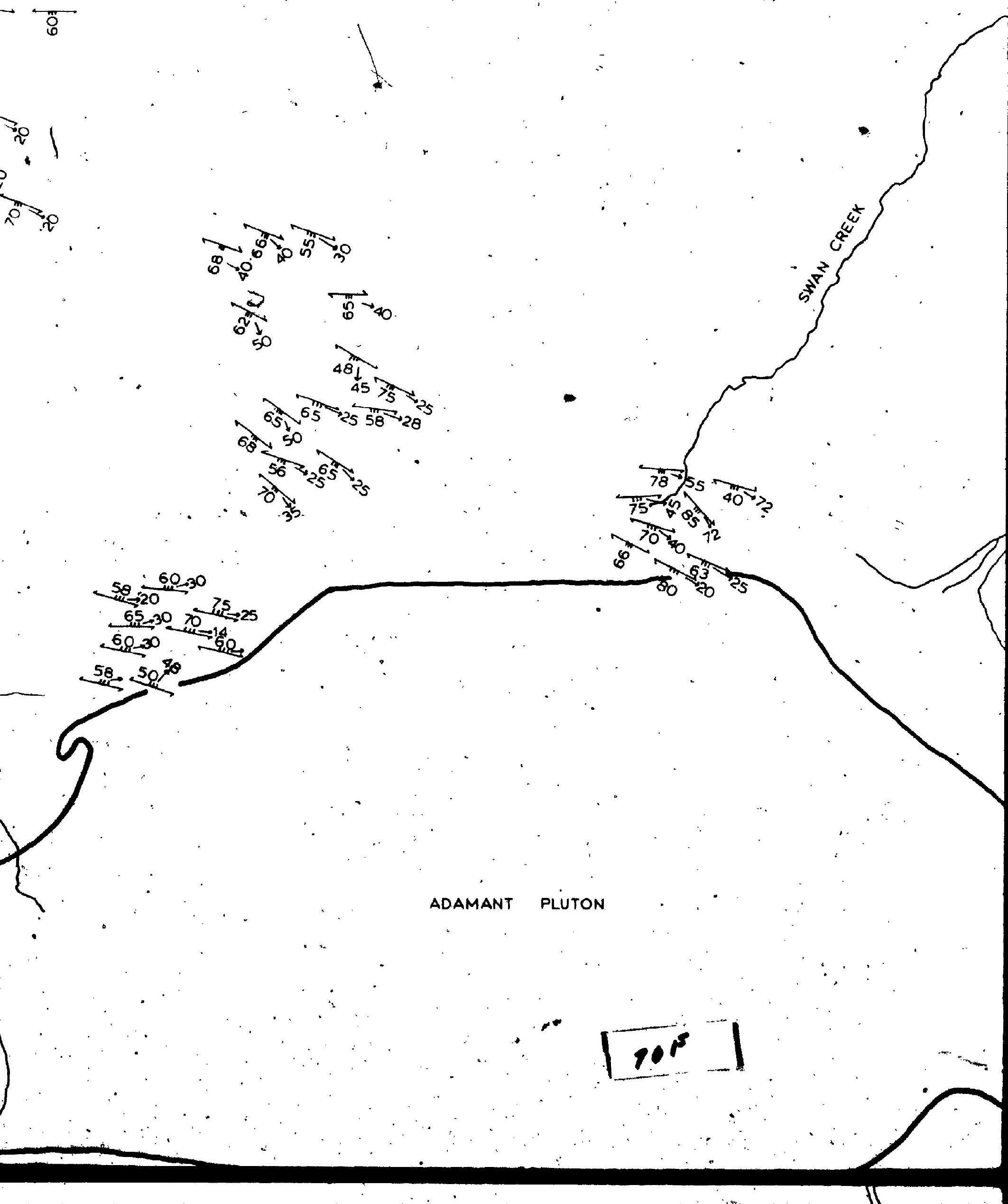




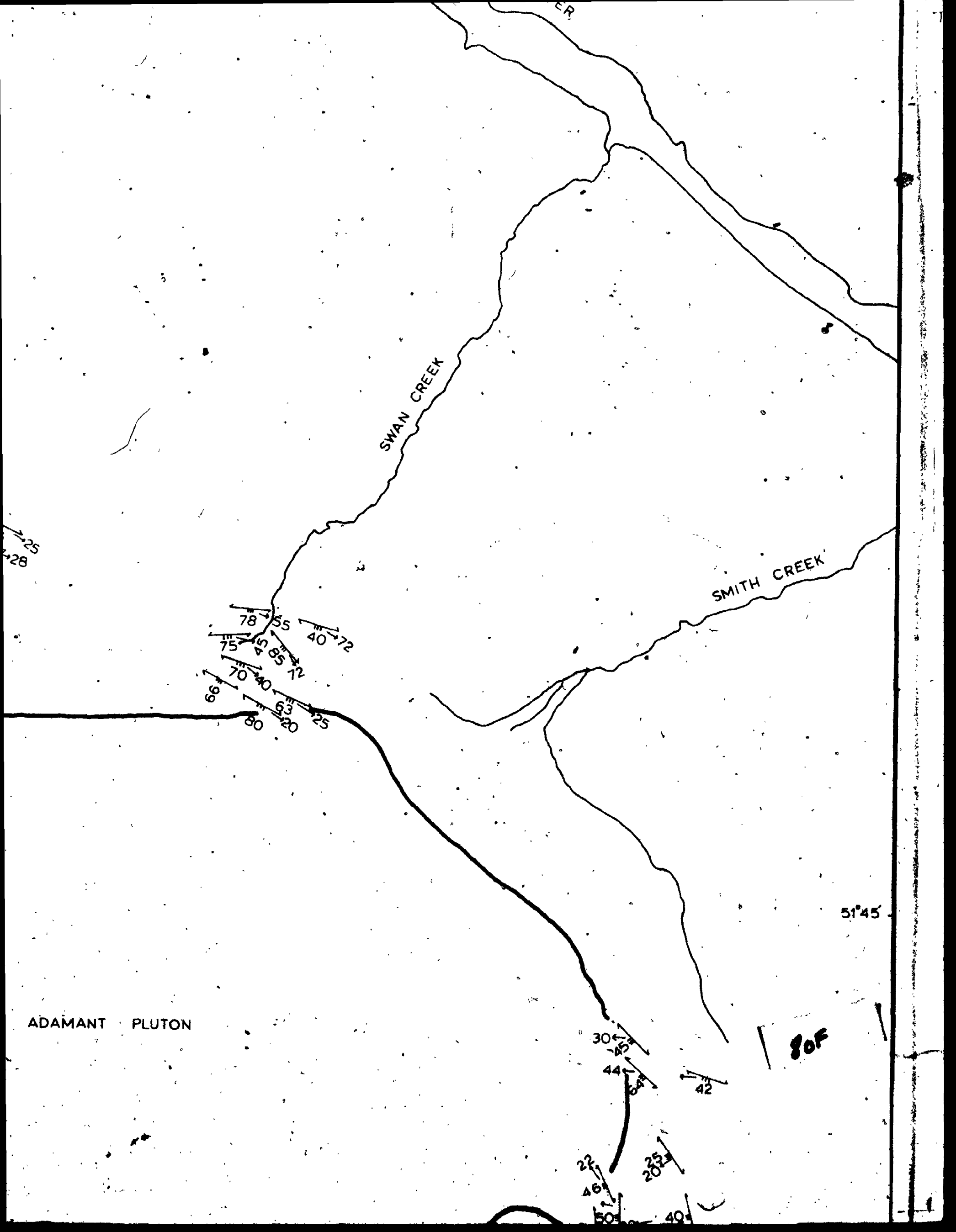





$$
\text { I of } 1
$$

fig. 15 


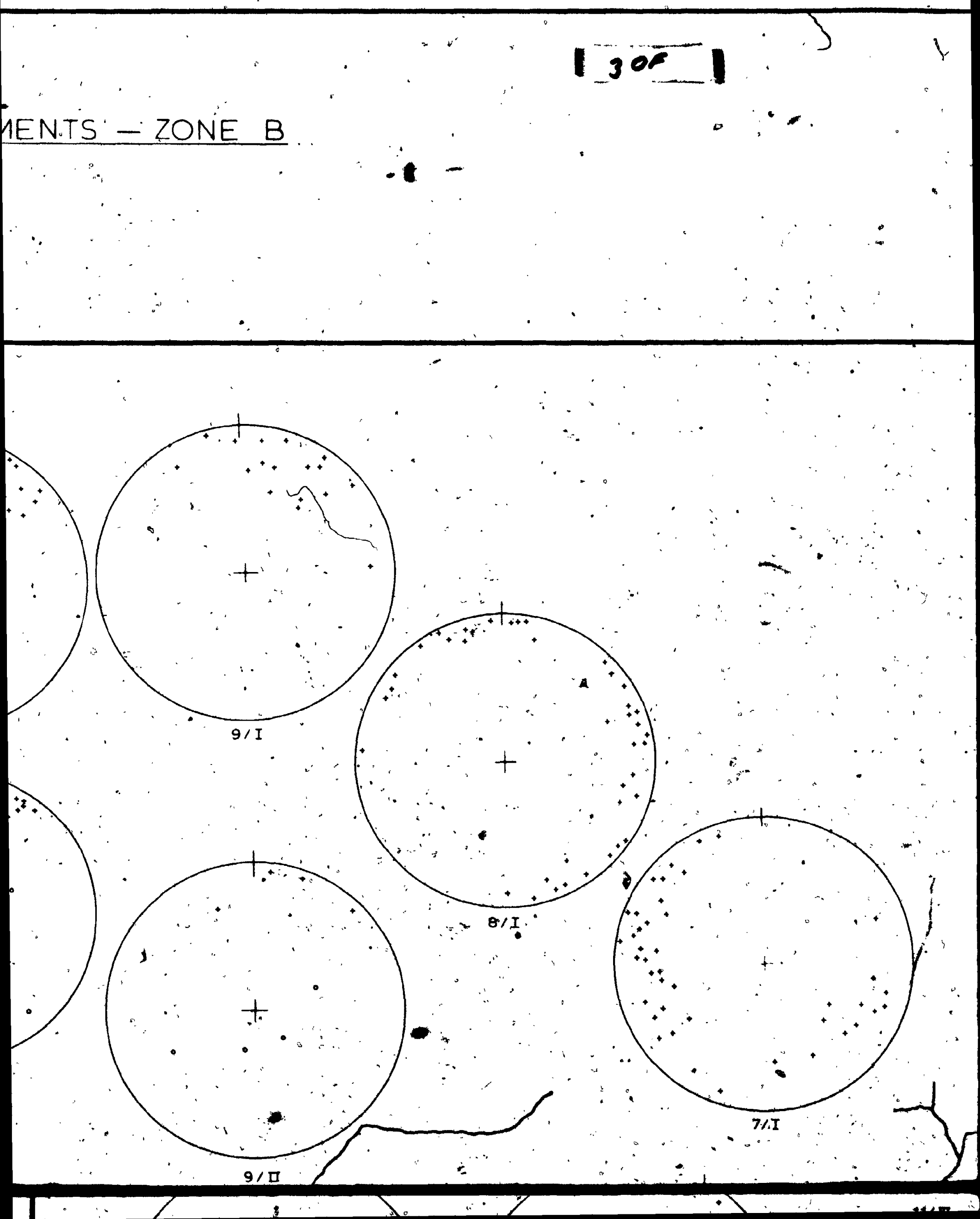





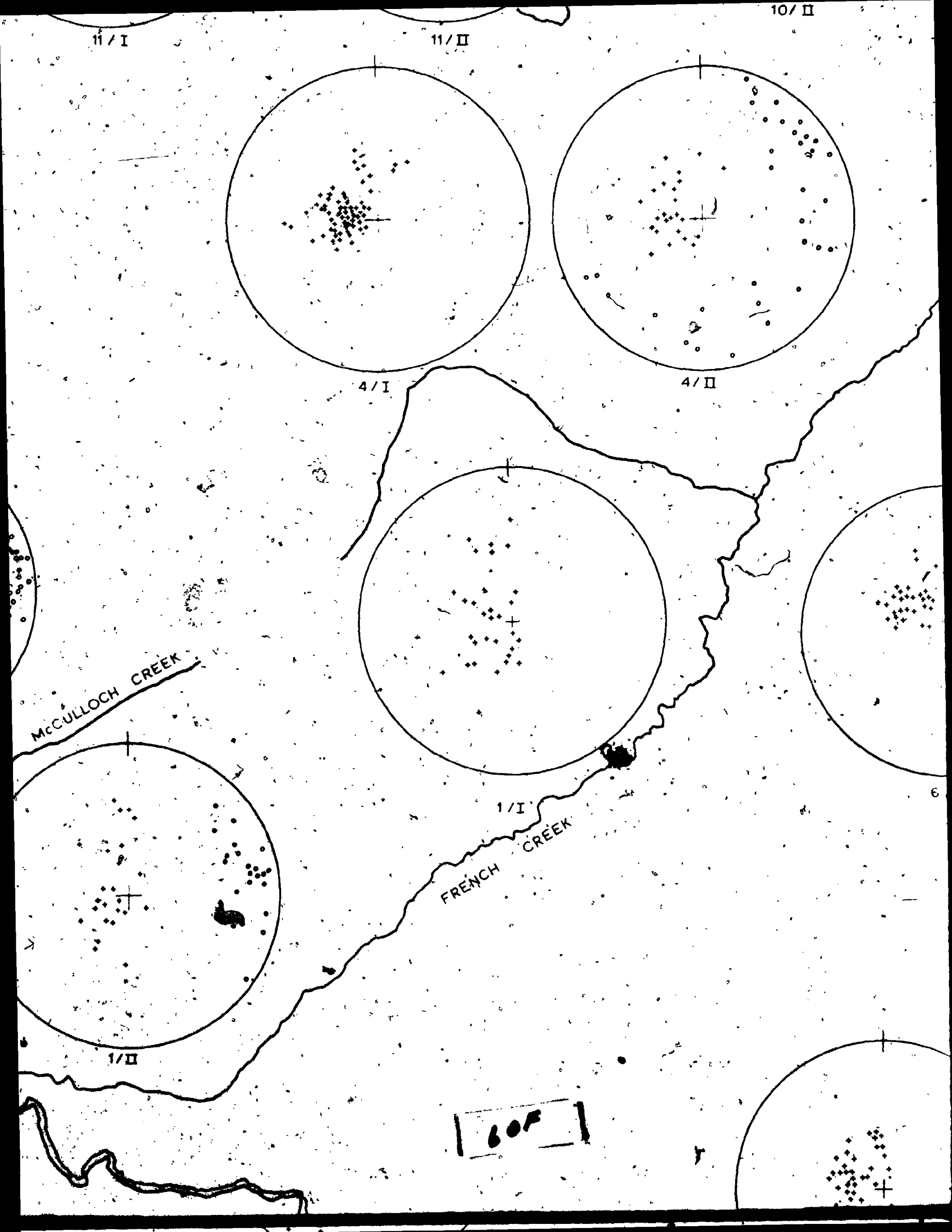





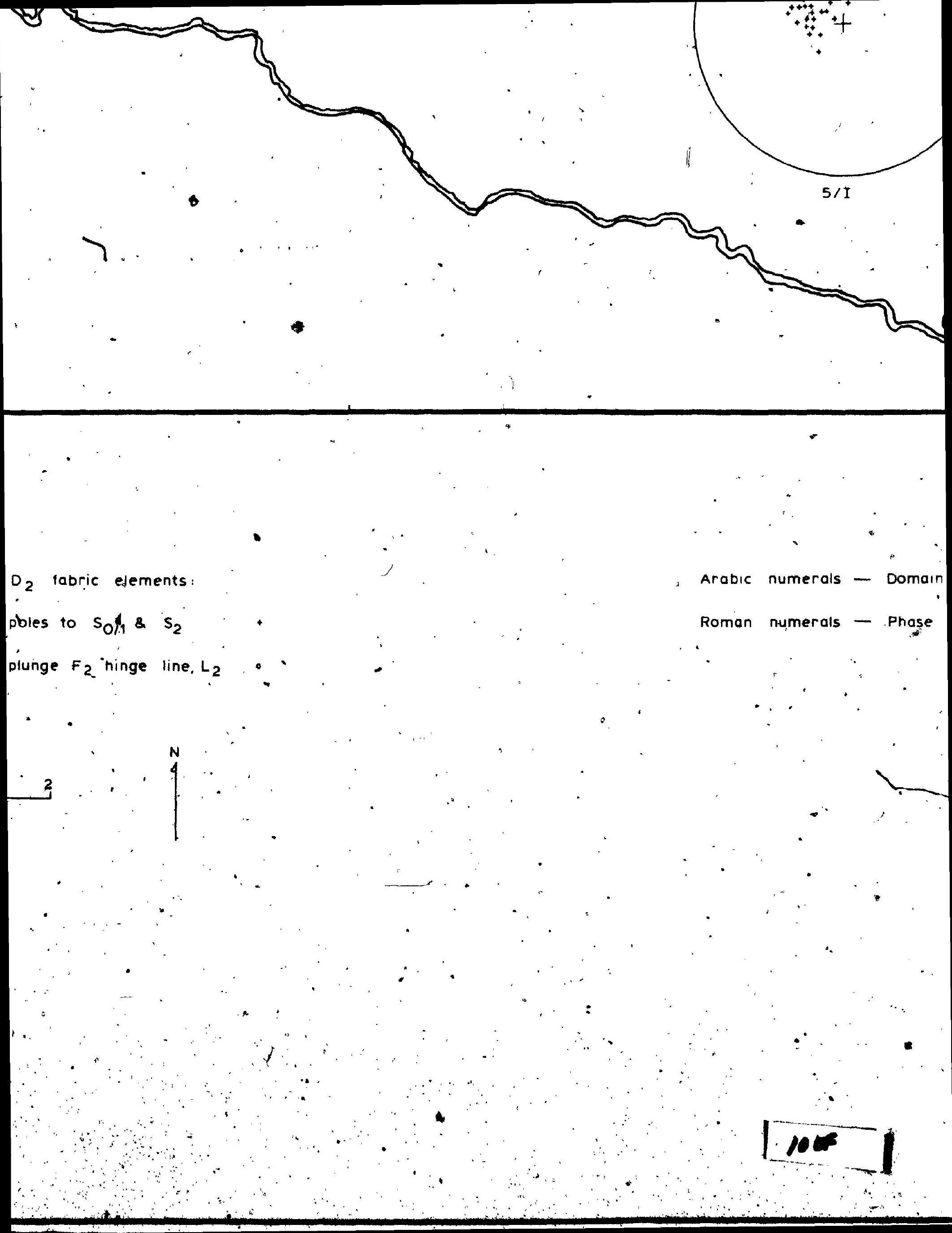




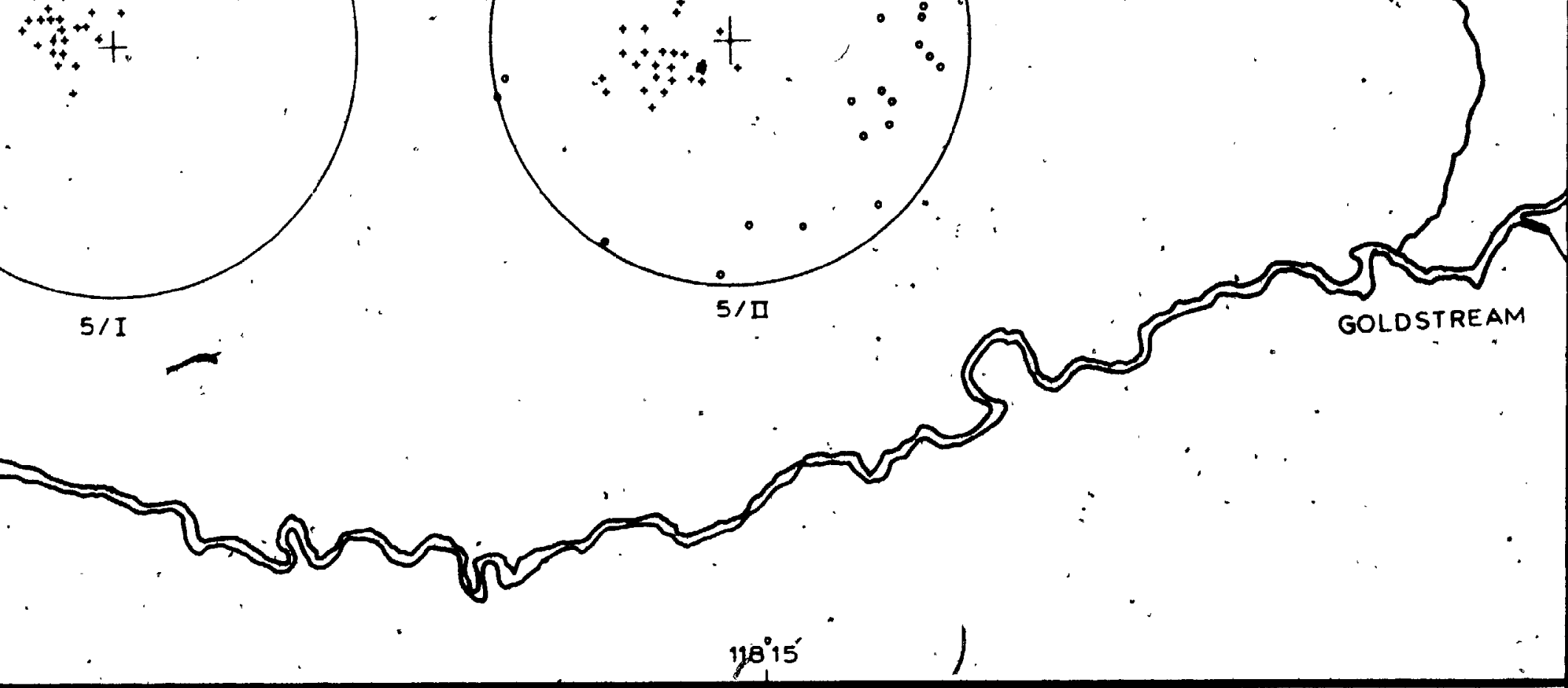

umezals - Domain number.

- Bigmouth. I Plution. I uumerals - Phase of deformation.
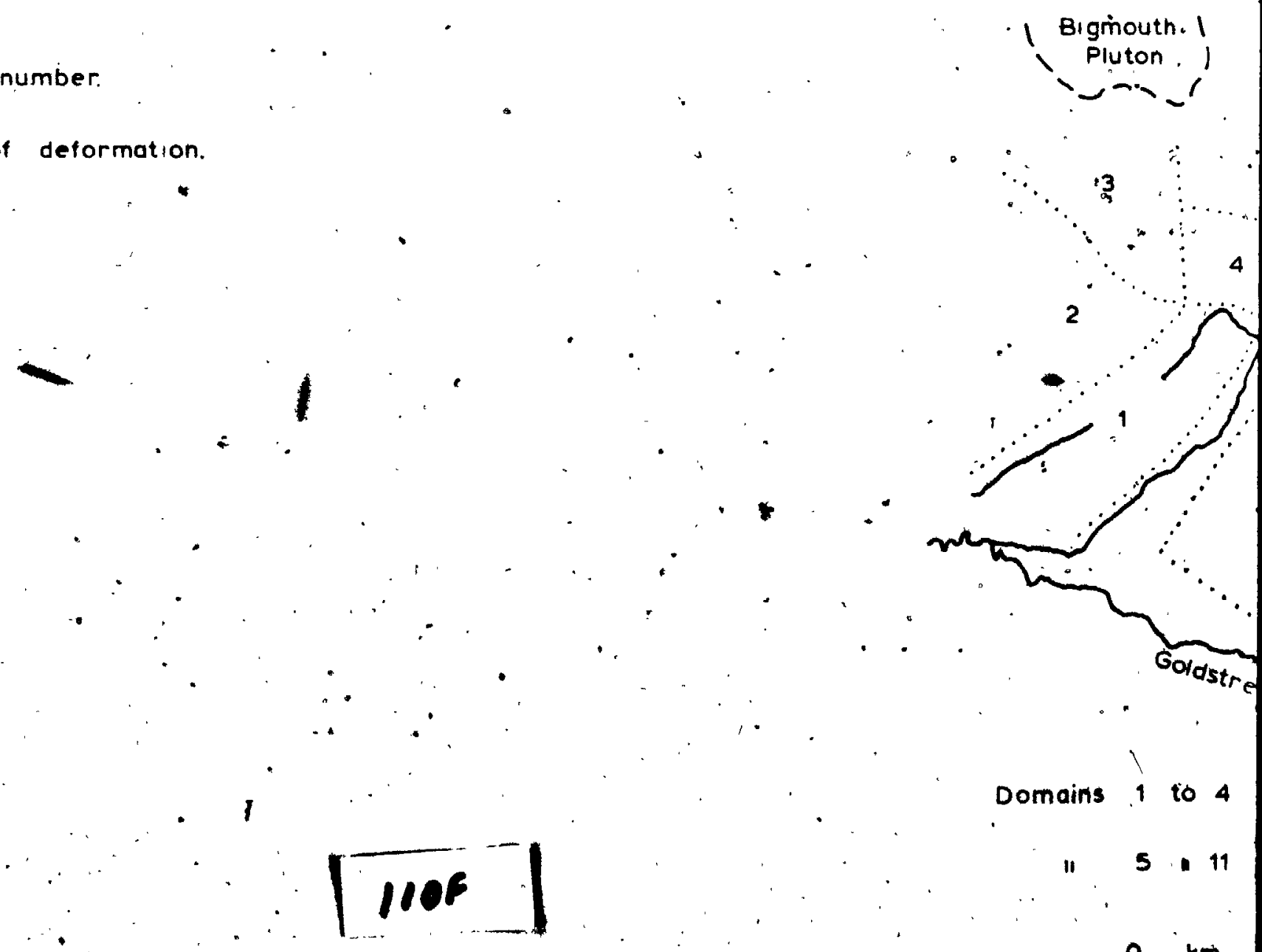

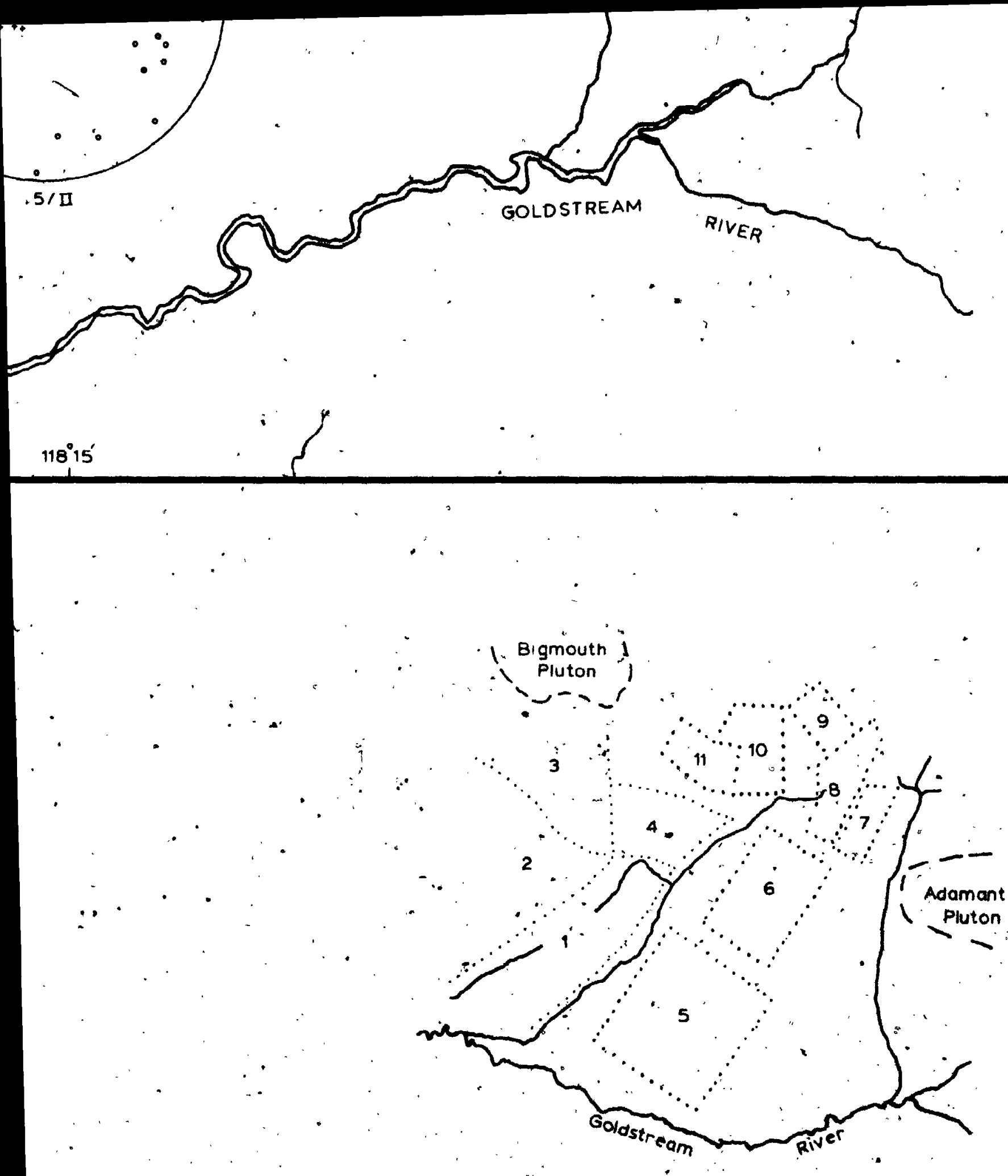

Domains 1 to 4 influsive - van Der Leeden, 1976 $A$

$$
\text { " } 5 \text { "11 i" - Franzen, } 1974 .
$$

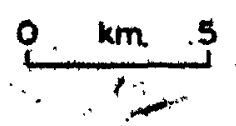

$120=12$ 


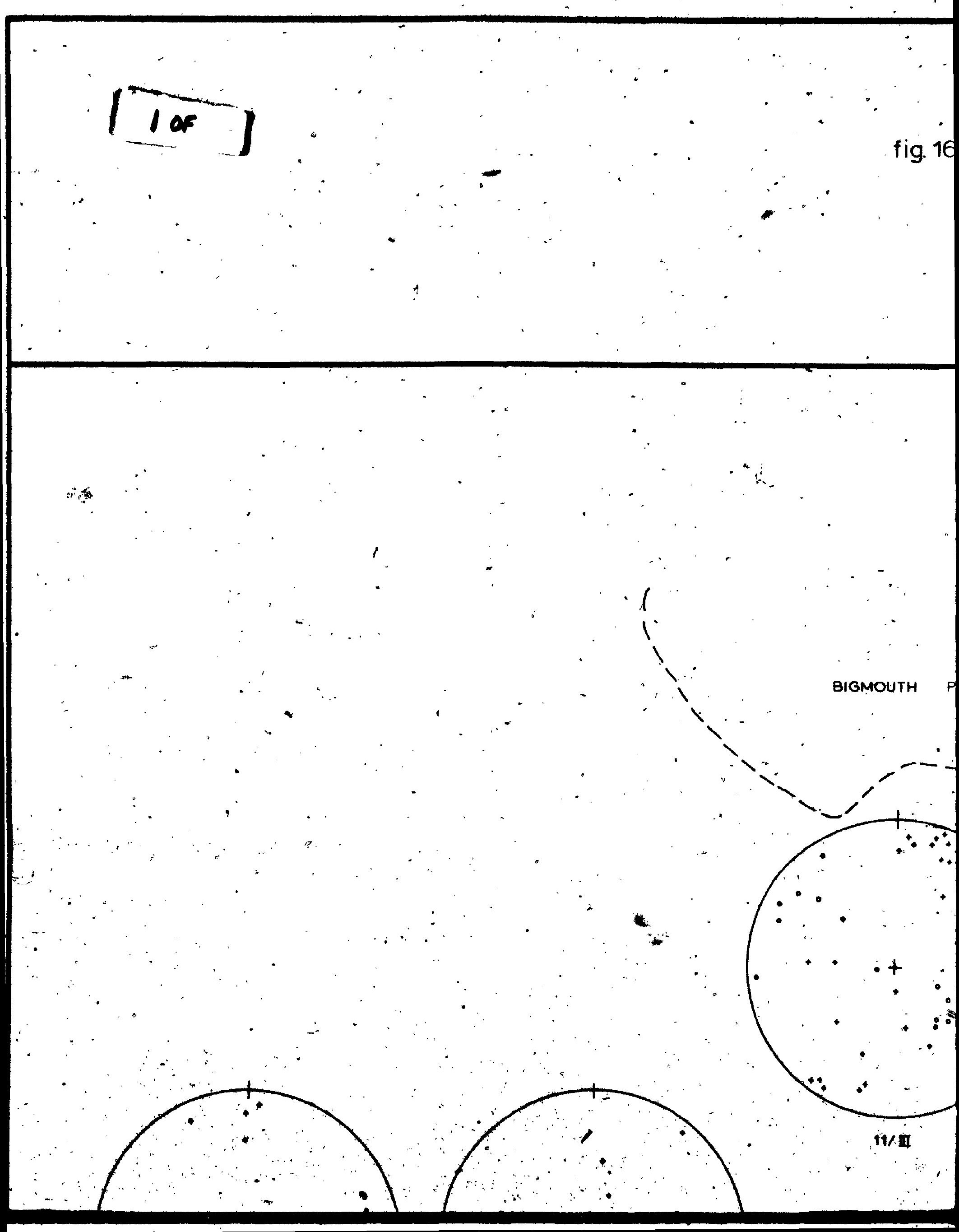






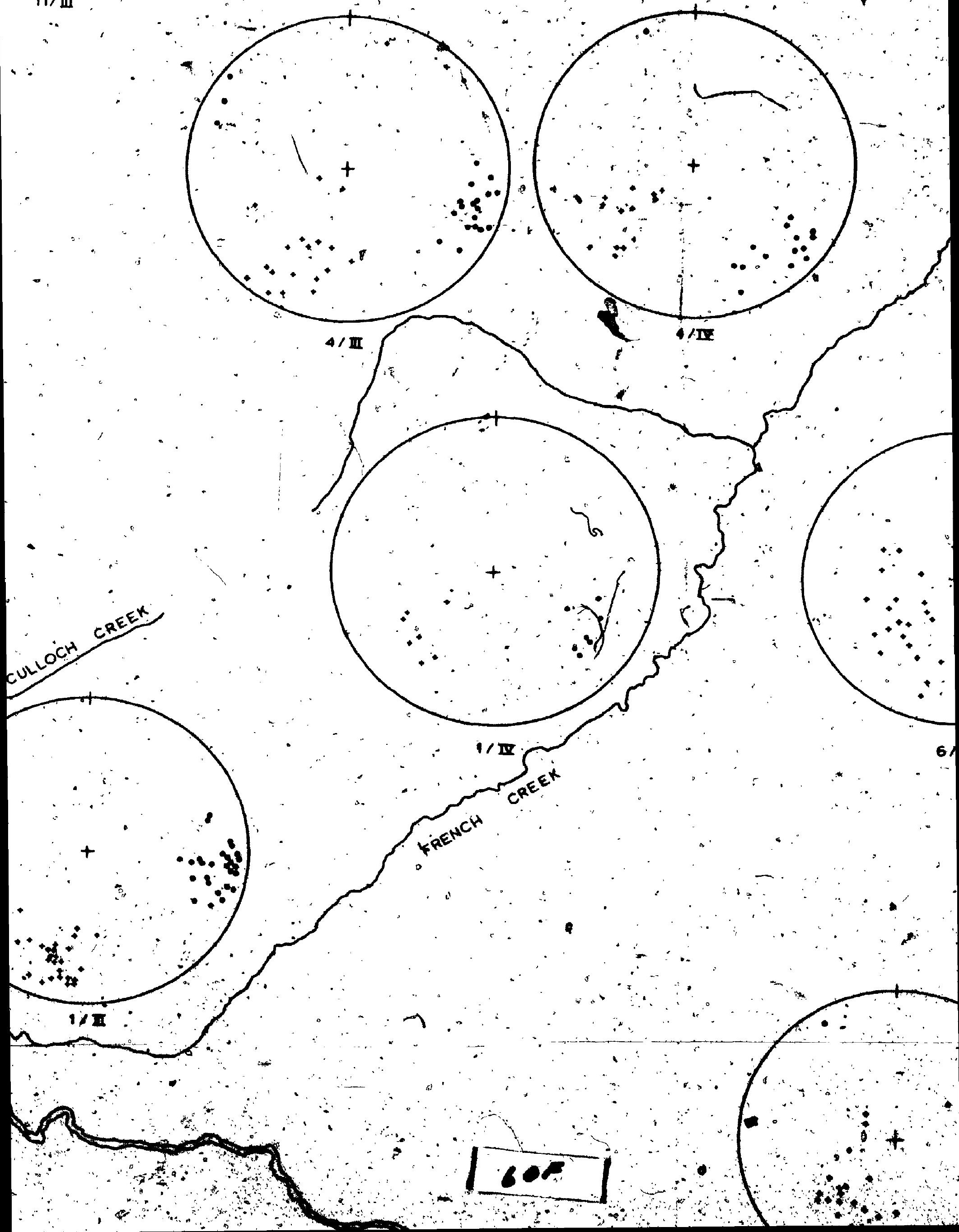






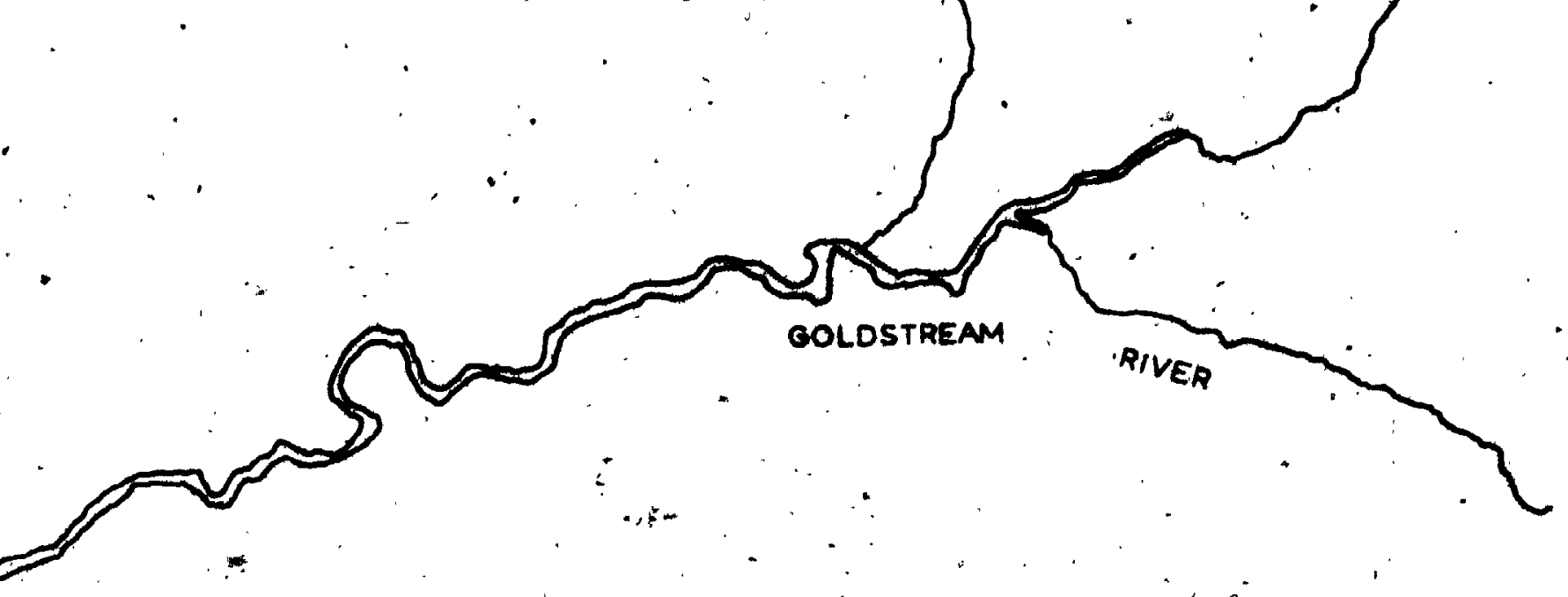

118. 15

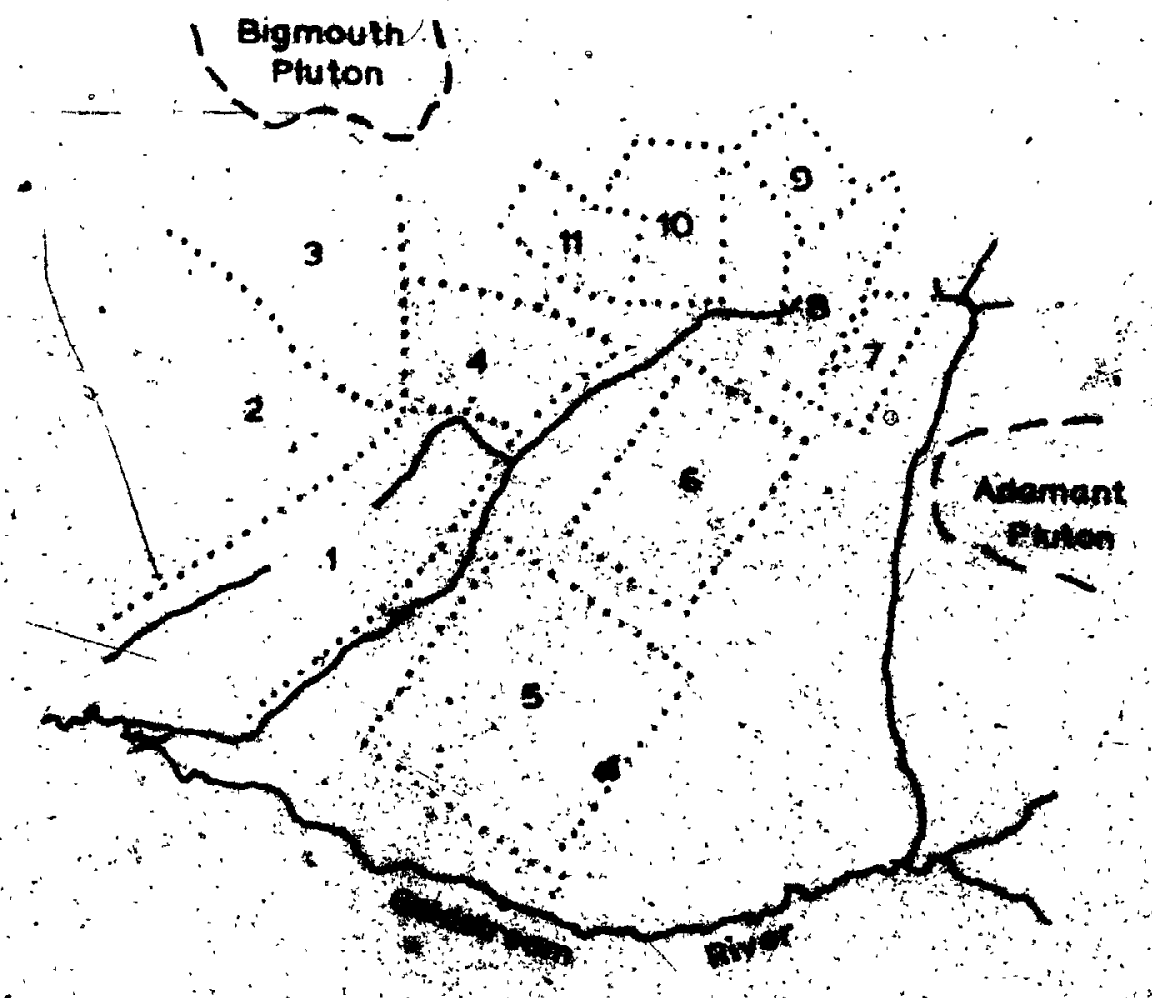

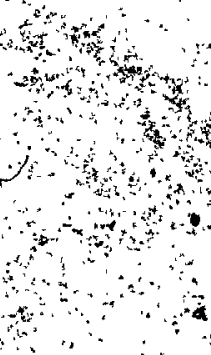

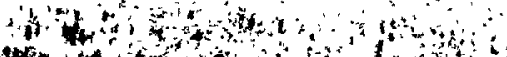

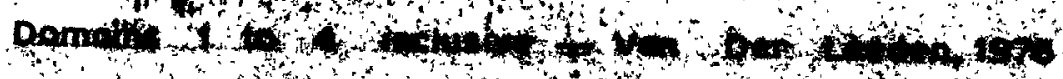

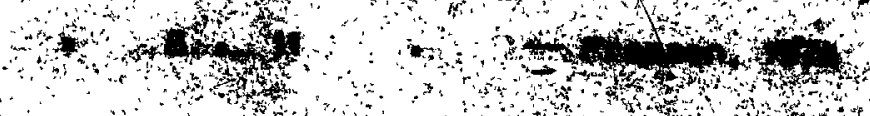

$+2$

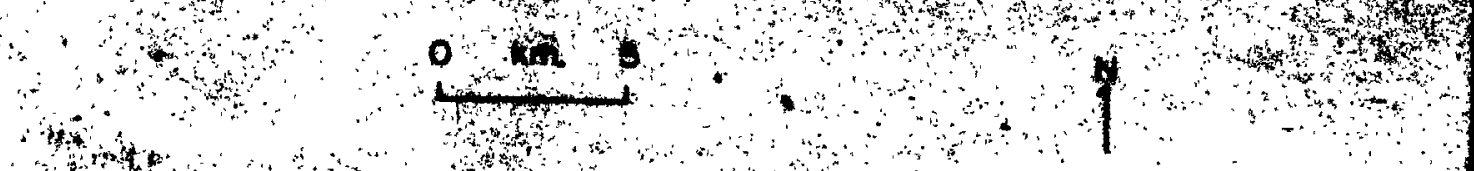

isting

a 

$20 \%$.

fig 17 AXIAL SURFACE TRACE MAP - ZONE

e of $D_{1}$ nappe

- $D_{2}$ antiform with plunge direction

" $D_{2}$ synform

" $D_{3}$ antiform

" $D_{3}$. synform'

elk fault zone. 

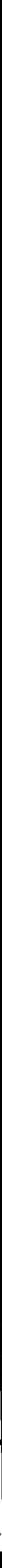



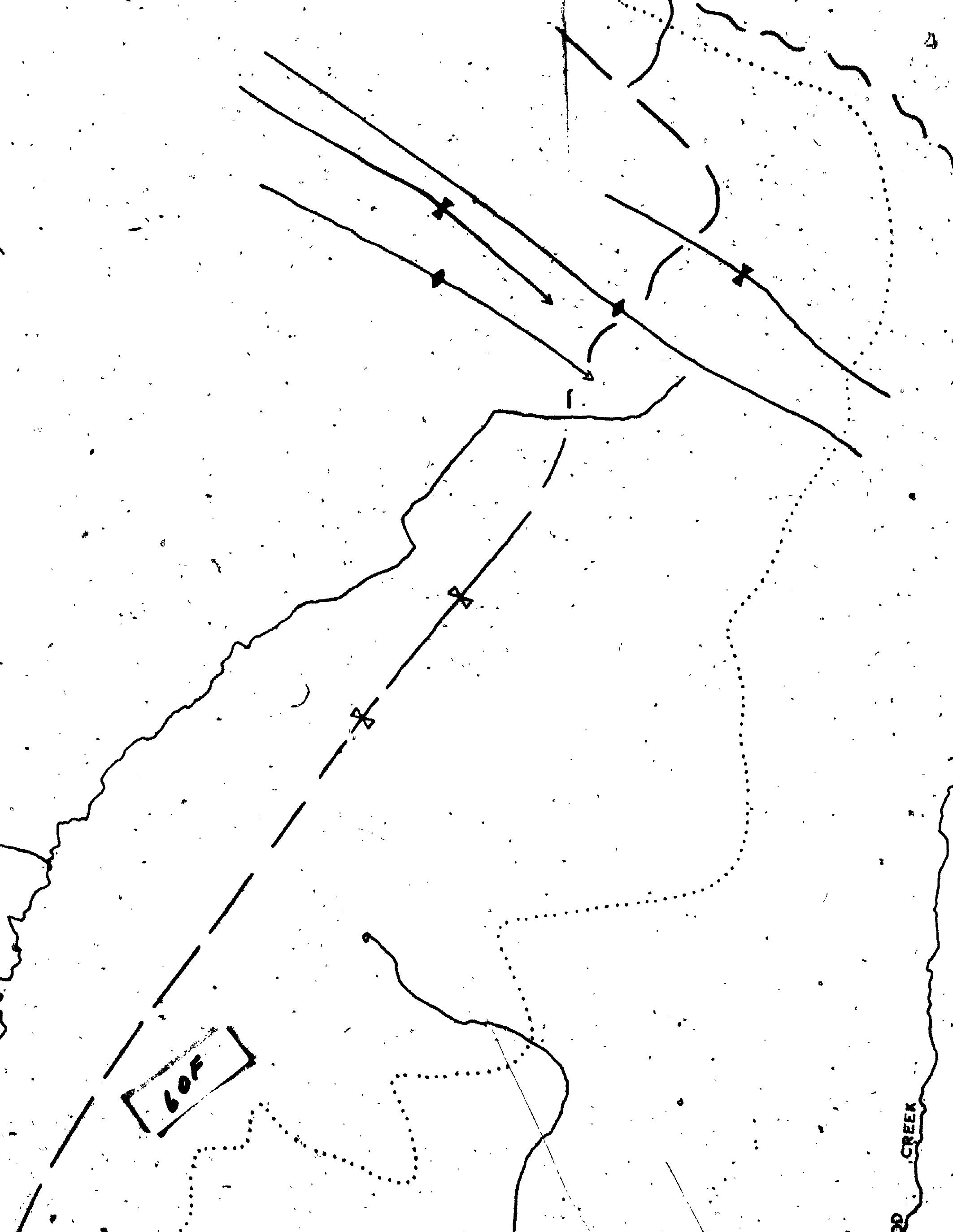




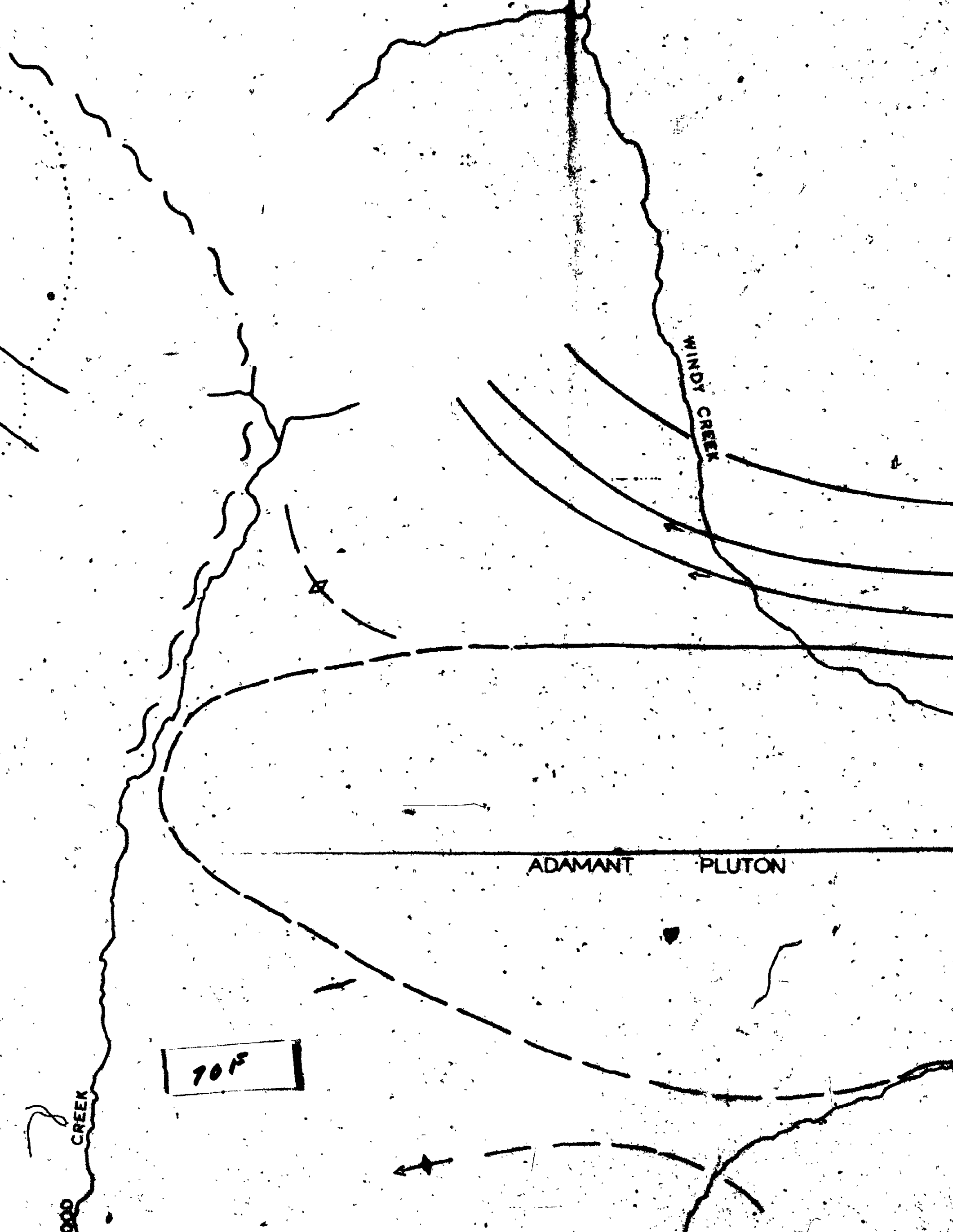





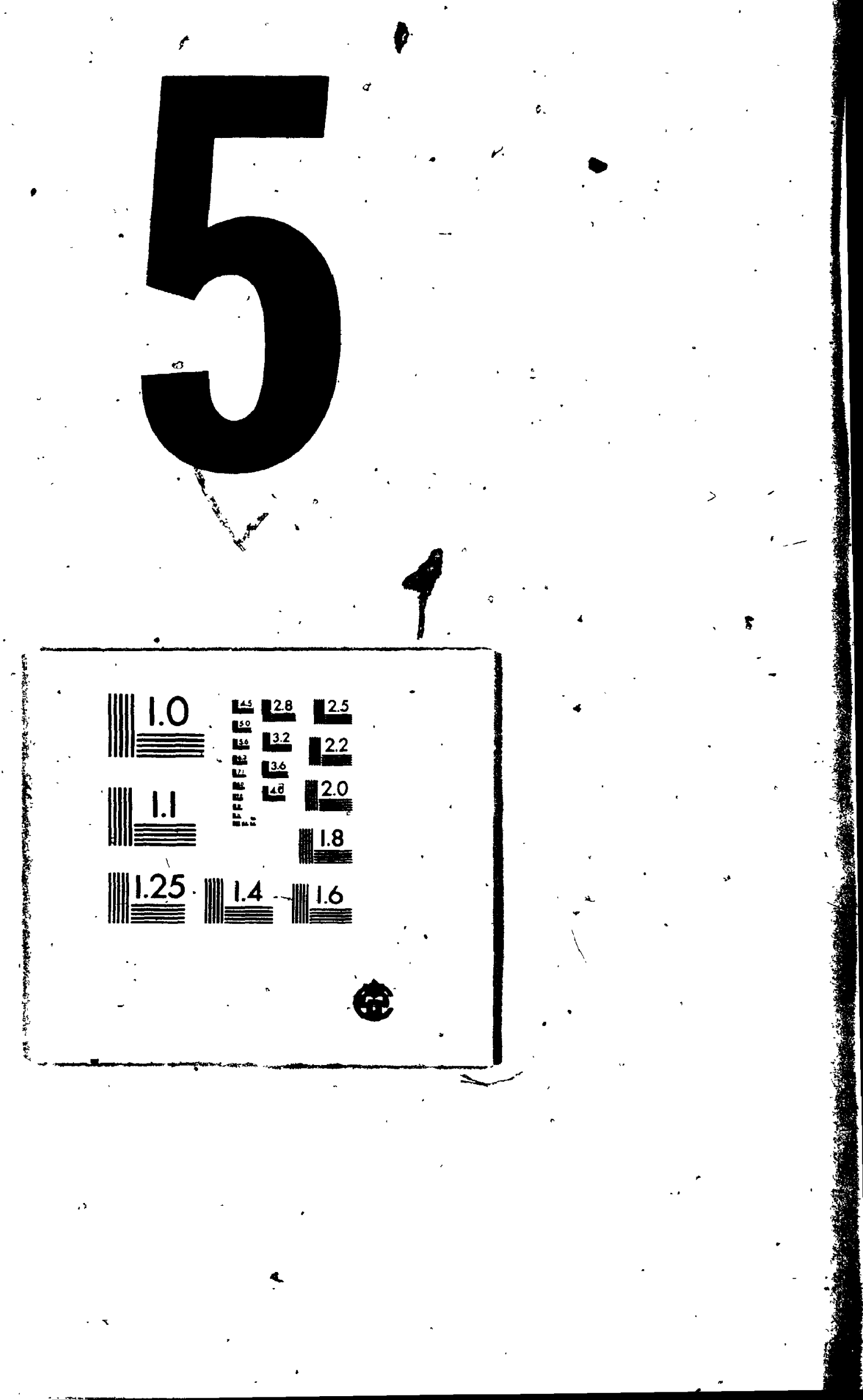




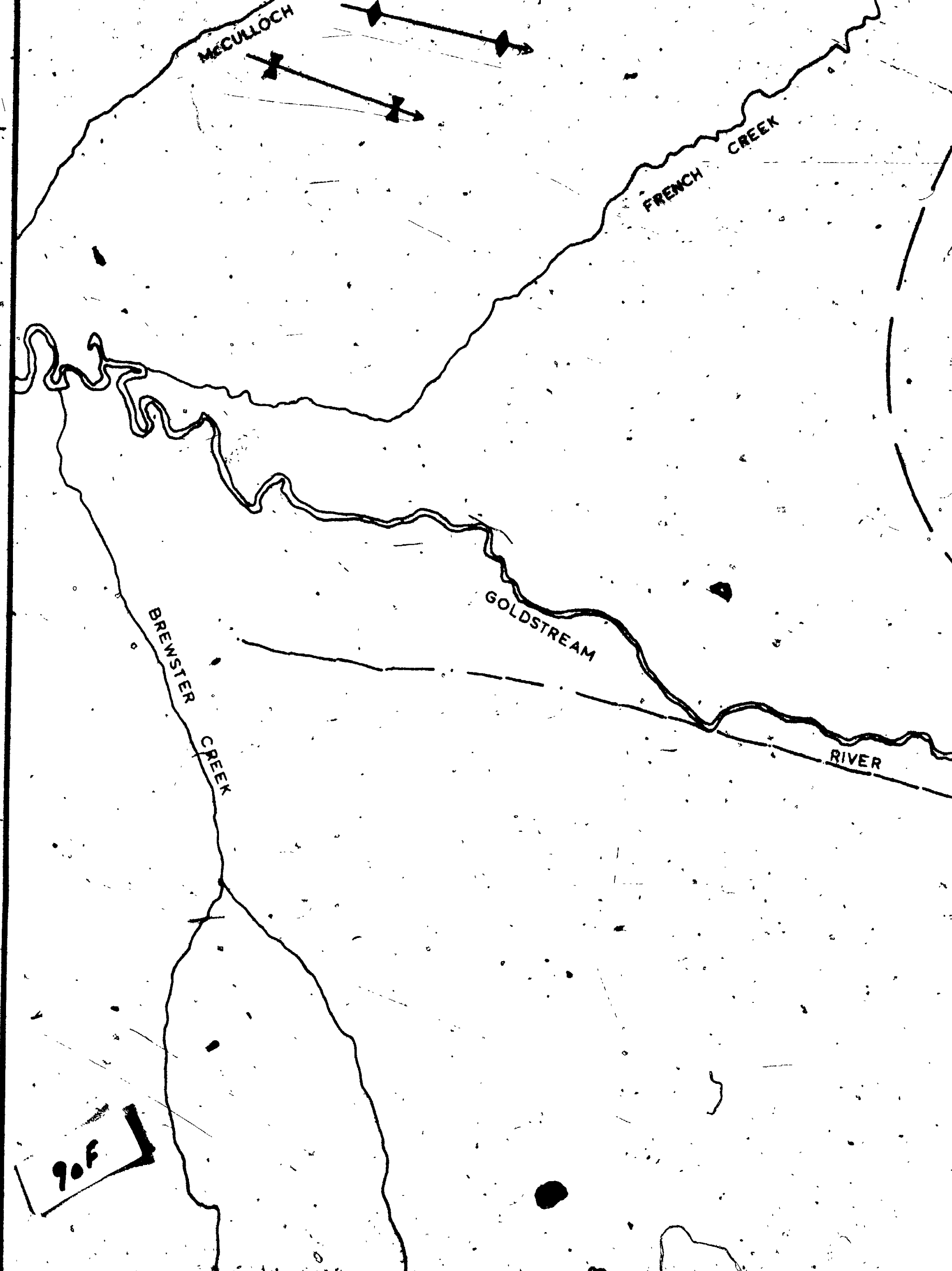




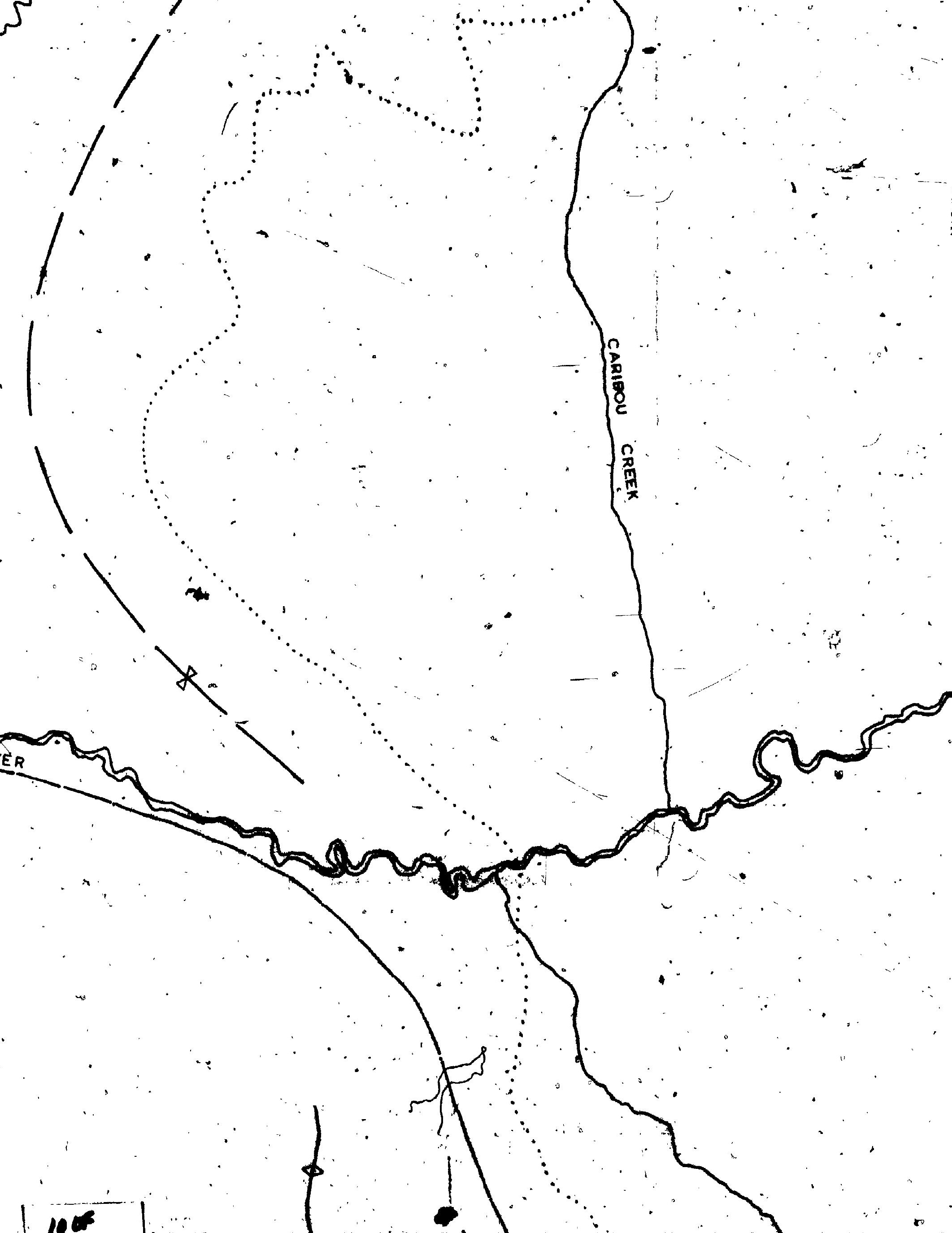






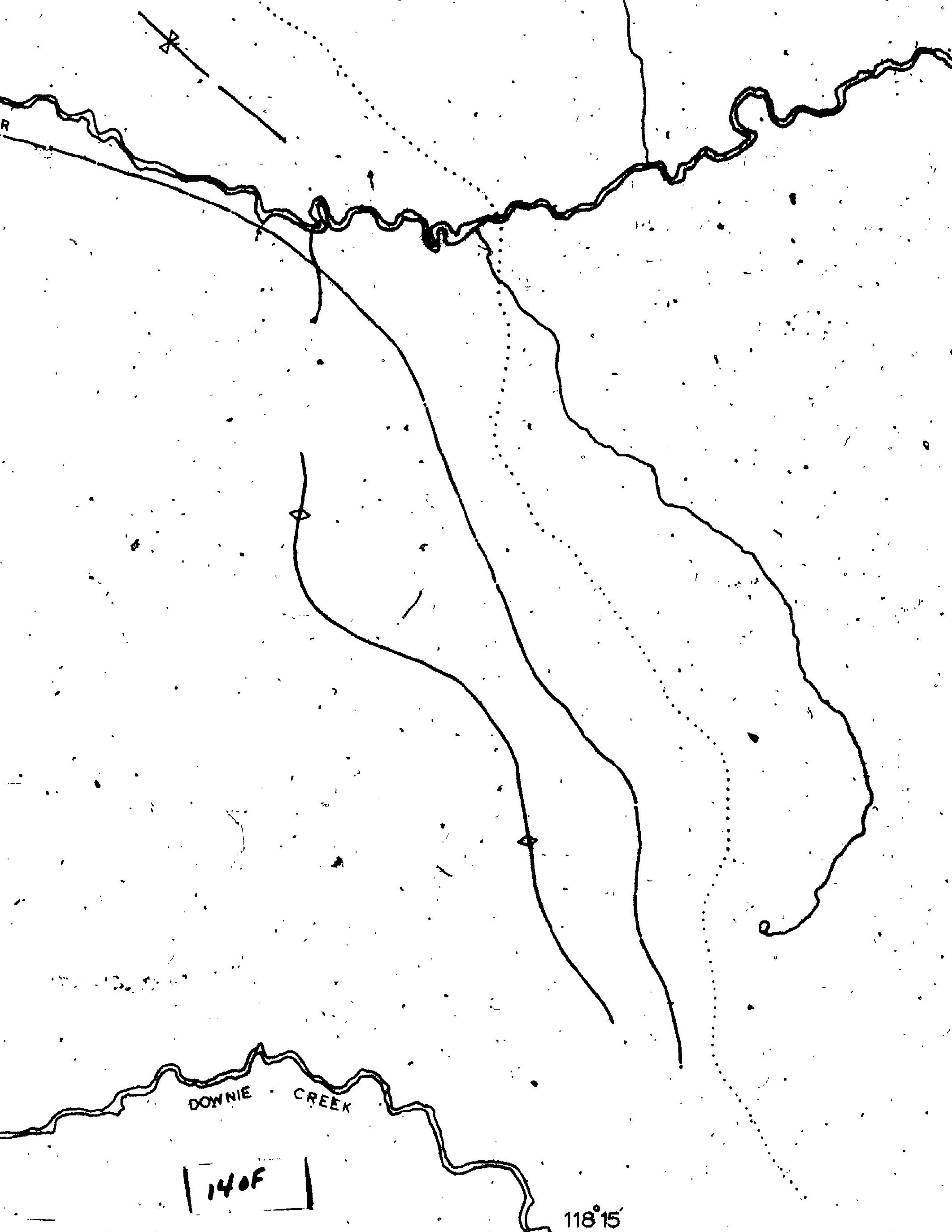





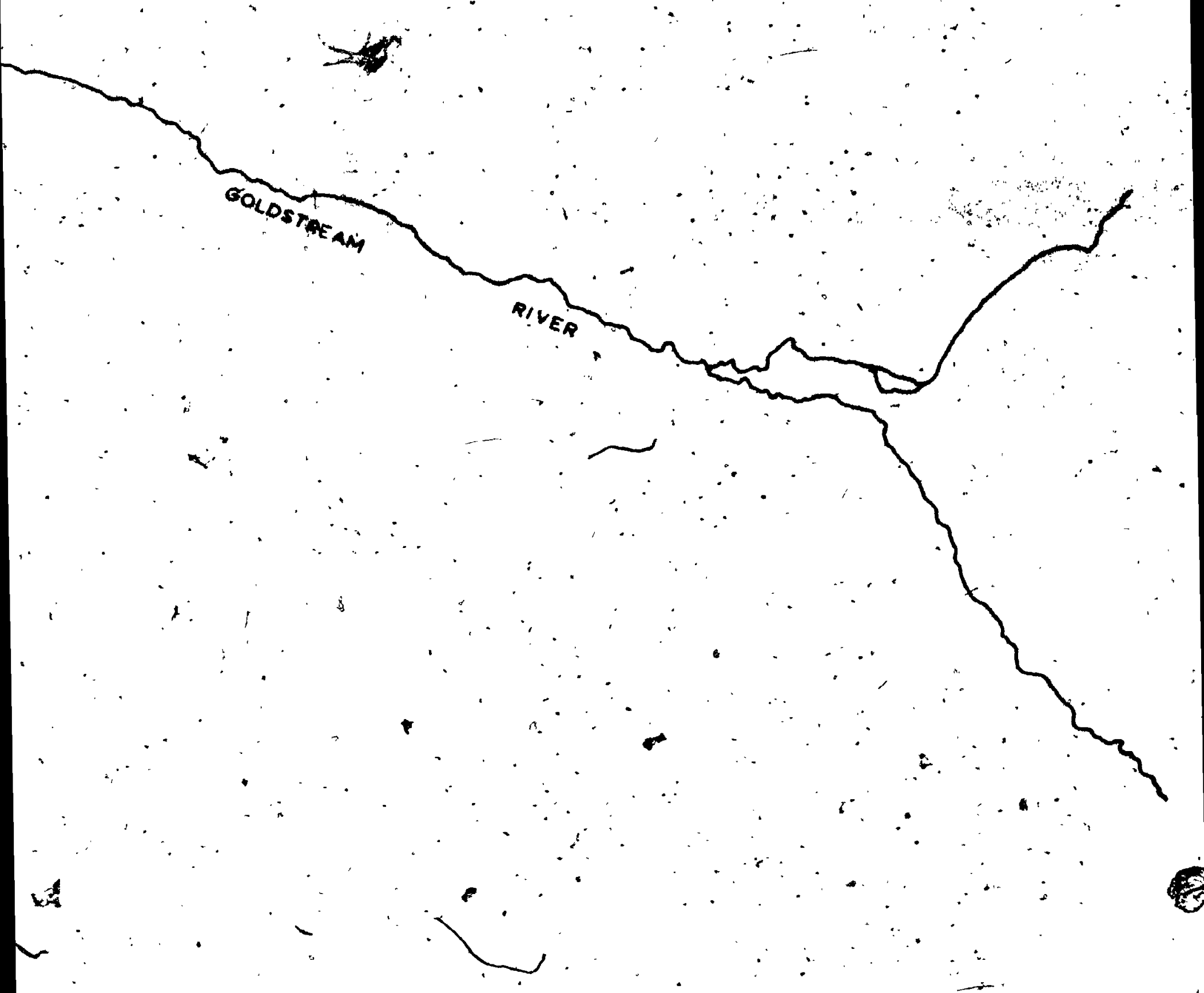



2 of.

action of Regional Trends around Adamant Pluton

$\sim$ Fault zone

$\mathrm{N}$ Nepheline syenite gneiss

B. Bigmouth granitic pluton

4 Hamill Group

HORSETHIEF .CREEK GROUP

3. Upper Politic member

2 Middle Marble member

3

1 Lower, Politic member 



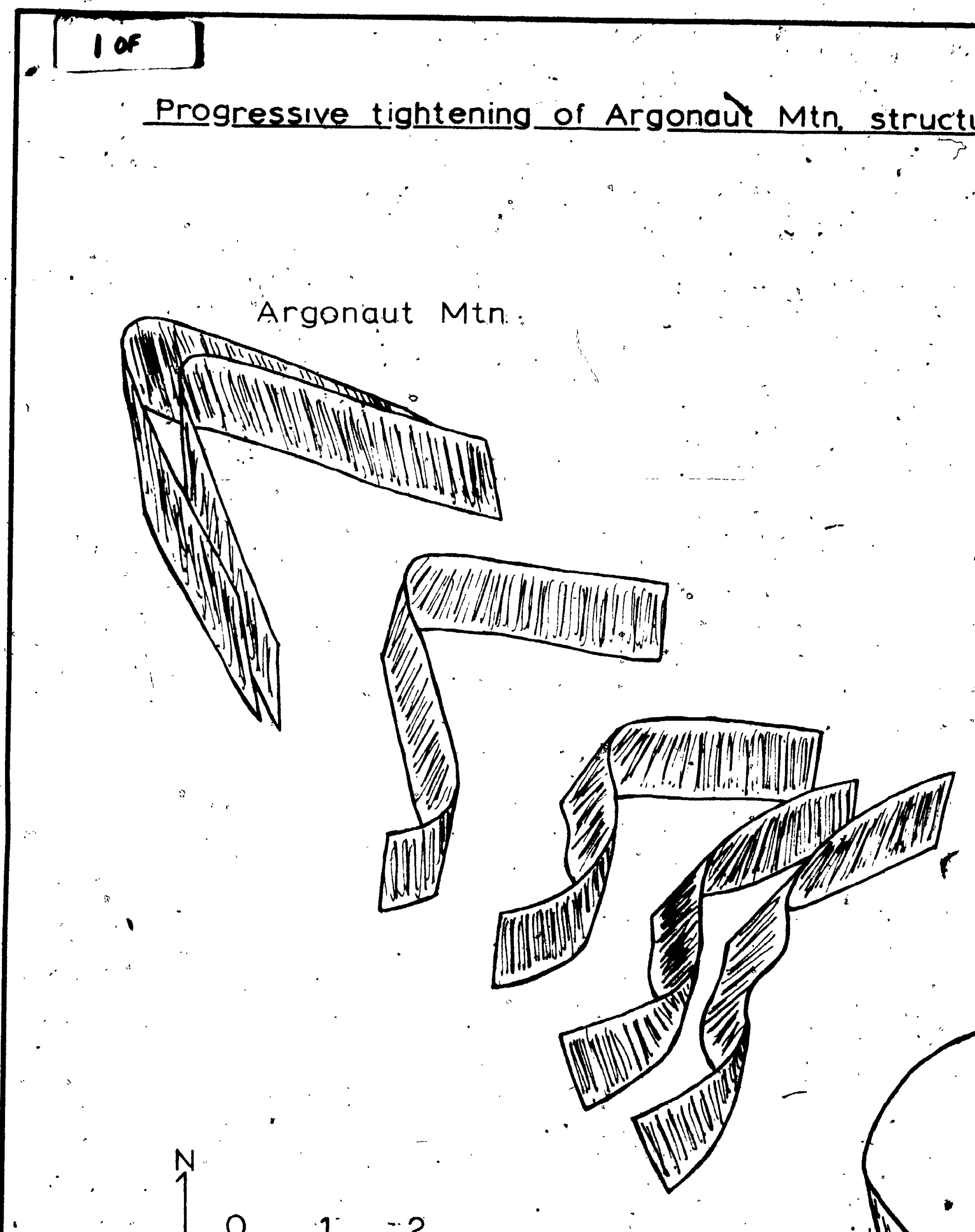


gonaut Min, structure away from Adamant Pluton.

fig. 21 

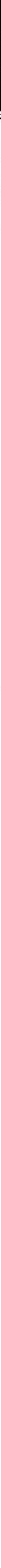
Legend

Foliation (inclined, vertical)

Lineation

Geological contact (defined, approximate, assumed)

Adamant Pluton: -

Hypersthene-aúgite monzonite

Monzonite, transitional between 1 and 2.

Hornblende granodiorite, quartz monzonite.

Biotite -hornblende granodiorite, quartz diorite

te

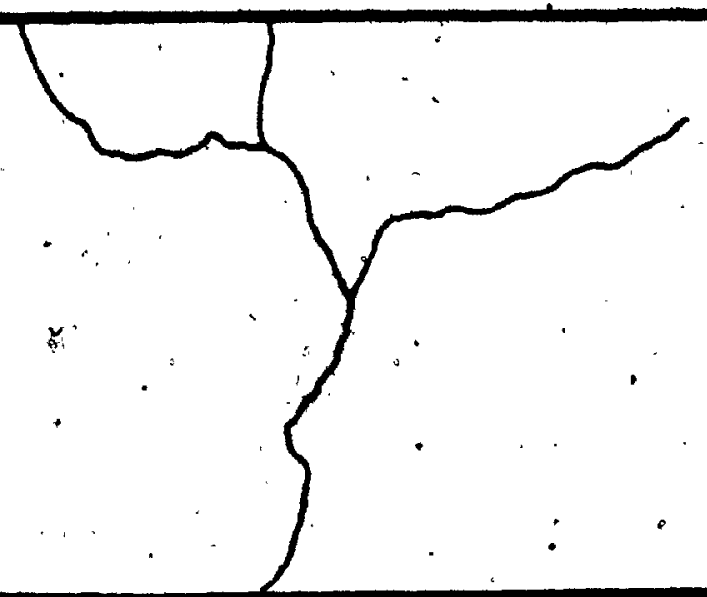

1,07 
fig. 23 FABRिIC ELE 


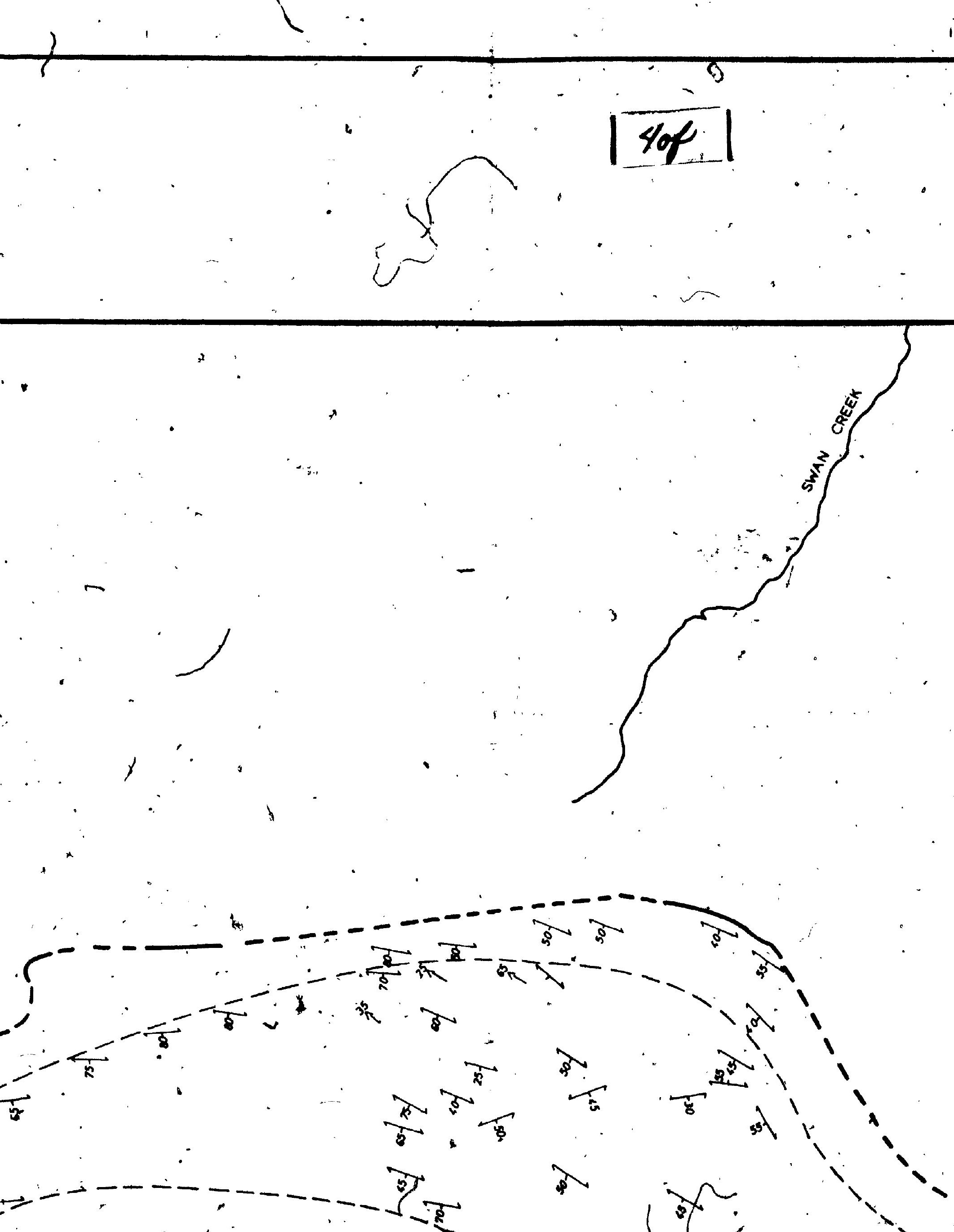






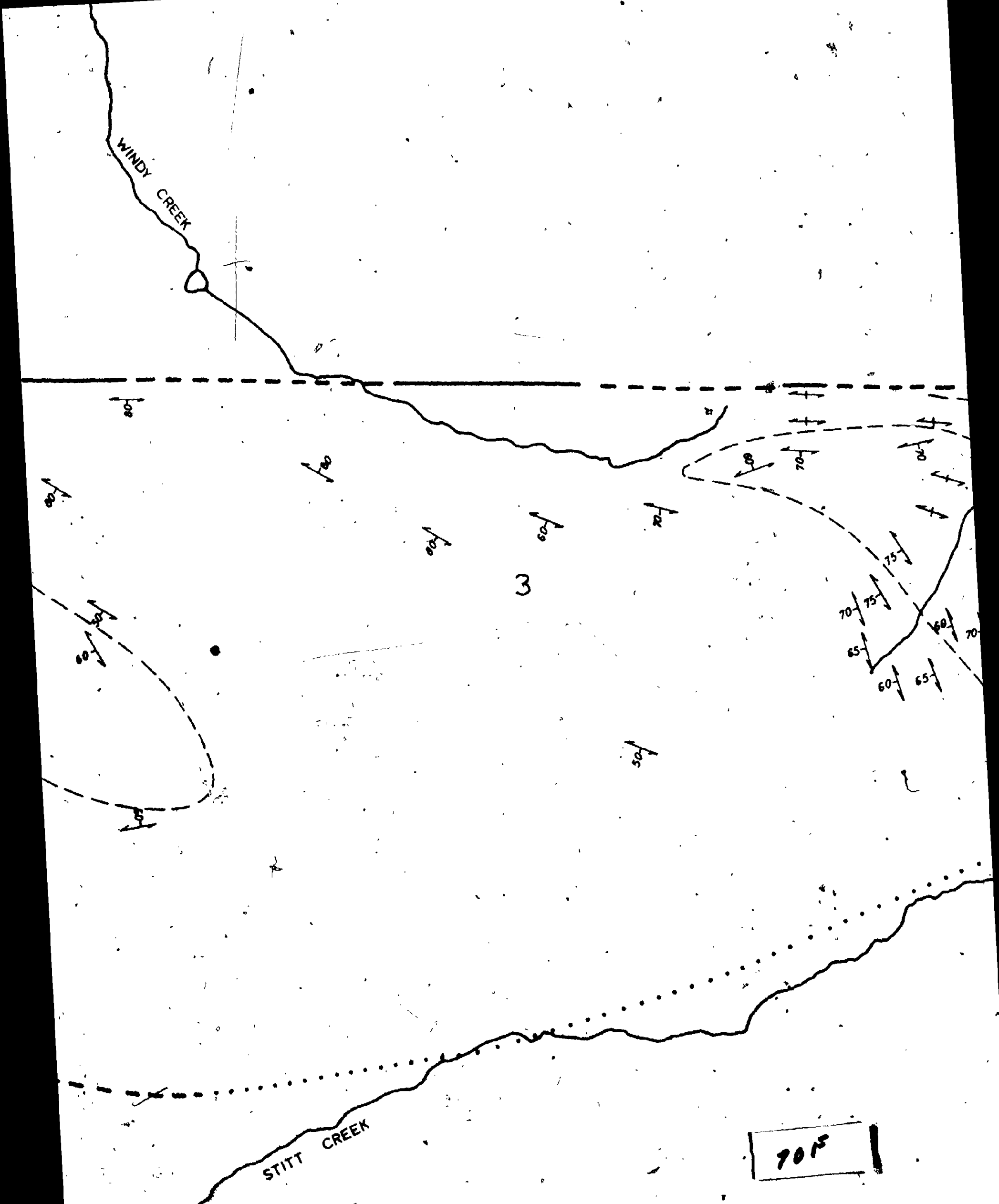




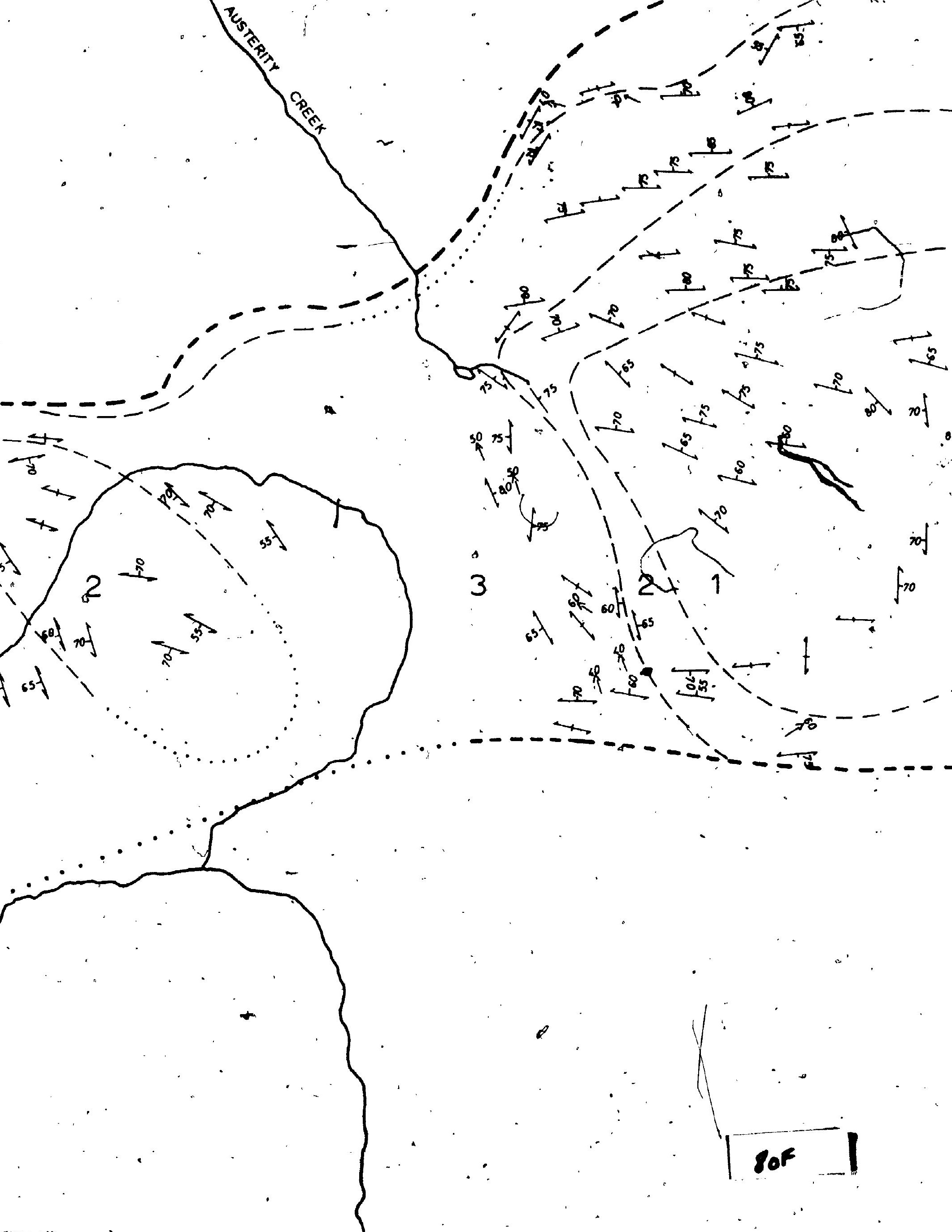




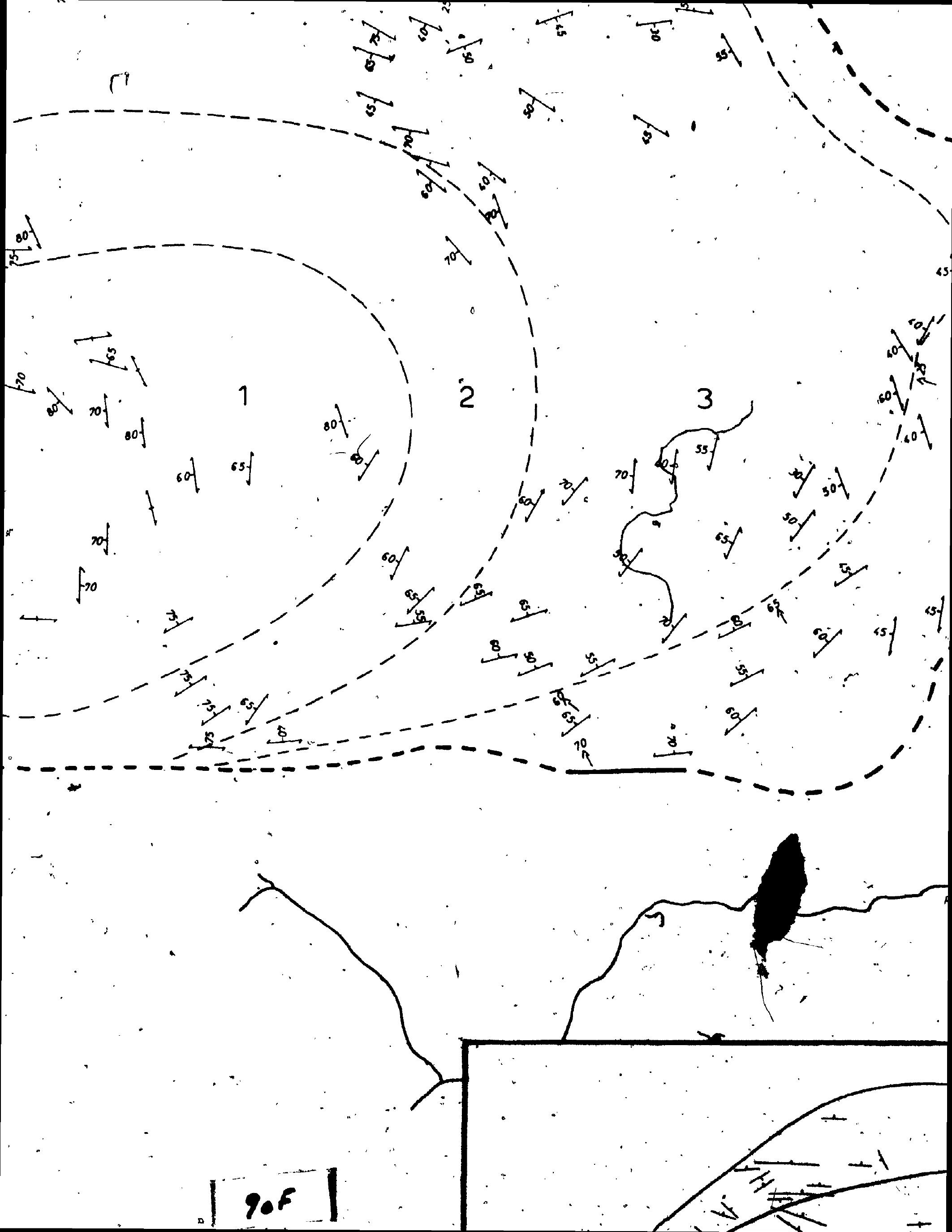




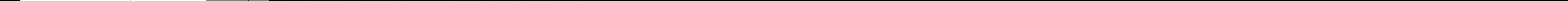




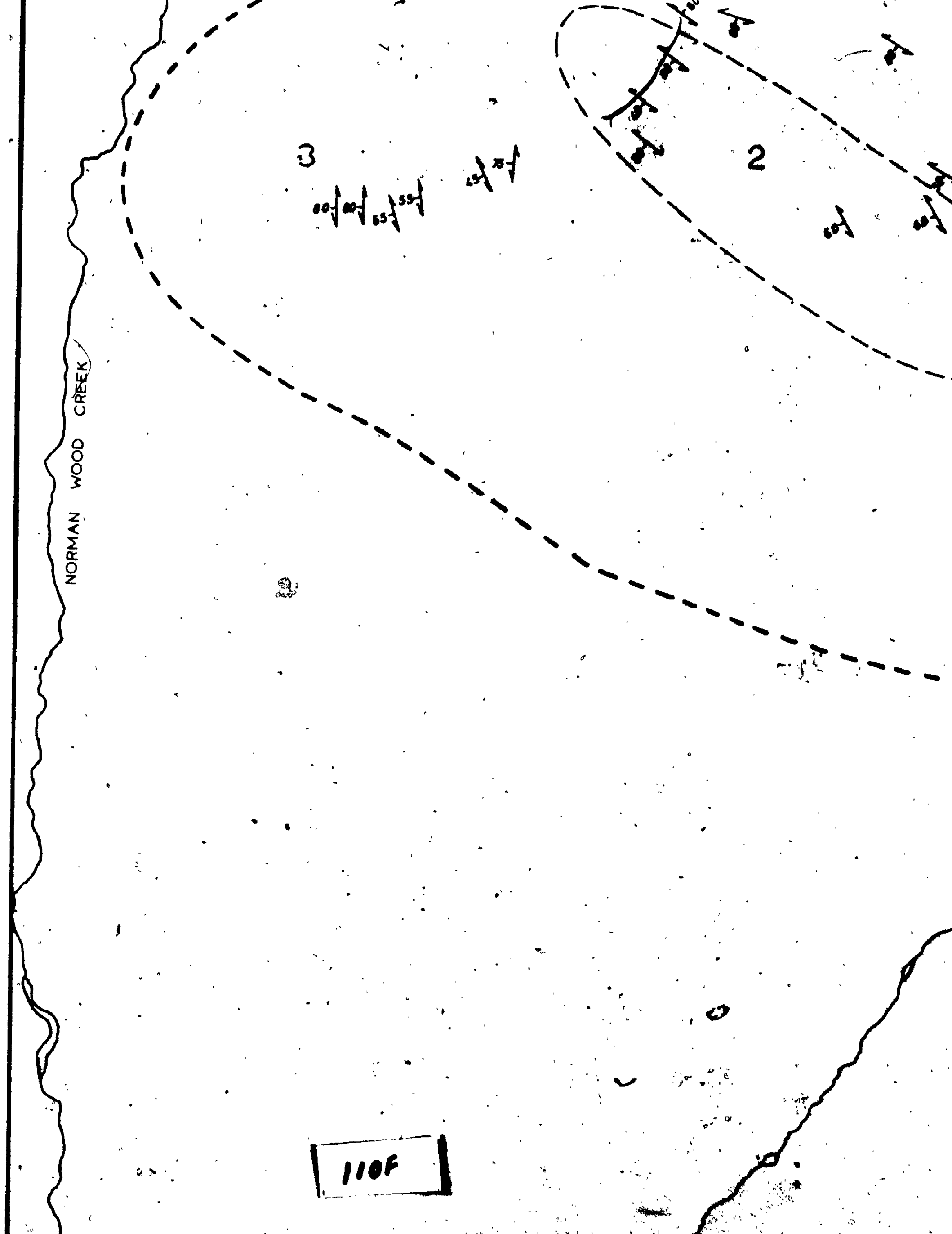




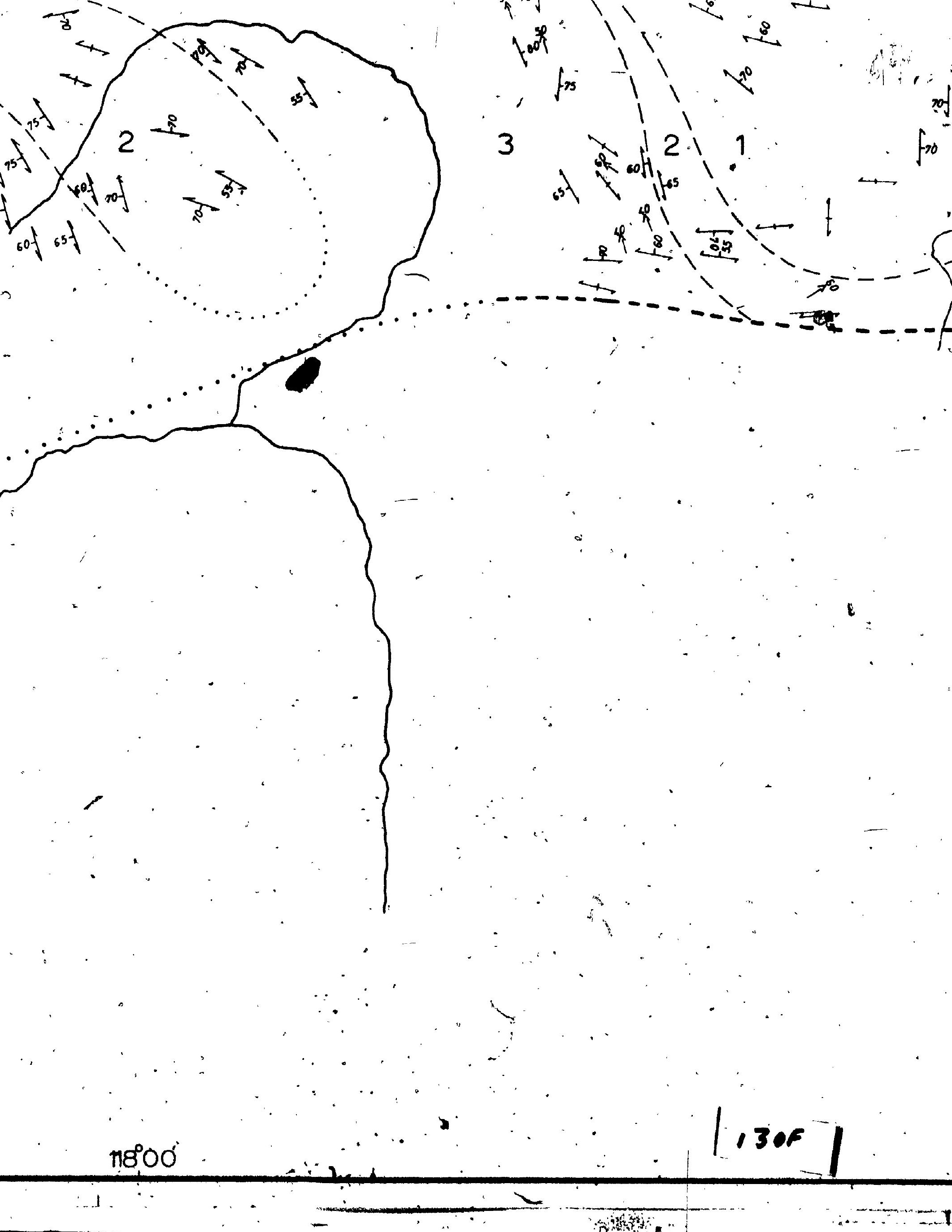




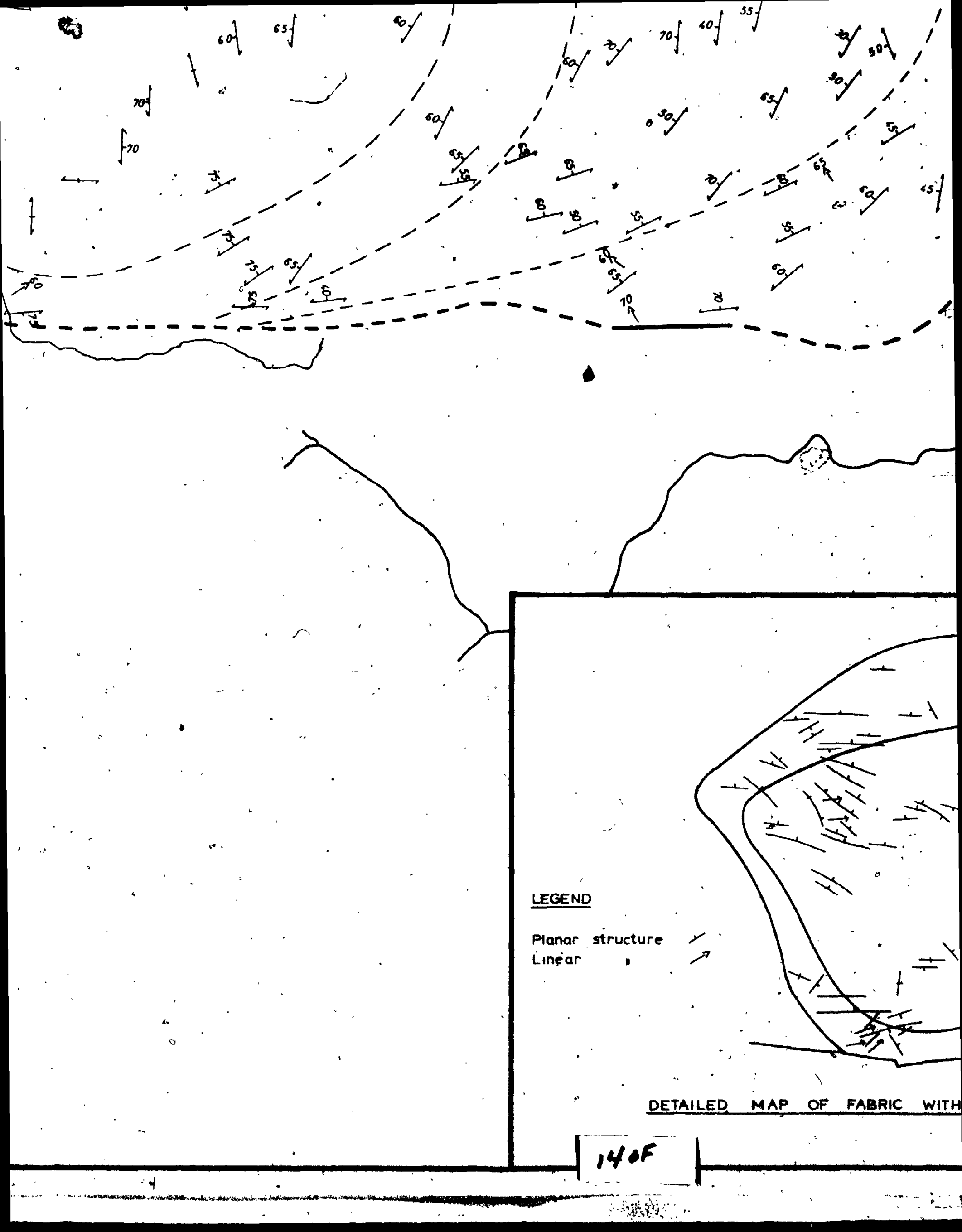




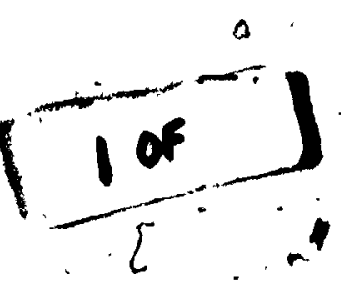

$\because$

$\therefore$

- staurolite garnet biotite mus

- kyanite staurolite garnet $b$

- kyanite garnet biotite

$\Delta$ sillimanite kyanite garnet -

- sillimanite garnet biotite

isograd (defined by first app disappearance of $a^{\circ} \mathrm{g}$ 
Metamorphic assemblages adjacent to the.

biotite muscovite quartz

garnet biotite

otite

garnet biotite

biotite

first appearance or

ce e of a given mineral) 

nant. pluton 4of

fig $26^{\circ}$
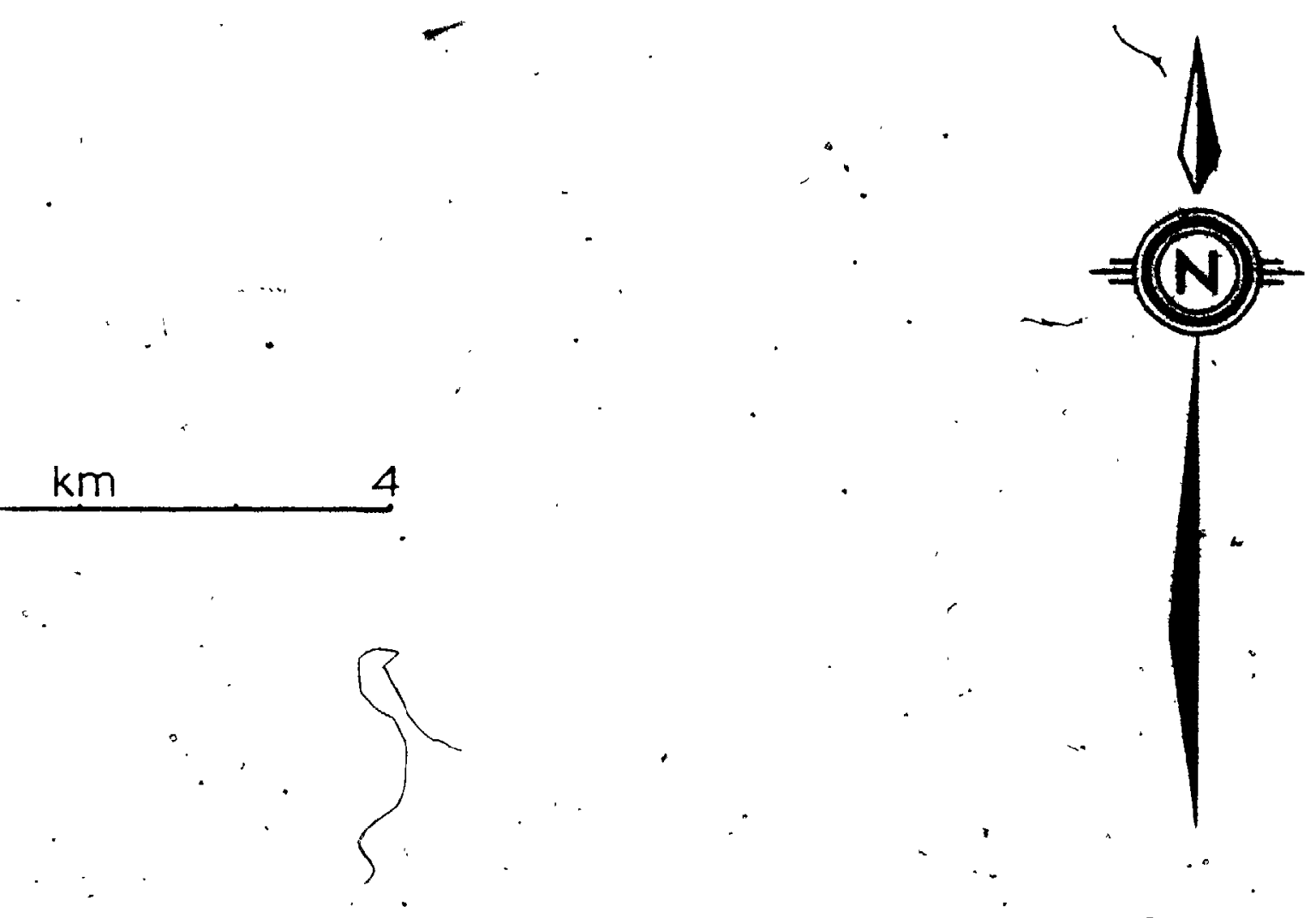





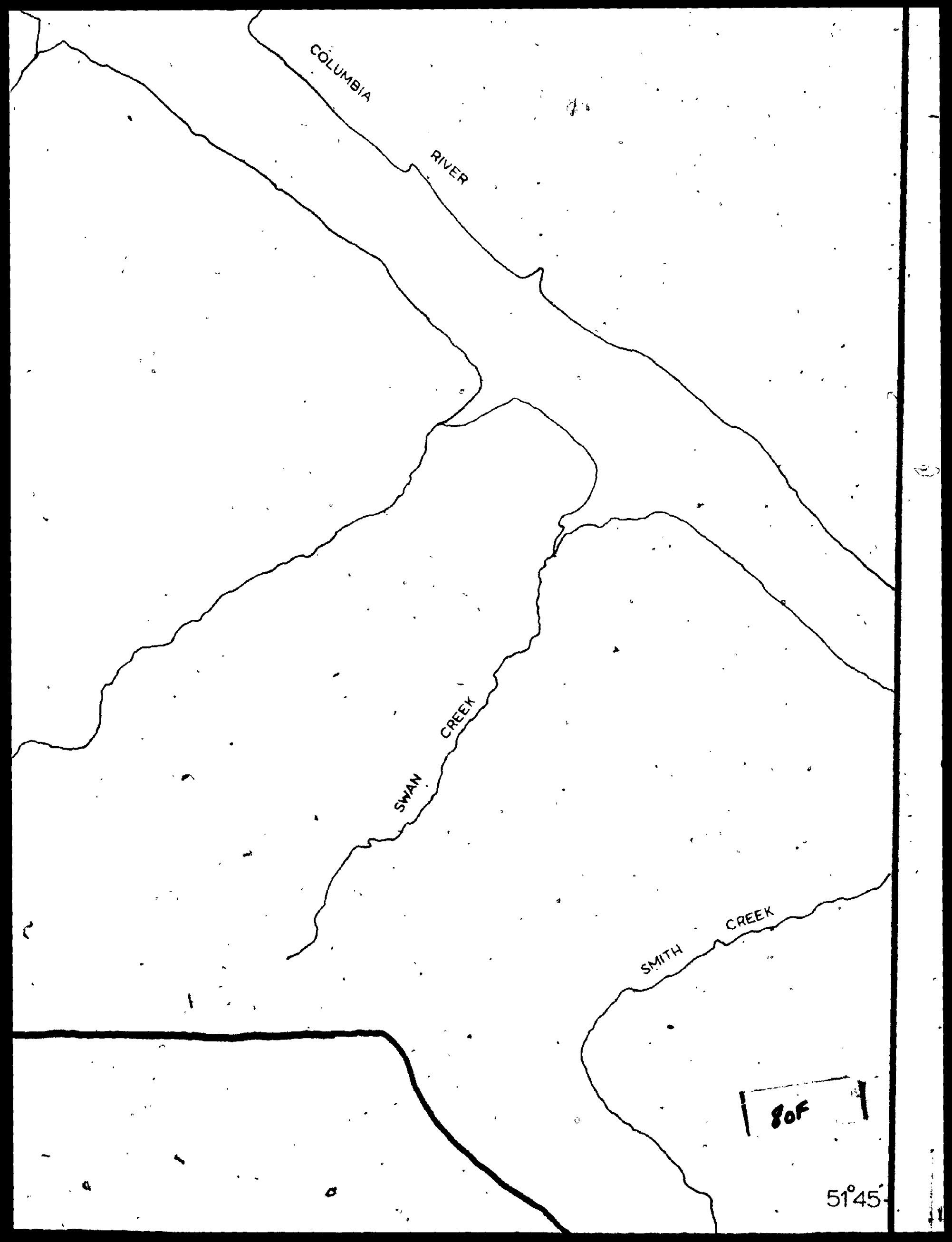




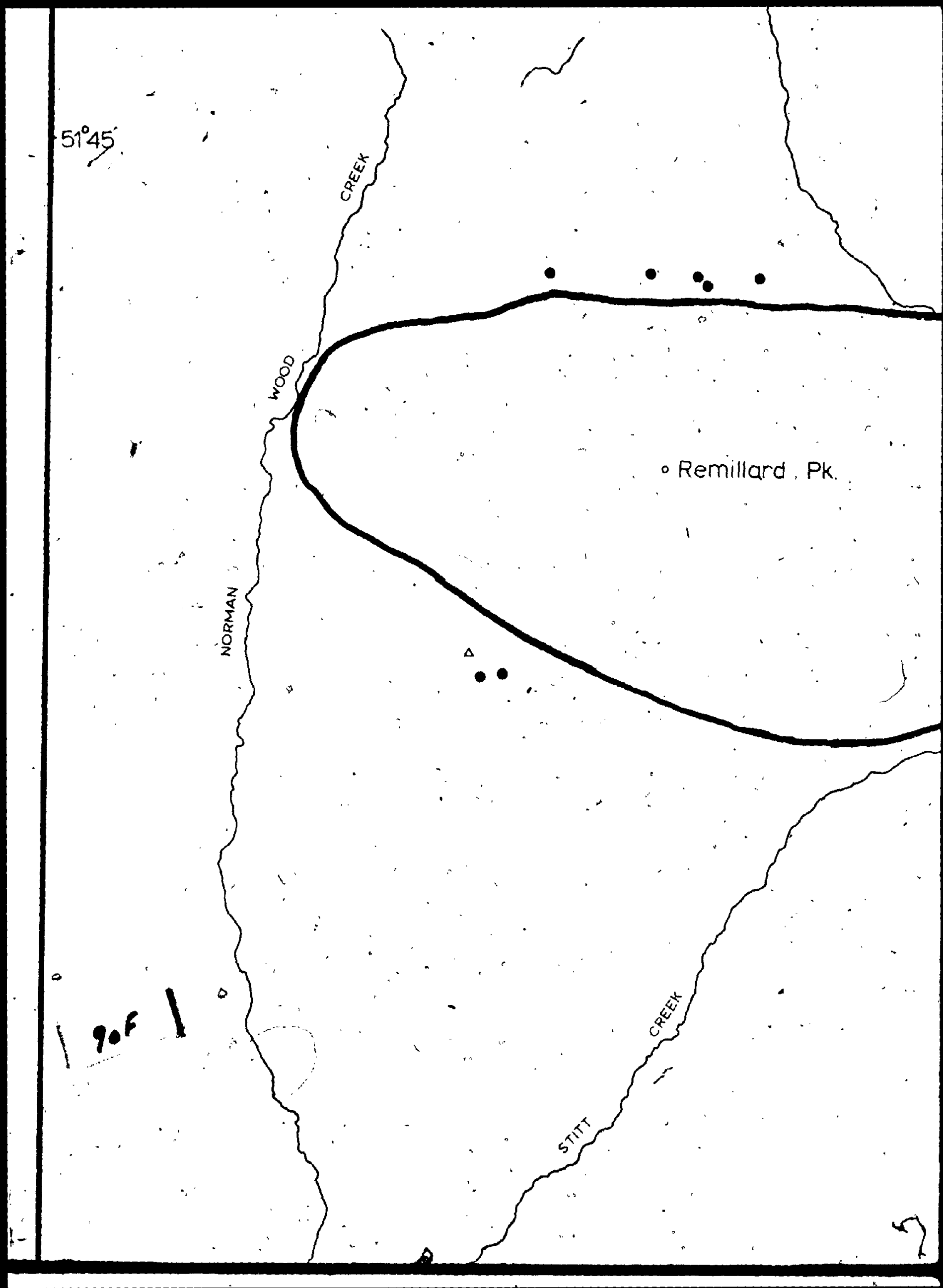






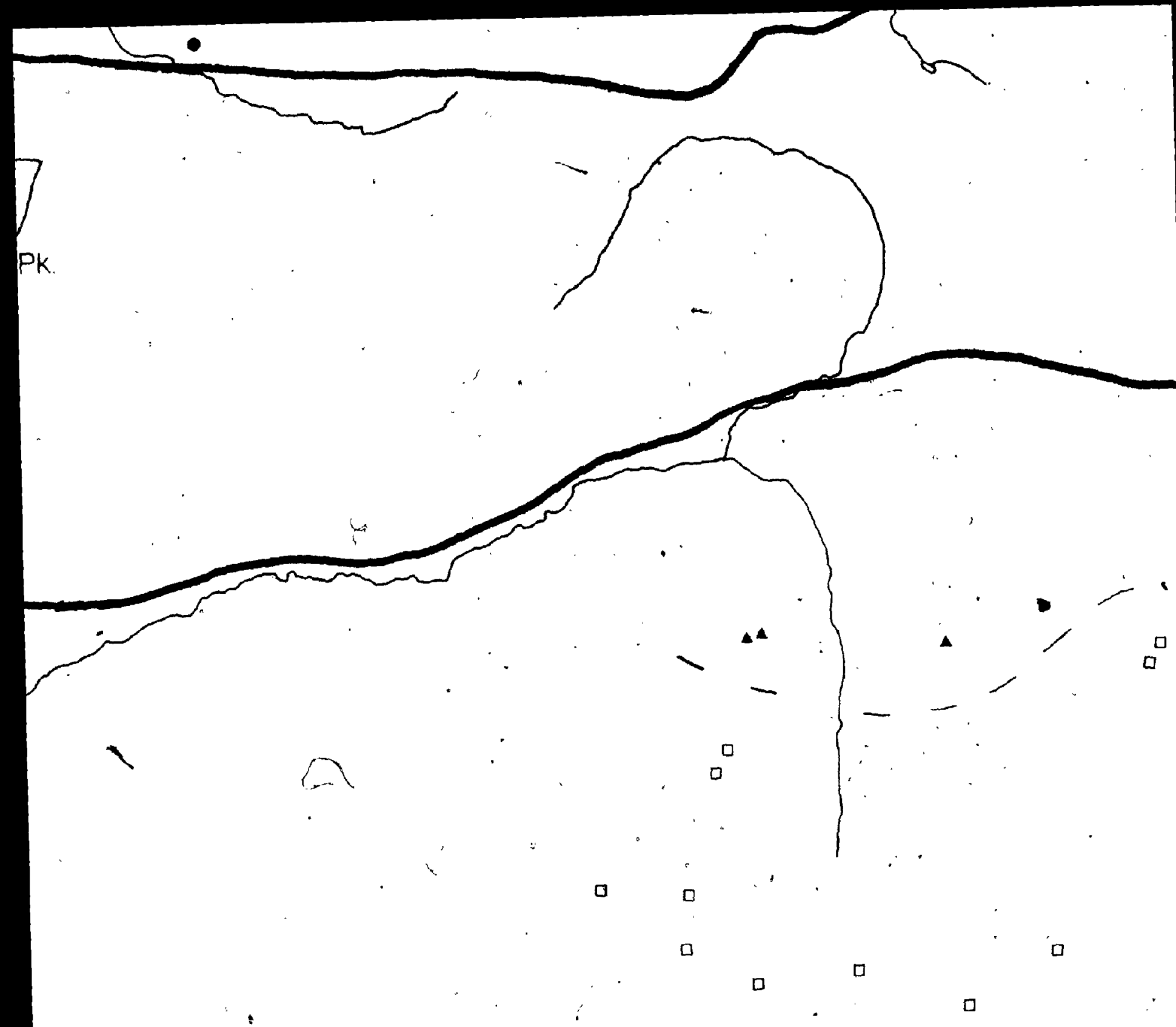

- Goldstream Mtn.

$|140 \mathrm{~F}|$

$118^{\circ} 00^{\circ}$ 


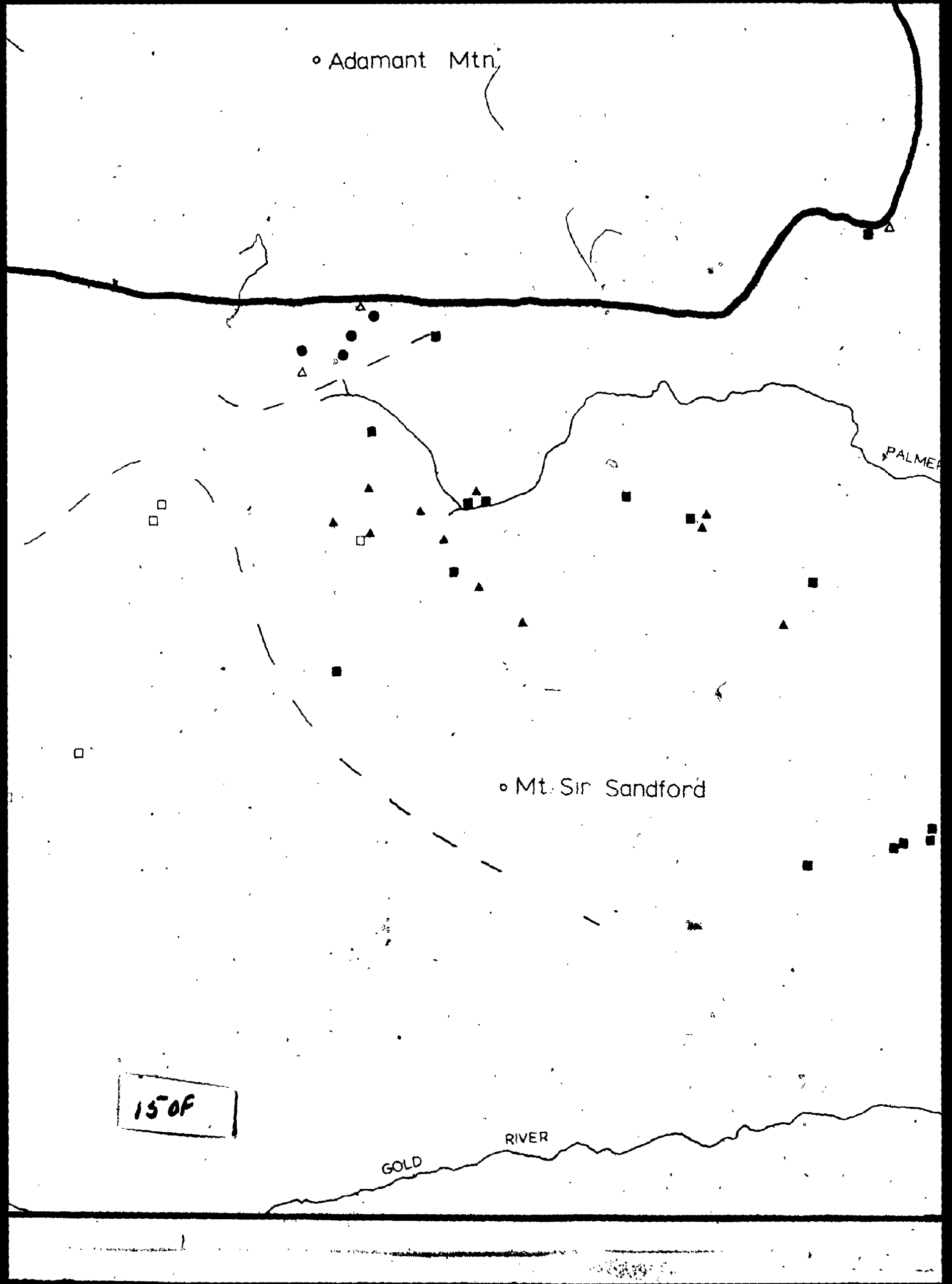


- Adamant Mtr

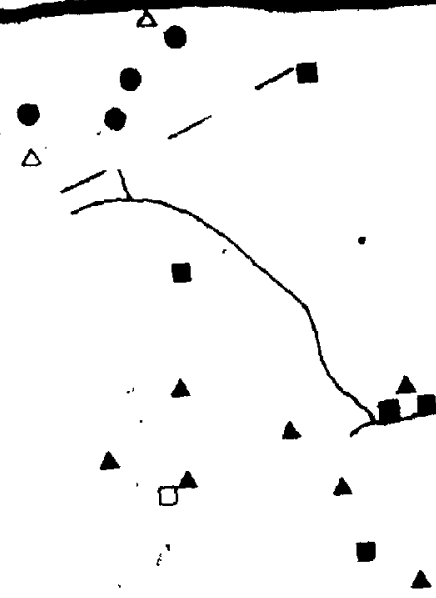

$\Delta$

- Mt. Stockmer

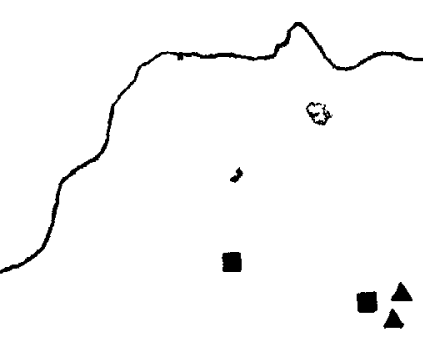

-

-

I
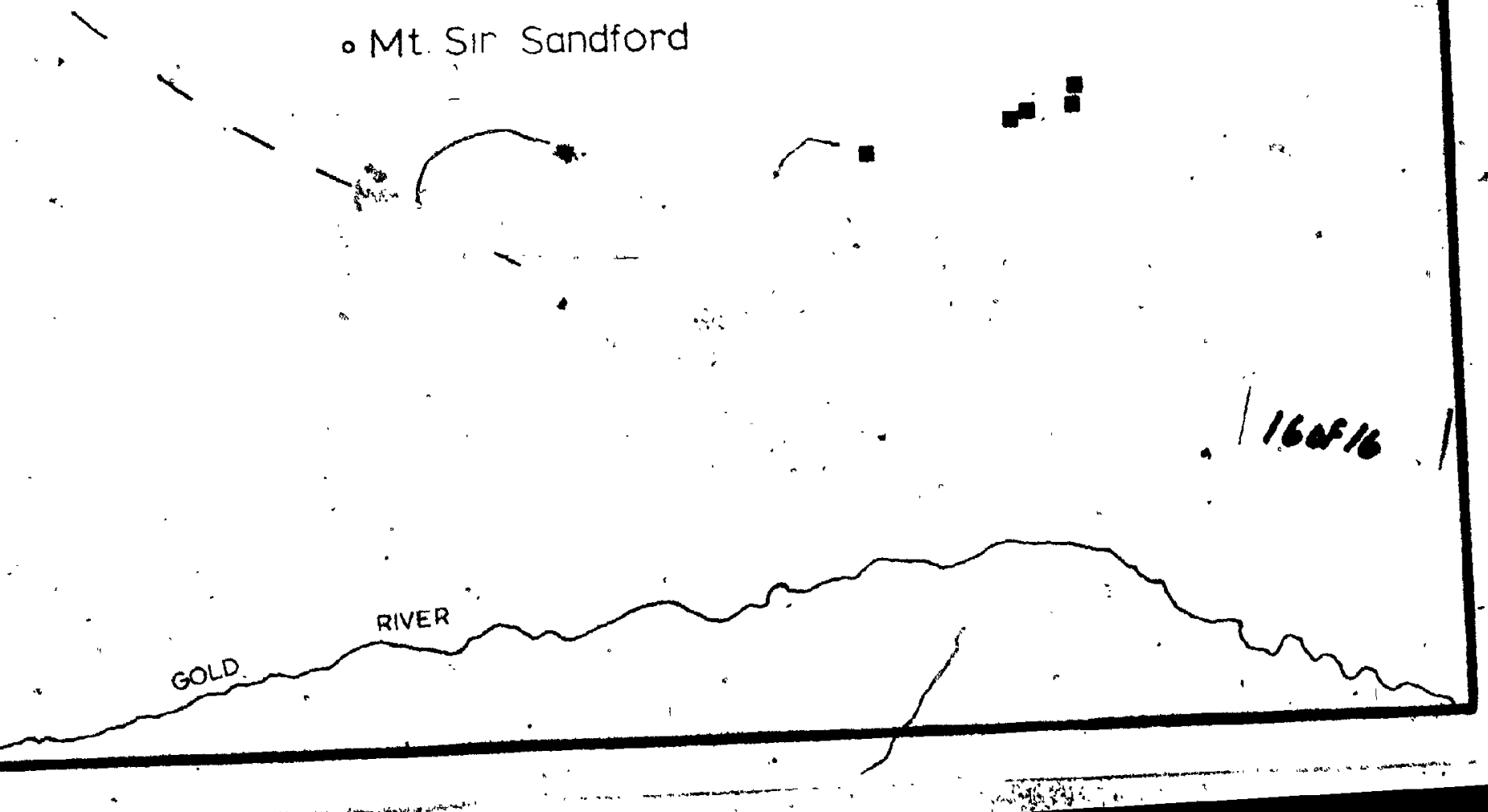
lof 1

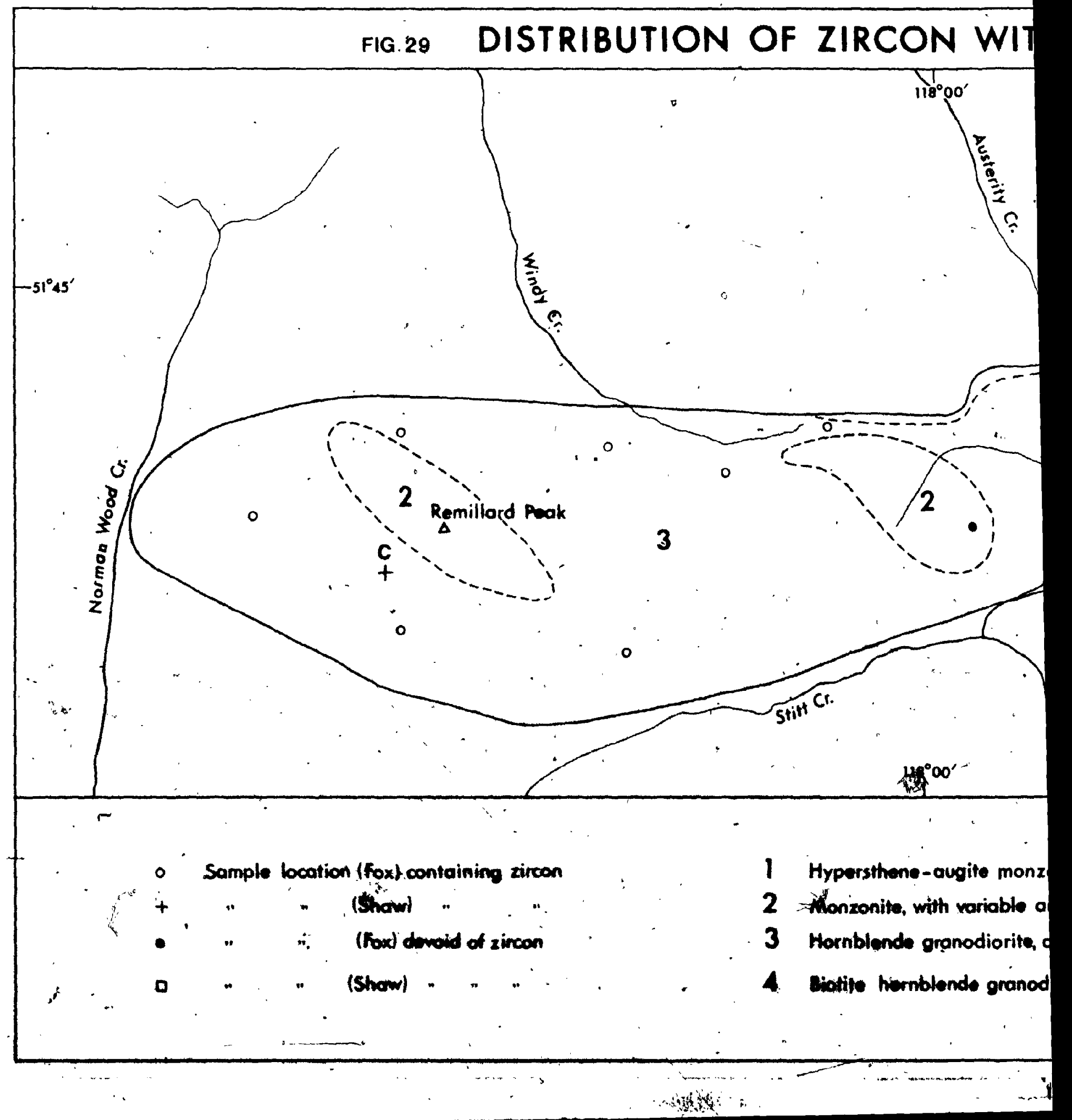





\section{iof I}

fig. 31

Dist

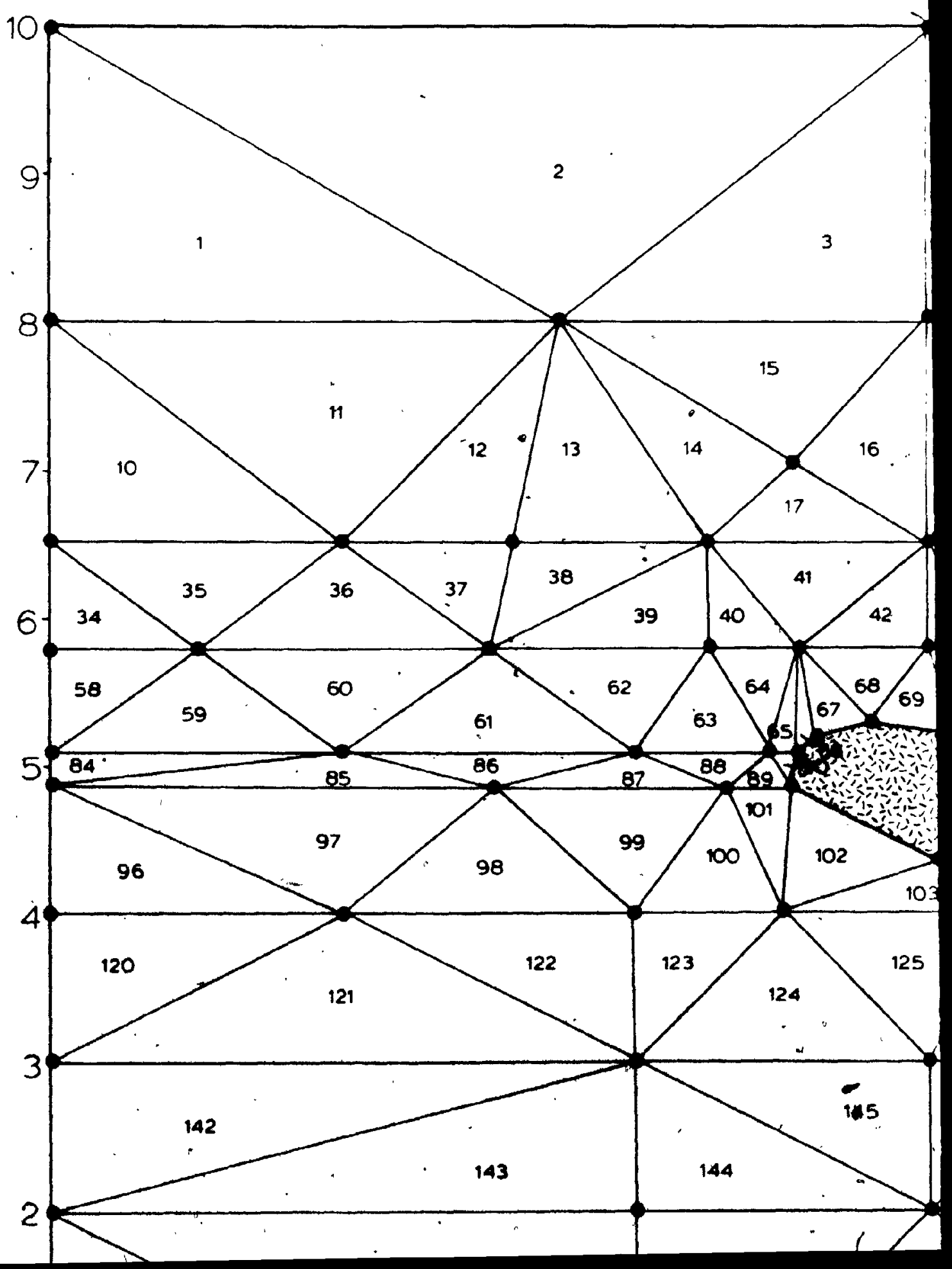




\section{F}

Distribution of Elements, Layout 1

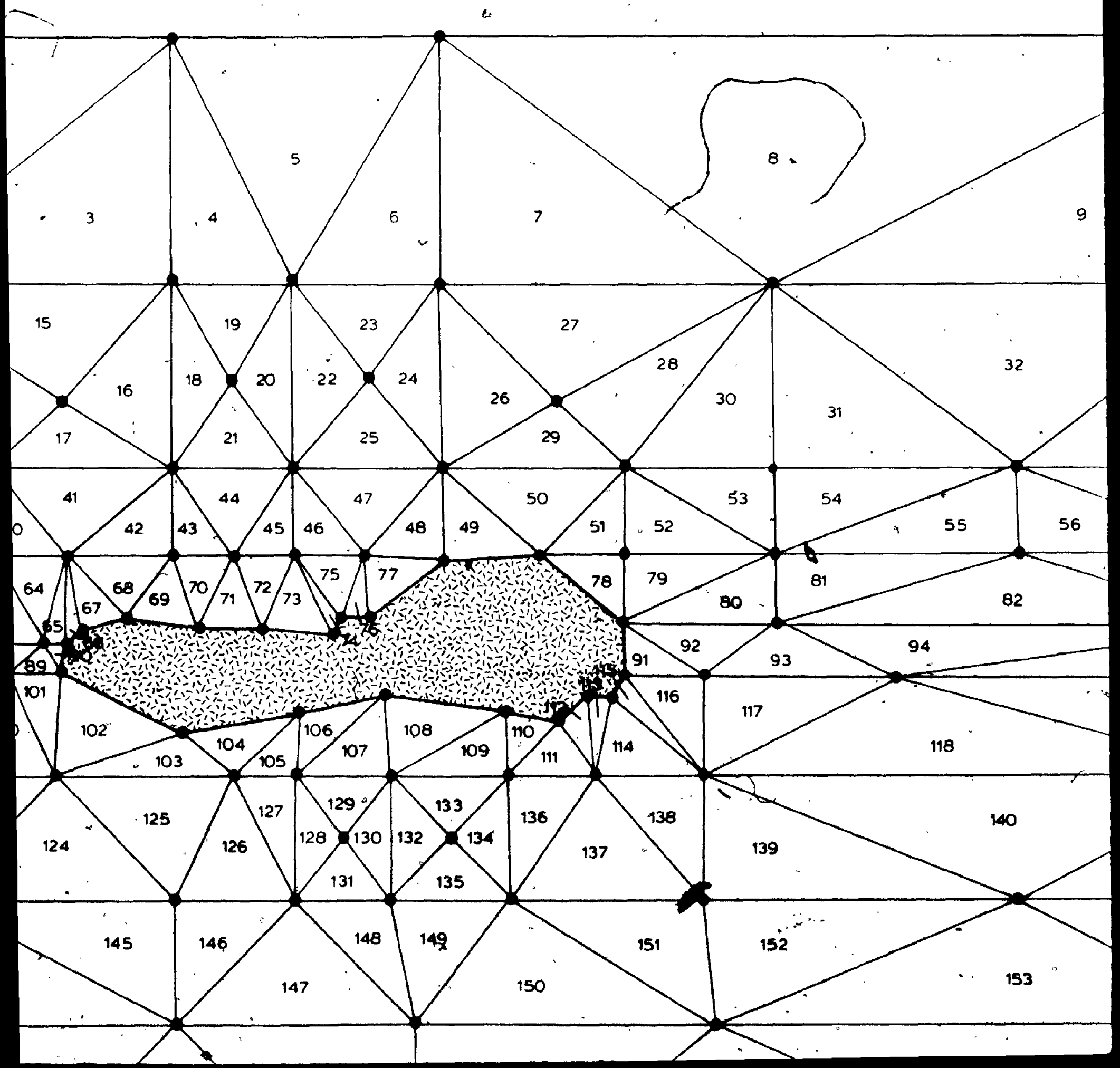




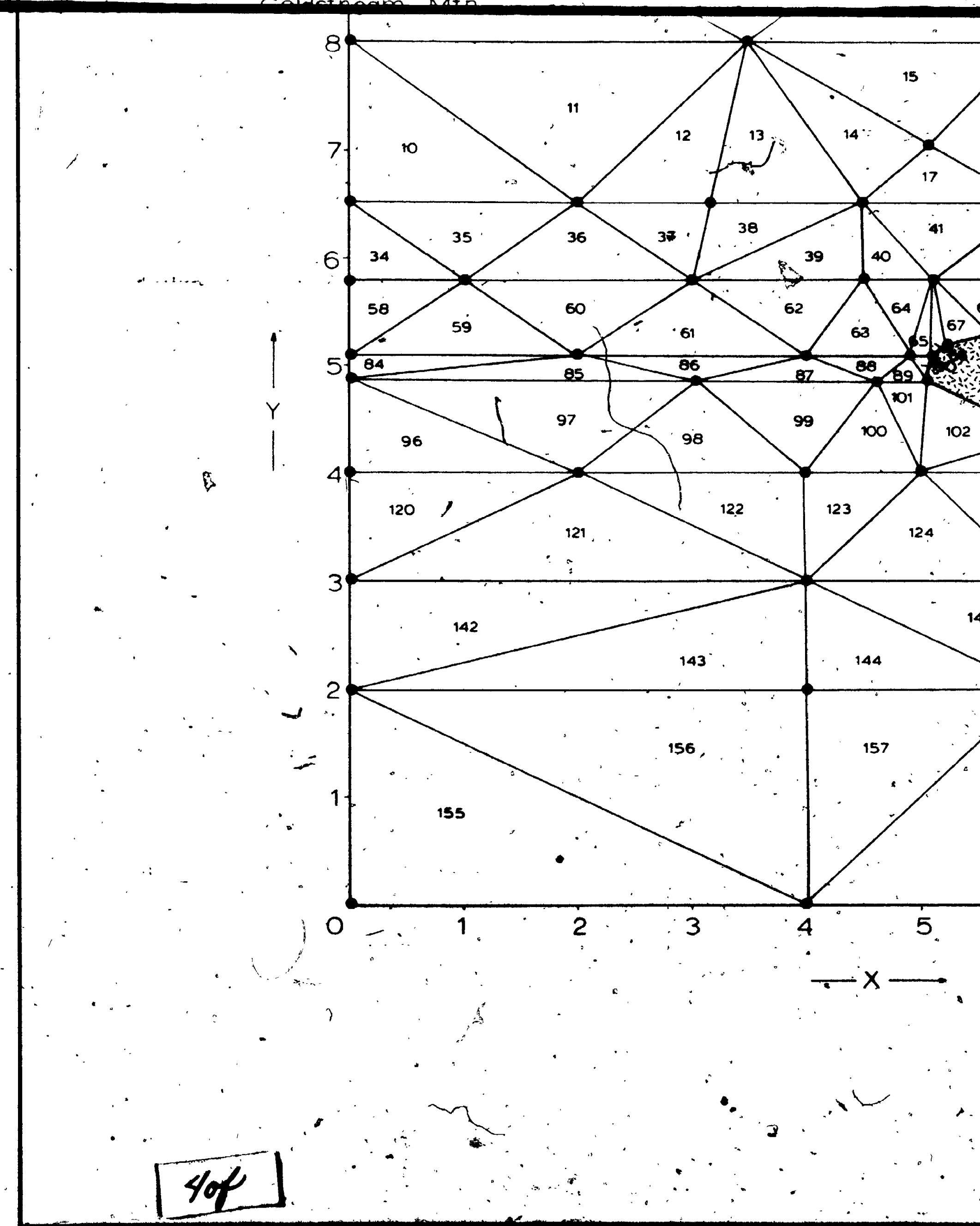




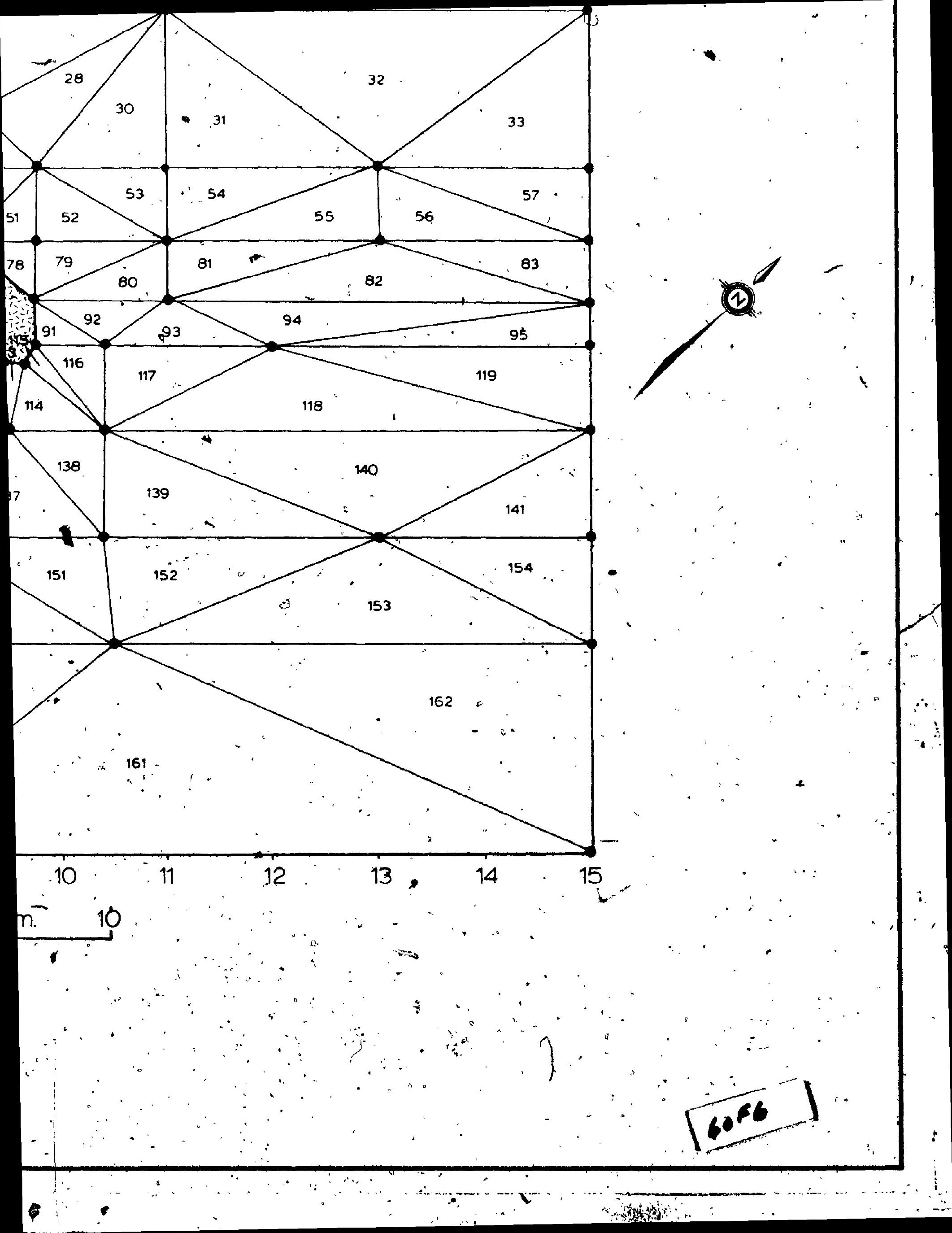






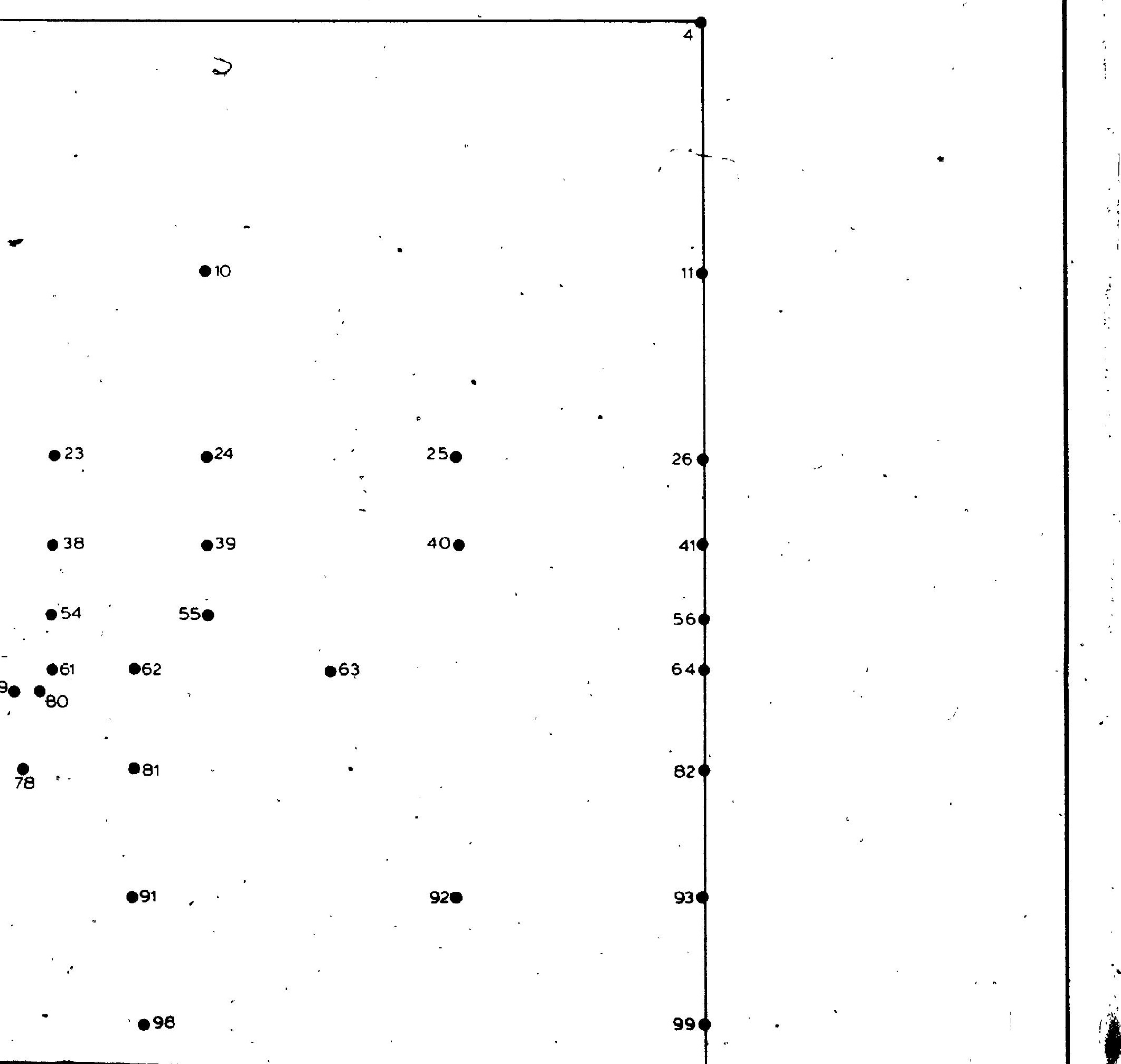


7

8

9

- 10

016

15

30
018

020

220
8

19
23

$-32$

$\lcm{33} \quad 034 \cdot 035$

$0^{36}$

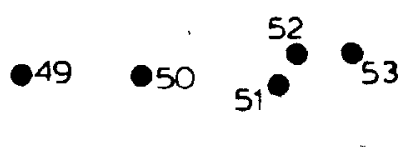

21

37

- 38

.54
24

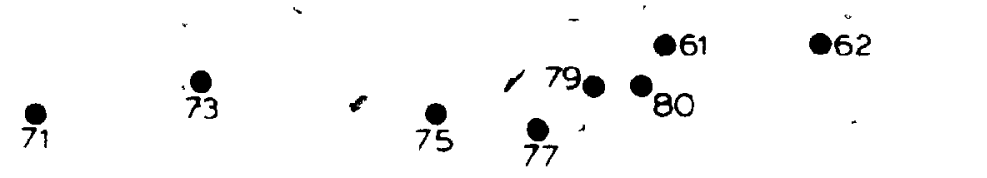

$70.72 \quad 74$

76

78

87

85

86

98

190

96

$97^{\circ}$

102

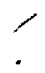

$\bullet 63$

40 


$$
\text { Tor } 1
$$

fig. 33 Principal

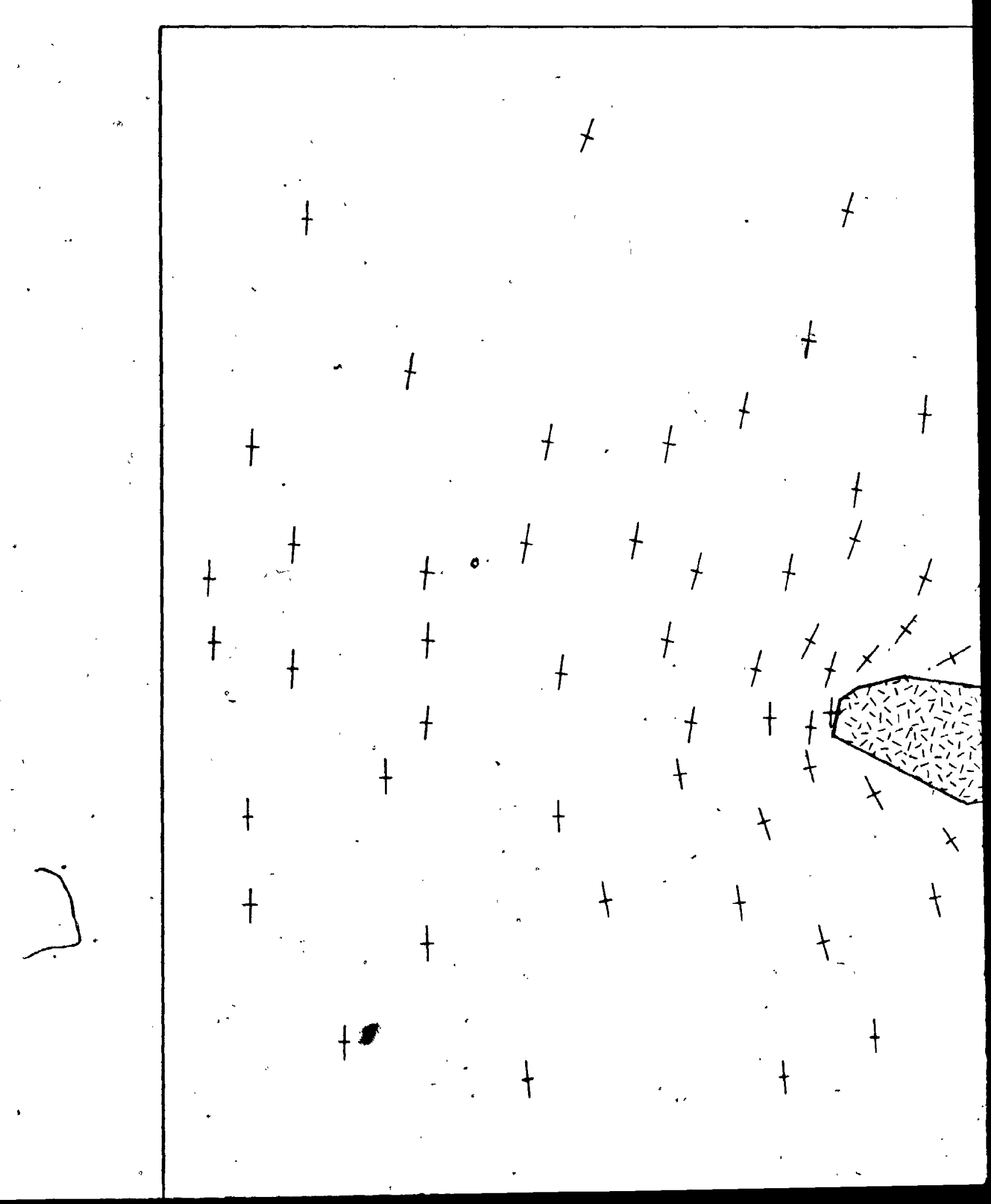


$(20 \%)$

Principal Stress Components, Layout 1

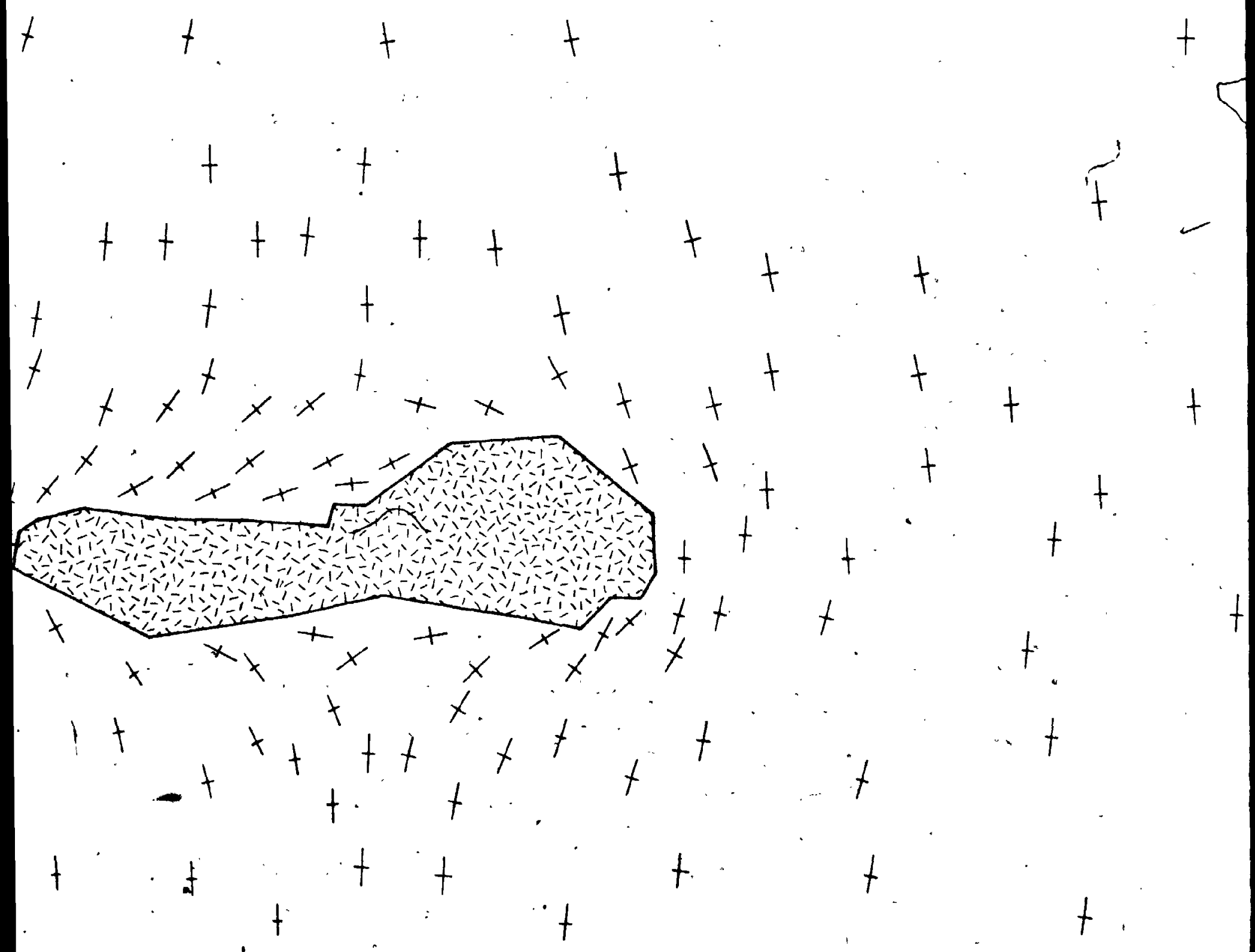




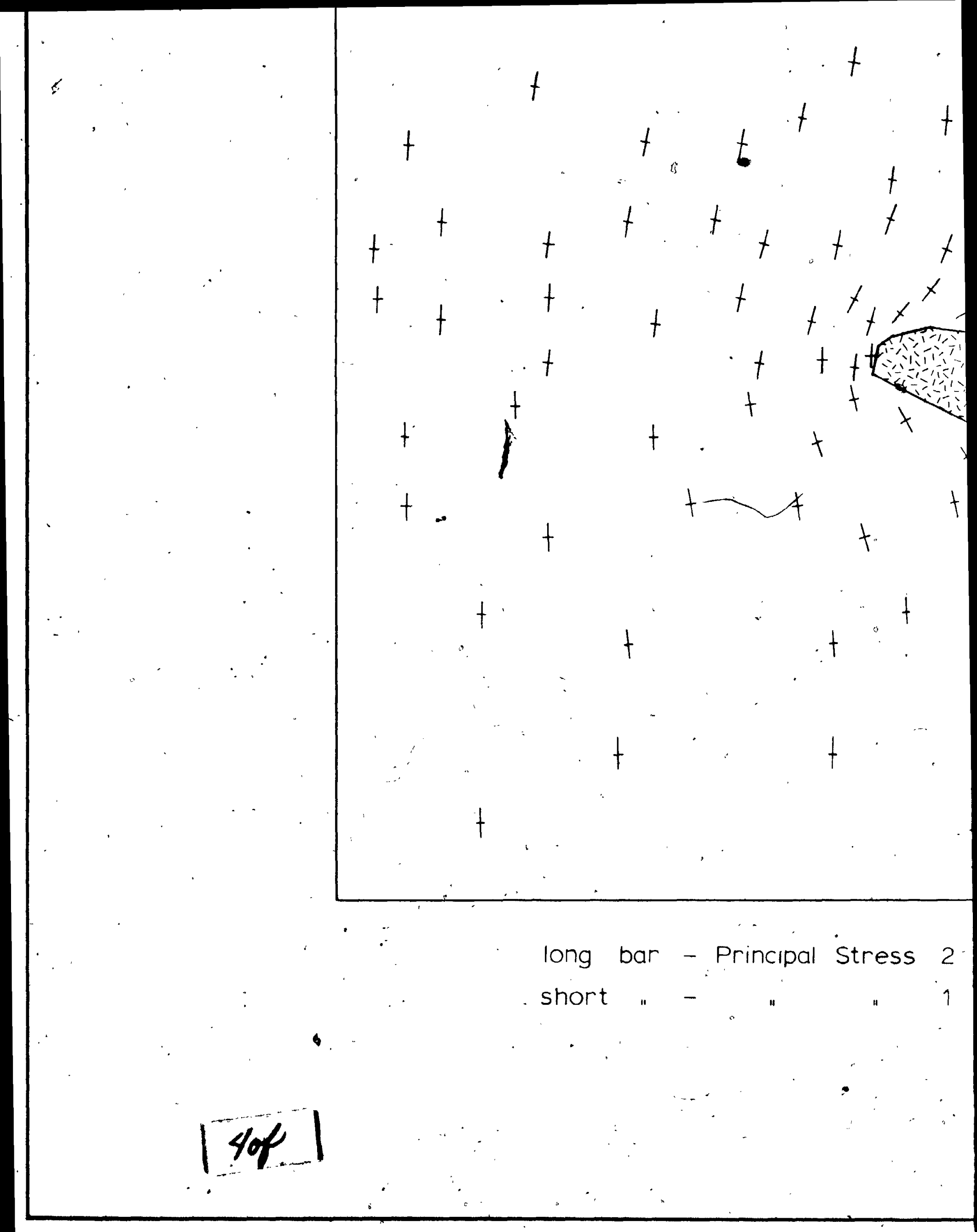




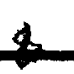

$$
2 \text { of }
$$

34 Trend of Principal Stress 2; Layout 1

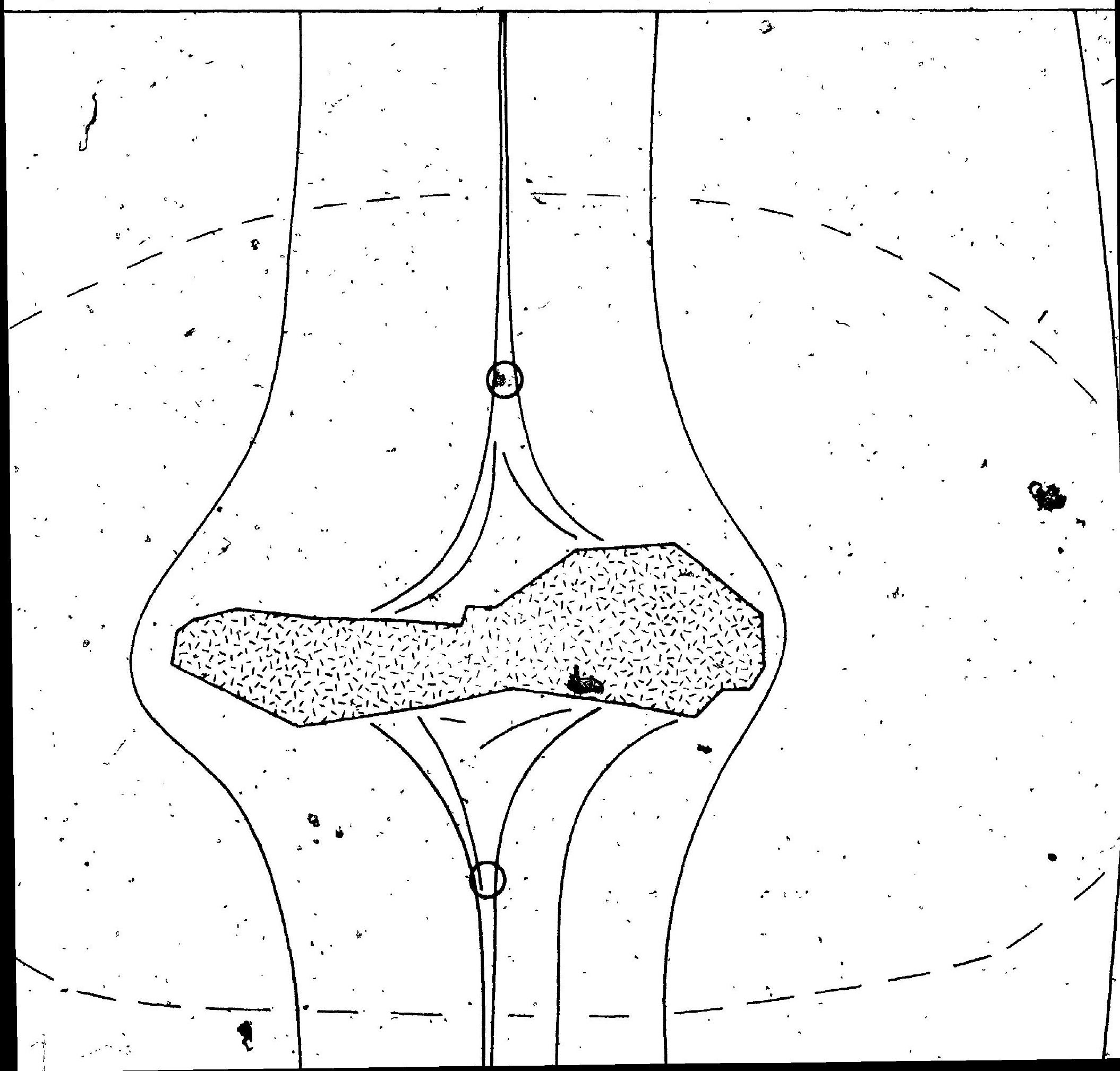


-ayout 1

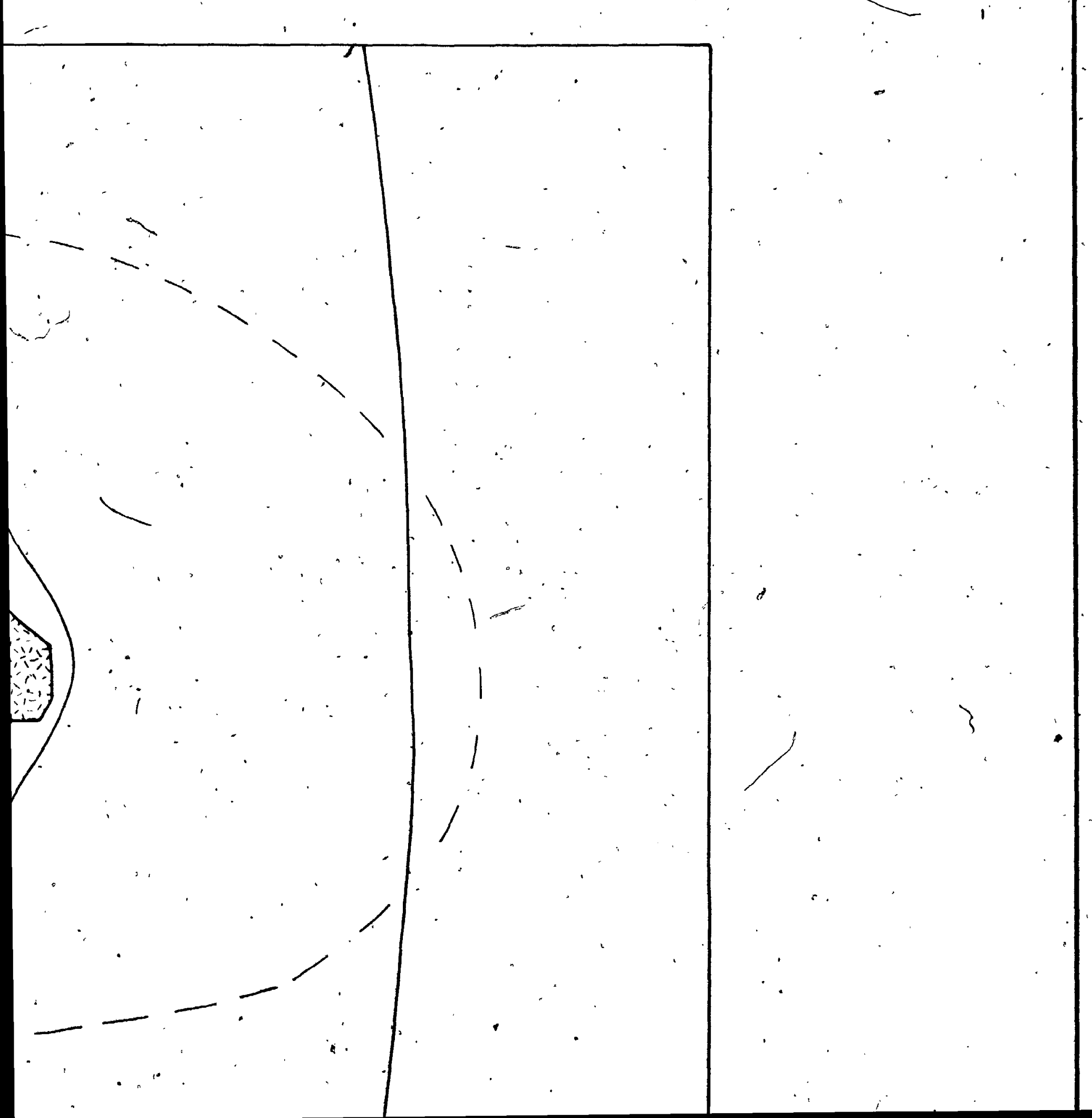




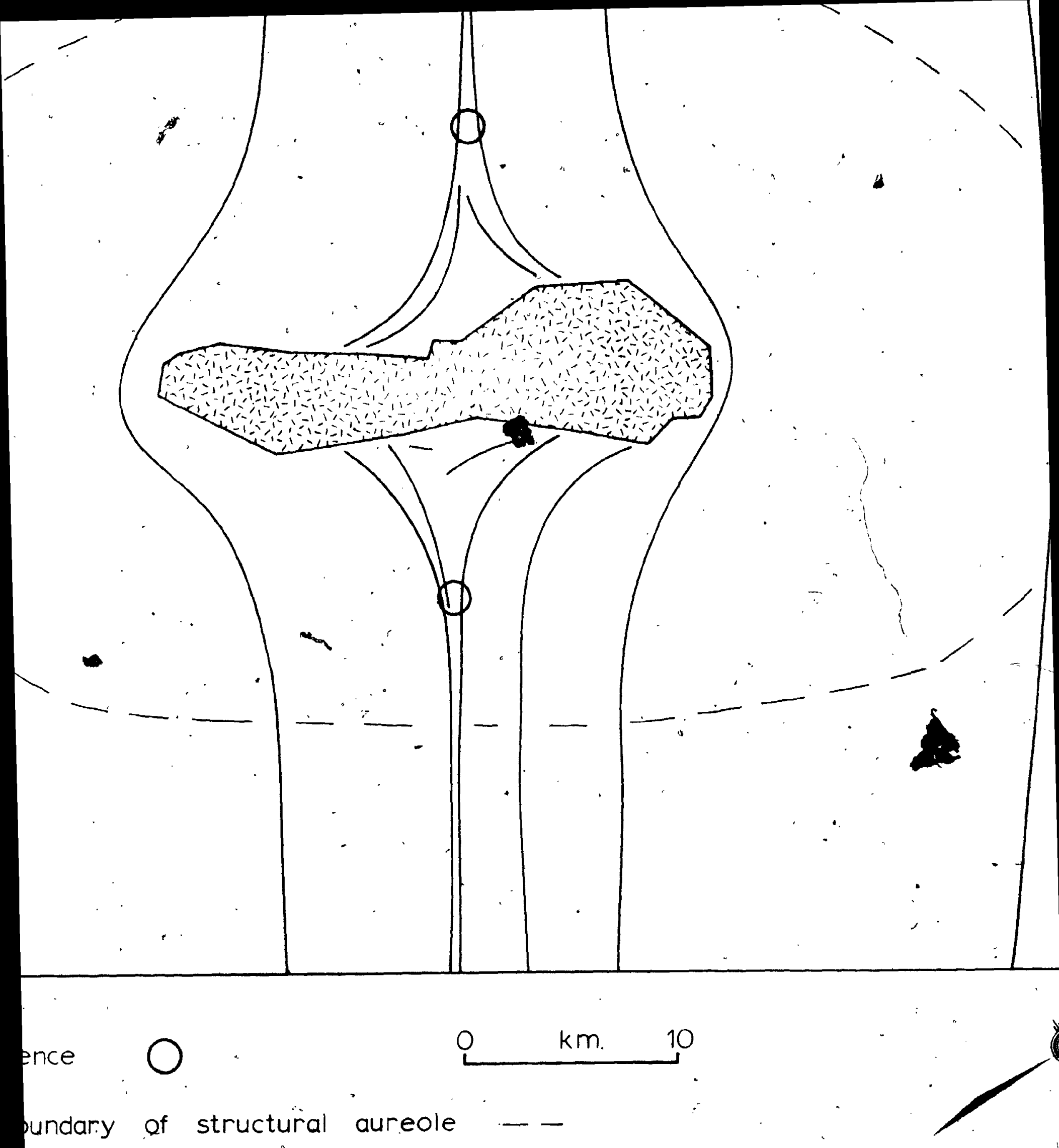


fig. $35:$ DISTRHB
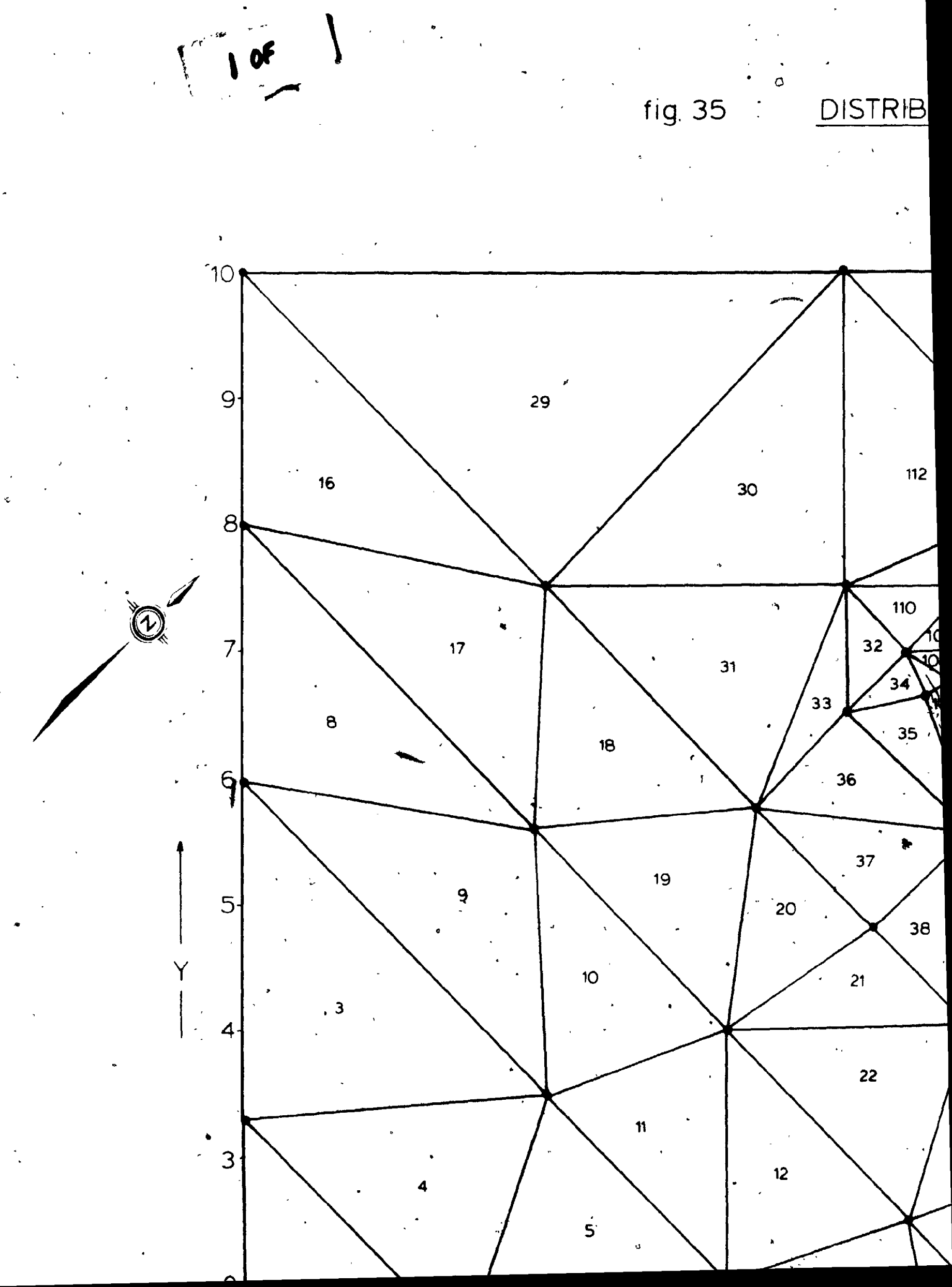


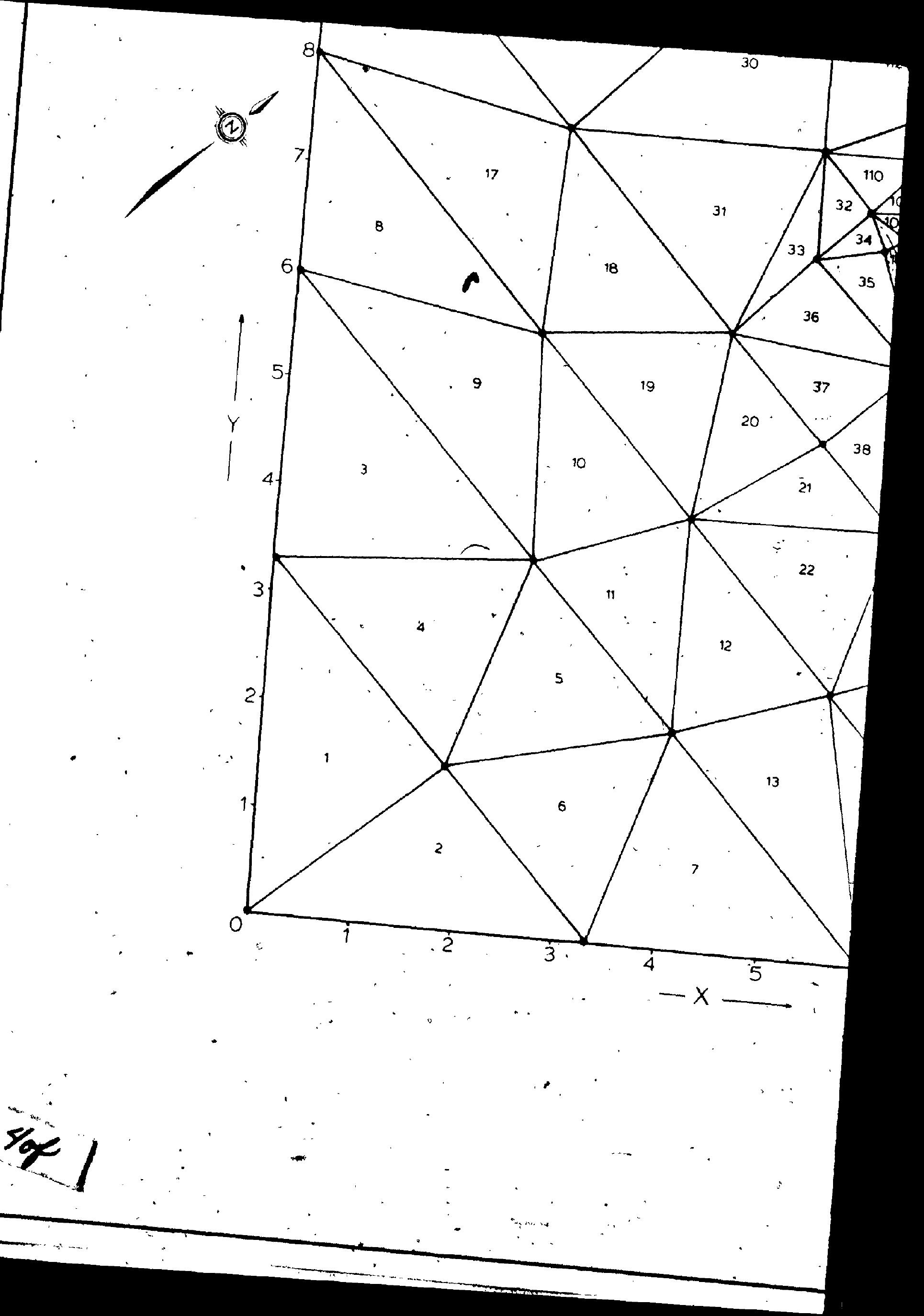




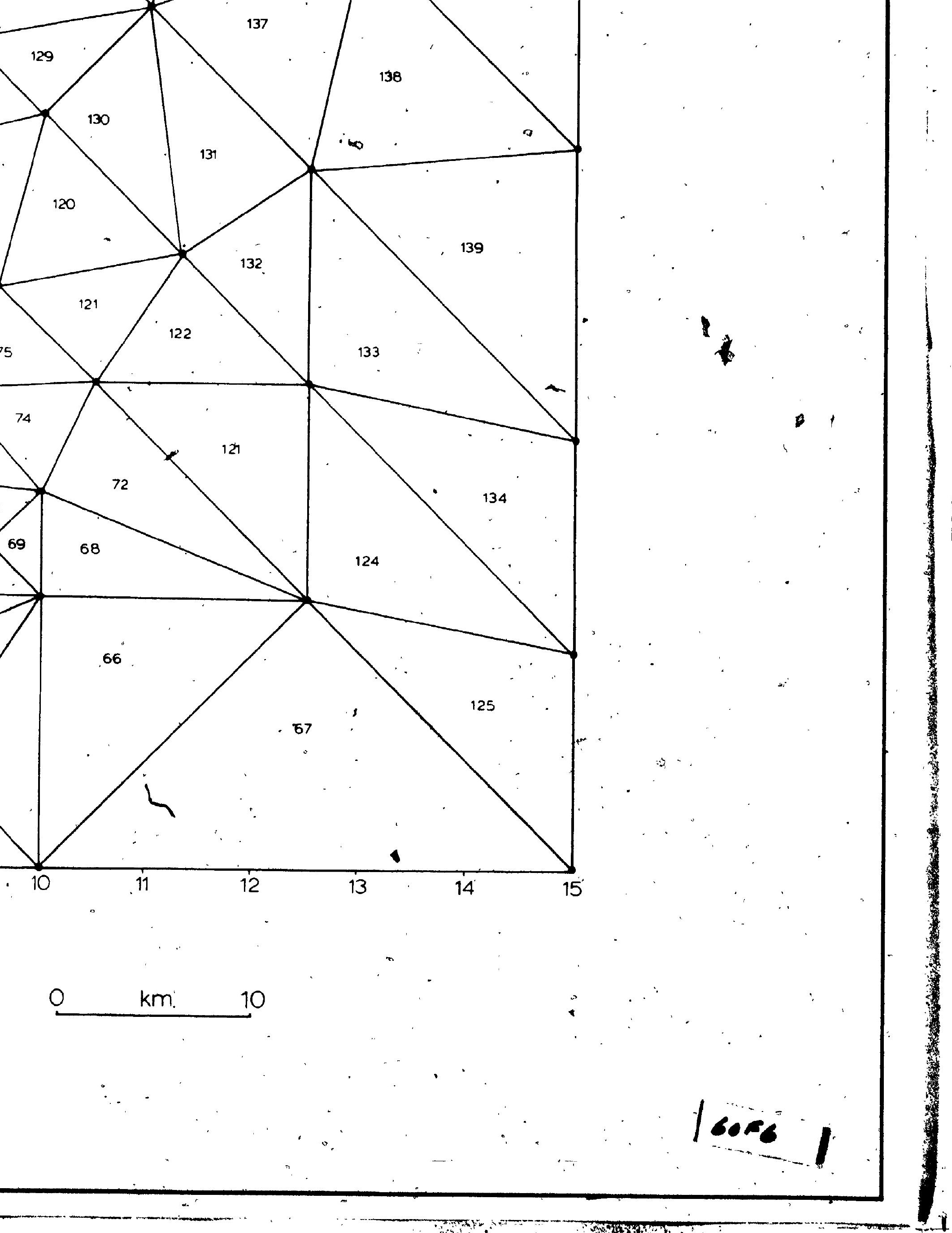


100 I

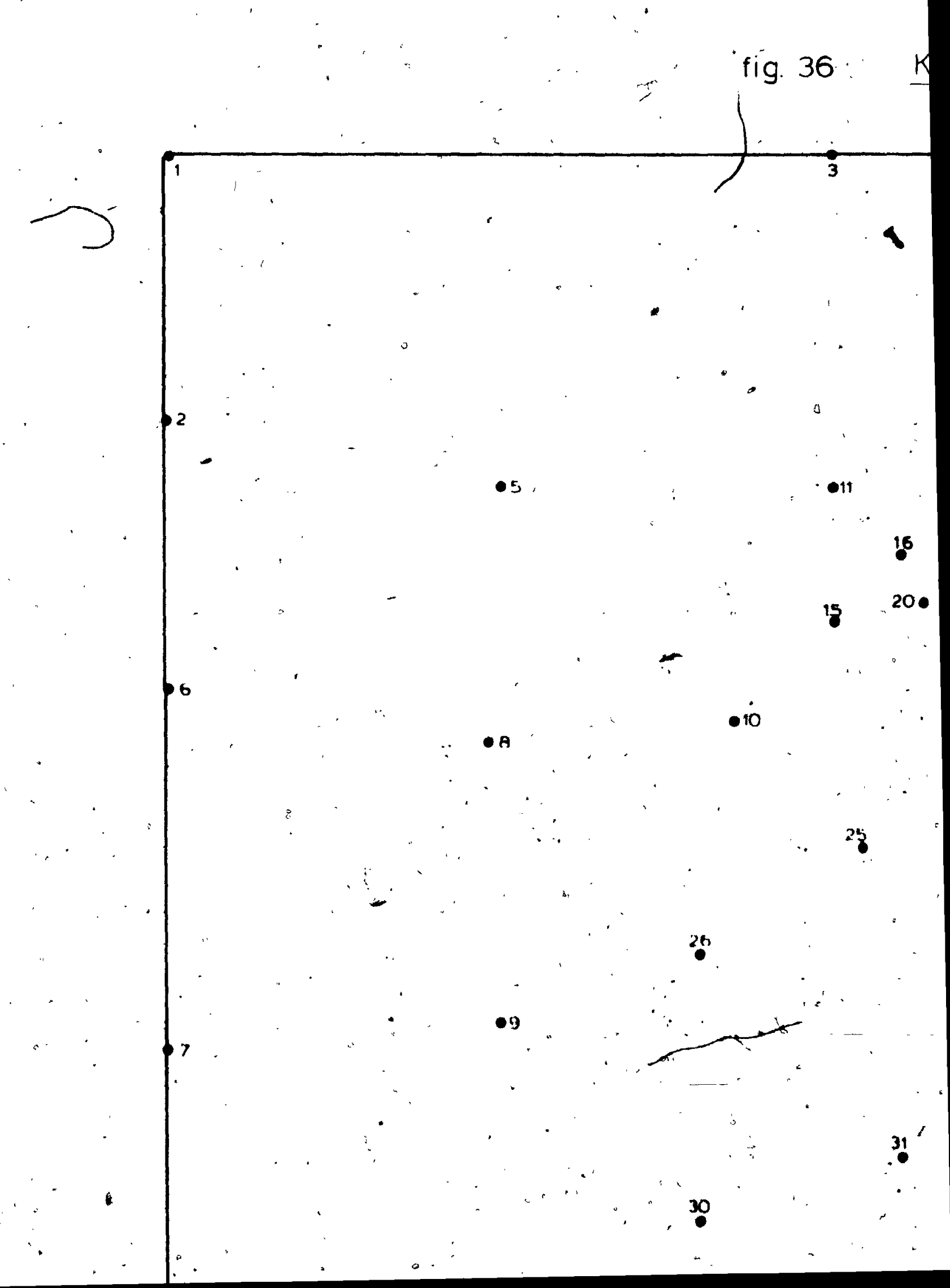





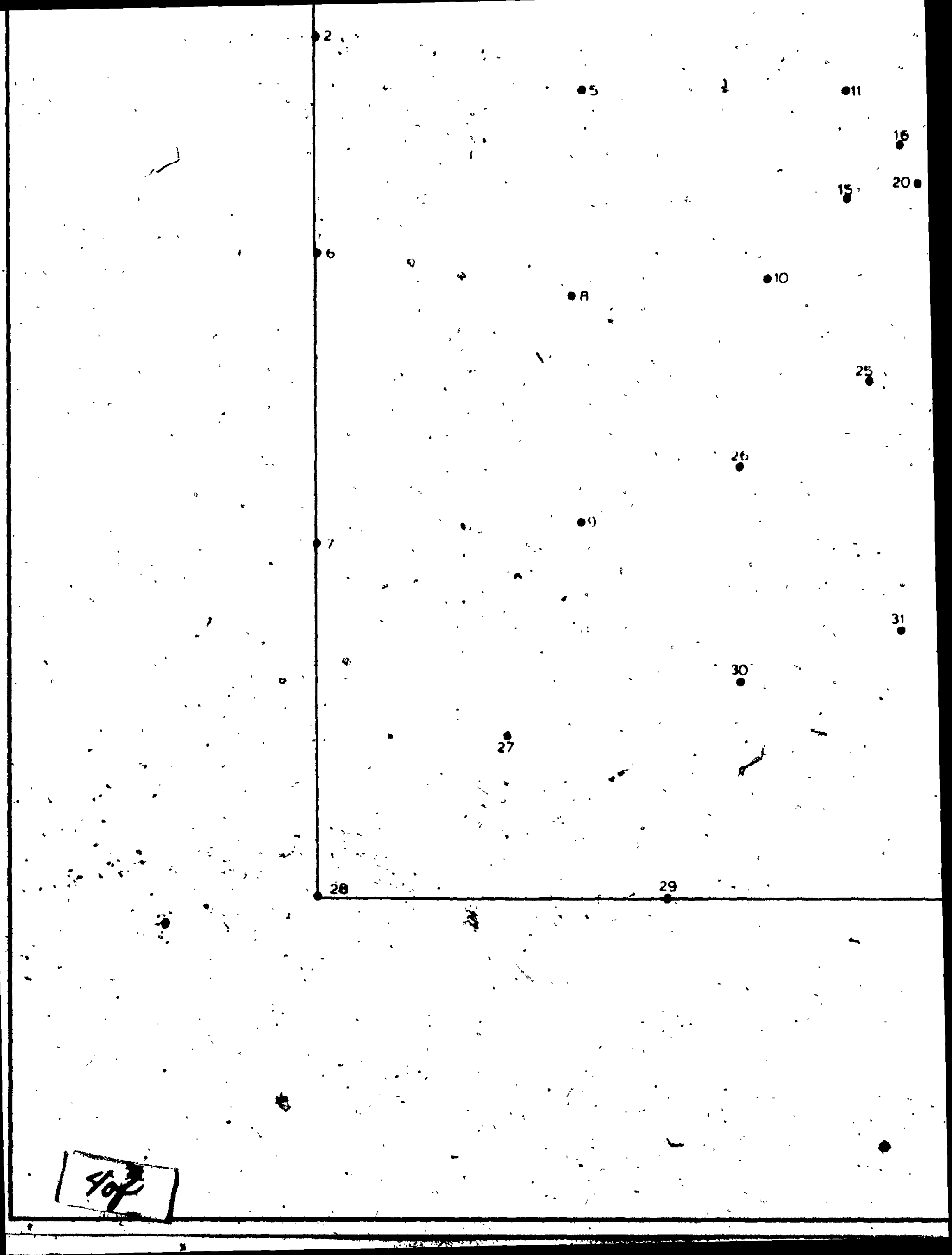


43

$\stackrel{\circ}{46}$

917

.42

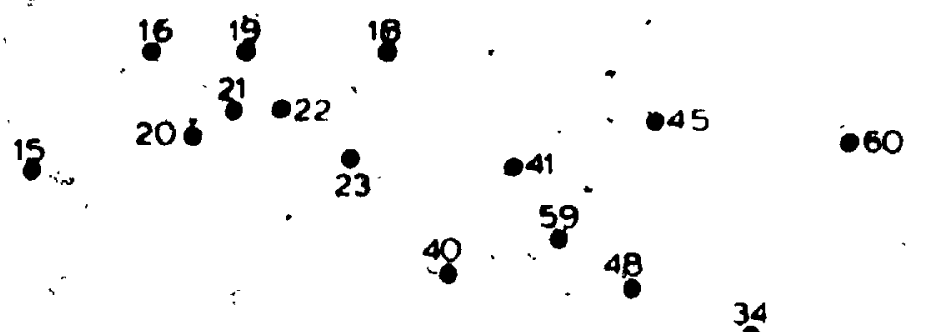

56.

- 10

$024.47^{\circ}$ bi $490^{30} 053$

75

23

20
$\therefore$
30
0

44

.
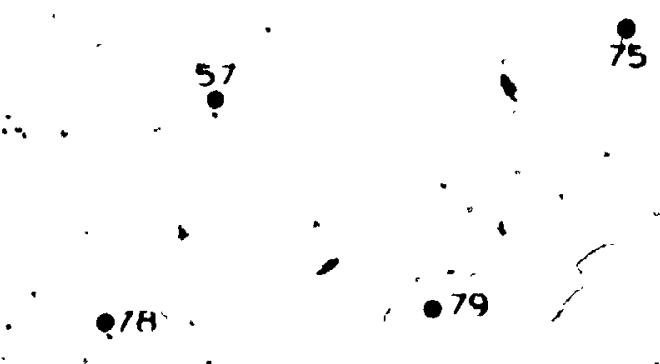

31

In

33

hi

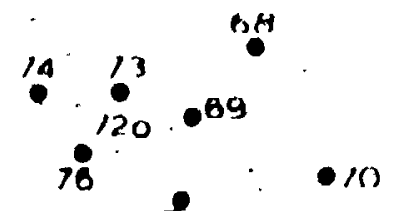

$67^{-3}$

63

520

966

- 80

32

65

84

m

$1 \cdot \quad 82$

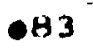

o 81

l

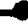




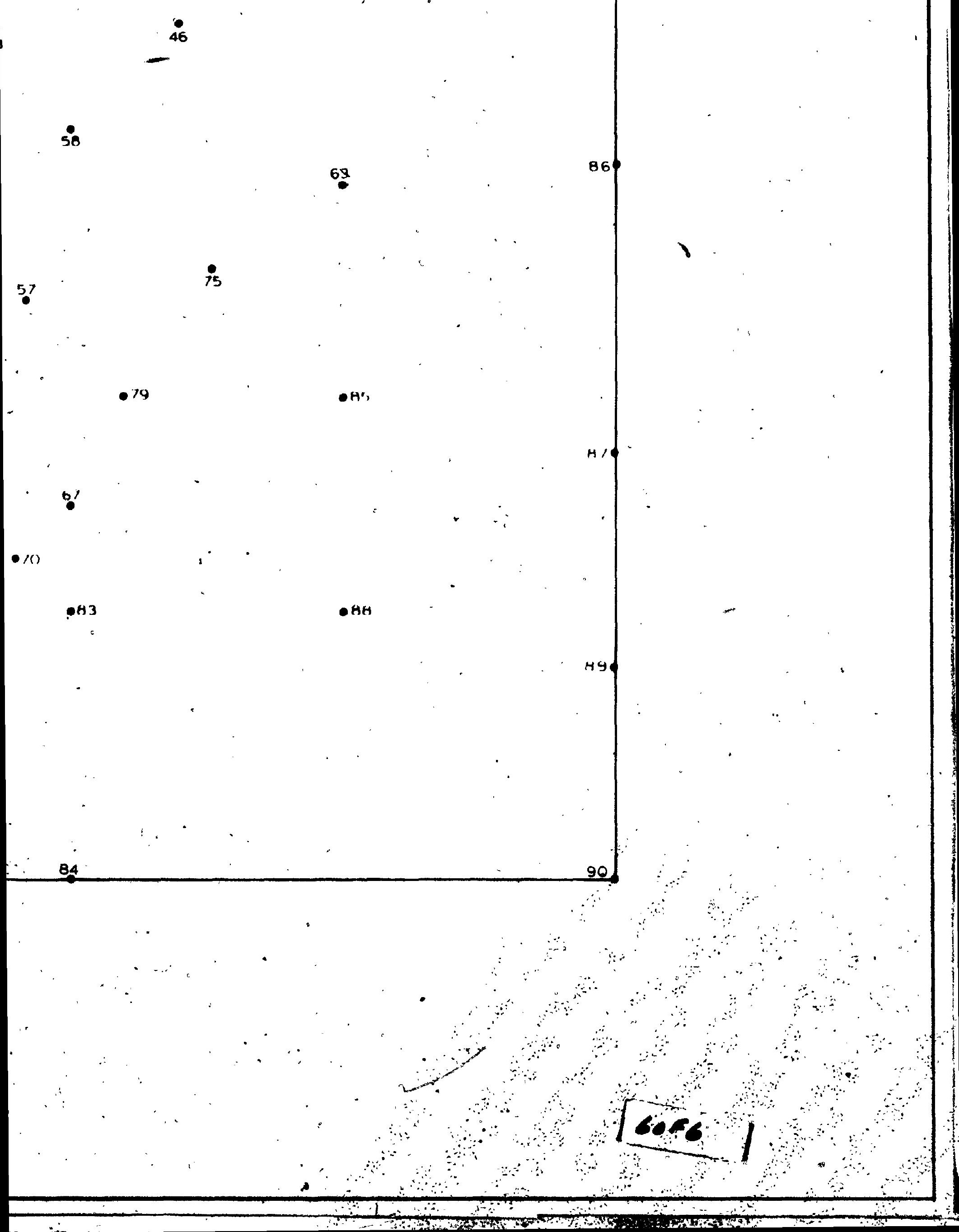


1 of

fig. $37 \quad$ Principa

$c$

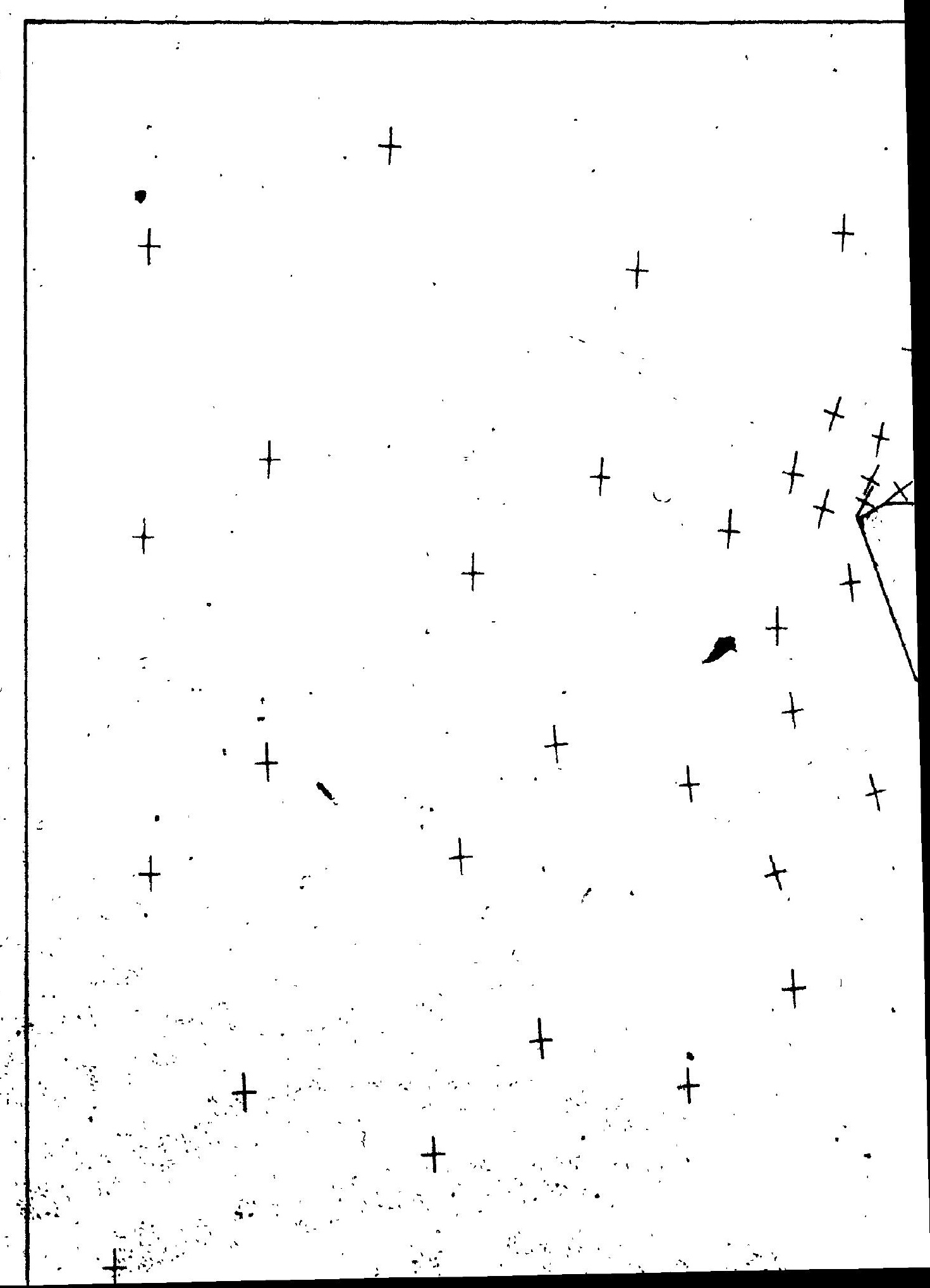


Principal Stress Components, Layout 2

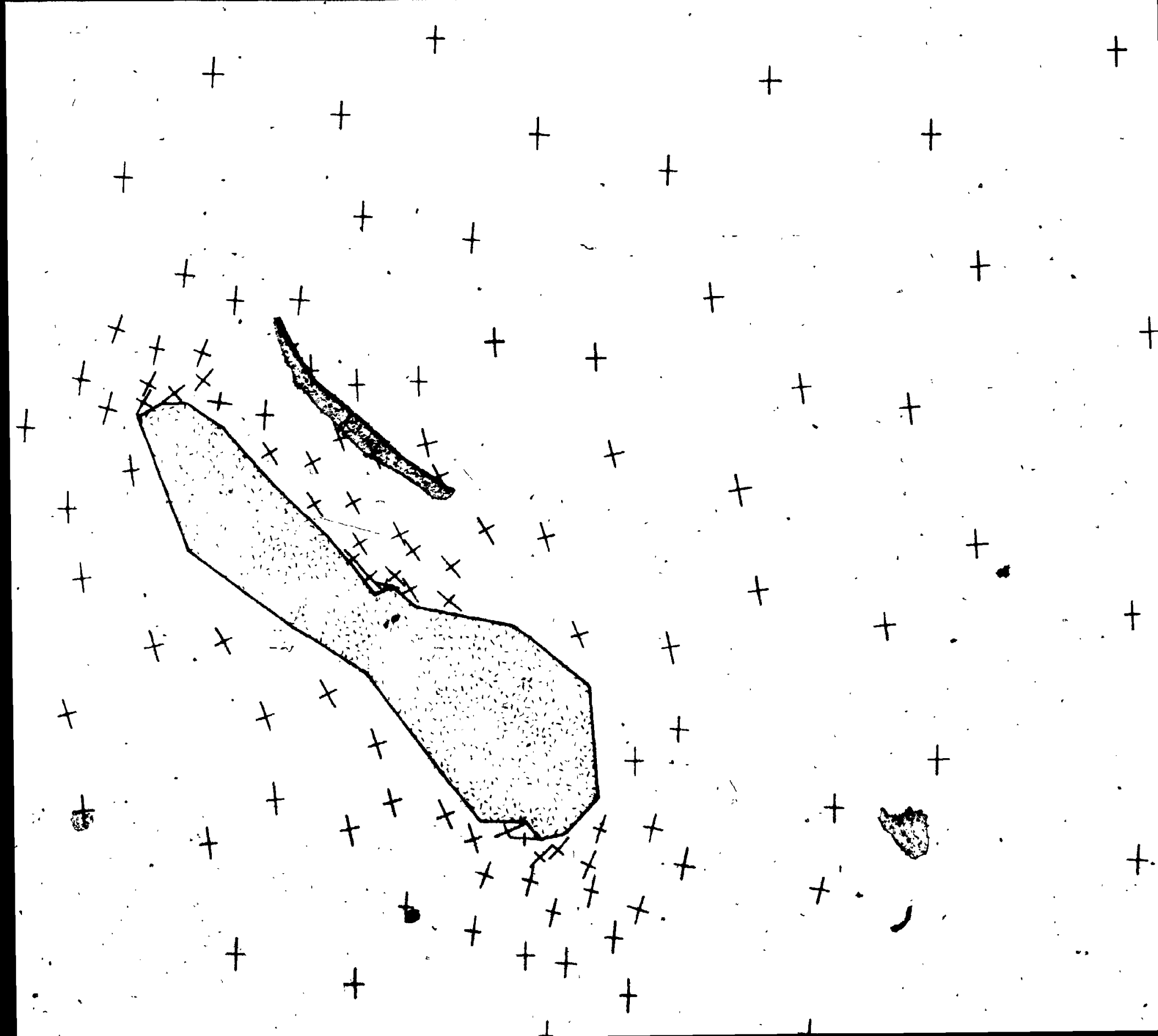





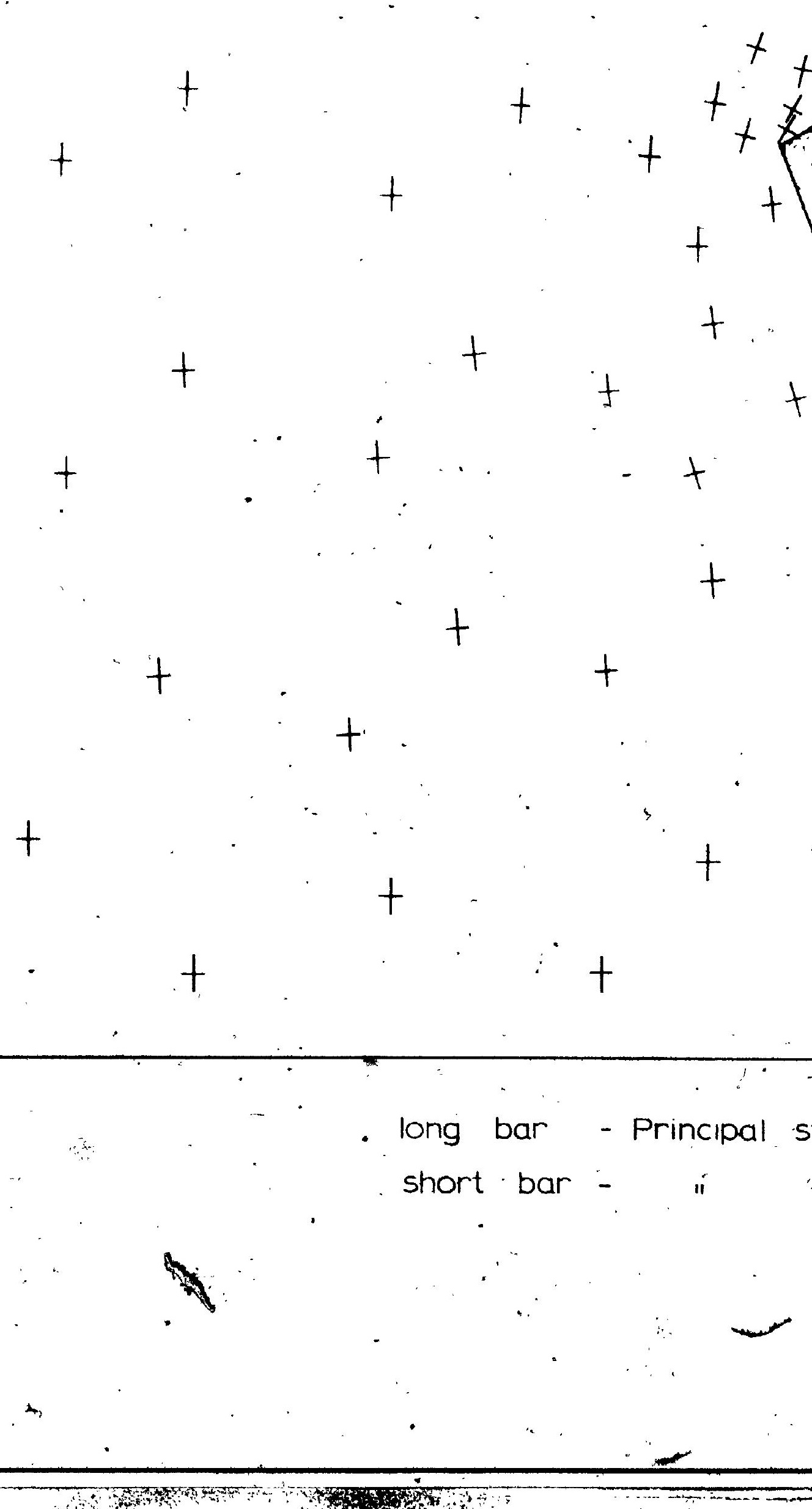


$+$

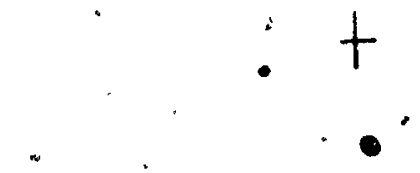

$+$

t

$+$

$+$

t

$+$

$t$

-

t

$+$

$+$

$+$

$+$

$\dot{t}$

t

$+$

$\mathrm{km}: 10 \therefore$.

't 



$$
5
$$





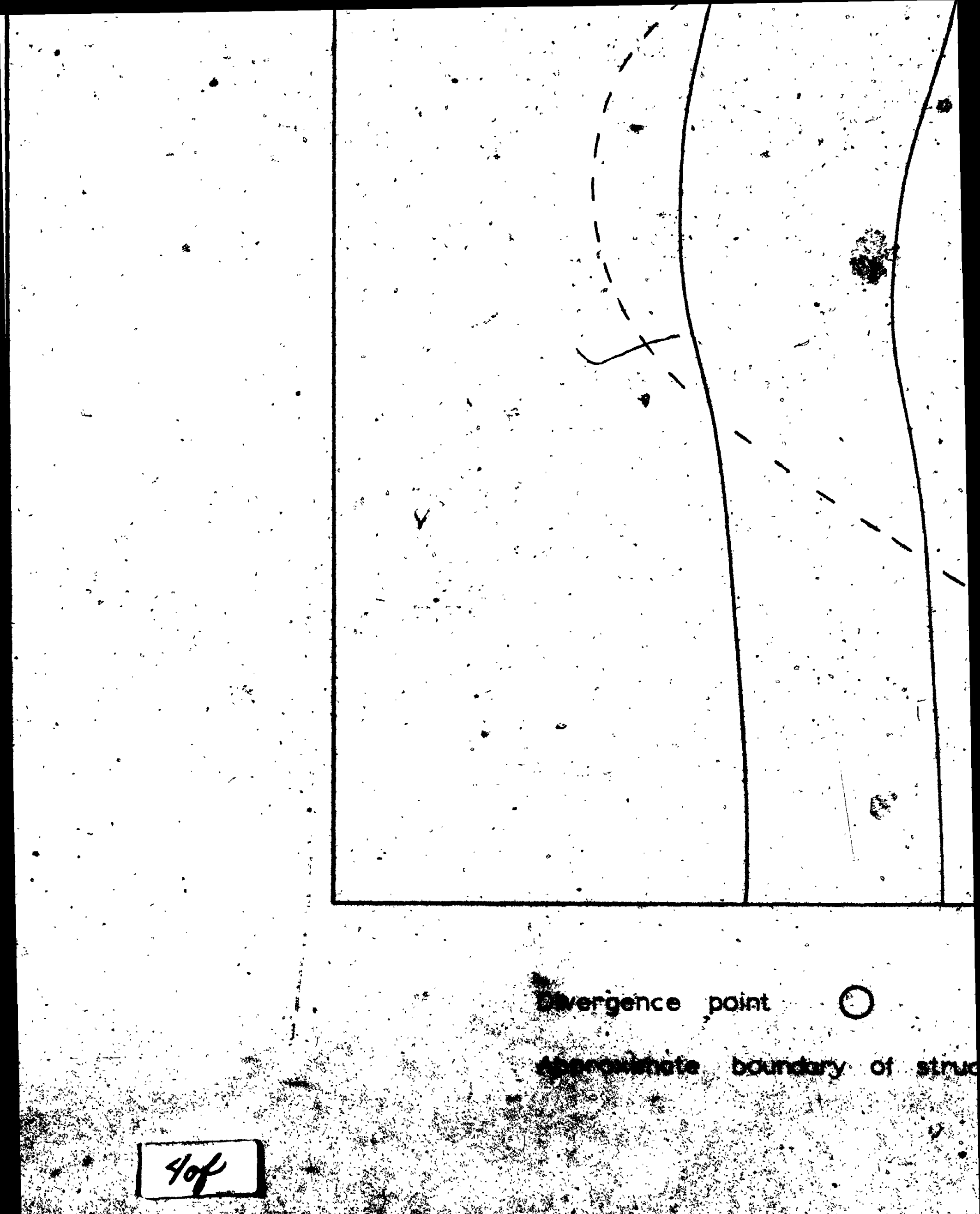

Wy

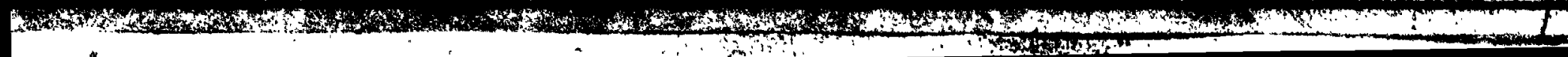




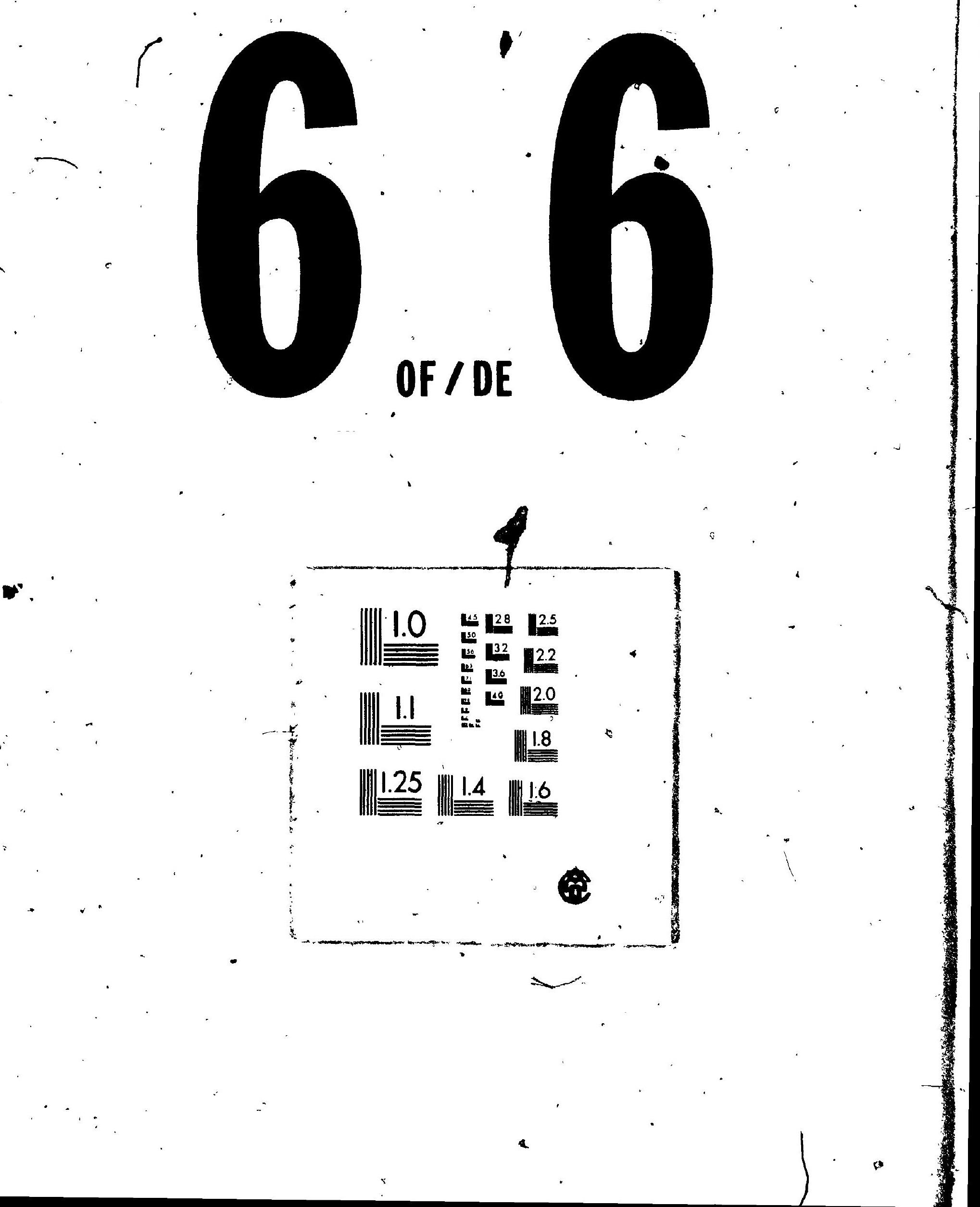




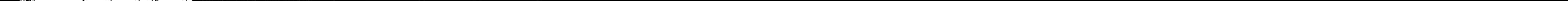




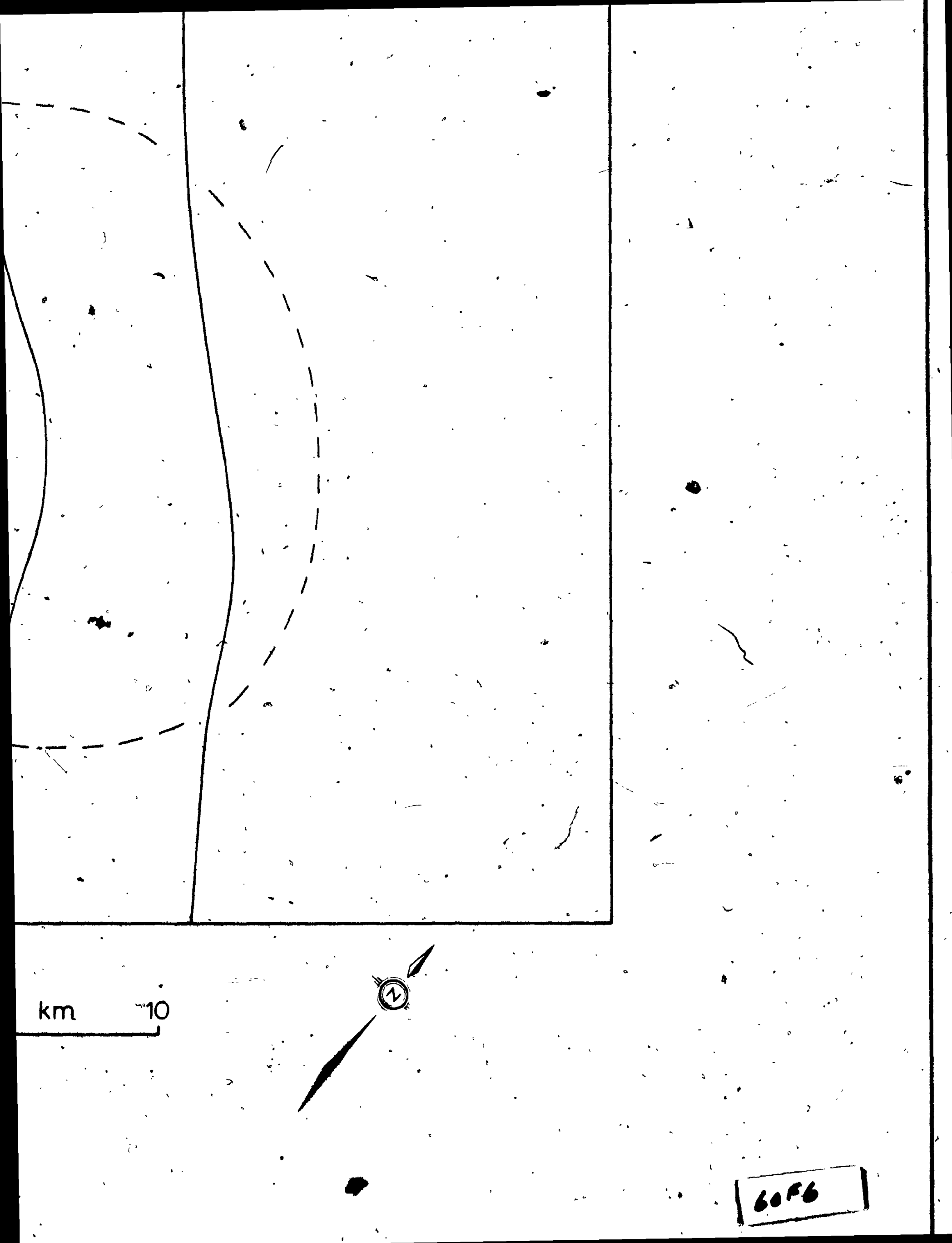



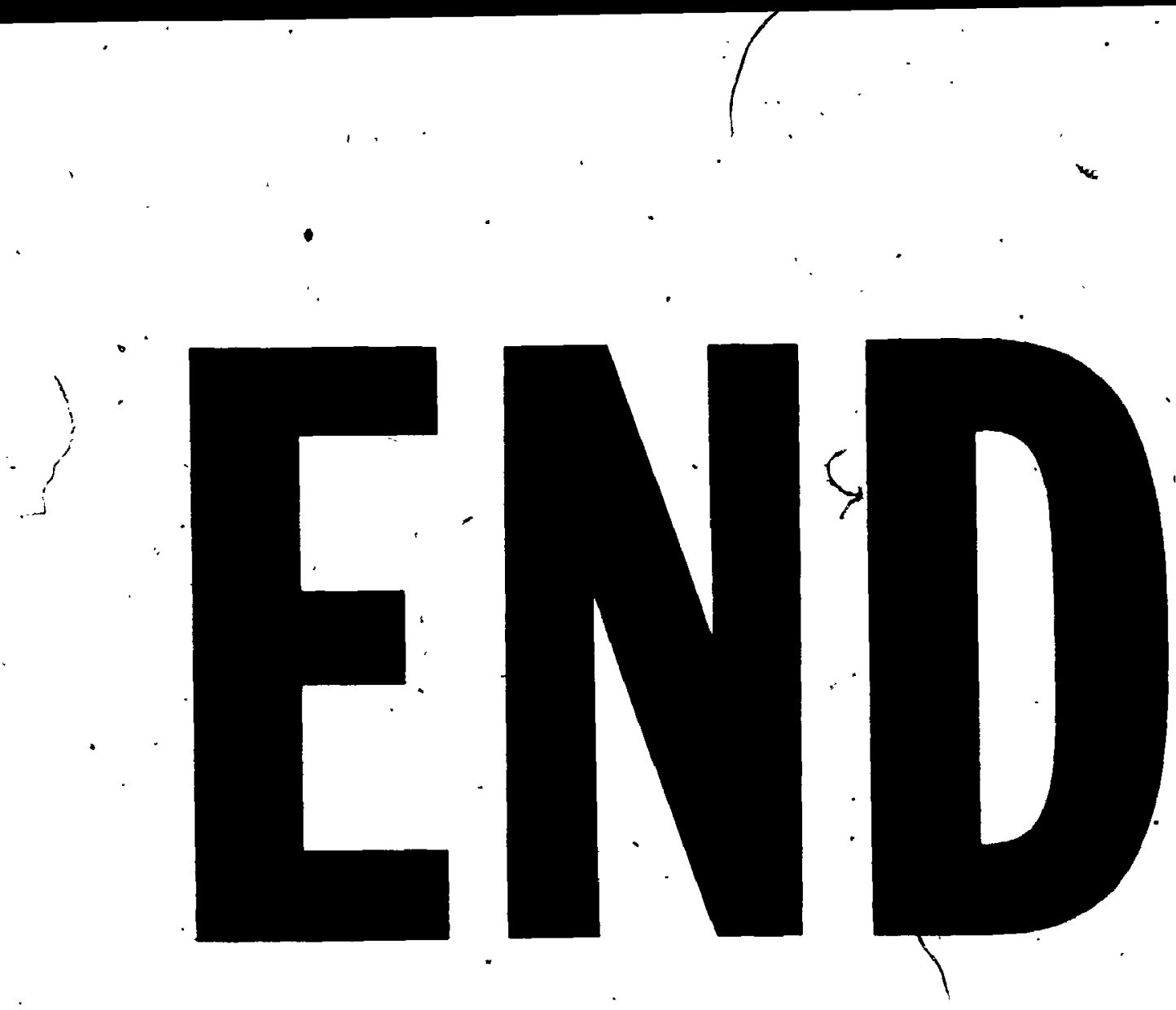

-7 in
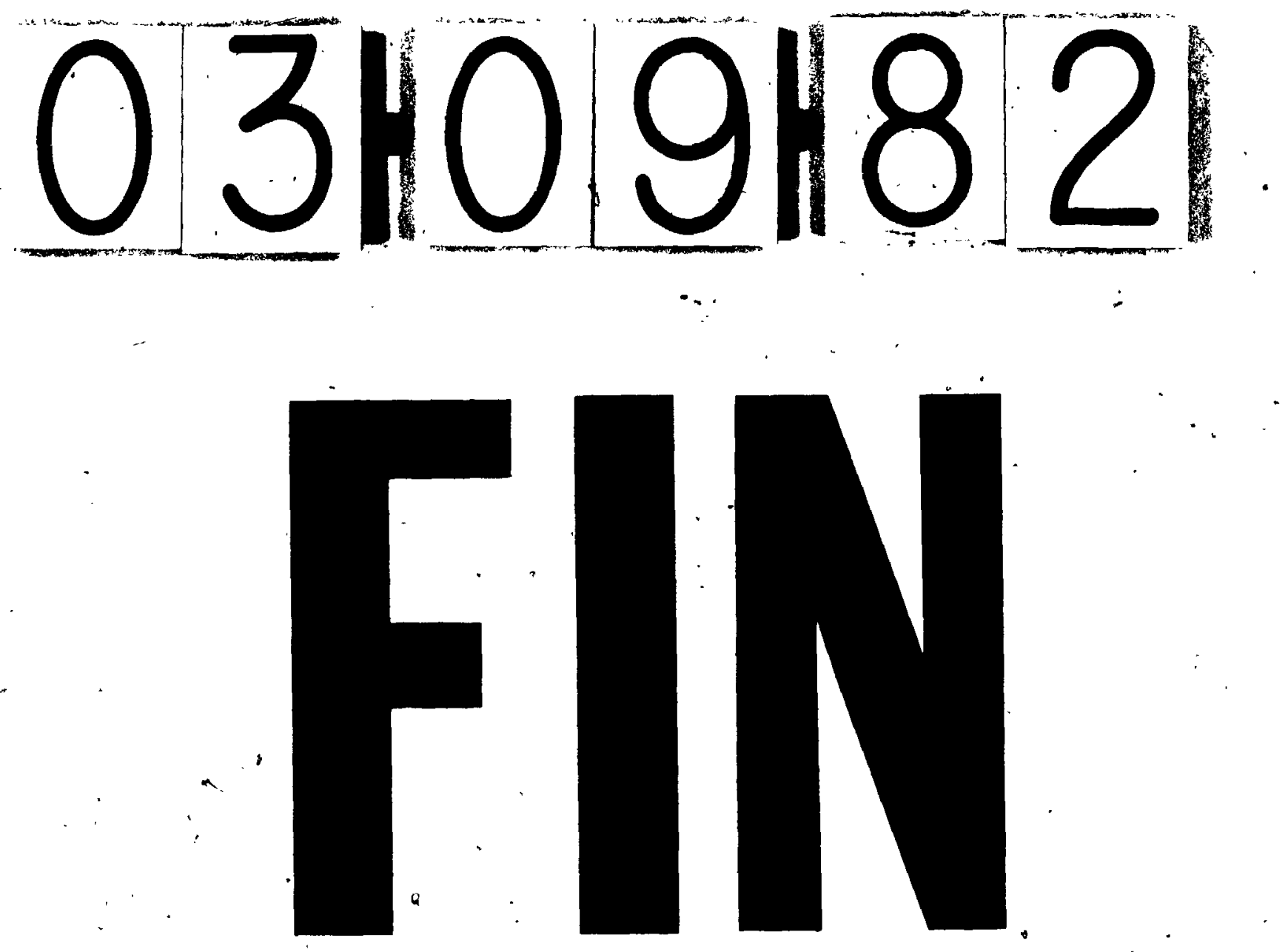